EXAMINING THE EVOLVING ENVIRONMENTAL PROTECTION POLICY CONVERGENCE IN THE ONTARIO MUNICIPAL DRINKING WATER, WASTEWATER AND STORMWATER SECTORS: ANALYSIS OF STATE/NON-STATE GOVERNANCE AND THE VALUE OF AN ENVIRONMENTAL MANAGEMENT SYSTEM STANDARD FOR THE WASTEWATER AND STORMWATER SECTORS

\author{
by \\ Edgardo Tovilla \\ M.Sc. (Eng.) Environmental Water Pollution Control, University of Sheffield, 1996 \\ B.Eng. Civil Engineering, National University of Mexico (UNAM), 1992

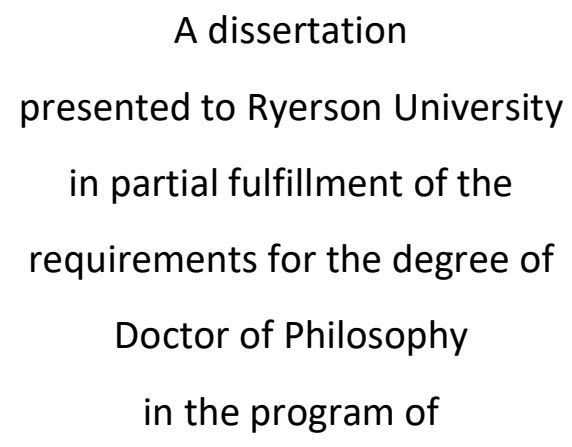 \\ Environmental Applied Science and Management
}

Toronto, Ontario, Canada, 2020

(C) Edgardo Tovilla, 2020 


\section{AUTHOR'S DECLARATION FOR ELECTRONIC SUBMISSION OF A DISSERTATION}

I hereby declare that I am the sole author of this dissertation. This is a true copy of the dissertation, including any required final revisions, as accepted by my examiners.

I authorize Ryerson University to lend this dissertation to other institutions or individuals for the purpose of scholarly research.

I further authorize Ryerson University to reproduce this dissertation by photocopying or by other means, in total or in part, at the request of other institutions or individuals for the purpose of scholarly research.

I understand that my dissertation may be made electronically available to the public. 


\title{
EXAMINING THE EVOLVING ENVIRONMENTAL PROTECTION POLICY CONVERGENCE IN THE ONTARIO MUNICIPAL WATER, WASTEWATER, AND STORMWATER SECTORS: ANALYSIS OF STATE/NON-STATE GOVERNANCE AND VALUE OF AN ENVIRONMENTAL MANAGEMENT SYSTEM STANDARDFOR THE WASTEWATER AND STORMWATER SECTORS
}

\author{
Edgardo Tovilla \\ Doctor of Philosophy \\ Environmental Applied Science and Management \\ Ryerson University
}

2020

\begin{abstract}
The central question this dissertation attempts to answer is whether there is practical value in Ontario legislatively mandating that municipalities implement an environmental management system (EMS) standard for their wastewater and stormwater activities, to be added to the drinking water quality management system standard (DWQMS) that is already statutorily required. This research explores the evolving governance approaches of the municipal drinking, wastewater and stormwater sectors in Ontario, examining theories of governance, a review of the literature concerning policy convergence and standards as instruments of organizational innovation and the legal and policy framework within which municipal water management takes place.

The research method employed a combination of semi-structured interviews, case studies and a focus group as data gathering techniques. The research finds evidence in support of and wide recognition of the practical value of EMS by assisting municipalities in meeting their environmental objectives, addressing environmental and property damage risks, providing an additional mechanism of public accountability, transparency, and improving alignment with the existing legal structure. It was also apparent that there is no political appetite in the provincial government to embark on a mandated EMS, so the preferred option at this time is a provincially-endorsed, voluntary sector-specific standard for wastewater and also for
\end{abstract}


stormwater, which could constitute a catalyst to boost voluntary uptake of EMS by small to medium municipalities (as it is already occurring with large municipalities). This standard could be based on a customized variation of the ISO 14001, DWQMS and other standards to address existing regulatory gaps.

The research also reveals that Ontario municipal water management governance is notable because governments are drawing on independently developed and implementing non-state forms of regulation (such as EMS standards), in which private sector, civil society and multistakeholder rule instruments, processes, institutions and actors all perform important roles in support of conventional state-based regulation, showing both horizontal and vertical policy convergence.

A limitation of the research is that it focuses on water governance of municipalities of one jurisdiction. Future research could examine the practical utility of examining water governance to other contexts (e.g., water governance for First Nations, and in non-Canadian jurisdictions). 


\section{ACKNOWLEDGEMENTS}

I have benefited greatly from the wisdom and kindness of many people in the governance network for the Ontario water, wastewater, and stormwater community. This dissertation would not have been completed without their generous support.

First of all, I want to thank my doctoral supervisor, Dr. Kernaghan Webb, for his tireless guidance, support and the very generous time he invested in helping me craft this dissertation. Although we started in 2013 with a keen interest on innovative approaches of environmental governance in the Canadian metal mining sector, he was equally supportive and enthusiastic when, in 2015, the innovative approaches related to the municipal water sectors captured my interest and attention instead. Thanks!

My dissertation supervisory committee, Dr. Cory Searcy and Dr. Alex Wellington, deserve a huge thank you as well, both for their inspiring classroom lectures as well as for their candid advice during my research candidacy proposal and initial examination. Also, thanks to Dr. Michal Bardecki, another member of my candidacy examination committee, not only for devoting his time and experience to assist me, but for granting me the privilege of becoming a graduate student. When I first embarked in this adventure back in 2013, he was the EnSciMan Program Chair, and generously allowed me to join the program on a part-time basis. I am also thankful to the additional members of the Examination Committee, Dr. Andrew Laursen, Dr. Arnold Yuan, and Dr. Andrea Bradford, who kindly agreed to participate in the defence process, for their time to review this dissertation, and their valuable input to my work. Thanks to my colleagues, Madeleine Martin and Zaker Khan, Ryerson PhD students who helped me take notes in the focus group session, and whose detailed transcripts made my analysis easier.

This research was generously supported by very kind donors without whose help it would have been much harder, if not impossible, to reach the finish line. I am deeply thankful for the support I received from the Ryerson Graduate Award, the Mitacs Accelerate Program, in partnership with SAI Global; the Ryerson University's Geoffrey Bruce Fellowship in Fresh Water Policy, made possible thanks to the generous donation of Ms. Erika v. C. Bruce; and the Region of Peel's Tuition Assistance Program. 
Throughout the years that it took to complete the doctoral program and finish my dissertation, at my places of employment I was very fortunate to work under incredibly generous supervisors and colleagues who never hesitated to support my commitment to pursuing a PhD. Therefore, I want to express my sincere appreciation and gratitude to Agatha Garcia-Wright, Ian Parrott, Aziz Ahmed, Vince Pileggi, Neil Parrish and Mansoor Mahmood at the MECP; to John Thompson at the City of Barrie; and to Andrew Farr, Anthony Parente and Elaine Gilliland at the Region of Peel. Without their support this work would have not been possible.

A total of 25 interview respondents and 14 focus group participants, including 12 professionals from the case studies from Richmond Hill, York Region and Durham Region, contributed to this research. All of them are highly-regarded professionals in the water profession, working in various government, consulting and non-governmental organizations. As per the Ryerson University Research Ethics Board rules I have to maintain their names anonymous, but I openly express my gratitude to each and every one of them for their time, wisdom, and knowledge, which were crucial to my research findings and observations.

I am also grateful to the community of professionals within the Water Environment Association of Ontario (WEAO), the Canadian Water and Wastewater Association (CWWA), the Canadian Association on Water Quality (CAWQ), the Ontario Water Works Association (OWWA), and the Municipal Water Wastewater Regulatory Committee (MWWRC), who opened their doors at their conferences and symposia for me to regularly provide updates related to this research. Feedback and comments from their members at these conferences were very beneficial.

I also want to thank the Water Quality Research Journal, Water Canada magazine, and the Ryerson University Innovation Newsletter for their 2017 and 2018 publications regarding this research early findings. Their support was very encouraging.

A big thank you to Martin Boyd for proof reading the entire dissertation so it flows better and, hopefully, reaches a wider audience, both inside and outside Academia. Thanks to John Rampal for providing me with a better geographic mapping to illustrate the case study areas. 
Pursuing a PhD while holding a full-time job and being a father of three would not have been imaginable, let alone doable, without the outright support of my family and friends. I want to thank my adored wife, Dr. Martha Batiz, for her words of encouragement since day one. Martha has been, and continues to be, a source of inspiration for the past 20 years. A huge thanks to my children, Ivana, Natalia and Marco, for their patience during all those weekends I was away from them either studying, writing essays, doing research, and crafting this document. A special thank you to Dr. Kenneth Bartlett and Dr. Gillian Bartlett, whose tree-tops guest room became a safe harbour and provided me with an inspiring environment to write the initial version of this dissertation. Many thanks, as well, to Don and Jan Cross, who generously welcomed me at their place to make revisions to the dissertation. And last, but not least, I thank my parents, who planted the seed for this dream many years ago. 


\section{TABLE OF CONTENTS}

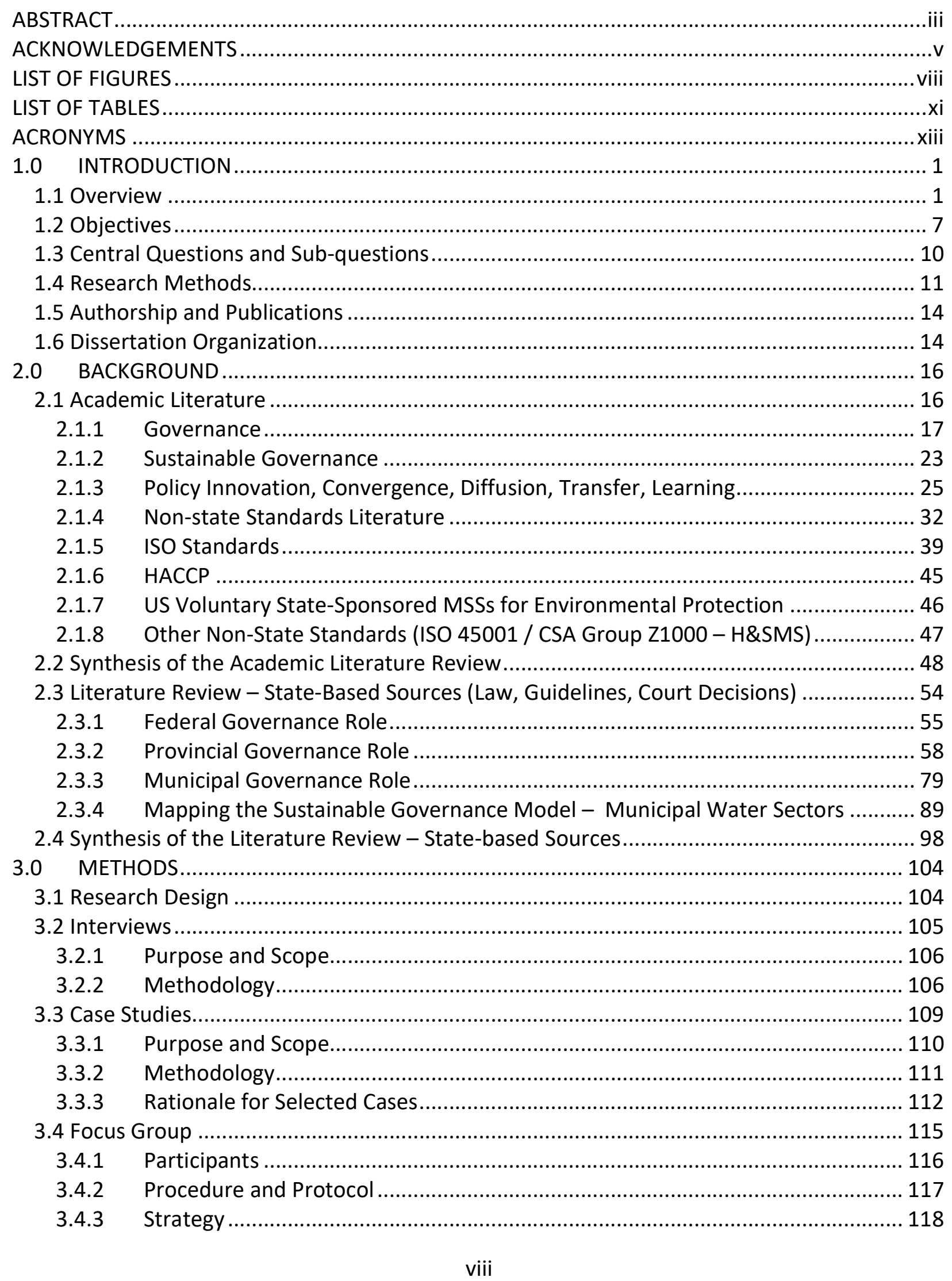




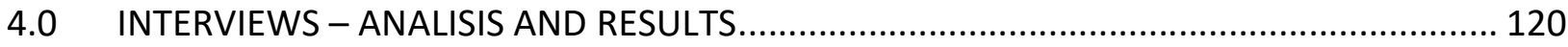

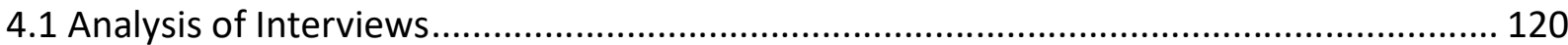

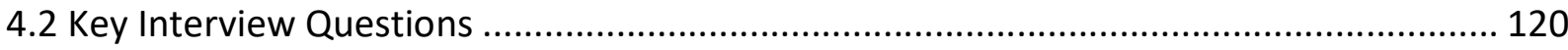

4.3 Enablers, Barriers, Governance, Structure and Procedural Aspects............................. 122

4.4 Relevant Positions by Sector (municipal, consultants and ENGOs) ............................... 128

4.5 Synthesis and Preliminary Conclusions of Chapter.................................................. 134

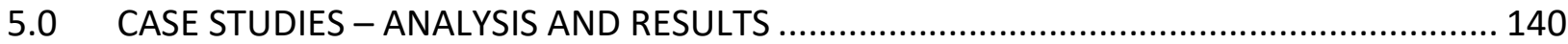

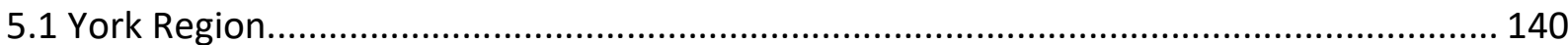

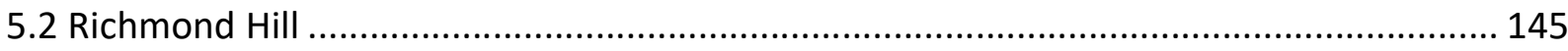

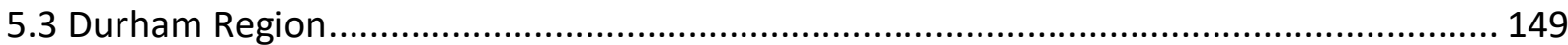

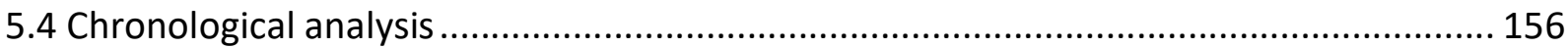

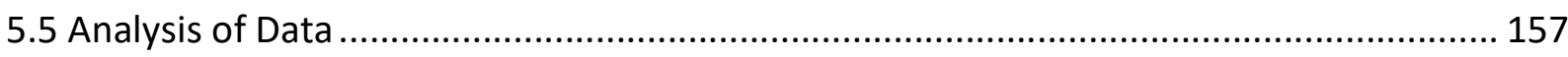

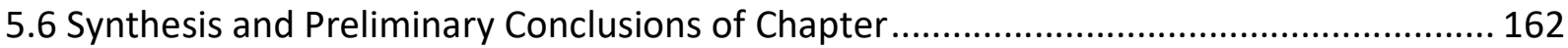

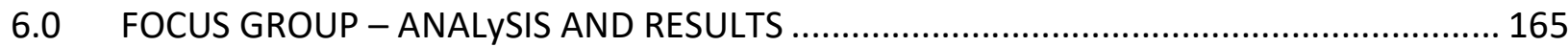

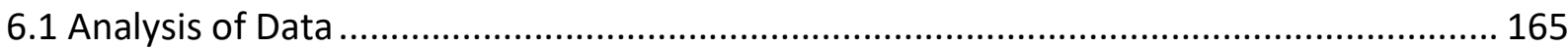

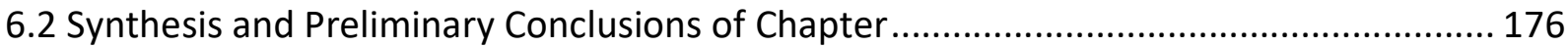

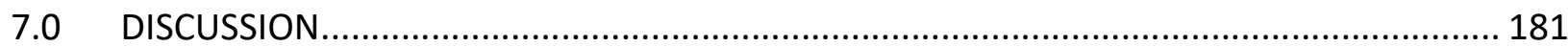

7.1 Connecting the Theoretical Concepts with the Research Findings............................... 181

7.2 Factors For and Against the Use of MSS Standards for Wastewater and Stormwater .... 187

7.3 Regulatory Gaps and Complementarity of an MSS in the Ontario Water Sectors .......... 191

7.3.1 Considerations for Selecting an MSS for the Water Sectors ............................. 191

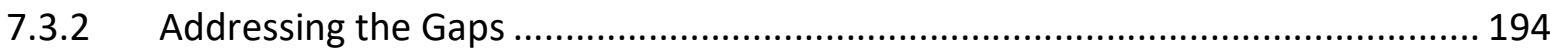

8.0 CONCLUSIONS AND RECOMMENDATIONS.......................................................... 199

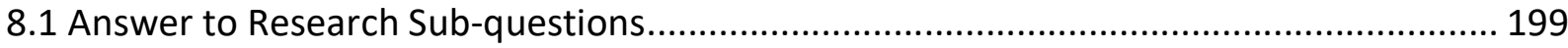

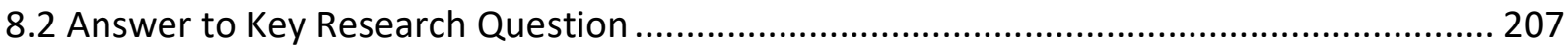

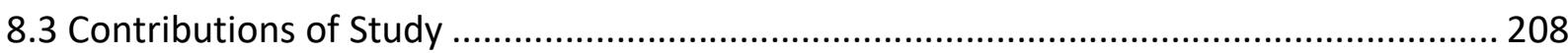

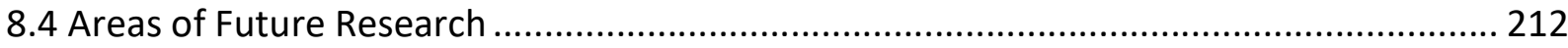

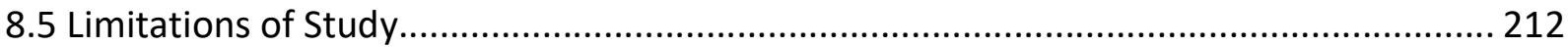

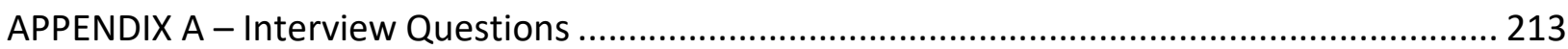

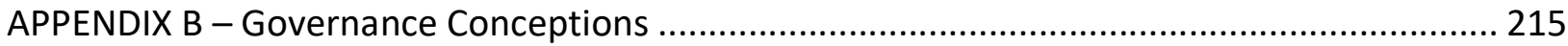

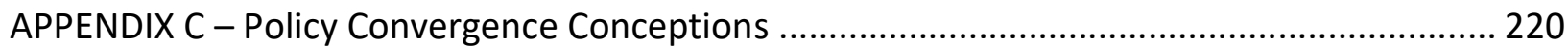

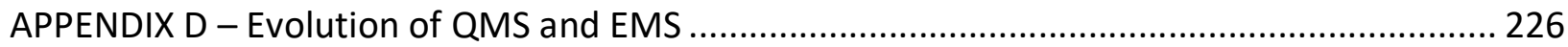

APPENDIX E - Canadian Laws - References to ISO 14001................................................... 229

APPENDIX F - Short Summaries of Municipal ISO 14001 Experience ..................................... 232

APPENDIX G - Ryerson University Research Ethics Board.................................................. 255

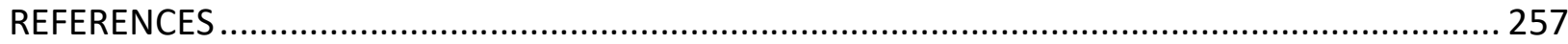




\section{LIST OF FIGURES}

Figure 1. Depiction of a Sustainable Governance Approach - Municipal Water Sector ............... 5

Figure 2. Synopsis of the Incremental Research Sequence ............................................. 12

Figure 3. Policy Innovation Triggers / Sources for State and Non-state Standards ................... 36

Figure 4. QMS, EMS and CSR for Water/Wastewater Systems ........................................ 43

Figure 5. High Level Plan-Do-Check-Act Structure of the EMS* ........................................... 44

Figure 6. Overlap of Elements Common to ISO 9001 and ISO 14001*.................................. 44

Figure 7. Governance Models and Levels of Participation of Non-state Actors........................ 49

Figure 8. Conservation Authorities and Regional Municipalities in the GTA ......................... 62

Figure 9. Growth of EMS for Water and Wastewater System Components in Canada .............. 82

Figure 10 Sustainable Governance Map for the Municipal Water Sectors (State-based

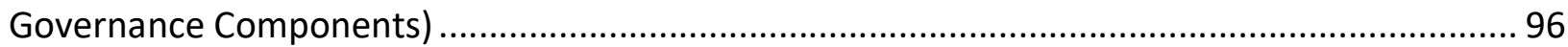

Figure 11. Sustainable Governance Map for the Municipal Water Sectors (State and Non-state

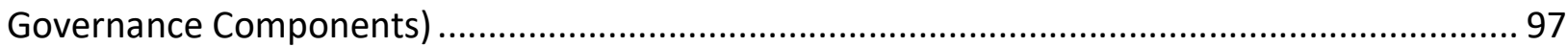

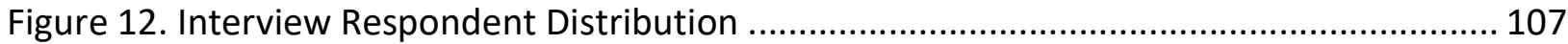

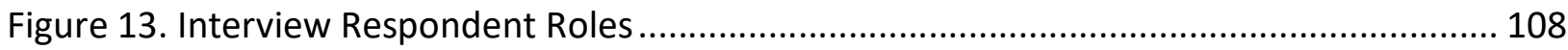

Figure 14. Interview Respondents' MSS Expertise (DWQMS, ISO 9001 \& 14001)................... 108

Figure 15. MSS Enablers - Governance and Policy Aspects ............................................... 125

Figure 16. MSS Enablers - Structure and Process Aspects............................................. 126

Figure 17. MSS Barriers - Governance and Policy Aspects ............................................... 127

Figure 18. MSS Barriers - Structural and Process Aspects ............................................. 128

Figure 19. York Region and Richmond Hill Location ..................................................... 145

Figure 20. DWQMS Single Inputs \& Outputs (Controls: QMS Process) ................................. 192

Figure 21. EMS Wastewater - Multiple Inputs \& Outputs (Controls: EMS Process)................. 193 


\section{LIST OF TABLES}

Table 1. Chronology of Governance Conceptions and Characteristics.................................... 19

Table 2. Policy Convergence Concepts and Examples .......................................................... 31

Table 3. State and Non-state Rule Instruments and Voluntary Instruments .......................... 38

Table 4. Prominent Risks/Hazards vs. Most Adequate MSS ............................................... 52

Table 5. Contributing Elements Leading to the Walkerton Tragedy .................................... 67

Table 6. Acts, Regulations, and Guidelines Promulgated Following the Walkerton Inquiry........ 68

Table 7 Connecting Contributing Elements to the Walkerton Tragedy and Water Regulations . 69

Table 8. Federal, Provincial, Municipal Regulatory Framework Relevant to ISO 14001 ............. 78

Table 9. Examples of Lawsuits due to Environmental Offenses \& Remediation Costs ................ 86

Table 10. Lessons from Canadian Municipalities Led by Court's Decisions to Adopt MSS .......... 88

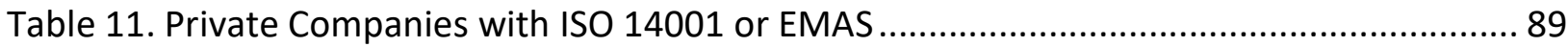

Table 12. Municipalities with ISO 9001, ISO 14001, OR HACCP ........................................... 114

Table 13. Selection of Municipalities for the Case Study Method ........................................ 114

Table 14. Governance, Structure, and Process - Enablers and Barriers .............................. 123

Table 15. Municipalities' Specific View-points .................................................................... 129

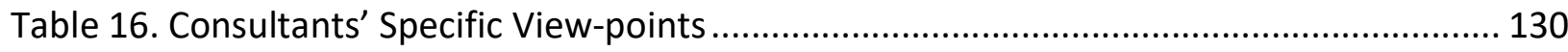

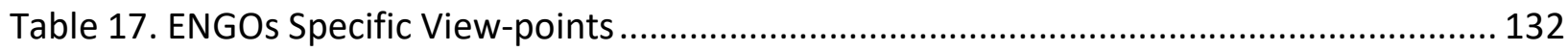

Table 18. York Region and Richmond Hill - Management System Standards ........................ 141

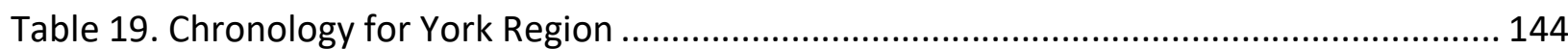

Table 20. Chronology for Richmond Hill EMS ................................................................. 146

Table 21. Durham Region - Integrated Management System (2006-2016)........................... 151

Table 22. Durham Region - Integrated Management System (2017- Onwards) ..................... 153

Table 23. Chronology for Durham Region IMS ............................................................... 154

Table 24. Consolidated chronology (York Region, Richmond Hill, Durham Region) .................. 156

Table 25. Lessons from Other Canadian Municipalities' Experience with MSSs ...................... 161

Table 26. Focus Group Participant Categories and Argument Counts by Topic....................... 166

Table 27. Gaps in Legislation and How the DWQMS Fills Them in Drinking Water .................. 196

Table 28. Critical Control Points for Municipal Drinking Water Systems (DWQMS)................. 197 
Table 29. CPPs Proposed for Wastewater / Stormwater Systems ....................................... 197

Table 30. Summary of Historical Events Leading to the ISO 9001, ISO 14001 and DWQMS ..... 228 


\section{ACRONYMS}

ACRWC: Alberta Capital Region Wastewater Commission

AWWA: American Water Works Association

BMP: Best Management Practices

BUILD: Building Industry and Land Development Association

CICA: Canadian Institute of Chartered Accountants

CEAA: Canadian Environmental Assessment Act

CCME: Canadian Council of Ministers of the Environment

CCP: Critical Control Points

CELA: Canadian Environmental Law Association

CEPA: Canadian Environmental Protection Act

CGG: Commission of Global Governance

CMOM: Guide for Evaluating Capacity, Management, Operation, and Maintenance

CSA: Canadian Standards Association

CSO: Combined Sewer Overflow

CSR: Corporate Social Responsibility

DFO: Department of Fisheries and Oceans Canada

DWQMS: Drinking Water Quality Management System

EASR: Environmental Activity and Sector Registry

ECA: Environmental Compliance Approval

ECCC: Environment and Climate Change Canada

ECO: Environmental Commissioner of Ontario

EIS: Environmental Impact Statement

EMS: Environmental Management System

ENGO: Environmental Non-governmental Organizations

EPA: Ontario Environmental Protection Act

FCM: Federation of Canadian Municipalities

GTA: Greater Toronto Area

HACCP: Hazard Analysis and Critical Control Points

IMS: Integrated Management System

ISO: International Standards Organization

MCEC: Manitoba Clean Environmental Commission

MCEA: Municipal Class Environmental Assessment

MDW: Municipal Drinking Water

MEA: Municipal Engineers Association

MECP: Ontario Ministry of the Environment, Conservation and Parks

MMAH: Ontario Ministry of Municipal Affairs and Housing

MOL: Ontario Ministry of Labour 
MSS: Management System Standards

MTO: Ontario Ministry of Transportation

MWWRC: Municipal Water and Wastewater Regulatory Committee

NEMISIS: Canada's National Enforcement Management Information and Intelligence System

NMA: Ontario Nutrient Management Act

NRC: Canadian National Research Council

OCSI: Ontario Coalition for Sustainable Infrastructure

OCWA: Ontario Clean Water Agency

OGCA: Ontario General Contractors Association

OH\&S: Occupational Health and Safety

OHSA: Occupational Health and Safety Act

OMAFRA: Ontario Ministry of Agriculture, Food and Rural Affairs

OMWA: Ontario Municipal Water Association

OPSD: Ontario Provincial Standards Drawings

OPSS: Ontario Provincial Standards Specifications

OPWA: Ontario Public Works Association

OSWCA: Ontario Sewer and Watermain Construction Association

OWRA: Ontario Water Resources Act

OWWA: Ontario Water Works Association

POO: Provincial Officer's Order

PPP: Public-Private-Partnerships

PSAB: Public Sector Accounting Board

PWQO: Provincial Water Quality Objectives

QMS: Quality Management System

SCC: Standards Council of Canada

SDWA: Ontario Safe Drinking Water Act

SOWC: Southern Ontario Water Consortium

SSO: Sewer System Overflow

SWM: Stormwater Management

WEAO: Water Environment Association of Ontario

WEF: Water Environment Federation

WPCP: Water Pollution Control Plant

WSER: Wastewater Systems Effluent Regulations

WWTP: Wastewater Treatment Plant 


\subsection{INTRODUCTION}

\subsection{Overview}

This dissertation explores the evolving governance approaches of the municipal drinking, wastewater ${ }^{1}$ and stormwater sectors in Ontario, focusing on the apparent inter-connection or bridging between state (government-based) and non-state forms of regulation, ${ }^{2}$ where private sector, civil society and multi-stakeholder rule instruments, processes, institutions and actors all perform important roles in support of conventional state-based regulation. This dissertation involves the following: (i) an examination of theories of governance, (ii) a review of the literature concerning policy convergence and standards as instruments of organizational innovation, (iii) an exploration of the legal and policy framework within which municipal water management takes place, (iv) semi-structured interviews with persons knowledgeable in municipal water management, $(v)$ case studies of municipalities that have employed management system standards for water management, and (vi) a focus group with experts to discuss reform alternatives. All of this is undertaken with a view to understanding the value of a legislatively mandated environmental management system standard for Ontario municipal wastewater and stormwater management, to be added to the drinking water quality management system that is already in place.

The initial impetus for innovation in municipal water governance in Ontario was the Walkerton tragedy (2000), when an estimated 2,300 people became seriously ill and seven people died from exposure to microbially contaminated drinking water in Walkerton, Ontario, a town of approximately 5,000 people located northwest of Toronto (Hrudey et al., 2002: 98101). Following this tragedy, an independent inquiry and several lawsuits (Wellington, Burley \&

\footnotetext{
${ }^{1}$ The term wastewater in Canadian federal and provincial legal contexts, has the same meaning as "sewage" (both are fluids carrying pollutants). This study uses both terms interchangeably. Moreover, in federal and provincial legislation the terms wastewater and sewage refer to both sanitary wastewater and stormwater. This study uses the terms wastewater and stormwater as distinct concepts, as the two terms have different management requirements for their infrastructure and are subject to different "inputs". Stormwater is subject to the uncertainties of weather conditions (i.e. rain intensity and duration), while wastewater has more defined sources and generally has separate drainage systems.

${ }^{2}$ Non-state standards are standards developed by non-state entities in response to public concerns, human tragedy, environmental crises or as precautionary measures (Kollman et al., 2002: 43). While government rule instruments provide minimum standards, non-state standards are developed and updated more frequently and may be more stringent than government criteria (Fulponi 2006:10; Delmas et al., 2008:75).
} 
Rollinson-Lorimer, 2010: 522-529) led to a series of legislative, policy and governance responses (Johns, 2014b: 215) that focused on the drinking water sector. In particular, following Justice O'Connor's Inquiry recommendations (2002b), the government of Ontario modernized its legislation on municipal drinking water. The new regulatory framework consists primarily of three statutes, 11 regulations, and related guidelines (Table 6). The resultant new governance framework for Ontario's drinking water follows a risk-based management approach and includes a legislatively mandated quality management system developed for drinking water (the Drinking Water Quality Management Standard, or DWQMS). The DWQMS draws on the non-state ISO 9001 standard for Quality Management Systems (QMSs), as well as the Hazard Analysis and Critical Control Points (HACCP) for the food industry, and also considered elements of ISO 14001 standard for Environmental Management Systems (O'Connor, 2002a; and 2002b; City of London, 2008).

Beyond the drinking water context, there have been only marginal improvements to Ontario's municipal wastewater systems, such as O. Reg. 129/04 pertaining to the licensing of wastewater operators, but there has been no wholesale updating and integration with management systems akin to that now in place for drinking water. The municipal wastewater and stormwater sectors have largely been left behind, still operating pursuant to a regulatory governance structure originally established in the 1950s under the Ontario Water Resources Act (OWRA).

The argument put forward in this dissertation is that there is a growing governmental recognition in federal-provincial-municipal legal frameworks for recognition of the value of drawing on non-state environmental management system (EMS) standards as part of environmental protection efforts, evidenced in the voluntary actions of some municipalities to adopt non-state environmental management system standards in their operations. There is also considerable support for the use of environmental management system standards in Ontario's municipal wastewater and stormwater sectors, evidenced in interviews conducted for this research with municipal and other officials. At a theoretical level, this support for the use of non-state EMS standards is consistent with academic conceptions of policy convergence and policy transfer, both in what is described here as horizontal policy convergence (i.e. from non- 
state to state, and from one municipality to another), vertical policy convergence (i.e. support for the use of non-state environmental management system standards by municipalities from federal government sources, provincial government sources and the courts), including a quasivertical policy convergence (i.e. the courts acting as facilitators to resolve issues from federal and provincial jurisdiction as those apply to municipalities and ordering the adoption of EMS or in some cases ISO 14001), and with related concepts of policy transfer and policy diffusion. The criteria used for assessing the policy convergence in this study includes:

$\checkmark$ Explicit use of non-state rule instruments (e.g. ISO 14001, ISO 9001, Blue Flag beach certification).

$\checkmark$ Explicit integration of non-state processes (e.g. third-party auditing/certification).

$\checkmark$ Explicit reliance upon non-state institutions (e.g. using CSA, a non-state standards body, to develop a DWQMS or customized wastewater or stormwater EMS standard;

Environmental Defence, the body in administering the Blue Flag program).

$\checkmark$ Explicit involvement of non-state actors (e.g. MECP-accredited registrars such as BSI and SAI Global, to obtain third-party certification under the DWQMS, Swim Drink Fish).

The use of EMS standards initiated, developed and regulated by non-state actors is also consistent with certain conceptions of governance that recognize the value of using the nonstate rule instruments discussed in the dissertation, and aligns especially well with the concept of sustainable governance (Webb, 2005: 278-279). The sustainable governance approach is based on the premise that a combination of state and non-state rule instruments, institutions, processes and actors is particularly well positioned to address complex and evolving environmental issues and other issues of public interest - involving collaboration between state and non-state actors in some cases and more of a check-and-balance dynamic in others.

In Ontario, in the broader context noted above, after 10 years of experience with the provincially required DWQMS, municipalities have generated a body of knowledge about the value of management system standards (MSSs), and this knowledge is now proactively being expanded from its use in drinking water management to wastewater and stormwater (Tovilla and Webb, 2017a: 225). Research for this dissertation suggests that there is a slow but steady transfer of knowledge concerning MSS approaches from the municipal drinking water to 
wastewater and stormwater sectors. In part, the transfer involves a community of officials in municipal water utilities that are growing more knowledgeable about, benefiting from and drawing on MSSs to address environmental performance in their operations.

The proposition explored in this dissertation is that ISO QMS and EMS standards appear to be forming a conceptual "bridge" between state and non-state actors (Weiss, 2000: 810), as innovative forms of regulation, with an increasing reference to such standards in legislation and related government documents and in court decisions leading to policy convergence among the three levels of government with respect to the value and use of QMS standards for drinking water activities and EMS standards in support of environmental protection objectives (Tovilla and Webb, 2017a: 224). The conventional command and control regulatory responses to water regulation have been characterized by commentators as an often costly approach to regulation, that tends to be inefficient, with a stifling effect on innovation, enforcement difficulties, an excessive focus on "end-of-pipe" solutions, and a propensity for creating "adversarial relationships" (Sinclair, 1997: 530-531).

At the other end of the extreme in terms of regulatory options would be self-regulation approaches developed and implemented exclusively by the private sector, in which there would potentially be no governmental involvement. Such a self-regulation approach may or may not support governmental objectives. The use of a non-state regulatory approach such as some variation on the ISO 14001 EMS standard, which is reviewed and approved for operation by governmental actors, appears to align well with the concept of sustainable governance, in that both state and non-state actors, instruments, institutions and processes are involved, with both collaboration and "check-and-balance" dynamics.

Figure 1 offers a depiction of a sustainable governance perspective on the array of state and non-state actors (and associated rule instruments, institutions, processes and actors) variously involved in municipal water governance. For the purposes of Figure 1, municipalities are positioned at the centre of a sustainable governance-type system with evolving roles for state and non-state actors, all of which provide some form of regulatory and non-regulatory stimuli for improved water management and environmental protection, leading toward a state/ nonstate convergence of governance approaches applying to municipal water management. 


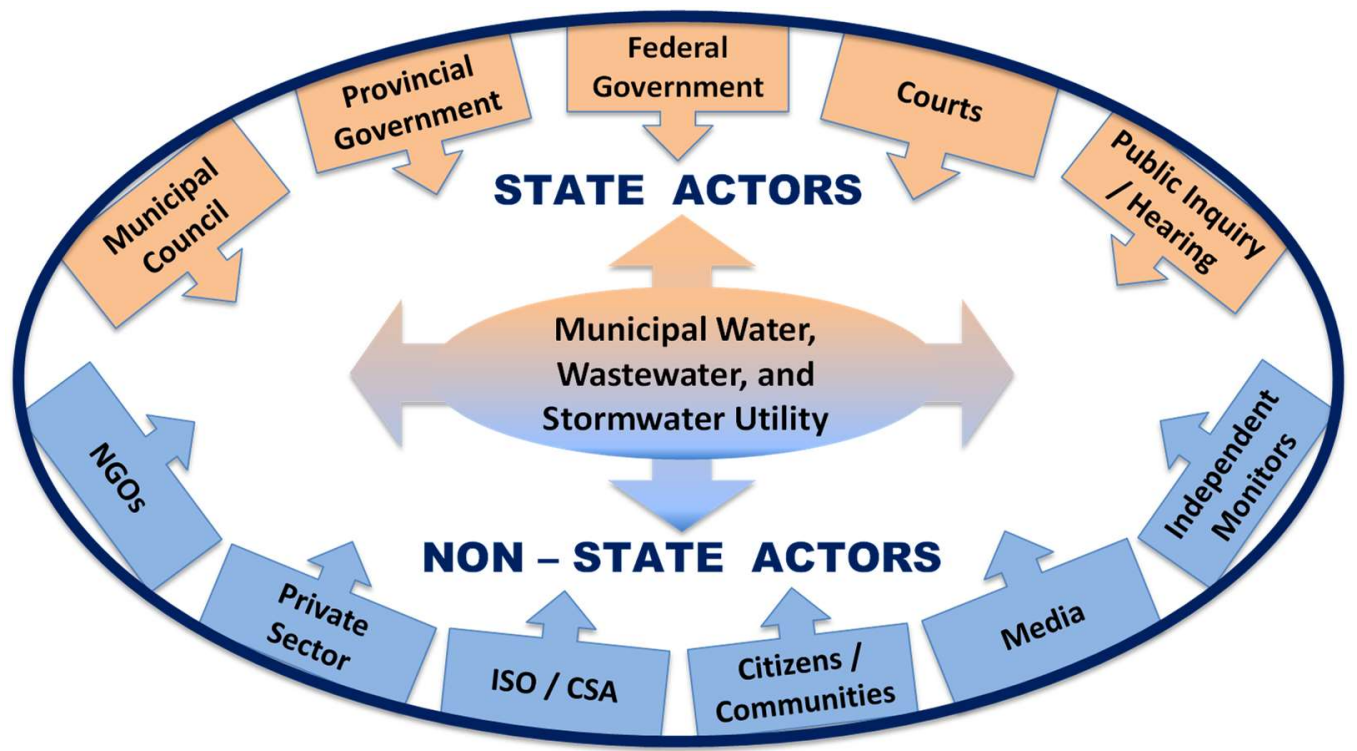

Figure 1. Depiction of a Sustainable Governance Approach - Municipal Water Sector

Municipalities are uniquely placed to highlight particular regulatory gaps and limitations that have been revealed in the implementation of the regulatory framework put in place following the Walkerton Inquiry (2002). An increasing reliance upon EMS and certification can be seen as a partial response to some of the previously existing gaps and limitations in the regulatory approach. While the situation has improved with the introduction of a quality management system standard for the protection of drinking water, the wastewater and stormwater regulatory regimes have been left largely untouched and still rely largely on a regulatory framework put in place in the 1950s. Preliminary research suggests that ISO-type environmental management system standards could be useful supplements for wastewater and stormwater regulation, with the EMS standard supplementing conventional command and control regulation (Tovilla and Webb, 2017a: 224).

As noted in the dissertation title, this work core theme is the "value" of EMS standards for the municipal wastewater and stormwater sectors, and for the purposes of the dissertation, what is meant by "value" is the practical utility of municipalities applying environmental management system standards to assist in achieving environmental objectives and societal expectations, as part of broader assemblage of rule instruments, processes, institutions and actors that all are involved in the regulatory governance. Practical utility is here considered to 
include such features as: possible assistance in meeting legal requirements and thereby decreasing the likelihood of regulatory violations taking place, assistance in demonstrating due diligence when violations have occurred, possible operational financial efficiencies, increasing consistency in the operation of infrastructure and assistance in demonstrating accountability, transparency and good governance to the public and other stakeholders.

As is discussed later in the dissertation, while non-state standards such as ISO 9001 and ISO 14001 have largely been adopted by profit-driven organizations to improve market share and to "signal" good conduct to consumers/ public/ suppliers, as well as to assist them in demonstrating to governments, the public and the courts that they are acting in a diligent way in attempting to comply with the law and meet societal expectations of good conduct and good business practices. In a similar manner, the suggestion made here is that Canadian municipal governments are adopting non-state MS and other standards, not to supplant conventional state regulation but to complement this regulation, and thereby help to satisfy the increasing demands on them for accountability and transparency, and to provide additional assurances that they are making their best efforts to protect human health, environmental and economic interests, reduce risks, and address legal duties.

Furthermore, it appears that both business private and public sectors are being incentivized to adopt non-state MS and other standards through legal developments (e.g. the due diligence defence) and through pressure from environmental NGOs and the media (Figure 3). While some scholars have expressed concern that adoption of non-state standards represents evidence that governments are getting out of the business of regulating (hollowing out of the state), research for this study shows that governments are adding a scaffolding of new laws in which the non-state standards are only one component. For example: in Ontario, there has been a build-up of new legal structure around the DWQMS (pursuant to the Safe Drinking Water Act, 2002, so that the DWQMS becomes a tool used in achieving the goals of the Safe Drinking Water Act); at the federal level, the Canadian Environmental Enforcement Act, 2010 represented a new layer of federal legislation introduced in 2010 that references use of management system standards as part of a broader regulatory enforcement regime; and the 
Ontario Environmental Penalties Regulation, 2007 (Table 8) makes direct references to ISO 14001 and EMS as part of a broader environmental penalties approach.

\subsection{Objectives}

This dissertation is intended to generate research recommendations for shaping public policy regarding governance of water management activities in Ontario. The dissertation examines a perceived evolving policy convergence in state/non-state environmental protection in the Ontario municipal drinking water, wastewater, and stormwater sectors, and explores the idea that this policy convergence is occurring in two dimensions:

$\checkmark$ horizontal (i.e. from non-state to state rule instruments and associated institutions, processes and actors).

$\checkmark$ vertical (i.e. across federal, provincial and municipal levels of government and a parallel quasi vertical judicial convergence (i.e. with Canadian courts at various levels drawing on EMS standards in their decisions as applied to municipal governments and firms, with the courts thereby acting as "facilitators" in the application of federal and provincial environmental laws applying to municipal governments and other organizations).

The dissertation explores the practical utility of a mandated environmental MSS to be applied to the municipal wastewater and for the stormwater sectors, similar to the DWQMS that has been developed for the municipal drinking water sector. This, in an attempt to address the perceived obsolescence of the Ontario regulatory framework for municipal wastewater and stormwater (see Chapter 2.3.2), which is largely based on regulations of the 1950s (for wastewater) and the 1970s (for stormwater); and also to assist municipalities to address perceived risks associated with environmental protection of rivers and lakes and property damage (e.g. basement flooding) due to raw sewage spills, overflows, stormwater flooding and other hazards (see Table 4 and Chapter 7.3).

Municipalities have a unique position as they are regulated by two other levels of government, and as public entities are subject to more accountability, transparency and related responsibility requirements than private entities such as for-profit companies. Not only are municipalities subject to federal and provincial regulation, but they are also public authorities 
that regulate industry and business within their boundaries. As will be discussed below, there have been numerous court decisions charging municipalities with violations of federal or provincial water protection regimes, and in some cases this has resulted in municipalities implementing EMSs and obtaining certifications to those standards.

The research undertaken for this dissertation suggests that the adoption of MSSs and certification for wastewater and stormwater aligned to ISO 14001 could be expected to generate value and positive benefits, including incentivizing ongoing performance improvements and technological innovation. In addition, the adoption of EMS standards and certification processes could create an extra layer of protection in the form of non-state inspection and compliance activity beyond that conducted by governmental inspection and compliance activities.

The research outlined here reveals that some municipalities in Ontario and elsewhere have already voluntarily secured ISO 14001 certification for their water/wastewater/stormwater operations. Arguably, one motivation for the adoption of EMS is recognition of the potential for the regulated entity to rely upon certification as a defense of due diligence in the event of prosecution, as a strategy to reduce regulatory liability (and if convicted, there could be grounds for the regulated entity to file a lawsuit for negligent certification). This can be seen as additional support for the proposition that there is convergence between state and non-state sectors in recognition of the value of adopting EMS and other non-state governance approaches as a way to stave off regulatory liability (i.e. to forestall, counter, and defend against prosecutions under environmental protection laws and regulations).

Drawing on the foregoing, the position explored in this dissertation is that there appears to be value in developing a provincially mandated Wastewater and Stormwater Environmental Management System Standard that is aligned with the DWQMS, ISO 9001 (QMS), ISO 14001 (EMS), and HACCP, in the interest of ensuring a harmonized consistent approach across the drinking water, wastewater and stormwater contexts.

\section{Key contributions}

Through its examination of use by municipalities of EMS standards, the following aspects are identified as key contributions of this study: 
1. Empirical support concerning the way governments are drawing on independently developed non-state rule instruments, processes, institutions and actors in support of implementation of municipal environmental public policy (e.g. ISO 14001, third party audits, Blue Flag program), why they are drawing on these non-state approaches, and how these regulatory innovations align with theories of governance.

2. Research demonstrating innovative forms of policy convergence happening in the Ontario municipal wastewater and stormwater sectors by adopting and/or transferring elements from the drinking water regulatory regime in two dimensions: at the horizontal level (i.e. governments adopting non-state approaches, e.g. municipalities using environmental management system standards -EMSs) and at the vertical level (i.e. federal and provincial governments drawing on management systems standards to be applied by municipalities, with a parallel quasi-vertical judicial application of management systems standards in their application of federal and provincial laws to municipal governments and other organizations).

3. Examination of the ways that individual municipalities are (voluntarily) being "regulated" by non-state rule instruments, processes, institutions and actors in support of public policy objectives and doing so in advance of formal governmental laws and policies incorporating non-state rule instruments (this shows how non-state initiatives contribute to long-term sustainability, even when state action is not yet forthcoming).

4. Support for the proposition that there is considerable practical utility in municipalities being subject to a provincially required Wastewater and Stormwater Environmental Management System Standard aligned with the ISO 14001 EMS, in a manner similar to the DWQMS that is already in place. While a mandated standard may not appear viable at this time, an alternative option is to have a provincially endorsed, voluntary EMS standard developed by a standards organization such as the CSA, which may be a catalyst to boost voluntary uptake of MSSs by municipalities.

The research methodology applied in this study involved interviews, case studies and a focus group, a combination that involved both a sequential process and triangulation of data. The sequential approach consisted in using the coding of data from the interview respondents to 
assist in identifying municipalities for the case studies. Subsequently, the case studies were analyzed and provided a basis for the focus group session. Thus, the author built on and learned from first the interviews, then the case studies, and finally the focus group session. The interviews, case studies and focus group also assisted in triangulation of the data, allowing for confirmation of or adjustment in findings based on data collected in each of the interviews, case studies and focus group research.

In summary, the dissertation should assist academics, governments and non-state actors in understanding the ways in which non-state MSS can and are being used in support of public policy objectives, and the practical utility of the Ontario provincial government legislatively requiring that Ontario municipalities adopt an EMS standard to assist in meeting Ontario environmental public policy objectives, in a similar manner to the way the provincial government has required Ontario municipalities to adopt a quality management system standard to assist in meeting public policy objectives concerning the provision of safe drinking water for Ontarians.

\subsection{Central Questions and Sub-questions}

One central question and six sub-questions form the focus of this research. The central question is: is there value in creating a provincially mandated municipal wastewater environmental management system standard, and a stormwater environmental management system standard?. The sub-questions are:

1. How do academic conceptions of governance, policy convergence and management systems standards assist in understanding Ontario's evolving approach to municipal water regulation?

2. What scholarly conception of governance best aligns with Ontario's evolving approach to municipal water regulation?

3. Are management system standards likely to have neutral, positive, or negative effects on the performance of Ontario municipal water management activity? 
4. Which MSS standards relevant to the water sectors (ISO 9001 - QMS, ISO 14001 - EMS and HACCP) are best suited to address municipal water, wastewater and stormwater activity?

5. Why are municipalities in Ontario and other jurisdictions adopting quality and environmental management system standards, such as those set out in ISO 9001 and ISO 14001?

6. How (if at all) has the voluntary adoption of MSSs (in the form of ISO 9001 and/or ISO 14001) evolved over time, for the municipal water, wastewater and stormwater sectors?

\subsection{Research Methods}

For this study, a multi-method approach was followed using non-experimental methods, applying descriptive and qualitative research components (semi-structured interviews, a focus group, and case studies) in a "staged" or sequential approach. The multi method research approach will allow for what Cresswell et al., referencing Hossler and Vesper, refer to as a "concurrent triangulation method design" (2007: 162), indicating a triangulation of data collection, separate data analysis, and the integration of databases at the interpretation or discussion stage of the report, and a way to test validity (Carter et al, 2014: 545). The multi method approach applied in this study used three different data collection techniques: semistructured interviews, a case study method, and a focus group (Figure 2). The proposed methods are considered "applied science" as they are focused on immediate application.

\section{Literature Review}

One of the objectives of the literature review is to place the research work conducted by others in the context of its contribution to the understanding of the proposed research. This process allows for a sound perspective to identify what has been done before and where this proposal is going (Salkind, 2012: 46). The literature review in this study is presented in two parts. First, the academic literature is examined; and then, government law and policy is considered. In this section sub-questions 1 and 2 will be addressed. 


\section{$\underline{\text { Interviews }}$}

Semi-structured interviews were conducted to better understand the experience and insights of professionals and practitioners, to gather empirical information, as well as attitudes, beliefs, prejudices, preferences, and opinions, using both closed-ended and open-ended questions. This allowed interviewees to elaborate on points of interest and thus increase the value of the data. The list of initial questions used in the interview are included in Appendix A. This information collected is intended to facilitate a better understanding of people's perceptions in order to address particular questions (Salkind, 2012: 199).

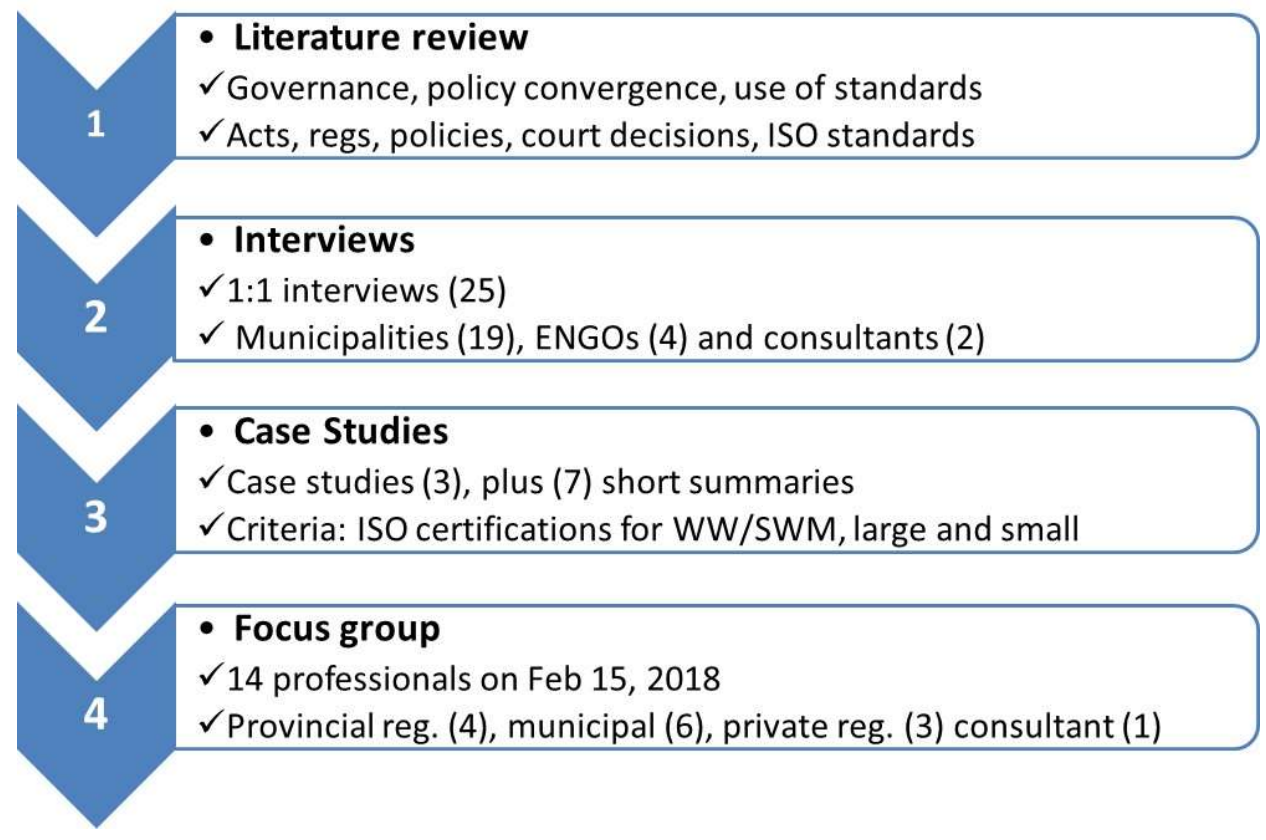

Figure 2. Synopsis of the Incremental Research Sequence

For the selection of interview subjects, to assist in ensuring that a diversity of perspectives was considered, an effort was made to include government officials with direct experience in municipal water governance, consultants with similar experiences and environmental nongovernmental organizations (ENGOs) with particular interest in water issues. In this section sub-questions 3 and 4 will be initially addressed, as well as opinions examined to address the central research question. 


\section{Case Studies}

Another research method employed in the dissertation was the case study, which involved drawing on publicly available literature as well as interviews to better understand the experiences of municipalities with management system standards. The literature on case studies suggests that they can provide insights concerning motivation, inspiration and illustration (Siggelkow, 2007: 21). Three municipalities in Ontario were selected for application of the case study method. These municipalities all have experience with ISO 9001, ISO 14001 and HACCP certifications. The case studies were undertaken to assist in understanding the motivations, challenges, and benefits of implementing ISO 9001, ISO 14001, and HACCP certification, and facilitated evaluations of the complementarity of the DWQMS, ISO 9001, ISO 14001 and HACCP. In this section sub-questions 5 and 6 will be triangulated with data obtained from interviews, as well as opinions examined to address the central research question.

\section{Focus Group}

The focus group method was employed for this research to gather information and bring various viewpoints together in a relatively short period of time. It can also offer insights into topics not previously fully understood and provides an opportunity for researchers to understand how different focus group members arrive at their conclusions.

For this study, the focus group method was planned as the last thread to tie everything together and obtain feedback and criticism from expert practitioners. Its purpose was to build on the preliminary results of the literature review, the semi-structured interviews and the case studies. It also assisted in corroborating and triangulating the research process and all research questions, particularly the main research question. For this focus group, the author moderated the session and the PhD Supervisor acted as a participant observer. Two graduate students were recruited as recorders of conversations and to facilitate the planned breakout sessions. In this section sub-questions 3 to 6 will be further reviewed and the central research question will be addressed with all focus group participants. 


\subsection{Authorship and Publications}

Edgar Tovilla is the author of the dissertation. The dissertation was prepared with input from and under the supervision of Dr. Kernaghan Webb, as part of the author's doctoral degree in the Environmental Applied Science and Management program.

During the course of the research for this dissertation, an article was prepared by the author under the supervision of Dr. Kernaghan Webb, which was published in the Water Quality Research Journal (Tovilla and Webb, 2017a). Preliminary findings at different stages of the research were presented at multiple provincial and national conferences and articles were published on conference proceedings and magazines. Edgar Tovilla was the main author of these articles, drafting the originals and receiving guidance and editorial assistance by Dr. Kernaghan Webb. These conferences and articles included: the Water Environment Association of Ontario conference proceedings (Tovilla, 2017); the National Water and Wastewater Conference in Montreal, in November 2018 (Tovilla and Webb, 2018); the Research Policy Brief and annual report for the Ryerson University's Geoffrey Bruce Fellowship in Fresh Water Policy (where the author was the inaugural recipient of the Fellowship). Finally, preliminary findings and observations from this research were scheduled for a presentation at the Water Environment Association of Ontario - Utility Management Forum annual conference in Burlington, ON, presented in October 2019.

\subsection{Dissertation Organization}

The dissertation is organized as follows: Chapter 2.0 focuses on two areas. First, there is an exploration of the underlying theoretical aspects of the study, including an examination of scholarly conceptions of regulatory governance in environmental contexts, policy convergence and related concepts such as policy transfer and policy diffusion, as well as the academic literature on management system standards as they relate to water, wastewater and stormwater systems. Second, there is a literature review of the legal and policy framework within which municipal water governance operates, focusing on government use of management system standards, including the analysis of federal, provincial and municipal laws and regulations and court decisions. 
Chapter 3.0 describes the research methods applied in this study including the interviews, case studies and focus group. Chapter 4.0 describes the lessons learned from the semistructured interviews conducted for the dissertation. Both state and non-state respondents knowledgeable about municipal water management were interviewed. Chapter 5.0 consists of the lessons learned from case studies of three Ontario municipalities that have adopted management system standards and summaries of seven other municipal experiences. Chapter 6.0 sets out the results of the focus group session, which involved both state and non-state participants. Finally, a discussion of Chapters 2.0 to 6.0 is provided in Chapter 7.0 and key conclusions, recommendations, contributions of this study and possible further research are discussed in Chapter 8.0. 


\subsection{BACKGROUND}

This chapter is divided into two areas, a review of the academic literature and a review of government sources (law, guidelines and court decisions). The review of academic literature pertaining to public policy assists in understanding Ontario's approach to regulating municipal drinking water, wastewater and stormwater. In particular, the academic literature concerning governance, policy convergence and management system standards is examined. This literature review is undertaken with a view to addressing the following research sub-questions:

1. What scholarly conception of governance best aligns with Ontario's evolving approach to municipal water regulation?

2. How do academic conceptions of governance, policy convergence and management systems standards assist in understanding Ontario's evolving approach to municipal water regulation?

\subsection{Academic Literature}

The insights developed in this section are intended to assist in analysis of Ontario's approach to municipal water regulation, which takes place in subsequent sections of the dissertation. Before proceeding further in this academic literature review, it is perhaps useful to provide a note to the reader concerning the somewhat divergent nomenclature used by governance scholars, and the approach taken in this dissertation.

A review of the literature reveals that some authors refer to "public" and "private" approaches to governance(e.g. Peters and Pierre, 1998), while others speak of "government" and "non-governmental" approaches to governance (e.g. Johns et al 2018: 317, 322), and others (e.g. Webb 2005: 242-249), refer to "state" and "non-state" governance. Webb also divides the "non-state" category into private sector and civil society components. For the purposes of this dissertation, the nomenclature of state and non-state governance is preferred, because it allows for optimal nuanced recognition that in the "non-state" category there are important sub-categories relevant to this study related to private (business) governance instruments, institutions, processes, and actors (such as the HACCP standard, in whose development the Pillsbury Company, NASA and the U.S. Army Laboratories played leading 
roles $^{3}$ ), there are governance approaches developed by civil society organizations (such as the Blue Flag beach certification standard that addresses the cleanliness of beaches for swimming ${ }^{4}$ ), and there are hybrid approaches (such as those developed by non-state organizations like ISO and CSA, which involve government, private sector and civil society stakeholders ${ }^{5}$ ). The categories of "state" and "non-state" governance terminology, and related sub-categories will be used wherever possible throughout the rest of the thesis, given their optimal alignment with the activities associated with water regulation at the municipal level in Ontario.

\subsubsection{Governance}

Especially since the 1990s, the literature pertaining to public policy governance has evolved from an almost exclusive focus on state actors to conceptions that variously recognize roles of non-state actors. Rosenau and Czempiel referred to governance in the international context as "activities backed by shared goals that may or may not derive from legal and formally prescribed responsibilities and that do not necessarily rely on policy powers to overcome defiance and attain compliance [....] It embraces governmental institutions but it also subsumes informal, non-governmental mechanisms whereby those persons or organizations within its purview move ahead, satisfy their needs, and fulfill their wants" (1992: 4).

Established in 1992 with the support of the United Nations Secretary General, the Commission of Global Governance (CGG) in its 1995 report Our Global Neighbourhood, provided the following definition of governance:

[....] governance is the sum of the ways in which individuals and institutions, in public and private spheres, manage their common affairs in order to accommodate diverse and conflictual views (Boas, 1998: 119).

A particular strength of this definition is its recognition that both state and non-state entities are involved in governance. For the purposes of this dissertation, the CGG definition of governance will be adopted, as it aligns with conceptions by scholars like Rosenau and Czempiel

\footnotetext{
${ }^{3}$ Safe Food Alliance - History of HACCP, [Online]: https://safefoodalliance.com/haccp/the-history-of-haccp/ [10 May 2019]

${ }^{4}$ City of Toronto Blue Flag Beaches, [Online]: www.toronto.ca/311/knowledgebase/kb/docs/articles/torontowater/blue-flag-beaches-status-of-beaches.html [18 Jan 2019]

${ }^{5}$ The CSA Group has approx. 10,000 volunteer members representing public, private and civil society organizations, working on multiple committees, [Online]: www.csagroup.org/about-csa-group/ [9 May 2019]
} 
(1992: 4), referred to above, Webb (2005, as discussed below), and open-ended governance definitions such as that of Hatfield-Dodds et al (2007), who define governance as follows:

[....] the institutional arrangements which shape actors' decisions and behaviour, including the exercise of authority within groups or organizations (such as firms or nations) (2007: 3).

In this conception, Hatfield-Dodds, give emphasis to the "exercise of authority" between groups and organization, which involves both state and non-state actors. This is of particular importance given the shift towards participatory and collaborative forms of governance.

In recent years, scholars have adopted a range of different terms to describe state and nonstate governance in the public interest, including multi-level governance, adaptive governance, participatory governance, collaborative governance, network governance and sustainable governance (discussed below). These characterizations of governance are relevant in the environmental field where scholars draw on them in their discussion of effective environmental governance in the public interest (e.g. Ostrom, 1994: 20; Holzinger et al., 2011: 28; Newig, 2012: 48; Hogl et al., 2012: 9; Nagendra and Ostrom, 2012: 124).

Table 1 offers an overview of a number of these scholarly conceptions of governance in chronological order (i.e. according to when the conception in question first appeared in the academic literature), examining how the scholars describe their particular conception of governance, their use of state and non-state categories, any key typological considerations associated with their conception, and any particular issues or challenges that it poses. A review of those conceptions of governance is included in Appendix B. 
Table 1. Chronology of Governance Conceptions and Characteristics

\begin{tabular}{|c|c|c|c|c|c|}
\hline & Conceptualization & Authors & Role of gov't/private sector/civil society & Typology & Challenges \\
\hline 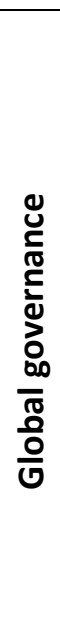 & $\begin{array}{l}\text { Rosenau defines it as "systems of rule at all } \\
\text { levels of human activity-from the family to } \\
\text { the international organization-in which the } \\
\text { pursuit of goals through the exercise of } \\
\text { control has transnational repercussions". } \\
\text { Influence of int'l. organizations and } \\
\text { agreements to reflect on globalization and } \\
\text { the growing interdependence of states } \\
\text { (CGG, Kooiman). } \\
\text { The World Bank identifies government } \\
\text { capacity building (1992) and good } \\
\text { governance (1994) as governance trends. }\end{array}$ & $\begin{array}{l}\text { Rosenau, } \\
\text { et al (1992) } \\
\text { W. Bank } \\
(1992, \\
1994) \\
\text { Kooiman } \\
\text { (1993, } \\
\text { 1999) } \\
\text { CGG (1995) } \\
\text { Weiss } \\
\text { (2000) }\end{array}$ & $\begin{array}{l}\text { Rosenau recognizes the role of "informal non-gov't } \\
\text { mechanisms" referring to persons or organizations, and } \\
\text { the role of government to accommodate and cooperate } \\
\text { with the informal roles of civil society } \\
\text { Kooiman notes the "interest groups" in society, and the } \\
\text { limitation of state actors, recognizing the role of non- } \\
\text { state actors "and other levels of interactions besides } \\
\text { inter-state" actors (1999: 70-71) } \\
\text { Weiss noted that Global governance had a role in } \\
\text { "bridging the gap" between playing field and players } \\
\text { and the role of the UN in this regard (2000: } 810 \text { ). }\end{array}$ & $\begin{array}{l}\text { Emphasis on } \\
\text { transparency, } \\
\text { participatory } \\
\text { approaches, need } \\
\text { to consult with } \\
\text { private sector, } \\
\text { NGOs and civil } \\
\text { society. }\end{array}$ & $\begin{array}{l}\text { Mode of } \\
\text { governance } \\
\text { reacting to } \\
\text { perception of } \\
\text { interference, } \\
\text { tension and } \\
\text { legitimacy of } \\
\text { global integration } \\
\text { (Europe) and } \\
\text { development } \\
\text { intervention in } \\
\text { third world } \\
\text { countries }\end{array}$ \\
\hline 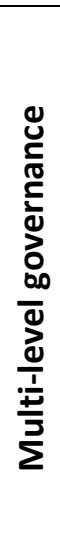 & $\begin{array}{l}\text { Marks describes MLG as "a system of } \\
\text { continuous negotiation among nested } \\
\text { governments at several territorial tiers" in } \\
\text { the context of EU integration. } \\
\text { Rhodes referred to policy networks, pointing } \\
\text { to analysis based on beliefs, practices, } \\
\text { traditions and dilemmas. } \\
\text { Cairney adds "a rejection of top-down } \\
\text { control" in contrast with a focus on } \\
\text { "bottom-up policy-making" (2015: } 32 \text { ). }\end{array}$ & $\begin{array}{l}\text { Marks } \\
\text { (1993) } \\
\text { Rhodes } \\
\text { (1997) } \\
\text { Bache, et al } \\
\text { (2004) } \\
\text { Cairney } \\
\text { (2012, } \\
\text { 2015) }\end{array}$ & $\begin{array}{l}\text { MLG is the opposite of the Westminster model (central } \\
\text { government, concentration of power). MLG suggests } \\
\text { interdependence of actors, delegated governance, } \\
\text { power diffusion and blurry lines of accountability. } \\
\text { Bache notes the increased participation of non-state } \\
\text { actors and complex overlapping networks. } \\
\text { Cairney (2015) recognizes multiple centres of authority, } \\
\text { and central government increasingly replaced by } \\
\text { bargaining government }\end{array}$ & $\begin{array}{l}\text { Rhodes: } \\
\text { Policy community } \\
\text { (participants, } \\
\text { interests) + issue } \\
\text { networks } \\
\text { (consultation, no } \\
\text { consensus) + } \\
\text { aspects (power, } \\
\text { resources, } \\
\text { structure) }\end{array}$ & $\begin{array}{l}\text { Recognition of } \\
\text { policy networks } \\
\text { as sources of } \\
\text { policy making and } \\
\text { drivers for } \\
\text { discussions. }\end{array}$ \\
\hline
\end{tabular}




\begin{tabular}{|c|c|c|c|c|c|}
\hline 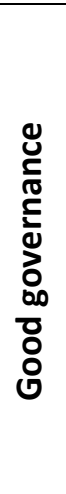 & $\begin{array}{l}\text { Boas characterizes it as "governance } \\
\text { interwoven with and embedded in a state- } \\
\text { civil society relationships" (1998: 119). } \\
\text { Kooiman defines good governance in } \\
\text { contrast with "corporate governance", as a } \\
\text { more relevant concept to national and } \\
\text { global situations (as opposed to corporate } \\
\text { organization, economic governance and } \\
\text { sectorial governing) (1999: 68) }\end{array}$ & $\begin{array}{l}\text { Boas } \\
(1998) \\
\text { Kooiman } \\
(1999) \\
\text { Weiss } \\
(2000)\end{array}$ & $\begin{array}{l}\text { Boas identifies risks associated w/consensus and the } \\
\text { need of a "broader... institutional/political interaction } \\
\text { within the public" to avoid conflict (pp.119). } \\
\text { Kooiman reflects on Good Governance as a World } \\
\text { Bank/UN concept to assist their involvement with } \\
\text { development interventions in Africa and Asia (1999:71). } \\
\text { Weiss notes the attenuation of undesirable aspects of } \\
\text { governance: the unrepresentative character of gov'ts. } \\
\text { and the inefficiency of non-market systems (pp. 801). }\end{array}$ & $\begin{array}{l}\text { Clear distinction } \\
\text { between public } \\
\text { and private } \\
\text { institutions, the } \\
\text { role of individuals } \\
\text { and society (to } \\
\text { avoid controversy) } \\
\text { in public policies } \\
\text { and relationships. }\end{array}$ & $\begin{array}{l}\text { Despite } \\
\text { recognition of } \\
\text { stakeholder } \\
\text { participation and } \\
\text { consultation, } \\
\text { government still } \\
\text { maintains leading } \\
\text { role in policy } \\
\text { development and } \\
\text { decision making. }\end{array}$ \\
\hline 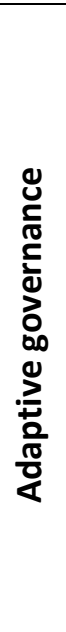 & $\begin{array}{l}\text { Ostrom (1999: 493) introduces polycentric } \\
\text { governance (ability of community members } \\
\text { to form self-governing institutions), and the } \\
\text { value of resilient systems of governance. } \\
\text { Dietz et al. define adaptive governance as a } \\
\text { way to convey the "difficulty of control, the } \\
\text { need to proceed in the face of substantial } \\
\text { uncertainty, and the importance of dealing } \\
\text { with diversity and reconciling conflict among } \\
\text { people and groups who differ in values, } \\
\text { interests, perspectives, power, and the kinds } \\
\text { of information they bring to situations". }\end{array}$ & $\begin{array}{l}\text { Ostrom } \\
(1994, \\
1999) \\
\text { Dietz et al. } \\
\text { (2003) } \\
\text { Hatfield- } \\
\text { Dodds } \\
\text { (2007) } \\
\text { Nagendra, } \\
\text { Ostrom } \\
\text { (2012) }\end{array}$ & $\begin{array}{l}\text { This conception defines broad aspects of institutional } \\
\text { arrangements, effective conflict resolution, and } \\
\text { mechanisms for inducing compliance (Ostrom, 1994:9). } \\
\text { Nagendra and Ostrom build on the concept of adaptive } \\
\text { governance and polycentric arrangements to } \\
\text { emphasize the need to "decentralize government } \\
\text { arrangements", and the importance of self-governed } \\
\text { institutions as a framework for governance (2012:104) } \\
\text { Hatfield-Dodds explains adaptive governance as } \\
\text { consensus building necessary for contentious political } \\
\text { issues in order to obtain a "license to operate", and as } \\
\text { an economic tool for market success (2007:9). }\end{array}$ & $\begin{array}{l}\text { Dietz et al defined } \\
\text { the need for: } \\
\text { Multiple parties } \\
\text { involved + } \\
\text { allocation of } \\
\text { authority to allow } \\
\text { for adaptive } \\
\text { governance at } \\
\text { multiple levels + } \\
\text { employing a } \\
\text { mixture of } \\
\text { processes }\end{array}$ & $\begin{array}{l}\text { This conception, } \\
\text { while recognizing } \\
\text { the need for } \\
\text { institutional } \\
\text { processes does } \\
\text { not provide clarity } \\
\text { in terms of actors, } \\
\text { civil society } \\
\text { representation } \\
\text { and use of policy } \\
\text { tools. }\end{array}$ \\
\hline
\end{tabular}




\begin{tabular}{|c|c|c|c|c|c|}
\hline 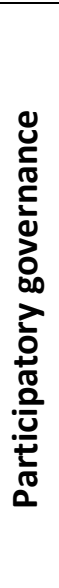 & $\begin{array}{l}\text { Milward et al notes the increasing role of } \\
\text { non-profits and private sector firms, not only } \\
\text { being consulted but implementing policies } \\
\text { and delivering public services. } \\
\text { Fung and Wright describe it as a reaction to } \\
\text { the decline in the effectiveness of } \\
\text { democratic institutions due to the } \\
\text { complexity and size of the issues they face. } \\
\text { Hogl et al. describe it as granting by state to } \\
\text { non-state actors of enhanced modes of } \\
\text { participation in governance (2012:15). }\end{array}$ & $\begin{array}{l}\text { Milward et } \\
\text { al (2000) } \\
\text { Fung et al, } \\
\text { (2001) } \\
\text { Kohler-K, } \\
\text { (2010) } \\
\text { Hogl et al. } \\
\text { (2012), } \\
\text { Newig } \\
\text { (2012) }\end{array}$ & $\begin{array}{l}\text { The role of society, represented by non-profits, private } \\
\text { firms, and ordinary people is clearly stated. } \\
\text { Recognizes the declining efficiency of state actors and } \\
\text { the need to complement their activity with non-state } \\
\text { actors. } \\
\text { Kohler-Koch (2010: } 100-102,105) \text { emphasizes society's } \\
\text { multiple functions (performative function and } \\
\text { representative function) as a complementary role to } \\
\text { state actors outside the formal representative } \\
\text { apparatus of state actors - (as a complement to, not a } \\
\text { replacement of that apparatus). }\end{array}$ & $\begin{array}{l}\text { Both state and } \\
\text { non-state actors } \\
\text { are conceptualized } \\
\text { and multiple } \\
\text { functions } \\
\text { identified. }\end{array}$ & $\begin{array}{l}\text { Although an } \\
\text { improvement on } \\
\text { the } \\
\text { "consultation" } \\
\text { approach of the } \\
\text { 1990s, the role of } \\
\text { non-state actors } \\
\text { remains merely a } \\
\text { policy tool for } \\
\text { legitimacy of state } \\
\text { decision-making }\end{array}$ \\
\hline 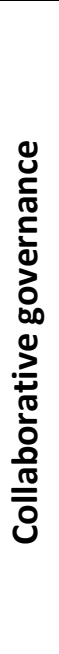 & $\begin{array}{l}\text { "a governing arrangement where [...] public } \\
\text { agencies directly engage non-state } \\
\text { stakeholders in a collective decision-making } \\
\text { process that is formal, consensus-oriented, } \\
\text { and deliberative and that aims to make or } \\
\text { implement public policy or manage public } \\
\text { programs or assets." Ansell (2007:544) } \\
\text { Other scholars associate it with PPP and a } \\
\text { means of leveraging private sector controls. } \\
\text { Amsler associates CG theory with } \\
\text { relationships: management, politics and law. }\end{array}$ & $\begin{array}{l}\text { Ansell et al } \\
\text { (2007) } \\
\text { Rosenbloo } \\
\mathrm{m} \text { et al } \\
\text { (2013) } \\
\text { Lindgren et } \\
\text { al, (2011) } \\
\text { Amsler } \\
\text { (2016) }\end{array}$ & $\begin{array}{l}\text { It evolved from concepts of public-private-partnerships, } \\
\text { where there are two actors involved: public and private } \\
\text { sectors, bringing a consensual approach to decision- } \\
\text { making (Ansell et al, 2007: 548) } \\
\text { Rosenbloom et al. define "clean" collaborative } \\
\text { governance (public participation) as a way of reducing } \\
\text { corruption risks (2013: 545). } \\
\text { Amsler criticizes the lack of legal framework for CG and } \\
\text { proposes the need for legal authorities to allow public } \\
\text { managers to engage in CG approaches in the U.S. }\end{array}$ & $\begin{array}{l}\text { Ansell et al. have } 6 \\
\text { criteria for CG: } \\
\text { Public agencies- } \\
\text { initiated forum + } \\
\text { forum w/non-state } \\
\text { actors + decision- } \\
\text { making forum + } \\
\text { consensus-based + } \\
\text { formal forum + } \\
\text { public policy focus. }\end{array}$ & $\begin{array}{l}\text { This is the first } \\
\text { conception } \\
\text { formally using a } \\
\text { consensus- } \\
\text { oriented } \\
\text { approach and } \\
\text { private sec. roles } \\
\text { In CG the central } \\
\text { actors are govt. } \\
\text { and private sec., } \\
\text { with society } \\
\text { having a lesser } \\
\text { role. }\end{array}$ \\
\hline
\end{tabular}




\begin{tabular}{|c|c|c|c|c|c|}
\hline 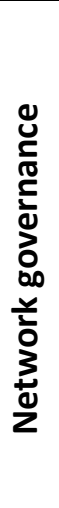 & $\begin{array}{l}\text { "a particular framing of collective decision- } \\
\text { making that is characterized by a trend for a } \\
\text { wider range of participants to be seen as } \\
\text { legitimate members of the decision-making } \\
\text { process ... it requires... to manage through } \\
\text { networks... under a new public value } \\
\text { management paradigm", Stoker (2006:41). } \\
\text { Bevir defined "hybrid" actors: multi- } \\
\text { jurisdictional and plural stakeholders. }\end{array}$ & $\begin{array}{l}\text { Stoker } \\
(2006) \\
\text { Bevir } \\
(2011)\end{array}$ & $\begin{array}{l}\text { Stoker notes that network governance brings } \\
\text { motivational elements to the governance model, } \\
\text { whereby governments benefit from their involvement } \\
\text { in networks and partnerships with others formed in the } \\
\text { context of mutual respect and shared learning (2006: } \\
51,55) \text {. } \\
\text { Bevir characterizes roles in decision-making at various } \\
\text { levels of participation by state and non-state actors, } \\
\text { including government at local, regional, national and } \\
\text { international levels "working together in networks". }\end{array}$ & $\begin{array}{l}\text { Stoker's Network } \\
\text { governance relies } \\
\text { on a system of } \\
\text { dialogue and } \\
\text { exchange, resulting } \\
\text { in legitimate } \\
\text { democracy and } \\
\text { effective } \\
\text { management, or } \\
\text { public value mgmt. }\end{array}$ & $\begin{array}{l}\text { NG means gov't } \\
\text { managers rely on } \\
\text { networks to } \\
\text { increase value in } \\
\text { the decision- } \\
\text { making process. } \\
\text { Networks are no } \\
\text { longer merely } \\
\text { "nice to have", } \\
\text { but a necessity. }\end{array}$ \\
\hline 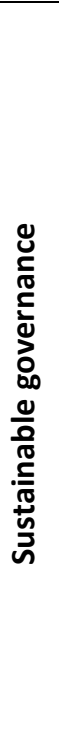 & $\begin{array}{l}\text { Sustainable governance recognizes that } \\
\text { policy activities "... are initiated at the } \\
\text { behest of government, others independently } \\
\text { of government;" (Webb et al, 2004: 103). } \\
\text { "... harnessing the energies, expertise, and } \\
\text { advantages of multiple actors, instruments, } \\
\text { institutions, and processes" (Webb, 2005: } \\
275 \text { ). } \\
\text { It incorporates the concepts of "societal re- } \\
\text { regulation", "meta-governance" and the } \\
\text { cumulative product of governance initiatives } \\
\text { and seven types of regulation, with three of } \\
\text { them depending solely on civil society } \\
\text { (Steurer, 2013: 387). }\end{array}$ & $\begin{array}{l}\text { Webb, } \\
\text { Morrison } \\
(2004) \\
\text { Webb } \\
(2005) \\
\text { Lemos et al } \\
(2006) \\
\text { Steurer } \\
(2013)\end{array}$ & $\begin{array}{l}\text { Sustainable governance recognizes that the private } \\
\text { sector and civil society can also initiate, develop and } \\
\text { implement valuable regulatory governance activities } \\
\text { independently of government, and that governments } \\
\text { are not the only ones who set policy or implement } \\
\text { policy. There is increasing evidence of non-state actors } \\
\text { driving policy agendas and playing a role in decision- } \\
\text { making, development, implementation, and monitoring } \\
\text { (Webb, 2005: 277-279). } \\
\text { This conception addresses the issues of resilience, } \\
\text { sustainability, complementarity, and stability. This is } \\
\text { relevant if a particular rule instrument, process, or } \\
\text { institution has not been able to deliver or delivers } \\
\text { poorly, or if new governments come in with different } \\
\text { priorities. }\end{array}$ & $\begin{array}{l}\text { Webb (2005): } \\
\text { Rule instruments } \\
\text { (laws, regs.) + } \\
\text { institutions (gov't } \\
\text { agencies, industry } \\
\text { bodies, ISO) + } \\
\text { processes (audit, } \\
\text { certification) + } \\
\text { actors (gov't, } \\
\text { private sector, civil } \\
\text { society, NGOs) }\end{array}$ & $\begin{array}{l}\text { SG enables more } \\
\text { sophisticated } \\
\text { examination of } \\
\text { state and non- } \\
\text { state actors. } \\
\text { It suggests that } \\
\text { other forms of } \\
\text { governance also } \\
\text { occur in a } \\
\text { rivalrous and } \\
\text { adversarial form } \\
\text { providing } \\
\text { beneficial checks } \\
\text { and balances in } \\
\text { society. }\end{array}$ \\
\hline
\end{tabular}




\subsubsection{Sustainable Governance}

Webb (2005: 243, 280) defines sustainable governance as:

[....] [a] systematic approach to governing that focuses on developing - and putting in place the conditions for the development of innovative institutions, instruments, and [....] actors, often working in partnership with each other [....] [with a] certain amount of 'creative tension' [....] where industry and nongovernmental association[s] [....] recognize and attempt to harness the value of both collaboration as well as rivalrous check-and-balance initiatives [....] [with the] systematic support for an enhanced role for civil society.

Sustainable governance recognizes that the private sector and civil society can operate in a collaborative manner with state actors but can also initiate, develop and implement valuable regulatory governance instruments and approaches independently of government, and under a rivalrous, competitive or "check-and-balance" dynamic. Webb (2005: 243, 280; 2015c: 4) suggests that the combined involvement of state and non-state instruments, institutions, processes and actors involved in governance, sometimes operating independently, sometimes collaboratively, and sometimes in more of a check-and-balance role, increases the capability of the overall governance framework to respond to new and evolving issues and challenges, thereby creating a more sustainable and resilient governance approach. The emphasis on the fact that non-state actors can develop and operate regulatory governance initiatives in the public interest independently of government, and that a certain amount of rivalrous interaction between state and non-state actors in governance can be valuable, are distinctive characteristics of the sustainable governance model when compared with the other conceptions of governance examined as part of the research for this dissertation. Thus, Webb's model involves state and non-state actors sometimes working collaboratively, but also sometimes in a non-collaborative and perhaps adversarial activity. Webb also usefully classifies state and non-state governance into four key components (2005: 242-249) which include:

- rule instruments - normative documents that articulate acceptable vs. unacceptable behaviour (e.g. laws and regulations, inter-governmental arrangements, and non-state standards, certification programs, and self-regulatory codes); 
- institutions - entities involved in developing and implementing rule instruments (e.g. government regulatory agencies, inter-governmental bodies, private standards bodies, industry self-regulatory bodies);

- processes - activities associated with development and implementation of rule instruments (e.g. enforcement of laws, certification and auditing of private rule systems); and

- actors - individuals and entities involved in governing (e.g. government, private sector actors including individual businesses, and civil society actors including nongovernmental organizations and individual citizens).

Webb suggests that, when taken together, the combination of state and non-state rule instruments, institutions, processes and actors, operating collaboratively at times and in more of a rivalrous manner at other times, will lead to a more resilient and responsive (and hence sustainable) governance approach over time than will more state-focused approaches, since it recognizes the possibility that at any given time, a state or an independently developed nonstate initiative may be able to respond to a new or emerging issue.

The concept of sustainable governance described above aligns with Steurer's (2013: 387) description of a constellation of actors involved in (state and non-state) governance. Steurer divides governance into seven basic types of regulation, four of which are state-based: public policies with varying degrees of government involvement (hard and soft regulations); and three types of non-state regulation: "depending solely on civil society (civil regulation), on businesses (industry or business self-regulation) or on both (civil co-regulation). Steurer also introduces the concepts of "hybrid regulation" and "meta-governance" (governance of governance) pointing to the "cumulative product of spontaneous governance initiatives that coincide with forceful global trends" (2013: 387).

This sustainable governance model offers specific components that are very useful in describing and analyzing the municipal water sector, in that it:

- enables more sophisticated examination of state and non-state arrangements;

- highlights that non-state actors can initiate, develop, implement and monitor policy activity independently of any state support; 
- suggests that both collaborative and rivalrous interactions between state and nonstate actors can contribute to sustainable governance;

- recognizes the increased likelihood that a combination of state and non-state governance elements with independent and collaborative components is particularly well suited to addressing new and evolving issues, and is therefore a governance approach that is responsive, resilient and sustainable over time; and

- applies within local, provincial, national and/or international contexts.

Examples of collaborative and check-and-balance state and non-state governance activity in the area of Ontario water protection are discussed in detail later in the dissertation, including a description of the government established non-state Source Water Protection Committees which, over a period of nine years, completed all 19 Source Water Protection Plans with detailed policies to be implemented by the provincial government (Abouchar, 2015: 1), the use of the CSA Group (a non-state, non-profit organization) to formulate the government Drinking Water Quality Management Standard (DWQMS), which is strongly based on the ISO 9001 for quality management and the HACCP standard for the food industry (Chapter 2.1.4), and checkand-balance approaches including private prosecutions (i.e. NGO/citizen-initiated) to ensure compliance with water protection laws, and NGO-initiated monitoring and reporting of noncompliant water activity (Chapter 3 ).

Webb's sustainable governance conception will be used as the primary lens through which governance activities will be examined in this dissertation, since it appears to align closely with the range of state and non-state governance activities associated with Ontario water protection.

\subsubsection{Policy Innovation, Convergence, Diffusion, Transfer, Learning}

An exploration of policy convergence and related concepts such as policy diffusion, transfer and learning is provided here in recognition of the fact that Ontario municipalities and other levels of government are drawing on non-state policy innovations such as environmental management system standards (MSSs) in their approaches to drinking water, wastewater and storm water issues. The literature on policy convergence, diffusion, transfer, learning and other related concepts "emerged from a general interest in policy innovation, which was traced 
either to political, social and economical characteristics internal to the state or alternatively to intergovernmental diffusion processes" (Lenschow et al., 2005: 799).

Historically, policy innovation has been connected to the diffusion of new information as a public good (Nelson, 1959: 298; Bennett, 1991: 299), but also as a provider of solutions to market failures (Llerena and Matt, 2005: 1). Lenschow suggests various sources of policy innovation, including new policy ideas, uncertainty, new rule instruments, new policy styles, stricter policies or new scientific insight (2005: 802). In his study of innovation policy, Foray (2018: 16) posited entrepreneurial initiatives as another source of policy innovation. Other factors include natural disasters, disease, tragedies and catastrophic events such as West Nile Virus, hydraulic dam failures, climate change, and the Walkerton outbreak (Weber and Rohracher, 2012: 1037; Gislason, 2013: 188; Tovilla, Webb, 2017b: 1). However, in this study, policy innovation is examined through the lens of policy changes due to policy diffusion, convergence, transfer and learning.

There has been significant research associated with policy convergence and related concepts such as policy diffusion, policy transfer, policy learning, emulation, lesson-drawing, isomorphism, social learning and harmonization (Stone, 1999: 51). The topic received significant attention in the context of the European integration (1992), globalization and international trade in the early 1990s. At that time, the focus was on the adoption, transfer or influence of policies between state actors, on both national and international levels (Bennett, 1991: 215; Strang and Meyer, 1993: 497; Strang and Soule, 1998: 265; Stone, 1999: 55; and Simmons and Elkins, 2004).

Policy convergence is strongly rooted in government-to-government action, while recognizing multiple state and non-state actors influencing the policy development process (Bennett, 1991: 215). Bennett also suggests that convergence occurs "through autonomous preferences of policy markets to fashion convergence policies" (1991: 2015). A commonly accepted definition of policy convergence by Lenschow et al, (2005: 798) is:

[....] the process of adoption of similar policy goals and ideas of a policy, the instruments applied, or the setting or the "calibration" of these instruments [....] and in jurisdictions with similar culture, institutions and economy. 
In this definition Lenshow et al. noted the calibration or adjustment of policy rule instruments as a characteristic of convergence. This is important given that such calibration appears to be occurring in the Ontario water management state rule instruments (see Chapter 2.3.2).

Holzinger and Knill's definition of convergence is more simplistic, as "the growing similarity of policies over time" (2005: 776). In the study by Howlett et al. it was found that "treaty-based harmonization lies at the basis of any convergence found in Canadian environmental policies" (2010: 91), suggesting and reinforcing the idea of government-centric convergence, learning and diffusion.

The above contrasts with the concept of convergence posited by Strang and Macy (2001: 147), which focuses on non-state actors (the organization and managerial decision-making of firms) as highly dependent on the evaluation and assessment of policy settings, structures and performance. In their analysis, they conclude that convergence is only likely in cases of worthy innovations and performance-based best management practices.

In line with theoretical constructs by Rogers (1983; 2003) and Strang and Meyer (1993: 487) related to policy innovation directly linked with diffusion and convergence processes, Strang and Macy suggest that models of innovation involve emulation by organizations trying to improve "by imitating their most successful peers" (2001: 147). They conclude that convergence could lead to more efficient organizations. This research is relevant in that it argues that influencers often consciously advertise their "winner" strategies, while adopters feel the pressure from their own organizations to emulate peer success. In Strang and Macy's view, cognitive and social biases towards successful strategies have powerful effects, even when precautionary approaches are taken by testing and piloting performance.

Furthermore, Heichel, Pape and Sommerer (2005: 825) reinforced the arguments of Simmons and Elkins (2004: 171) that convergence is primarily based on domestic factors also influenced by policy and that sector-specific characteristics play a significant role in determining the causal factors of policy convergence. Heichel et al. (2005: 834) conclude that causal factors for convergence are primarily based on domestic factors, which act as "filters" of external processes. 
Additional contributions have been made by Lenschow et al. (2005: 797) with their proposed framework for analysing domestic factors of policy diffusion and convergence. These factors included culture (predominant religious tradition), institutions (public and private relations) and economy (economic development). They concluded that if two or more jurisdictions have relatively similar factors (culture, institution and economy), then their policy goals, rule instruments or settings may be "calibrated" or convergent on those points (2005: 810).

The above concepts have been complemented by Knill (2005: 769-771), who identifies two types of causal factors for policy convergence:

1. The causal factors triggering the convergence: (a) similar policy problems; (b) imposition of policies; (c) harmonization of policies through national or international law; (d) market competition; and (e) transnational communication.

2. Facilitating factors influencing the effectiveness of convergence: (a) institutional similarity of jurisdictions (countries); (b) cultural ties and similarities; (c) socioeconomic structures; and (d) coalition of domestic actors diffusing policy.

Another contribution to policy convergence theory has come from Holzinger and Knill (2005: 778), who examine the degree, scope and direction of convergence:

1. Degree of convergence: related to the policy outcomes and degree to which the adopters achieve their policy goals.

2. Direction of convergence: typically related to the extent of state intervention or to the strictness of a regulation, i.e. how lax a standard is or how much command and control (hard regulation) will be imposed to ensure policy goals are achieved.

3. Scope of convergence: associated with the number of countries and policies that are actually affected by a certain convergence mechanism.

Most of the scholars noted above conceptualize policy convergence and related terms as an evolving concept: while initially (pre-1990s) a state-centric phenomenon, it now involves a constellation of multiple state and non-state actors, also described as influencers and adopters (post-2000s) (Howlett et al., 2010: 85). Academic understanding of the concept of policy convergence was consolidated with Knill's causal and facilitating factors (2005: 769-771), and 
Holzinger and Knill's degree, scope and direction of convergence (2005: 778). Scholars identify policy convergence as a prevalent condition in various fields, and as a "rule" in the environmental field, with international and transnational influencers, multiple means of communication and the similarities of environmental pollution problems and potential solutions as causal factors for convergence.

Examples of policy convergence include the regulatory changes in the early 1990s after the EPA in the United States discovered the presence in 1987 of "dioxins in pulp and paper effluents, fish caught downstream from pulp mills, and various paper products including coffee filters, milk cartons and disposable diapers" (Harrison, 2002: 65). In his study of the impacts of regulatory standards, Harrison noted the convergence in both regulatory standards (statebased instruments) and industry performance standards (non-state instruments) and their simultaneous implementation in Sweden in 1990, in Canada in 1991, and in the United States in 1998 (2002: 72).

Other examples of policy convergence include: the development by OECD countries of common market and ozone layer protection policies (Botcheva and Martin, 2001: 1), where despite different externalities affecting member countries, convergence has proven to have a positive beneficial effect on individual member countries. More recent studies on policy convergence by Jörgens, Lenshow and Liefferink, (2014) conclude that there is a clear trend towards policy convergence in multiple fields such as technology, health, trade and other areas. In particular, in the case of the environment there is:

[....] increasing evidence that legal harmonization as well various types of transnational communication lead countries to mutually adjust their [environmental] policy goals [and] policy instruments (2014: 1-2).

This characteristic of policy convergence noted by Jörgens et al. is important as it highlights the evidence of harmonization in the environmental policy making arena. In their study of causes of policy convergence in the environmental field, Holzinger and Knill conclude that "imposition, international harmonization, regulatory competition, transnational communication, and independent problem-solving" are shaping and defining the scope, degree and direction of environmental policy convergence (2005: 279). In another study Hozinger, Knill and Sommerer 
(2011: 20) reviewed environmental policy items in 24 countries from the 1970 s up to the 2000s, and also the level of convergence between mandatory, non-mandatory and trade-related policies, and found that convergence appears to be the rule in the environmental field. In terms of trends of policy convergence in the environmental field, they concluded that:

[....] [t]here is a general trend of convergence. Compared with the overall trend, the degree of convergence is lower with respect to exact policy settings. As expected, homogeneity increased more strongly for obligatory policies than for non-obligatory ones, and more strongly for trade-related policies than for non-trade-related ones (2011: 38).

These findings by Hozinger, Knill and Sommerer are consistent with the characterization of policy convergence in the environmental field as noted earlier by Jörgens et al. (2014: 1). Relevant examples involving non-state actors include the findings by Strang and Macy (2001: 147) regarding convergence on organizational and managerial decision making. In their study of organizational and behavioural models, they found that "firms respond to perceived failure by imitating their most successful peers" and that this in turn "generates empirically plausible cascades of adoption, even if innovations are entirely worthless" (2001: 147).

Heichel, Pape and Sommerer (2005) reviewed 74 empirical studies on policy convergence in different fields and time periods, mainly from the 1970s up to 2005, and concluded that there "is no homogenous picture for policy convergence", and that the literature is diverse in multiple respects, thus making "an overall assessment of policy convergence impossible" (2005: 817).

Table 2 offers an outline of the policy convergence conceptions including policy diffusion, policy transfer and policy learning. A more detailed review of these conceptions is included in Appendix C.

The next step is to consider whether theoretical concepts of governance and convergence described above are related to the normative documents or practice of management system standards, with a focus on QMS and EMS in the context of the Ontario municipal water sectors. This is important, as this relationship may point to a simultaneous occurrence of these concepts and practices or normative documents to reflect what is actually happening as the modernized post-Walkerton policies for drinking water are slowly permeating and transferring lessons learned to the wastewater and stormwater sectors. 
Table 2. Policy Convergence Concepts and Examples

\begin{tabular}{|c|c|c|c|}
\hline & Conceptualization & Authors & Examples \\
\hline 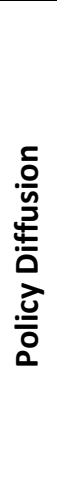 & $\begin{array}{l}\text { Occurs when an innovation is communicated through } \\
\text { certain channels over time among the members of a } \\
\text { social system (Strang et al., 1993: 487-488). } \\
\text { Occurs where policy settings such as globalization, } \\
\text { economy, institutions, administration, culture, and } \\
\text { other policy issues, affect the rate of diffusion and } \\
\text { transfer of policies. Does not automatically lead to } \\
\text { convergence as foreign models are likely to be changed } \\
\text { to fit national institutional structures and policy styles } \\
\text { (Lenschow et al., 2005: 799). }\end{array}$ & $\begin{array}{l}\text { Bennett (1991) } \\
\text { Meyer (1993) } \\
\text { Strang et al (1993) } \\
\text { Lenschow et al } \\
\text { (2005) } \\
\text { Heichel et al (2005) } \\
\text { Knill (2005) }\end{array}$ & $\begin{array}{l}\text { Climate change policy } \\
\text { diffusion due to } \\
\text { international activity, and } \\
\text { network groups (Knill), } \\
\text { e.g. UNFCCC. } \\
\text { Global need to deal with } \\
\text { transnational } \\
\text { externalities (ozone layer } \\
\text { reduction). }\end{array}$ \\
\hline $\begin{array}{l}\frac{1}{0} \\
\frac{1}{0} \\
\frac{2}{2} \\
\frac{\partial}{0} \\
\frac{0}{0}\end{array}$ & $\begin{array}{l}\text { Occurs when knowledge about policies, administrative } \\
\text { arrangements, institutions, etc., in one time and/or } \\
\text { place is used in the development of policies, } \\
\text { administrative arrangements and institutions in another } \\
\text { time and/or place (Dolowitz, Mash (2000: 5), Stone, } \\
\text { 1999: } 51 \text { ). } \\
\text { Associated with mechanisms of coercion and multi- } \\
\text { lateral cooperation where policies may be forced as } \\
\text { conditions for economic incentives (Holzinger et al., } \\
\text { 2005: 779) }\end{array}$ & $\begin{array}{l}\text { Stone (1999) } \\
\text { Dolowitz, Marsh } \\
\text { (2000) } \\
\text { Holzinger et al (2005) }\end{array}$ & $\begin{array}{l}\text { IMF, Wold Bank loan } \\
\text { conditions for developing } \\
\text { countries. } \\
\text { Private product standards } \\
\text { being "forced or relaxed" } \\
\text { by countries as per } \\
\text { market forces by WTO } \\
\text { rules, etc. (Holzinger et } \\
\text { al). }\end{array}$ \\
\hline 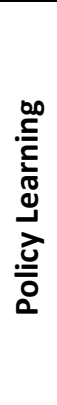 & $\begin{array}{l}\text { It occurs as a way to improve or enhance policy-making } \\
\text { based on the evaluation of past experiences, associated } \\
\text { with domestic and foreign jurisdictions. Applies to } \\
\text { intergovernmental diffusion processes from the } \\
\text { receiver country perspective, from one country to } \\
\text { another (Lenschow et al., 2005: 799; Holzinger et al., } \\
\text { 2005: } 279 \text { Alcantara et al., 2012: 112). }\end{array}$ & $\begin{array}{l}\text { Lenschow et al } \\
\text { (2005) } \\
\text { Holzinger et al (2005) } \\
\text { Alcantara (2012) }\end{array}$ & $\begin{array}{l}\text { Rational and selective } \\
\text { approach to evaluate } \\
\text { foreign political economy } \\
\text { models (Simmons et al) } \\
\text { Great Lakes } \\
\text { transboundary policy } \\
\text { networks (Song et al, and } \\
\text { Martin and Webb) }\end{array}$ \\
\hline 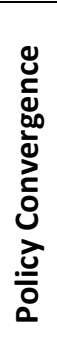 & $\begin{array}{l}\text { Occurs as the process of adoption of similar "goals and } \\
\text { ideas of a policy, the instruments applied, or the setting } \\
\text { or the "calibration" of these instruments, and likely to } \\
\text { occur in "jurisdictions with similar culture, institutions } \\
\text { and economy" (Lenschow et al.) }\end{array}$ & $\begin{array}{l}\text { Strang (2001) } \\
\text { Heichel et al (2005) } \\
\text { Lenschow (2005) } \\
\text { Knill (2005) } \\
\text { Holzinger et al (2005) } \\
\text { Liefferink (2016) }\end{array}$ & $\begin{array}{l}\text { OECD common market } \\
\text { and ozone layer } \\
\text { protection policies } \\
\text { (Botcheva et al.). } \\
\text { Domestic environmental } \\
\text { policies across countries } \\
\text { (Liefferink) }\end{array}$ \\
\hline
\end{tabular}




\subsubsection{Non-state Standards Literature}

This section covers the academic literature regarding non-state standards, also referred to in this study as non-state rule instruments. This review assists in understanding the increasing trend among private and public entities of relying on non-state standards to complement statebased rule instruments in order to address their limitations and fill gaps. In particular, the academic literature concerning management system standards (MSSs), their historical context and evolution, strengths and weaknesses, as well as their use in the environmental arena are examined, including particular applicability to and suitability for the municipal water sector.

It is important to clarify that in this section, while references are made to ISO 9001 (QMS), ISO 14001 (EMS) and the Hazard Analysis and Critical Control Points (HACCP) as precursors of the mandatory Ontario's Drinking Water Quality Management Standard (DWQMS), this section covers the discussion to provide context to the understanding and evolution of MSSs as they are applied by both state and non-state actors. Detailed discussion concerning the Walkerton tragedy (2000) and the factors leading to the establishment of the DWQMS, as a mandatory rule instrument for drinking water systems in Ontario is covered in Chapter 2.3.2. Finally, this section provides summaries of selected experiences in the USA with EMS and also the use of other non-state MSSs by the water management government sector.

\section{Standards and Voluntary Codes}

The term standards is a synonym to voluntary codes, which Webb describes as voluntary rule systems, "used since earliest times to articulate shared norms and to structure interpersonal relations, and indeed [they] pre-date the modern state" (2004: 4). In his study of voluntary standards, Webb provides historical references to the European Middle Ages, when merchant guilds regulated virtually every aspect of a given commercial activity, from market access through means of production, product and price, enforcement of contracts (2004: 4). Further examples of voluntary codes include the Better Business Bureau, created in the late 1800s as a non-profit organization, governed by business members and focusing on fair business ethics and consumer protection; and the International Chamber of Commerce's Code of Advertising Practice, first published in 1937 (Webb, 2004; Kolb, 2008). The World Trade Organization's Agreement on Technical Barriers to Trade, defines a "standard" as (Webb, 2004: 12): 
[....] [a] document approved by a recognized body, that provides, for common and repeated use, rules, guidelines or characteristics for products or related processes and production methods, with which compliance is not mandatory. It may include [....] symbols, packaging, marking or labelling requirements as they apply to a product, process or production method.

This definition is in contrast with the one offered by the International Standards Organization (ISO), which adds the terms "consensus" and "optimum". ${ }^{6}$ These terms associate the concept with a process for its development (consensus), and a process for determining what is considered acceptable:

[.... [a] document established by consensus and approved by a recognized body that provides, for common and repeated use, rules, guidelines or characteristics for activities or their results, aimed at the achievement of the optimum degree of order in a given context.

Generally, standards or voluntary codes are developed by non-state actors to "bridge the gap" (Weiss, 2000: 810) and address limitations in state-based command-and-control rule instruments. These limitations are summarized by Webb (2004) and include: expensive enforcement processes; jurisdictional constraints; vulnerability to inconsistent and inadequate enforcement due to staff and resource cutbacks and associated downturns in government and public attention; and a tendency toward inflexibility including a "going by the book" attitude to compliance. Webb defines voluntary codes as:

- commitments not required by legislation or regulations;

- agreed to by one or more individuals or organizations;

- intended to influence or control behaviour; and

- to be applied in a consistent manner or to reach a consistent outcome.

The concept of standards or voluntary codes as non-state rule instruments has evolved from the idea of standards developed to address non-state actors' needs to standards that are readily applied and used by state actors. Either through referencing state-based laws, or as a proactive measure to ensure a higher level of due diligence, or to fill gaps in legislation, or as a resource in sentencing by courts, non-state standards are increasingly being used by all the

${ }^{6}$ ISO, ISO/IEC Guide 2:2004 Standardization and related activities-General Vocabulary [2004], definition 3.2 
three levels of government, and are therefore evolving from non-enforceable rules into enforceable requirements (Chapter 3).

A review of the literature on management system standards (MSSs) provides insights into their original uses, strengths and weaknesses, leading to an exponential development of new sector specific standards for various sectors. As applied in this study, MSSs are normative documents that articulate acceptable vs. unacceptable behavior i.e., consistent with the conceptualization of "rule instrument" by Webb (2005: 242-249).

Scholars point to an increasing uptake of specific non-state standards by state environmental regulations, noting that while state rule instruments provide minimum standards, non-state standards are developed and updated more frequently and may be more stringent than government criteria (Fulponi 2006: 10; Delmas et al, 2008: 75). The academic literature on MSSs has centred on the motivations for their adoption, the value of the business and critical factors for successfully implementing them (Fulponi, 2006: 1; Searcy et al., 2012: 278).

Other studies have documented additional benefits of being registered to the standard, such as having an increased competitive advantage and transparency of MSS (Psomas et al., 2011: 502; lonascu et al. 2017: 166). There is, however, not much literature on the application of MSSs by public entities, and how state actors are drawing from MSSs to accomplish their policy goals and meet societal expectations. While there are similarities (e.g. the consensual process of ISO-type standards is similar to the modern consultative-based approach for government regulation), ISO-type standards are perceived as more transparent since many non-state actors participate in the consensus-based decision-making process.

As discussed above, MSSs were developed to address different issues and are updated continuously to address evolving needs, societal expectations and market demand. Some scholars suggest that the increasing adoption of MSSs provides a variety of potential benefits, such as relief from the need for certain onerous command and control measures, enhanced cost efficiency and improved stakeholder relations, among other advantages (Henriques et al., 2008: 162). 
The literature concerning government and industry participation in sponsored voluntary environmental programs shows that both government and industry recognize the importance of the brand value of MSS, in part because of the influence of their stakeholders on their business and corporate social responsibility practices (Webb, 2015a: 30; Darnall et al., 2010: 303; Delmas et al., 2011: 107, 124). Others have concluded that organizations are motivated to adopt such standards to increase their internal efficiency and external legitimacy, as well as to create shareholder value and help organizations respond to stricter regulations (Hart and Milstein, 2003: 56; Delmas et al., 2011: 106).

Nonetheless, there is literature critically assessing and questioning the salutary and beneficial aspects of voluntary MSS initiatives. Kollman \& Prakash (2002: 43), Chatterji \& Toffel (2010: 917), and Simpson \& Sroufe (2014: 830) argue that reporting and validation are deflectors of attention rather than performance and process improvements. The risk posed by a stagnant EMS, whether state-based or non-state, is that it may reduce the incentive for innovation, and some authors suggest, there is a risk that MSSs may inadvertently discourage diversity of environmental management practices by encouraging "going by the book" compliant behaviour (Chatterji \& Toffel 2010: 918, 919; Simpson \& Sroufe 2014: 845-846). Nonetheless, Arimura et al. (2008: 293) argues this also applies to command and control regulations.

Studies by Darnall and Sides (2008: 95) and by Alvarez-Garcia \& RioRama (2016: 1-2), have noted that ISO 14001, which may involve a third-party auditor, on average shows only modest environmental performance improvements, and increasing costs. Areas for improvement noted by Searcy et al. (2012: 278) include ISO 14001 to require third-party audits be publicly disclosed. With respect to the auto sector, some scholars have concluded that ISO 14001 or EMAS (the European equivalent of ISO 14001) is largely ineffective in improving compliance with environmental regulations because regulatory requirements already address these issues (Dahlström et al., 2003: 187). As noted by Alvarez-Garcia and RioRama, the underlying risk is that certified corporations will support innovation and diversity only when they receive a poor rating, or when an external actor or issue forces them to act (2016: 1-2). 
However, these critical arguments are outweighed by arguments in support of MSSs which underscore its benefits, including positive impacts on performance (for EMS), opportunities for innovation, enhanced cost efficiency, improved stakeholder relations, external legitimacy, and positive influence on stakeholders (Hart and Milstein, 2003:56; Henriques and Sadorsky, 2008: 162; Darnall et al. 2010: 303; Delmas et al, 2011: 125).

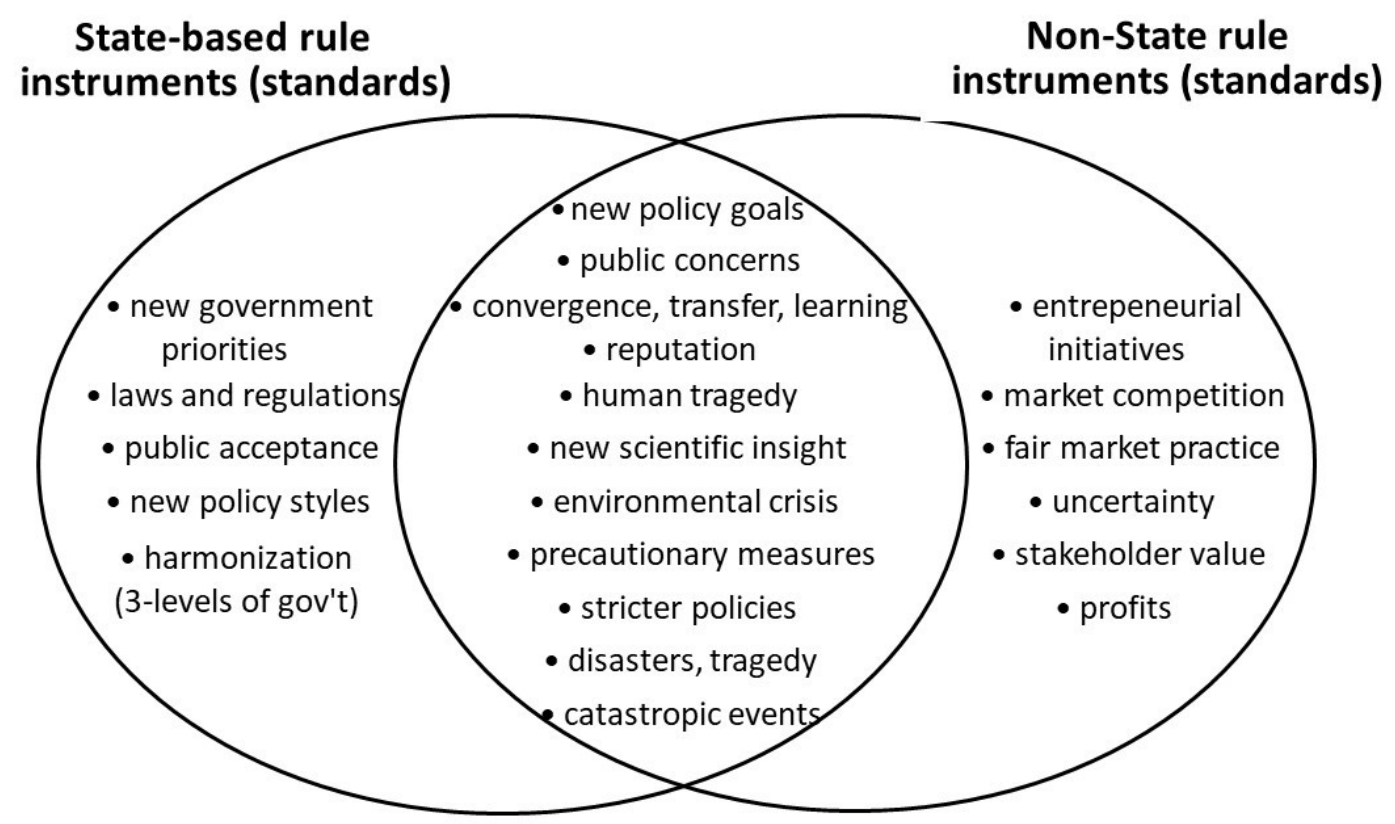

Figure 3. Policy Innovation Triggers / Sources for State and Non-state Standards

This review reveals that both state and non-state standards are developed in response to public concerns, human tragedy, an environmental crisis or as precautionary measures (Kollman et al., 2002: 46, 52). In addition, non-state standards are strongly rooted in market forces and profit-driven goals, and non-state MSSs may be more stringent than state-based ones (Fulponi, 2006: 10; Delmas et al., 2008: 75). This explanation for the factors that trigger standards intersects with the sources leading to policy innovation noted in Chapter 2.1.3., e.g. new policy goals, uncertainty, stricter policies, new scientific insight, disasters, disease, tragedies and catastrophic events. Figure 3 illustrates the triggers and sources for policy innovation and their intersections with state and non-state rule instruments: 


\section{Non-state MSSs in the Water Sectors}

In this section, the literature regarding MSSs relevant to the water, wastewater and stormwater sectors is covered. This review will assist in understanding the increasingly intertwined relationship of these standards with state-based law and their voluntary adoption by state actors, particularly municipalities.

There is significant academic literature on management system standards and how they are applied globally or by specific industrial sectors, but not much on their application to the municipal water sectors. In North America, municipal governments have been proactively adopting approaches in support of their water, wastewater and stormwater systems drawing on ISO standards (US.EPA, 2005; WEF, n/d). Municipalities in Ontario and other jurisdictions are adopting and adapting international, regional, and domestic standards in their own bylaws, or by implementing such standards in the expectation of improvements to transparency and accountability, and to potentially reduce liabilities (see Appendix F for illustrative cases).

Water-borne disease tragedies such as the cases of Milwaukee (1993), Walkerton (2000) and Flint (2014) have triggered state-based policies drawing on EMS, QMS and HACCP-type standards, or specifically referencing ISO 14001 as part of their rule instruments. Examples include: Wisconsin's “Green Tier” Program (WDNR, 2014); Ontario's DWQMS (MECP, 2006); and Michigan's Guide to Environmental, Health and Safety Regulations (Michigan State, 2018).

Other non-state MSSs widely used in North America include those related to engineering design of water, wastewater and stormwater works. The American Water Works Association (AWWA) standards for water quality, water pipes, water management, utility management, disinfection, ${ }^{7}$ the Ten State Standards, ${ }^{8}$ and the European standards for water re-use ${ }^{9}$ are other examples of standards that focus on water and wastewater works design and best design practices, that are widely used for the design of municipal water, wastewater and stormwater infrastructure (Minnesota State, 2019; New York State, 2014; MECP, 2008).

\footnotetext{
${ }^{7}$ AWWA, [Online]: www.awwa.org/publications/standards.aspx [22 Dec 2015]

8 Ten State Standards is a voluntary organization established in 1950, by public health and environmental managers from the U.S states around the Great Lakes-Upper Mississippi watershed and the Province of Ontario, [Online]: http://10statesstandards.com/ [12 Jan 2018]

${ }^{9}$ European standards for water re-use, [Online]: https://ec.europa.eu/irc/en/news/guidelines-better-water-reuseeurope [22 Dec 2015]
} 
In Ontario, there is a network of both state and non-state MSSs which are part of the governance structure for drinking water, wastewater and stormwater systems. Table 3 lists the large number of voluntary rule instruments specifically related to the drinking water sector, which is heavily regulated compared to the wastewater and stormwater sectors. Table 3 reveals the disproportionate imbalance between the drinking water sector, with a robust array of state regulations, and the wastewater and stormwater sectors' reliance on state-sponsored guidelines, design manuals, and voluntary approaches.

Table 3. State and Non-state Rule Instruments and Voluntary Instruments

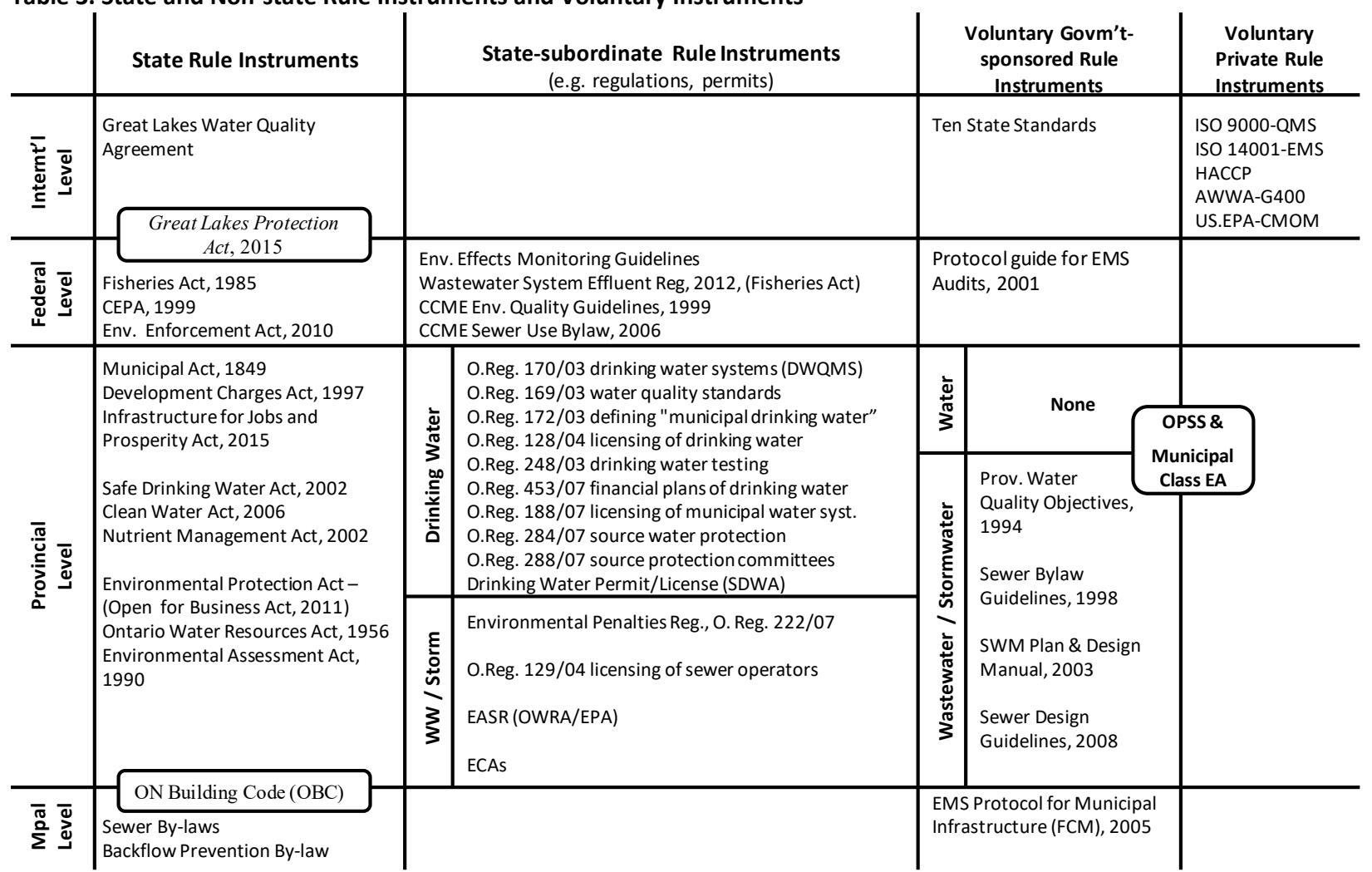

Several ISO standards are particularly relevant to municipal public works sectors, including ISO 9001, ISO 14001, ISO 45001 (Health and Safety Management Systems), ISO 55000 (Asset Management) and ISO 26000 (Social Responsibility). Heras-Saizarbitoria and Boiral (2013: 48) suggest that ISO 9001 and SO 14001 are the main global management standards, as they are most relevant to environmental management. In this study, the following standards are examined as they have played important roles in the creation of Ontario's DWQMS: 
- ISO 9001 (Quality Management Systems)

- ISO 14001 (Environmental Management Systems)

- HACCP (Hazard Analysis and Critical Control Points related to food products)

In Canada, early adopters of ISO 14001 for water and wastewater systems were documented by the Federation of Canadian Municipalities (FCM), in partnership with the Canadian National Research Council, in their 2005 report for EMS protocols (FCM/NRC, 2005). The report noted that at the time of writing, eight municipalities had established an EMS consistent with ISO 14001 and had received certification by an accredited third-party registrar. In addition, the FCM/NRC report stated that nine other municipalities were developing an ISO 14001-based EMS, and another five municipalities were considering the development of an EMS" (FCM 2005)

Historically, a major incentive for developing MSSs was to address inter-organizational and inter-jurisdictional harmonization and reduce inefficiencies (Heras-Saizarbitoria and Boiral, 2013; Franceshini, Galetto and Cecconi, 2006). Although primarily used by profit-driven organizations, there is increasing evidence of MSSs being used by all three levels of government to supplement government regulations (Table 8). For further reference, a synthesis of the evolution of environmental and quality MSSs is included in Appendix D.

\subsubsection{ISO Standards}

ISO is an independent, global non-governmental organization made up of members from the national standards bodies of 162 countries and is the world's largest developer of voluntary international standards. ISO has published more than 19,500 standards covering almost every industry (ISO, 2015). Created by ISO with specific purposes and mandates, all standards are established by technical committees and subcommittees. By definition, all ISO standards are voluntary in the sense that ISO is a non-state body and therefore is incapable of requiring an organization to comply with its standards the way governments can require and enforce adherence to laws. All ISO standards are reviewed every three to five years to establish whether a revision is required to keep it current and relevant to the marketplace (ISO, 2015).

Furthermore, there is a recent trend to develop more sector-specific standards based on ISO 9000 and ISO 14000 to meet sector-specific needs. Most sector-specific standards are 
developed by editing the ISO's main standards. For example, the ISO 29001 is a QMS standard developed for the petroleum, petrochemical and natural gas industries; the ISO 50001 for energy management is a hybrid combining elements of QMS, EMS and other standards; the ISO 45001 is for health and safety; the made-in-Ontario Drinking Water Quality Management Standard (DWQMS) is a standard for municipal drinking water systems based on the ISO 9001 and the HACCP (for the food industry). Other examples include more specific standards on areas such as the ISO 14006 for incorporating eco-design; and the ISO 14044 for guidelines on life-cycle assessments. Private companies typically adopt ISO standards, such as ISO 9001, ISO 14001 and ISO 26000, voluntarily as a way of signalling quality, environmental and social responsibility, and thereby securing an advantage over their competitors (Halley \& Boiral, 2009).

\section{ISO 9001 - QMS}

Created in 1987, the ISO 9000 family of standards focuses on quality management to ensure that organizations' products and services consistently meet costumer requirements, and that quality is consistently improved. This standard builds on the plan-do-check-act management system model (Figure 5). The ISO 9000 family of standards includes some of ISO's best-known standards (ISO, 2015), notably:

- ISO 9000:2015 - covers the basic concepts and language.

- ISO 9001:2015 - requirements of a quality management system (QMS).

- ISO 9004:2009 - how to make a quality management system efficient and effective.

- ISO 19011:2011 - guidance on internal and external audits for a QMS.

ISO 9001 standard has over one million companies and organizations in 170+ countries certified to ISO 9001 (ISO, 2015). In 2015, ISO released new versions of the ISO 9001 and ISO 14001 family of standards, making them easier to integrate. Prior to the 2015 version, the standard was revised in 1994, 2000 and 2008. The ISO 9001:2008 facilitated its integration with other standards. The improvements of the 2015 version, as described by BSI, include:

- “Greater emphasis on building a management system suited to each organization's particular needs.

- A requirement that those at the top of an organization be involved and accountable, aligning quality with wider business strategy. 
- Risk-based thinking throughout the standard makes the whole management system a preventive tool and encourages continuous improvement.

- Less prescriptive requirements for documentation: the organization can now decide what documented information it needs and what format it should be in.

- Alignment with other key management system standards through the use of a common structure and core text." (BSI, 2015)

A 2017 ISO survey reports 1.1 million ISO 9001 -QMS certifications world-wide. The report also reveals that most ISO 9001 certifications are registered by private corporations. It is estimated that a mere 1\% of QMS world-wide certifications are associated with "water supply" entities and/or "public administration" (ISO, 2017).

As Heras-Saizarbitoria and Boiral explain, the ISO 9001 standard "is not a performance standard measuring quality of companies' products or services. Rather, ISO 9001 proposes guidelines to systematize and formalize a series of company processes into a series of procedures, and to document implementation" (2013: 49). And citing Braun and Guler (2002), they conclude that ISO 9001 standardizes duties and roles, rather than goals or outcomes (Heras-Saizarbitoria and Boiral, 2013: 49).

\section{ISO 14001 - EMS}

First promulgated in 1996, the ISO 14001 (EMS) standard was designed to assist organizations in addressing their environmental impacts and obligations. The objective of this standard is "to support environmental protection and prevention of pollution in balance with socio-economic needs" (ISO 14001:2004). The ISO 14001 sets out criteria for an environmental management system (EMS), regardless of the organization's activity or sector. There are 24 supporting standards in the ISO 14000 family, focusing on specific processes such as audits, communications and life cycle assessment, as well as environmental challenges such as climate change. The ISO 14001 family of standards has the following best-known standards (ISO, 2015):

- ISO 14001: 2015 - requirements of an environmental quality management system.

- ISO 14004: 2004 - general guidelines on principles, systems and support techniques.

- ISO 14006: 2011 - guidelines for incorporating eco-design.

- ISO 14044: 2006 - guidelines for life cycle assessments. 
The recently revised ISO 14001:2015 addresses the change in environmental practices and brings a common framework to all management system standards, while also applying common language across all standards, with the following key changes (Leehane, 2015):

- Greater involvement of the leadership team in the management system to ensure the whole organization will be motivated to pursue the organization's goals and objectives.

- Improved risk management and environmental performance to protect the environment and reduce the risk of regulatory fines.

- A new integrated approach applicable to all new ISO management systems standards to integrate multiple management systems.

- Increased focus on lifecycle perspective rather than lifecycle assessment, with an emphasis on the supply chain, looking at the stages immediately adjacent to and on either side of the organization's operations and the potential for influence.

- Eco-designs to embrace innovation with a collaborative management approach with the cumulative power of a supply chain, leaning towards a corporate social responsibility (CSR) approach.

ISO 14000: 2015 brings elements of social responsibility from ISO 26000 (Social Responsibility) to a certification level. The corporate social responsibility standard (CSR) is meant for supply management activities outside of the direct control of the entity adopting the standard. Intertwined with social responsibility, the ISO 26000 places an emphasis on the organization's power to influence others. Figure 4 illustrates how these standards (QMS, EMS and (SR) can be seen as linked in the context of a water, wastewater and stormwater MSS (Tovilla and Webb, 2017a: 210).

The 2017 ISO survey reported a total of 346,000 ISO 14001 -EMS certifications world-wide in 171 countries (ISO, 2018). The report also reveals that most ISO 14001 certifications are registered by private corporations. An estimated $0.9 \%$ of EMS world-wide certifications are associated with "water supply" entities and/or "public administration" (there is no classification for their wastewater or stormwater) (ISO, 2017). 
Figure 5 illustrates the basic elements of the "plan-do-check-act" model of the EMS, and Figure 6 shows an overlap of elements common to ISO 14001 and ISO $9001 .^{10}$ This ISO 2015 upgrade allowed organizations adopting the MSS to facilitate and to ensure compatibility and ease when consolidating any firm's MSS into an integrated MSS.

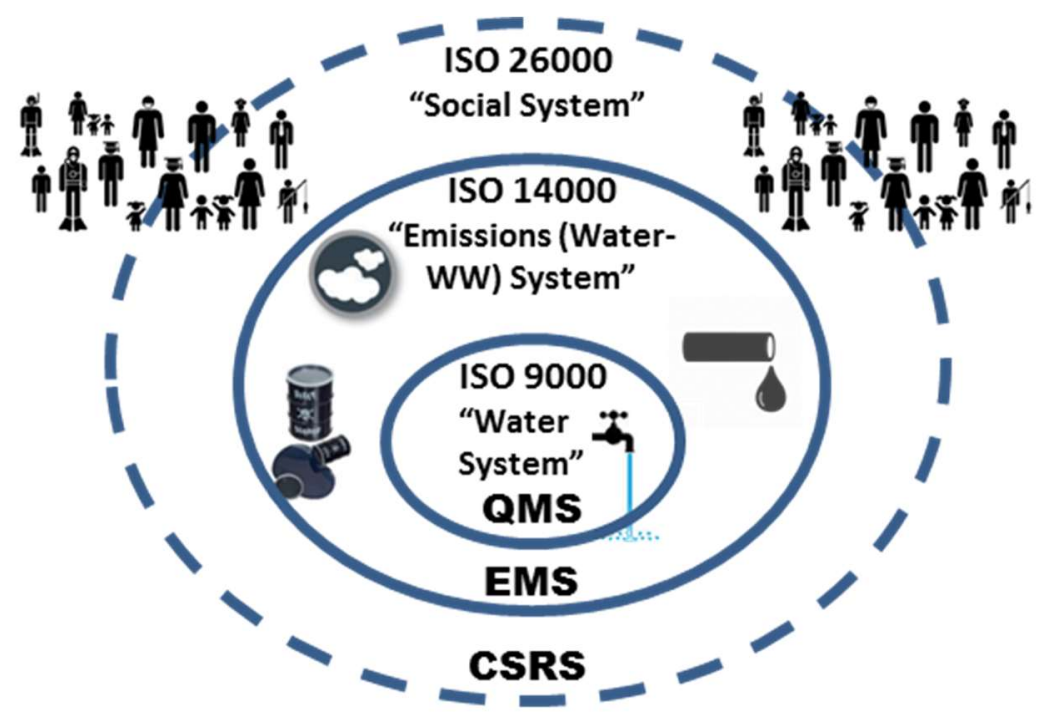

Figure 4. QMS, EMS and CSR for Water/Wastewater Systems

In their 2009 study of ISO 14001 in the water sector, Halley \& Boiral stated that private companies adopted ISO 14001 certifications for their operation of municipal water systems in order to secure an advantage over competitors. This advantage gave companies an increased incentive during the 2000s to adopt EMSs for water and wastewater management activities.

This supports the idea that EMSs are a non-state rule instrument innovation that is now being adopted by state entities, involving the notions of policy convergence, diffusion and transfer discussed above. While the $1 \%$ of certifications that are held by public sector organizations seems a very small proportion, this study suggests that the actual number might be larger. This study's findings show a number of municipalities in Canada adopting ISO quality and environmental MSS, and others cherry-picking from specific elements of MSSs but not necessarily adopting the entire MSS or obtaining accreditation, to create an ad-hoc MSS that meets their needs.

\footnotetext{
${ }^{10}$ Figure 6 is an adaptation from BSI Group (2019), a firm focused on audit, development and training services.
} 


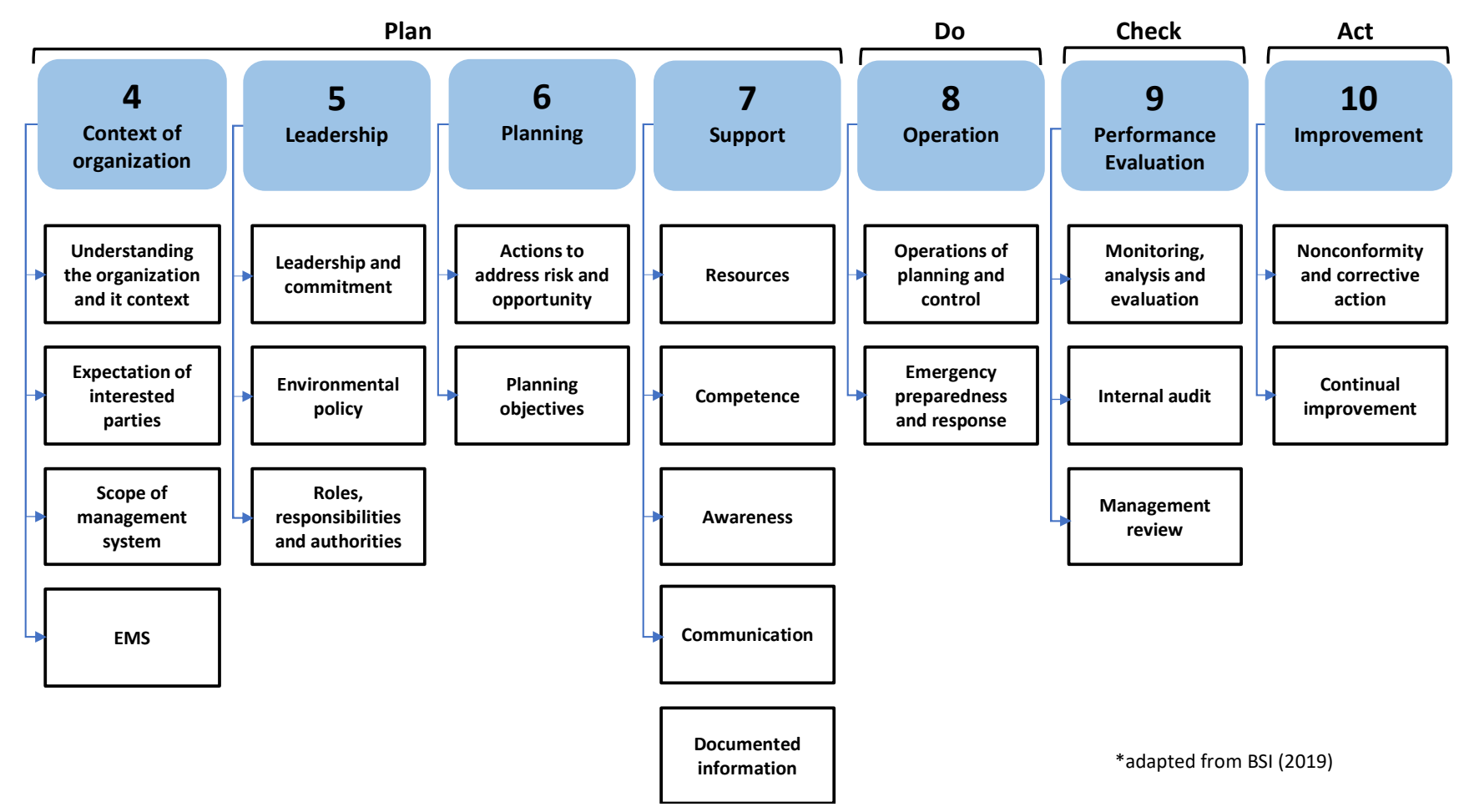

Figure 5. High Level Plan-Do-Check-Act Structure of the EMS*

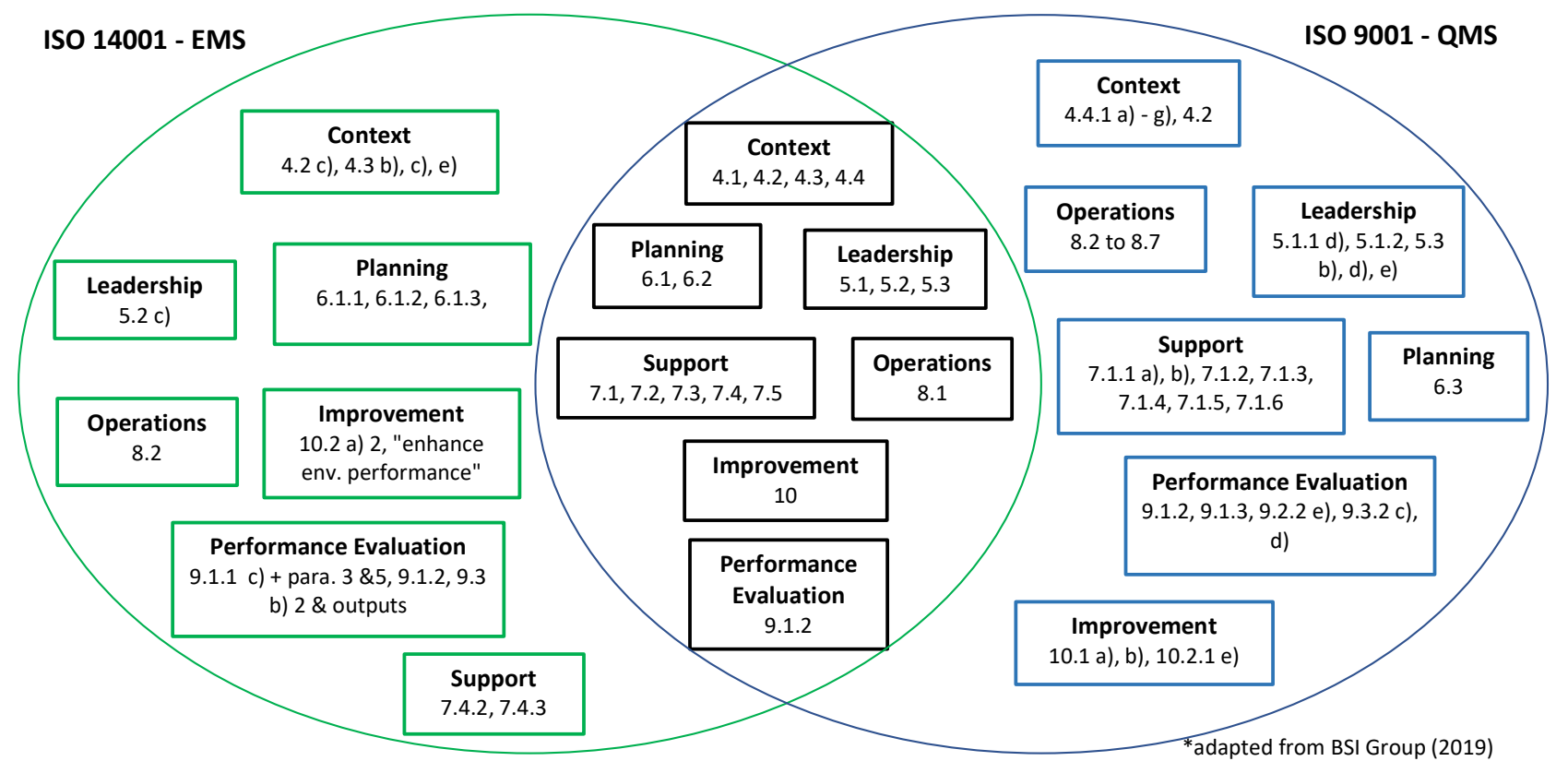

Figure 6. Overlap of Elements Common to ISO 9001 and ISO 14001* 


\subsubsection{HACCP}

An important private regulation relevant to the development of the DWQMS is the Hazard Analysis and Critical Control Points related to food products (HACCP). This is a management system that addresses food safety through the analysis and control of biological, chemical and physical hazards occurring throughout the food production process, from raw material production, procurement and handling, to manufacturing, distribution and consumption of the finished product (USFDA: 2015). The standard's origins date back to 1960, as the National Aeronautics Space Administration (NASA) partnered with the Pillsbury Company (a food processing company) and the US Army Laboratories to develop safe food for upcoming space expeditions. ${ }^{11}$ This program was designed to ensure pathogen-free food for their space program. An outbreak of botulism in 1972 from commercially canned potato soup prompted the US Food and Drug Administration to promulgate regulations drawing on many HACCP concepts, which by 1997 were adopted as mandatory by the USFDA (PSFS, 2005).

The basic criteria of the HACCP are built on a solid foundation of pre-requisite programs, with the recommendation that all pre-requisite programs should be assessed during the design stage and should be regularly audited thereafter. The HACCP has the following seven principles:

- Principle 1: Conduct a hazard analysis

- Principle 2: Determine the critical control points (CCPs)

- Principle 3: Establish critical limits

- Principle 4: Establish monitoring procedures

- Principle 5: Establish corrective actions

- Principle 6: Establish verification procedures

- Principle 7: Establish record keeping and documentation procedures

For the development of the DWQMS, the design of the standard combined the underlying principles of HACCP (such as the CCPs) with the preventative maintenance procedures for processing equipment to avoid unexpected equipment failure and loss of production. This practice has been documented in many jurisdictions (Damikouka, Katsiri, and Tzia, 2007: 138).

\footnotetext{
${ }^{11}$ Safe Food Alliance - HACCP History, [Online]: safefoodalliance.com/haccp/the-history-of-haccp/ [29 Mar 2017]
} 


\subsubsection{US Voluntary State-Sponsored MSSs for Environmental Protection}

In other jurisdictions, there has also been increasing use of international EMSs for municipal wastewater systems. In 2005, the US EPA created the Guide for Evaluating Capacity, Management, Operation, and Maintenance (CMOM) Programs at Sanitary Sewer Collection Systems, a guide that covers many of the elements of the ISO 14001 (US.EPA, 2005). This is a voluntary program, although it is also referred to in abatement orders to some municipalities "as required by Federal or State compliance, audit invitation, or violation response" (e.g. Springfield, Missouri) (WEF, n/d). As an example, several cities in North Carolina have implemented ISO 14001 for their wastewater systems (e.g. City of Gastonia 2000).

Relevant for their parallels to Walkerton, drinking water-related tragedies also occurred in Milwaukee, Wisconsin (1993), and Flint, Michigan (2014). In Milwaukee, an estimated 400,000 people became ill and 104 died in cases attributed to water contamination with Cryptosporidiosis (Naumova et al., 2003). This massive outbreak was reportedly caused by a failure at the city's water treatment plant in the testing protocols for detecting cryptosporidium oocysts that resulted from unprecedentedly high turbidity reported from Lake Michigan (Mackenzie et al., 1994). The failure was attributed to inadequate training of operators, negligent operators, the absence of a requirement for public reporting of lab results, and a general lack of control in water treatment plant operations (Behm, 2013). While an EMS is not required in the State of Wisconsin, the ISO 14001 standard is part of the "Green Tier", a voluntary state program established by legislation that is administered by the Wisconsin Department of Natural Resources. The program reduces liability for entities that adopt voluntary compliance (WDNR, 2014).

In 2013, in Flint, Michigan, also part of the Great Lakes watershed, the State of Michigan switched Flint's water supply from Lake Huron to the Flint River. This decision was made as a temporary measure while a new pipeline to bring a water supply from Lake Huron was built (CNN, 2019). In 2014, while the new pipeline was under construction, residents reported changes to their water tap colour, smell and taste. 12 people died in a Legionnaires' disease outbreak suspected to be linked to the Flint water supply (Detroit News, 2019). According to one class-action lawsuit, the State Department of Environmental Quality (DEQ) failed to 
monitor the water supply and treat it with anti-corrosive agents, and as a result the new water source eroded the iron water mains, increasing the lead concentration in the water distributed (US DCED Michigan, 2015). Scientific research conducted in 2014-2018 found results supporting the hypothesis that a system-wide proliferation of legionellae was responsible for the Legionnaires disease outbreak in the Flint region (Rhoads et al., 2017; Zahran et al., 2018).

The State of Michigan, in its 2018 update to The Michigan Guide to Environmental, Health and Safety Regulations (Michigan State, 2018) include a specific chapter for developing environmental management systems with specific references to the ISO 14001. These initiatives, at both federal (CMOM) and state levels (Wisconsin and Michigan) in the US, provide additional evidence of how relevant the EMS, and in particular the ISO 14001, has become for municipal water and wastewater systems.

\subsubsection{Other Non-State Standards (ISO 45001 / CSA Group Z1000 - H\&SMS)} Many jurisdictions have health and safety (H\&S) regulations with minimum standards, and there are also market-oriented MSS such as the international OHSA 18001, the International Labour Organization's ILO-OSH Guidelines ${ }^{12}$, and the CSA-Z100. The ISO recently published the ISO 45001 for Occupational Health and Safety, developed (as all ISO standards are), by a committee of international experts and following a generic MSS structure like the ISO 14001, and ISO 9001 (ISO, 2018).

Over 7,600 people die each day from work-related accidents or diseases - that's over 2.8 million per year. ${ }^{13}$ Construction work is a major activity in the water and wastewater industry (laying pipe underground, repairing pumping stations and leaks, that frequently occur in emergency situations, and upgrading facilities), and the risk associated with it (entering valve chambers, pumping stations, and other confined spaces exposed to toxic gases) require workers and management to be very diligent to ensure worker safety. Water utilities, both public and private, are keen to implement $\mathrm{OH} \& S$ policies aligned with the industry's best management practices (e.g. Windsor Utilities Commission, EPCOR, Halton Region, Peel Region).

\footnotetext{
12 ILO Occupational Safety and Health Management Systems, [Online]: www.ilo.org/global/topics/safety-andhealth-at-work/normative-instruments/WCMS 107727/lang--en/index.htm [02 Sep 2018]

${ }^{13}$ ISO 45001, [Online]: www.iso.org/iso-45001-occupational-health-and-safety.html [02 Sep 2018]
} 
In Ontario, the Occupational Health and Safety Act (1990) regulates the minimum requirements for OH\&S in the workplace. In 2017, the government of Ontario conducted public consultation through its Ministry of Labour to request input "to help create a voluntary accreditation program that will recognize employers who go above and beyond to promote health and safety practices" (MOL, 2017), with this voluntary accreditation to be aligned with international best management practices (MOL, 2017), such as those of the ISO and CSA. Thus, the use of management system standards in support of governmental objectives is an approach contemplated or used in Ontario not only in the environmental context, but also in other policy contexts such as labour/worker health and safety.

\subsection{Synthesis of the Academic Literature Review}

A review of the literature on governance shows a shift of emphasis over time from state-centric approaches to approaches that recognize the value of non-state governance. This evolution has taken governance from the pre-1980s conception of a government-centric paradigm (such as the Westminster model), into the post 1990s polycentric conception of multi-level, participatory, collaborative, network and sustainable governance recognizing the role of nonstate actors in decision making.

Figure 7 outlines the different levels of participation of state and non-state actors in governance decision-making. This figure shows an increasing level of influence by non-state actors over elements of policy decision-making (policy goal setting, implementing and monitoring policy, enforcing policy, achieving society's goals and policy implementation).

In this context, it is important to observe that both state and non-state standards Figure 3(Figure 7) bring benefits in terms of transparency, legitimacy, sustainability, accountability, effectiveness and efficient public policy and public administration, in what Hatfield-Dodds (2007: 9) refers to as a license to operate, or as referred to in the resource extractive industry context as a social license to operate ${ }^{14}$ (Webb, 2012c: 3, Demuijnck \& Fasterling, 2016: 675). This is particularly relevant in Ontario where the Walkerton tragedy (2000) triggered the

\footnotetext{
${ }^{14}$ Social licence to operate: was described as the organization's need to "adopt compliance measures beyond the minimum" to secure the approval and cooperation of affected communities and stakeholders (Webb, 2012c: 3, citing from Dashwood, 2007).
} 
involvement of state and non-state actors in re-formulating the governance of drinking water, and where there are elements that suggest that a similar new governance system is shaping the governance of municipal wastewater and the stormwater sectors and addressing public concerns about accountability and environmental protection. Up to this point there appears to be alignment of the Ontario water management sectors consistent with this evolving conception of governance. This phenomena appears to point to a sustainable governance approach as defined by Webb (2005: 243, 280; 2015c: 4), which will be examined in more detail in Chapter 2.3.

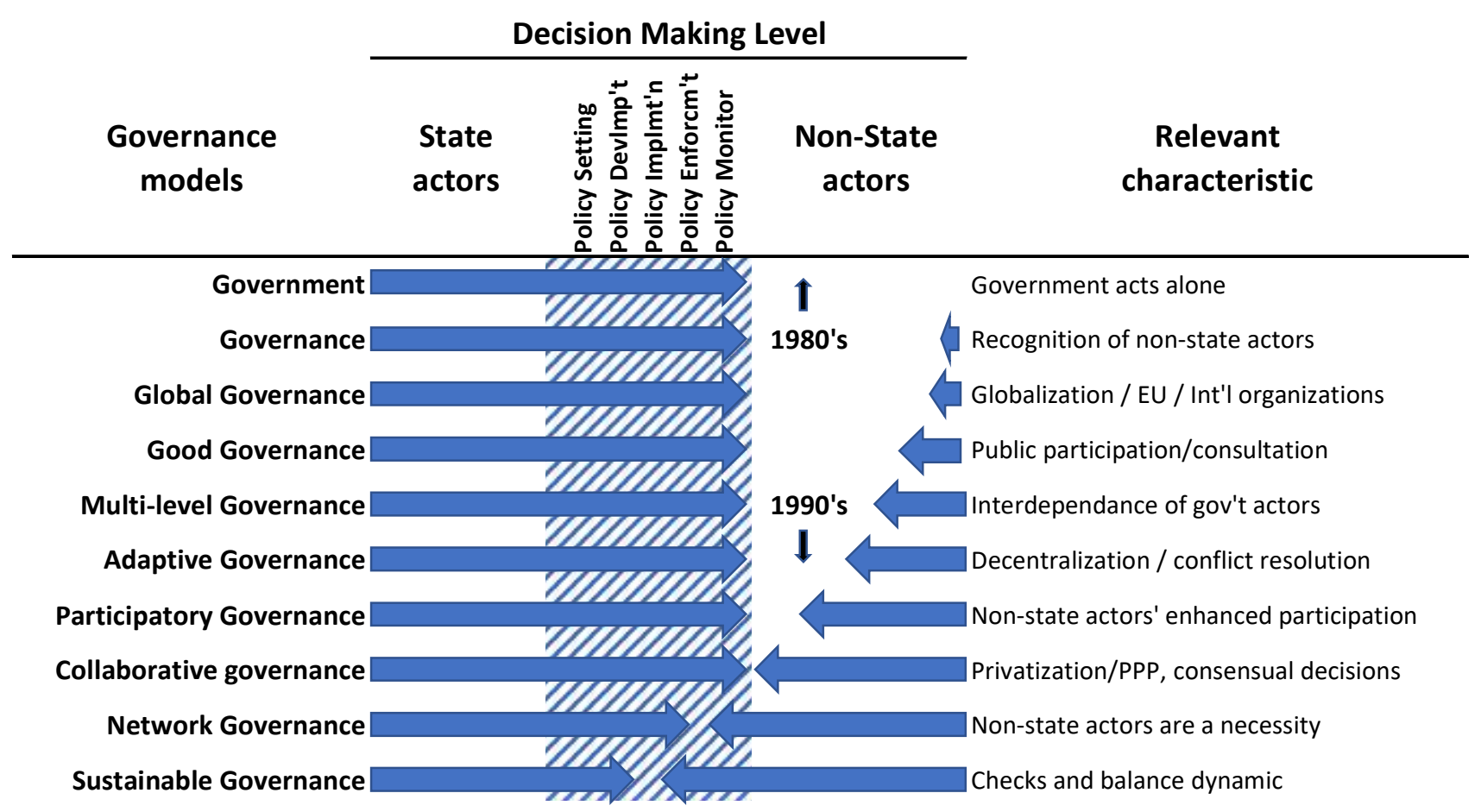

Figure 7. Governance Models and Levels of Participation of Non-state Actors

Second, the literature review has found an oversimplification in the perspective on how state actors appear to be adopting non-state actors' policies and rule instruments. This research makes a contribution to the literature on policy convergence by proposing the idea of convergence occurring in vertical and horizontal dimensions: horizontal (between state actors drawing on non-state rule instruments such as ISO management standards); and vertical (between the three levels of government), including a quasi-vertical dimension (e.g. the courts 
acting as facilitators to interpret and apply federal, provincial and other laws as applied to municipalities, including ordering municipalities to adopt EMS or in some cases ISO 14001). This works in both directions, as non-state actors also draw from government learning in the development of non-state sector-specific standards (Tovilla and Webb, 2017a: 222).

Finally, while there is significant literature on MSSs and ISO standards applied in private sector contexts, concerning various industries and the motives, performance and evolution of such standards, there appears to be very little literature about the use of MSSs in municipal water, wastewater and stormwater contexts. This is understandable given that less than $1 \%$ of worldwide ISO 9001 and ISO 14001 (EMS) certification holders are classified as "public entities". Most of the existing literature on MSSs for the water sectors is in the form of state and nonstate rule instruments (e.g., DWQMS, CMOM, AWWA-G400, Wisconsin's Green Tier Program, Michigan's EMS guide) and legally established quality management (O'Connor, 2002) and environmental management standards (see Canadian laws in Table 8; judicial cases in Chapter 2.3.3; and U.S. cases in Chapter 2.1.7).

In examining the concept of policy convergence and related concepts such as policy diffusion, policy transfer, lesson-drawing, it was found that since the 1980s policy convergence has been viewed as a phenomenon of increasing interest, especially in the context of the European market integration of 1992 and increasing globalization (Bennett, 1991; Strang and Meyer, 1993: 488; Strang and Soule, 1998: 266; Stone, 1999: 53; and Simmons and Elkins, 2004). Since the 2000 s policy convergence (and related terms) have been seen as a resource for innovation and more effective decision making (Stone, 1999: 52, 58; Strang and Macy, 2001: 148-149). Associated with this is the idea of imitating "success stories" (Heichel et al., 2005; Simmons and Elkins, 2004) and the proposition by Lenschow et al. (2005) of a more structured approach that analyzes domestic factors: culture (predominant religious tradition), institutions (public and private relations) and economy (economic development). If two or more jurisdictions have relatively similar factors (culture, institution and economy), then their policy goals, rule instruments or settings are likely to be "calibrated" or converge on those points.

In the specific case of environmental policy, it has been concluded by Lenschow et al. (2005) that "convergence appears to be the rule in the environmental field", noting the current 
enhanced transnational communication, regulatory competition, harmonization and parallel problem solving as major contributors to convergence in the environmental arena.

The concept of management system standards (MSSs) has been examined with a focus on quality and environmental MSSs (ISO 9001, ISO 14001 and HACEP), as these standards are more relevant to the management of the municipal water sector. MSSs are aligned with riskmanagement approaches to satisfy the needs of market-oriented organizations and represent a global view of civil society's expectations, which are playing an increasingly complementary role in environmental government regulations.

The ISO 9001 (or quality management system - QMS) standard was introduced in 1987, in part as a result of the interest of the manufacturing and defence industries in total quality management, and total productive maintenance (Sivaram and Devadasan, 2012; HerasSaizarbitoria and Boiral, 2013; Franceschini, Gelatto and Cecconi, 2006). A QMS is not a system for performance, but a system to ensure consistency in the manufacturing of products.

The ISO 14001 (or environmental management system-EMS) standard was first established in 1996. It also originated as a means of satisfying market-oriented organizations and was developed in response to legal cases prosecuting corporations or their directors for quasicriminal liability and its potential for due diligence defence. This situation provided an increased incentive during the 2000s for privately owned companies to adopt EMS.

While QMS and EMS approaches have been criticized by some scholars on a variety of grounds, (Chatterji \& Toffel 2010: 934, 936; Simpson \& Sroufe 2014: 833; Darnall and Sides, 2008: 95; Alvarez-Garcia \& RioRama 2016: 1; Dahlström et al., 2003: 187), other scholars have suggested that the benefits of MSSs outweigh the possible criticisms, focusing on their positive impact on performance (King et al., 2001: 1; Hart and Milstein, 2003: 56; Henriques and Sadorsky, 2008: 16; and Darnall et al., 2010: 283).

The ISO 9001 and ISO 14001 standards have become the world's most popular standards for QMS and EMS respectively, with 1.1 million ISO 9001 certifications, and 346,000 ISO 14001, certifications (ISO, 2017). An estimated 1\% of these world-wide certifications are associated with "water supply" entities and/or "public administration" (ISO, 2017), pointing to an increasing recognition by public administration entities of the value of non-state, market- 
oriented MMSs. This supports the idea that EMSs are a non-state rule instrument innovation that is now being adopted by state entities, reflecting the phenomena of policy convergence, diffusion and transfer discussed above.

Furthermore, the current trend is to develop sector-specific standards to meet sectorspecific needs. Most such standards are developed by editing the main ISO standards. This development is relevant given the fact that a sector-specific QMS was created to meet the needs of the Ontario government for drinking water systems in 2006. This Ontario-made standard was largely based on ISO 9001 and HACCP and was made mandatory. This review has found considerable empirical and documented evidence of the municipal use of MSSs (legislated or voluntary), drawing on:

- $\quad$ ISO 9001 (QMS) more suited to drinking water systems.

- ISO 14001 (EMS) more suited to wastewater and stormwater systems.

- $\quad$ HACCP more suited to drinking water systems.

This proposition is based on the nature of the inputs and outputs in the management of MSS processes in water and wastewater systems, the outcome in this research (interviews, case studies and focus group) and a simple evaluation of the environmental, health and property risks associated with them (Table 4). Additionally, federal, provincial and municipal laws, as well as the courts, are increasingly referencing ISO 14001 as a policy tool for environmental protection (Table 8).

Table 4. Prominent Risks/Hazards vs. Most Adequate MSS

\begin{tabular}{|l|c|c|c|c|}
\hline \multirow{2}{*}{$\begin{array}{c}\text { Municipal } \\
\text { water sectors }\end{array}$} & \multicolumn{2}{|c|}{ PROMINENT RISKS/HAZARDS } & \multirow{2}{*}{$\begin{array}{c}\text { Most Suitable } \\
\text { MSS Likely to } \\
\text { Address Risk }\end{array}$} \\
\cline { 2 - 4 } & Human health & Environmental & Property & QMS, HACCP \\
\hline Drinking water & Significant & Low & Low & Significant \\
\hline Wastewater & Medium & Significant & EMS \\
\hline Stormwater & Low & Significant & Significant & EMS \\
\hline
\end{tabular}

The US summaries of water contamination tragedies in Flint and Milwaukee, support the idea that the US federal and state governments are referencing and/or promoting the adoption 
of EMSs for water and wastewater systems. Nonetheless, the selection of a QMS or EMS should be based on a purposive and intentional consideration of the objectives to be accomplished.

In view of the Ontario Ministry of Labour's public consultation on voluntary standards, the use of MSSs in support of governmental objectives is clearly an approach being contemplated and used in Ontario not only in the environmental context, but also in other policy contexts such as labour/worker health and safety.

In summary, preliminary conclusions based on this literature review point to a constant evolution of public policy terminology relevant to this study, primarily:

- The term governance has evolved from a government-centric model into a sustainable governance model, where non-state actors are significant drivers of policy development and implementation in a rivalrous and adversarial dynamic.

- The term policy convergence has evolved from its initial conceptualization in the context of globalization and trade competition, into a more complex array of factors affecting the degree of convergence (extent of achievement of policy goals), direction (mandatory vis-à-vis voluntary rule instrument, enforcement and compliance capacity) and scope (number of laws, regulations or other policy tools involved). Moreover, there are factors within the context of the Ontario municipal water sectors that appear to align with those defined by Knill (2005), triggering and facilitating factors of convergence.

- The term management system standard (MSS) has also evolved, particularly as it relates to ISO 9001 (1987) and ISO 14001 (1996), from its origins as a means of addressing corporate profit-driven concerns to its current condition as a large family of standards expanding both in scope and in use, due to the increasing adoption by the public sector of elements to fill perceived regulatory gaps.

- Municipalities are increasingly adopting EMSs for environmental protection (Figure 9).

These preliminary conclusions will be further examined and referred to in the following sections with a review of the federal, provincial and municipal regulatory framework of the Ontario water sector. The purpose of such a review is to address the two research questions 
posed at the beginning of this chapter concerning what scholarly conceptions of governance best aligns with Ontario's water sectors, and how the theoretical conceptions of policy convergence and management systems standards assist in understanding Ontario's municipal water regulations.

\subsection{Literature Review - State-Based Sources (Law, Guidelines, Court Decisions)}

To understand the role that management systems standards (MSSs) can and do play in Canadian municipal environmental governance it is necessary to contextualize the standards within the broader legal framework, as reflected in laws, regulations, policy documents, guidelines and court decisions. In Canada, the regulatory governance of municipal drinking water, wastewater and stormwater systems is an activity involving all three levels of government (i.e. federal, provincial/territorial and municipal).

For the most part, the primary constitutional responsibility for inland waters lies with provincial governments (ECCC, 2015), but the federal and municipal governments also play important roles. Although provincial governments are ultimately responsible for the regulation of municipal drinking water, wastewater and stormwater systems, the federal role is important as it is the federal government that has responsibility for the protection of fish and fish habitat from potential contamination, and it is the federal government that has set minimum requirements for effluent discharges to the environment (e.g. through the federal Fisheries $A c t)$. Contamination may result from untreated municipal wastewater, untreated and potentially contaminated urban stormwater and its impact on rivers and lakes.

Through a delegated responsibility on behalf of provincial governments, municipal governments are given the primary mandate of developing and implementing the water/ wastewater/ stormwater infrastructure needed to satisfy urban and rural demands, as well as ensuring that their approach complies with federal and provincial requirements. To ensure compliance, this often means that municipalities adopt industry recognized best-management practices (BMPs), which may go above and beyond the provincially regulated minimum requirements. This is more relevant to wastewater and stormwater where provincial regulations are less restrictive and generally rely more on guidelines and manuals (Table 27). 
For the purposes of this study the terms "sewage" and "wastewater" have the same meaning (bearing in mind the definition of "sewage" provided in Ontario legislation ${ }^{15}$ ), and the term "stormwater" will be used separately to reflect the fact that the environmental impacts and management of stormwater are distinct from those of sanitary wastewater. This study therefore considers the terms wastewater/sewage as being in a different functional category from stormwater.

\subsubsection{Federal Governance Role}

Pursuant to the Constitution Act, 1867, the Government of Canada has certain regulatory responsibilities for protecting water quality, for conserving and protecting oceans and fisheries, and for overseeing issues associated with navigable waters and for inter-governmental and international affairs (Greenbaum \& Wellington, 2010). Under section 92A of the Constitution Act, 1867, the provinces have the authority over the "development, conservation and management of non-renewable natural resources."

Relevant federal statutes that govern aspects of aquatic environmental protection, include the Fisheries Act (as amended) and its regulations, the Canadian Environmental Assessment Act (as amended); and its regulations, the Canadian Environmental Protection Act, 1999 (as amended) and its regulations, and the Environmental Enforcement Act. In addition, the Canadian government also participates in the federal-provincial organization called the Canadian Council of Ministers of the Environment (CCME), which creates guidelines that are then reflected in federal and provincial laws. Established in the 1990s and comprised of the environment ministers from the federal, provincial and territorial governments, the CCME is the primary minister-led intergovernmental forum for collective action on environmental issues of national and international concern. ${ }^{16}$

The Fisheries Act is jointly administered at the federal level by the Department of Environment and Climate Change Canada (ECCC) and the Department of Fisheries and Oceans Canada (DFO). The DFO has significant responsibilities with respect to regulating the discharges of deleterious substances into waters frequented by fish covered by the Canadian Fisheries Act

\footnotetext{
${ }^{15}$ Ontario Water Resources Act, Section 1(1).

${ }^{16}$ CCME, [Online]: www.ccme.ca/en/about/index.html [10 Feb 2016]
} 
(subsection 36.3). For the wastewater and stormwater sector, the Fisheries Act has provisions protecting against deleterious deposits into waters frequented by fish. The Wastewater Systems Effluent Regulations (WSER), ${ }^{17}$ passed in 2012 pursuant to the Fisheries Act require municipalities to monitor and record the volume of wastewater entering a wastewater treatment system or the volume of effluent discharge to the environment on a daily basis. Provinces have similar laws already in place and are thus attempting to ensure that their own legislation is harmonized with WSER to avoid duplication. The need for a harmonized approach was highlighted in the Government of Canada's WSER Regulatory Impact Analysis Statement (RIAS). ${ }^{18}$ However, as of January 2019, only Quebec has reached an harmonized agreement with Canada. ${ }^{19}$ On July 5, 2019, the Ontario government announced a proposed new CanadaOntario Agreement on Great Lakes Water Quality and Ecosystem Health, which is intended to address some aspects of this harmonization. ${ }^{20}$

The Fisheries Act, 1985, gives courts the authority to engage in creative sentencing powers. Specifically, section 79(2) of the Act provides that the court may require an entity:

[....] to comply with any other conditions that the court considers appropriate for securing the person's good conduct and for preventing the person from repeating the offence or committing other offences under this Act.

This aspect is important, as there are examples of courts using creative sentencing to require funds to be provided to implement proactive monitoring (above and beyond regulatory requirements) and also to develop elements of MSS and in some cases outright ISO 14001 (e.g. City of Calgary, Alberta Capital Region Wastewater Commission). As will be seen in a subsequent part of this chapter discussing court decisions, the Canadian judiciary has used these sentencing powers to impose a requirement that an entity be certified to ISO 14001.

Also of relevance to this study, pursuant to s. 209(1) of the Canadian Environmental Protection Act, 1999 (CEPA), authority is given to the Governor in Council to pass regulations

\footnotetext{
${ }^{17}$ WSER Regulations, website (Fisheries Act), [Online]: http://laws-lois.justice.gc.ca/eng/regulations/SOR-2012139/FullText.html [10 Feb 2016]

${ }^{18}$ Office of the Auditor General of Canada, Implementation status of the Wastewater Systems Effluent Regulation, [Online]: www.oag-bvg.gc.ca/internet/English/pet 328 e 36429.html [10 Feb 2016]

${ }^{19}$ Canada Gazette Part II, October 17, 2018, [Online]: www.gazette.gc.ca/rp-pr/p2/2018/2018-10-17/pdf/g215221.pdf [10 Feb 2016]

${ }^{20}$ Environmental Registry of Ontario No. 019-0198, [Online]: https://ero.ontario.ca/notice/019-0198 [10 Feb 2016]
} 
concerning environmental management systems (at the time of writing, no such regulations have been passed). In addition, pursuant to section 291(1) of the Act, the court may order an offender:

(e) [....] to implement an environmental management system that meets a recognized Canadian or international standard [....]

(f) [....] to have an environmental audit conducted by a person of a class and at the times specified by the court and directing the offender to remedy any deficiencies revealed during the audit $[\ldots .$.

The Canadian Environmental Enforcement Act (2010) introduced new enforcement tools and fine regimes and strengthened sentencing provisions in federal environmental legislation, including CEPA. This legislation allows for orders that a judge may impose for a conviction for an environmental offense, thus "directing the offender to implement an environmental management system, pollution prevention plan or environmental emergency plan."

The federal government also has environmental assessment legislation in place. The Government of Canada has created guidelines that promote the voluntary adoption of EMSbased on ISO 14001. In 2001 the government published "A protocol guide for an EMS Audit" (Environment Canada, 2001), which states: "the protocol is based on the International Standard ISO/DIS 14001--Environmental Management Systems." ${ }^{21}$ For the municipal drinking water sector, working with the provinces and territories, the federal government has played a role in the development of national water quality rules such as the Guidelines for Canadian Drinking Water Quality, which were developed by the Federal-Provincial-Territorial Committee on Drinking Water ${ }^{22}$. These guidelines and related technical documents are used by provincial governments in the development of their own drinking water regulatory requirements.

Individual federal regulatory entities can impose conditions on licensees, including conditions pertaining to the use of environmental MSSs. For example, the Canadian Nuclear

\footnotetext{
${ }^{21}$ Environment Canada - Protocol for EMS Audit [Online]: http://publications.gc.ca/site/eng/104414/publication.html [10 Feb 2016]

${ }^{22}$ Health Canada website (21 Dec 2015), [Online]: www.canada.ca/en/health-canada/services/environmentalworkplace-health/water-quality/drinking-water/federal-provincial-territorial-committee-drinking-water-healthcanada.html [10 Feb 2016]
} 
Safety Commission, ${ }^{23}$ a federal government agency, as part of the 2017 REGDOC 2.9.1.

Environmental Protection Policy, requires both an environmental risk assessment and the application of ISO 14001, among other CSA Group standards (e.g. CSA N288.7 Groundwater protection, and CSA N2884 Environmental monitoring) for licence applications for proposed nuclear facilities. In addition to the licensee's ISO 14001 certification, this policy also requires a third-party audit (CNSC, 2017).

Just as private corporations can require that their suppliers meet certain environmental or other specifications (Webb, 2012a), so too can government entities use their contracting power to ensure that providers meet certain standards. An example of this is the Green Procurement Policy ${ }^{24}$ established in 2006 and administered by Public Services and Procurement Canada. Through this policy, goods and services are procured considering relevant aspects to elements of the ISO 14001 (e.g. life-cycle cost considerations, environmental performance, emissions to the environment, and climate-resilient infrastructure projects).

Taken together, the above-described federal legislative, regulatory, policy and other documents show considerable recognition by the federal government of the value of environmental management systems and of international environmental management system standards.

\subsubsection{Provincial Governance Role}

This section presents a review of relevant provisions in provincial legislation concerning governance of municipal drinking water, wastewater and stormwater, as well as provisions pertaining to offences, judicial sentencing capabilities and any particulars of the laws that specifically refer or apply to municipalities. This analysis is undertaken with particular attention to references or possible connections to the use of management system standards (MSSs) and of international MSSs in connection with governance of the municipal drinking water, wastewater and stormwater sectors. It will be seen that MSSs and ISO 14001 are specifically referenced in provincial law in apparent recognition of their potentially constructive role in

\footnotetext{
${ }^{23}$ Canadian Nuclear Safety Commission [Online]: http://www.nuclearsafety.gc.ca/eng/acts-andregulations/regulatory-documents/history/regdoc2-9-1.cfm [02 Sep 2018]

${ }^{24}$ Green Procurement Policy, is a Canadian government policy established in 2006 for procuring goods and services with a reduced environmental impact, [Online]: www.canada.ca/en/treasury-board-

secretariat/services/innovation/greening-government/green-procurement.html [12 Jan 2019]
} 
protecting the environment and human health. The alignment or "calibration" of provincial rule instruments according to a risk-based approach across the drinking water, wastewater and stormwater sectors, is supportive of and consistent with a movement toward the use of MSSs for all three sectors. As such, this is reflective of a policy transfer and convergence across the municipal drinking water, wastewater and stormwater sectors.

\section{Provincial Status Pertaining to Water, Wastewater and Stormwater Activity}

Relevant provincial statutes that govern aspects of municipal drinking water, wastewater and stormwater include: the Ontario Water Resources Act (as revised: first enacted in 1956), and its regulations; the Environmental Protection Act 1990 (as revised), and its regulations; the Safe Drinking Water Act (2002, as revised) and its regulations; the Nutrient Management Act (2002, as revised) and its regulations; the Clean Water Act (2006, as revised) and its regulations; and the Planning Act (1990) and its regulations. The EPA, OWRA, SDWA and CWA are administered and enforced by the Ontario Ministry of the Environment, Conservation and Parks (MECP). The Planning Act is administered by the Ministry of Municipal Affairs and Housing (MMAH); and the NMA by the Ministry of Agriculture, Food and Rural Affairs (OMAFRA).

For drinking water systems, the SDWA is directed at the prevention of drinking water health hazards and requires a QMS for all municipal systems. Specifically, sections 11(1), and 24(1) of the SDWA state:

11(1) Every owner of a municipal drinking water system [... is] responsible for the operation of the system [....] shall ensure [....] the drinking water system is operated [....] maintained [....] and satisfies the requirements of the standards prescribed for the system.

24(1) [....] requirement that the person establish and administer a program based on the Quality Management Standard for drinking water systems [.... and] to audit the level of conformity by accredited operating authorities with the Quality Management Standard.

A significant difference between the governance of municipal drinking water systems and that of wastewater and stormwater systems is the provincial government's ability to pre-authorize new developments and new infrastructure for the provision of municipal drinking water services. Similar provisions do not exist with respect to the wastewater and stormwater sectors. 
The SDWA also covers those potable water systems for consumers that are privately-owned and built (e.g., by developers) prior to public potable water being provided to consumers. Once built and hooked up, these private systems are transferred to municipalities. This is the case for new subdivisions and new land approved for development by a municipality. Specifically, section 53(1) of the SDWA, and section 2(2) of O. Reg. 172/03, state that:

53(1) No person shall construct a [....] municipal drinking water system that is intended to serve a major residential development within the geographic area of a municipality [....] unless the person obtains the written consent of the municipality to do so.

2(2) [....] [a municipal drinking water system is defined as a system] established in accordance with an agreement with a municipality, entered under the Planning Act, the Development Charges Act, 1997 or the Condominium Act, 1998.

The Planning Act, administered by the Ontario MMAH, provides under section 1(1) for the "land use planning system led by provincial policy" to "integrate[s] matters of [....] municipal planning decisions" and to "recognize the decision-making authority and accountability of municipal councils in planning," among other mandates. It is under this Act that a mandate is provided to municipalities to authorize land development inclusive of drinking water, wastewater and stormwater infrastructure, which at the time is owned by private entities. Typically, for infrastructure to service municipal residents this is stated in "subdivision agreements" for residential development; and for industrial and commercial sites, this is stated in "site plan approvals". Both subdivision agreements and site plan approvals contain infrastructure whose ownership is subsequently transferred to municipalities.

Relevant to the orientation of provincial policies towards a risk-based approach, O. Reg. 208/19, enacted in June 2019 under the Environmental Protection Act, (the prescribed person regulation), defines prescribed persons with authority to alter, expand sewage works (including stormwater works) effectively paving the way for future pre-authorized infrastructure owned by non-municipal entities. This regulation has the potential to transfer (or download) provincial regulatory functions of oversight to municipalities. The pre-authorizing of infrastructure expansions of wastewater and stormwater works for low-risk activities is similar to what has been in place since 2008-2009 for the municipal drinking water sector (when the O. Reg. 
188/07 for licensing of municipal water systems implemented a phased accreditation and licensing from January 2009 to June 2010). Specifically, sections 1(1) and 2(1) of the O. Reg. 208/19, state:

$1(1)[\ldots .$.$] any person who alters, extends, enlarges or replaces a sewer works [....] is$ prescribed for the purposes of clause 20.6(1)(c) of the Act.

$2(2)[\ldots .$.$] [the prescribed person's works of] altering, enlarging or replacing is carried out$ under agreement with a municipality, entered into under the Planning Act or the Development Charges Act, 1997.

Municipal wastewater discharges into the environment are governed by site-specific rule instruments (environmental compliance approvals, or ECAs), under the EPA and the OWRA. Sludge from wastewater treatment plants (WWTPs) is regulated under three acts: the EPA, the OWRA, and the Nutrient Management Act, administered by OMAFRA. Specifically, section 53(1) of the OWRA state:

53 (1) [....] no person shall use, operate, establish, alter, extend or replace new or existing sewage works except under and in accordance with an environmental compliance approval.

An additional level of oversight exists for flood mapping, erosion protection and watershed management through conservation authorities. The Conservation Authorities Act, 1990, established the creation of provincial conservation authorities with the mandate to manage and deliver "... programs and services that further the conservation, restoration, development and management of natural resources in watersheds in Ontario" 25 . The conservation authorities play a review and permitting role for new development and watershed restoration in support of municipal infrastructure for the municipal water sectors. Figure 8 shows nine of the 36 conservation authorities in Ontario, which are located in the Greater Toronto Area (GTA). The case studies analyzed in Chapter 5.0, are located under the jurisdiction of five of these conservation areas.

${ }^{25}$ Conservation Authorities Act, 1990, [Online]: www.ontario.ca/laws/statute/90c27 [17 Nov 2019]. 


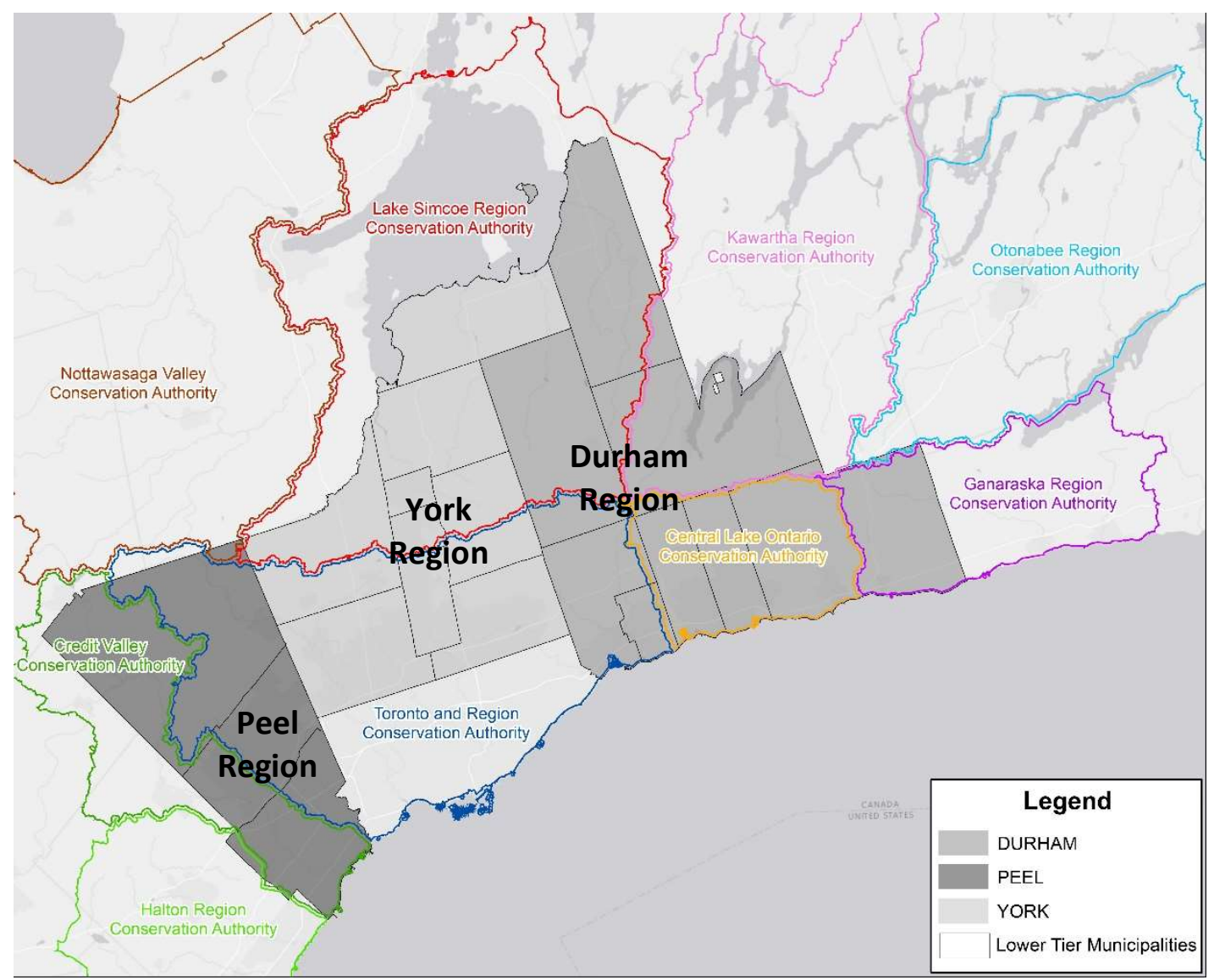

Figure 8. Conservation Authorities and Regional Municipalities in the GTA

As described in this section, while municipal drinking water governance was modernized after the Walkerton Inquiry (2002) and resulted in a multi-barrier and risk-based management approach, the wastewater and stormwater sectors had only marginal improvements and kept the same governance structure that had been established in the 1950s with the OWRA and in the 1970s for stormwater. This means that instead of having a risk-based approach, the wastewater and stormwater sectors continue to rely on a precautionary piecemeal approach where all sewage works require the same level of scrutiny regardless of risk or complexity.

A key element in this distinction is the Drinking Water Quality Management Standard (DWQMS), and a related grouping (or ecosystem) of drinking water regulations (Table 6), which are described and discussed in this section. As will be seen in the subsequent part of this section, this study suggests that a policy convergence seems to be in process, bringing the regulatory framework of the wastewater and stormwater sectors closer to that of the municipal drinking water regime in the sense of adopting a risk-based approach. 
Summarizing the post-Walkerton drinking water regulatory framework, the Canadian Environmental Law Association (CELA) notes in their Ontario SDWA 2011 report, that:

[a]Ithough the quality of raw water may vary from one community to another, the ultimate safety of drinking water depends on a multi-barrier approach, which includes: water source protection from contamination; effective treatment; frequent and comprehensive testing; vigilant monitoring and reporting; the training and competence of waterworks operators; a secure distribution system; and a quick response when problems are found (2011: 2).

In this context, it is important to observe that while the multi-barrier approach was part of the equation in the post-Walkerton regulations for municipal drinking water, such an approach (i.e. multiple regulations) have not been considered necessary to make a comparable MSS for the municipal wastewater and stormwater sectors. As will be discussed in a subsequent part of this chapter, there is an increasing trend among municipalities (in various Canadian jurisdictions) to proactively adopt environmental MSSs for their wastewater and stormwater activities, as well as adopting risks-based approaches to ensure they build the necessary infrastructure for the provision of municipal wastewater and stormwater activities (Chapter 2.3.3, and Figure 9).

The new post-Walkerton governance model for the municipal drinking water sector, saw more comprehensive responsibilities transferred to municipalities (sometimes referred to as "downloading"), including the pre-authorization by the provincial government of system modifications and expansions. Prior to the Walkerton tragedy (2000), the governance of municipal drinking water, wastewater and stormwater was the subject of a piecemeal approach involving project-by-project approval by the provincial government regardless of project risk or complexity. The governance model for municipal drinking water meant municipalities could allow for construction of low risk activities without further provincial approvals, provided that they met minimum design criteria, and other planning requirements. This is in contrast with the wastewater and stormwater sectors, where no such pre-authorization process is in place.

In summary, this section makes the connection between the important role MSSs are playing as an element of the provincial governance of municipal drinking water, introduced in response to the risk-based approach that modernized the delivery of municipal drinking water infrastructure and services in Ontario and transferred provincial regulatory functions to 
municipalities. This evident connection in the drinking water sector contrasts with the provincial governance of the municipal wastewater and stormwater sectors. Provincial initiatives started since 2010 are indicative of the province starting to "calibrate" (or align) its rule instruments across the drinking water, wastewater and stormwater sectors, moving towards the same risk-based approach through a patchwork of provincial regulations and provincial policy tools. This phenomenon shows recognition by the provincial government of the value of MSSs for the municipal wastewater and stormwater sectors.

There are indirect relationships between MSSs and other regulation worth noting. While it is not possible to draw a direct line connecting them with ISO or MSSs, amendments made since 2006 to two other provincial regulations and two new regulations enacted in 2015 and 2017 suggest parallels between provincial requirements and key elements required under the ISO environmental management system family of standards (Table 7). Also, a summary of explicit references in Canadian laws to ISO 14001 and to the DWQMS are listed under Table 8, and a more descriptive summary is included in Appendix $E$.

\section{Penalties and Violations}

The penalties for violation of the SDWA and the OWRA are set out in sections 108(1), 109(2) and 109(3) of the OWRA, and sections 141(1) and (2), 142(1) and (2), and 143(1) to (3) of the SDWA, with large fines (of up to $\$ 10$ million) and the possibility of imprisonment (of up to five years).

Relevant to this study, the OWRA contains provisions to reduce the amount of the penalties if there is an environmental management system (EMS) in place. Specifically, section 106(1) of the OWRA states:

[t]he regulations made under clause (15) (d) [including regulations governing the determination of the amounts of environmental penalties] must provide for a reduction in the amount of an environmental penalty if, at the time the contravention to which the penalty relates occurred, the person who is required to pay the penalty had in place an environmental management system specified by the regulations.

\section{Provincial Role - Municipal Drinking Water}

In 2000, the town of Walkerton, Ontario, home to approximately 5,000 people, was the subject of a water contamination crisis in which an estimated 2,300 people became seriously ill and 
seven people died from exposure to microbially-contaminated drinking water (Hrudey, et al., 2002: 98-101). The Walkerton tragedy marked a separation of the regulatory regimes controlling the drinking water sector on the one hand, and the wastewater and stormwater sectors on the other. With all three sectors previously being regulated under the same EPA and OWRA, the Walkerton tragedy resulted in a more modern regulatory framework for the drinking water sector, with the creation of the SDWA (2002) and the CWA (2006).

Currently, municipal drinking water systems are governed by two municipal-wide rule instruments: the municipal drinking water system-wide licence and an operating permit, issued under the authority of the SDWA. An operating authority holds a permit and the drinking water system as a whole is subject to a system-wide licence. Generally, every drinking water system has one operating authority and one licence for the system. System expansions are preauthorized under the licence according to a risk-based approach. For example, complex modifications involving water treatment technology or treatment systems require a full application to the MECP. Conversely, less risky system expansions such as buried pipe and replacement of equipment in the drinking water distribution system are pre-authorized.

Following the Walkerton tragedy, the combination of two court decisions, a provincial inquiry, and a class action lawsuit, provided a strong impetus for reform (Wellington, Burley, Rollinson-Lorimer, 2010: 522, 526-527) and led to a series of legislative, policy and governance responses (Johns, 2014b: 215). Wellington, Burley and Rollinson-Lorimer (2010: 526-527) summarized these judicial cases:

- In the case of R. v. Koebel and Koebel (2000), there were criminal charges that resulted in the conviction of the operators: one received a one-year prison sentence and the other a conditional six-month sentence.

- The Smith v. Brockton (2000) decision was a class action lawsuit under the Ontario Superior Court of Justice. In the settlement agreement, known as the Walkerton Compensation Plan, the province admitted no liability but guaranteed a minimum payment of at least $\$ 2,000$ to every person medically affected by the E.coli outbreak. The most serious claims were to be assessed individually with no cap stipulated on the amount of compensation. 
Chaired by Justice O'Connor, the Walkerton Inquiry had a two-part mandate: (1) to identify the cause(s) of the outbreak, including the role played in it by government policy, practice and procedure; and (2) to provide recommendations on how government can ensure the safety of the water supply in Ontario.

For Part One, Justice O'Connor ascribed responsibility to both the operators of the drinking water system and the provincial regulator; the former for "improper operating practices" and for practices "unacceptable and contrary to MOE guidelines and directives" (O'Connor 2002a). The MECP was ascribed responsibility for failing to take steps to both inform the operators of MECP requirements and require that they undergo appropriate training. It was concluded that it was unacceptable for the MECP to expect small water system operators to understand the science behind chlorination without proper training and background (Wellington et al. 2010).

Part Two of the public inquiry resulted in a total of 93 recommendations, with a key one being advocacy for a harmonized quality management system for all drinking water systems in Ontario. Specifically, Justice O'Connor recommended that:

[t]he Ministry of the Environment should initiate the development of a drinking water quality management standard for Ontario. Municipalities, the water industry, and other relevant stakeholders should be actively recruited to take part in the development of the standard. The water industry is recognized as an essential participant in this initiative [....] (O'Connor 2002b, recommendation \#53, p.26)

A number of factors were identified by Wellington et al. (2010) as contributing to this tragedy. Table 5Table 5 offers a summary and classification of these contributing factors under the headings: administrative, environmental, operational/technological and regulatory. These factors were addressed by subsequent government actions in the form of acts, regulations and guidelines. Specifically, these contributing elements are addressed in the DWQMS, and are also intrinsic elements necessary for any ISO 14001.

In effect, the Ontario government re-designed the governance framework for the municipal drinking water sector. This reform involved three new statutes and a dozen regulations developed in a span of five years (Table 6). While the focus was on a multi-barrier approach and source water protection, among other policies (Johns, 2014b: 220), Justice O'Connor's recommendations also included the development and implementation of a quality 
management system, which the Ontario government developed in partnership with the CSA Group (Tovilla and Webb, 2017a: 217; CSA Group, 2016).

Table 5. Contributing Elements Leading to the Walkerton Tragedy

Administrative

Lack of oversight by owner

The Walkerton water system was operated by a public utilities commission (PUC), a third party contracted by the municipality. The municipality as owner of the assets and financially responsible for capital management, had little knowledge of operations and challenges. They had a hands-off approach.

\section{Operational/Technological}

Lack of water quality data management

The source of Walkerton's water supply was groundwater controlled by a System Control and Data Acquisition (SCADA) system, which monitored pumping rates, but did not provide any information on water quality.

\section{Lack of training for operators}

The Walkerton operators obtained their operator licences as part of a voluntary "grandparenting" program in 1988, not having to take any courses or any examinations.

\section{Lack of monitoring of chlorination and turbidity}

1994 rules under the Ontario Drinking Water

Objectives for continuing monitoring were applicable to Walkerton; however, those rules applied to new wells only. Wells approved previously had no program to review them.

\section{Mislabelling of samples}

Samples taken were routinely mislabelled and therefore unreliable.

\section{Environmental}

\section{Lack of source water protection}

The well that caused the tragedy was vulnerable to surface water pollution from adjacent farms; compounded with the highly fractured bedrock and water penetration through rock fissures. PUC did not implement any explicit measures for source water protection; moreover, the municipality did not have the legal power to control land use on the adjacent farm.

\section{Regulatory}

Obsolete environmental protection legislation

Drinking water regs. (e.g. OWRA) dated back to 1950s, with no regs. for agricultural practices, left responsibility for regulating, approving, and inspecting water works to MECP, i.e. little responsibility transferred to the municipalities. Lack of funding and privatization of water labs

In 1995 the provincial gov't privatized water testing (attributable to a need for budget reductions), requiring private labs to notify MECP \& Medical Officer of Health of adverse test result.

\section{Lack of follow up on inspection reports}

Although as early as 1992, 1995 and 1998 inspection reports from MECP had noted concerns with bacteriological quality monitoring, no abatement actions were enforced by MECP.

\section{Impacts of government cutbacks}

A number of budget cuts to MECP between 1994 and 2000 reduced its environmental staff by $30 \%$, limiting its capacity for inspections, abatement and enforcement. 
Table 6 lists the three (3) acts and 12 regulations, including a mandatory quality management system known as the DWQMS. The O. Reg. 188/07 mandated a 2-year phase-in approach (2009-2010) to implement the new DWQMS. This new standard draws on the private sector ISO 9001 (QMS) and the food product-related Hazard Analysis and Critical Control Points (HACCP) approach (O’Connor, 2002a, and 2002b; City of London, 2008).

Table 6. Acts, Regulations, and Guidelines Promulgated Following the Walkerton Inquiry

\begin{tabular}{|c|c|}
\hline Acts & Regulations/Guidelines \\
\hline \multirow{11}{*}{$\begin{array}{l}\text { Safe Drinking Water } \\
\text { Act, } 2002 \text { (SDWA) }\end{array}$} & O. Reg. $170 / 03$ for drinking water systems (DWQMS) \\
\hline & O. Reg. 169/03 for drinking water quality standards \\
\hline & O. Reg. 172/03 for defining "municipal drinking water system" \\
\hline & O. Reg. $248 / 03$ for drinking water testing services \\
\hline & O. Reg. $128 / 04$ and O. Reg. $129 / 04$ certification of operators \\
\hline & O. Reg. 242/05 for compliance and enforcement \\
\hline & $\begin{array}{l}\text { Implementing Quality Management: A Guide for Ontario's Drinking Water } \\
\text { Systems (a.k.a. DWQMS Guidelines), } 2007\end{array}$ \\
\hline & O. Reg. $243 / 07$ for flushing for lead - schools, private schools, day nurseries \\
\hline & O. Reg. 453/07 for financial plans for municipal drinking water \\
\hline & O. Reg. 188/07 for licensing of municipal water systems \\
\hline & O. Reg. 205/18 for municipal residential systems in Source Protection Areas \\
\hline \multirow{2}{*}{$\begin{array}{l}\text { Clean Water Act, } \\
2006\end{array}$} & O. Reg. $284 / 07$ for source water protection areas and regions \\
\hline & O. Reg. $288 / 07$ for source protection committees \\
\hline \multirow{2}{*}{$\begin{array}{l}\text { Nutrient Mgmt. Act, } \\
2002\end{array}$} & O. Reg. $267 / 03$ for nutrient management \\
\hline & Ontario's Agricultural Planning Tools Suite (AgriSuite) - BMPs \\
\hline
\end{tabular}

Table 7 presents the connections between the issues contributing to the Walkerton tragedy shown in Table 5 and the new post-Walkerton regulations for drinking water shown in Table 6.

The DWQMS, promulgated in 2006, pursuant to the Safe Drinking Water Act (2002), addressed many of Justice O'Connor recommendations. For the development of the DWQMS, the MECP and the CSA Group partnered with four organizations to use their drinking water systems in a pilot project to test the standard. Two of the pilot systems, the Lake Huron Area Water System and the Elgin Area Water System (which supplies water to the City of London), were privately operated at the time and had obtained ISO 14001 for their drinking water 
systems in 2003 (City of London, 2008; and York Region, 2004). For the development of the DWQMS, the design of the standard combined the underlying principles of the HACCP (such as the Critical Control Points) with the preventative maintenance procedures for processing equipment to avoid unexpected equipment failure and loss of production (Damikouka et al., 2007).

Table 7 Connecting Contributing Elements to the Walkerton Tragedy and Water Regulations

\begin{tabular}{|l|l|}
\hline Issues Contributing to the Walkerton tragedy & Ontario drinking water regulations \\
\hline Lack of oversight by owner & O. Reg. 170/03 (DWQMS) \\
\hline Lack of source water protection & O. Reg. 284/07; O. Reg. 288/07 \\
\hline Lack of water quality data management & DWQMS \\
\hline Obsolete environmental protection legislation & See Table 6 \\
\hline Lack of training for operators & O. Reg. 128/04; DWQMS \\
\hline Lack of funding and privatization of water labs & O. Reg. 453/07; O. Reg. 248/03; DWQMS \\
\hline Lack of monitoring of chlorination and turbidity & DWQMS \\
\hline Lack of follow up on inspection reports & DWQMS \\
\hline Mislabeling of samples & O. Reg. 248/03; DWQMS \\
\hline Impacts of government cutbacks & O. Reg. 453/07 \\
\hline
\end{tabular}

The Canadian Standards Association (created in 1919 and now known as the CSA Group) is an independent membership-based corporation. It has no share capital, shareholders or other owners and is governed under the Canada Not-for-Profit Corporations Act ${ }^{26}$. CSA develops consensus-based standards in the areas of safety, quality, and performance, as well as testing and certifying of conformance to various standards that serve business, industry, government and consumers. ${ }^{27}$ Although a private standards development body, the CSA is part of the national standards system, administered by the Standards Council of Canada (SCC), which is the Canadian representative to the non-state international standards body of ISO.

The DWQMS provides a blended approach that combines the underlying principles of ISO 9001 (QMS), and the 1997 Hazard Analysis and Critical Control Points approach related to food products (HACCP). The basic criteria of the HACCP are built on a foundation of pre-requisite processes identified from the initial design phase of the process and with subsequent regular audits thereafter. The HACCP - CCP focuses on the food industry and entails widely applicable

${ }^{26}$ CSA Group, [Online]: www.csagroup.org/wp-content/uploads/csa-ar14-15-en-web.pdf [10 Feb 2019]

27 See Footnote No. 26 
preventative maintenance procedures for processing equipment to avoid unexpected equipment failure and loss of production. While there was consideration of ISO 14001 when the DWQMS was being developed (City of London, 2008), a review by the author of the original 2006 DWQMS found it did not contain the word "environment" or any clause pointing to "environmental protection". Questioned by the author about this during the MWWRC 2017 Annual Workshop, an MECP representative in charge of the DWQMS noted that such environmental protection was left for municipalities to determine as part of Element 21 of the Standard ("Continual Improvement"). ${ }^{28}$

The DWQMS is part of the provincial Municipal Drinking Water (MDW) Licensing regime. In order to obtain an MDW licence, among other licence application requirements, municipalities are required to have an Operational Plan (in the form of a quality manual) prepared in accordance with the DWQMS. The municipality has an underlying objective to satisfy the owner's responsibilities of due diligence and standard of care.

The DWQMS aligns with a "plan-do-check-act" management system model similar to that found in the ISO MSS family of standards. Key elements of the standard include:

- development of a quality policy;

- ensuring proper planning, implementation and operation of the policy;

- application of monitoring and corrective actions;

- risk assessment; and

- regular management review of how well the management system is operating, and continual improvement (Tovilla and Webb, 2017a; ISO 9001, 2015; ISO 14001, 2015).

The new drinking water regulatory regime saw a transfer of provincial responsibilities for drinking water systems to municipalities, plus a delegation of authority previously held by the province (e.g. approval of modifications and infrastructure expansions).

A key element that allowed all 444 municipalities to become compliant with the new DWQMS in a very short period of time (2009-2010), was the inclusion of a "common" risk assessment and mitigation component in the standard. These were a pre-identified set of

\footnotetext{
${ }^{28}$ The author was a participant (and presenter) at the MWWRC 2016 Annual Workshop and took the opportunity to ask the question from the floor (Tovilla, 2016).
} 
mitigation actions that in fact prevented the need for municipalities to develop expensive and complex risk assessments of their own. Borrowing the concept of "critical control points" from the HACCP, the DWQMS required CCPs to mitigate human health risks.

The CCP is defined in the DWQMS as "an essential step or point in the subject system at which control can be applied by the operating authority to prevent or eliminate a drinking water health hazard or to reduce it to an acceptable level". The pre-identification of CCPs allowed municipalities to concentrate their mitigation, control and monitoring activities on those areas, to ensure compliance with the DWQMS, and other water quality regulatory requirements. The CCPs for drinking water systems in Ontario include the following: source water protection, disinfection at treatment plant, water treatment processes, disinfection at storage and at distribution, and water storage levels (to guarantee positive pressure on the distribution system).

For example, disinfection of drinking water requires pathogen removal credits established under the Ontario Procedure for Disinfection of Drinking Water in Ontario, ${ }^{29}$ a procedure that is referenced as a requirement in area-wide drinking water permits. There are specific numerical indicators for the removal of pathogens by each type of treatment process. Another example is the sampling and testing of drinking water in the distribution system. O. Reg. 170/03 requires municipalities with systems that serve more than 100,000 people, to take 100 distribution samples for every 10,000 people served by the system, with samples "taken every month, and at least three of the samples being taken in each week." 30

After the regulatory modernization of the Ontario drinking water sector from 2002 to 2007, it would be reasonable to ask how safe Ontario's drinking water is today. In their 2011 report, the environmental non-governmental organization called Canadian Environmental Law Association (CELA) ${ }^{31}$ noted that:

[b]ased on monitoring results collected by the Ontario MECP, it appears that municipally treated drinking water usually meets Ontario's drinking water quality standards. High

\footnotetext{
${ }^{29}$ MECP Procedure for Disinfection, [Online]: www.ontario.ca/page/procedure-disinfection-drinking-water-ontario [12 Oct 2018]

${ }^{30}$ O. Reg. 170/03, Schedule 10, Section 10-1 and 10-2

${ }^{31}$ Canadian Environmental Law Association (CELA), created in 1979, is a non-profit organization established to use existing laws to protect the environment and to advocate environmental law reforms. [Online]:

http://www.cela.ca [12 Oct 2018]
} 
levels of contaminants are rarely found. The 2011 annual MECP report on municipal drinking water in Ontario found that the ministry's stringent drinking water standards were met in:

- $99.88 \%$ of drinking water tests from municipal residential systems, - $99.51 \%$ of drinking water tests from non-municipal year-round residential systems, such as mobile home parks, and - $99.49 \%$ of drinking water tests from non-residential and seasonal residential systems serving designated facilities such as day nurseries, schools and health centers (CELA, 2011, page 2).

More recent information from the MECP Chief Drinking Water Inspector Annual Reports from 2012-2015, indicate that province-wide $99.8 \%$ of all drinking water test results comply with Ontario's drinking water quality standards, and there is 98 to $99 \%$ compliance of non-municipal systems in the periods from 2012 to 2015 (MECP, 2016).

Furthermore, the same provincial reports for 2013-2016, for the municipalities included in the case studies presented in Chapter 5.0, York Region, Richmond Hill and Durham Region give all three municipalities ratings above $95 \%$, with $99 \%$ or more of the drinking water quality tests on most of their subsystems meeting the provincial standard. All ratings and test result percentages were even higher for 2014-2015, with numerous $100 \%$ ratings (MECP, 2015; 2016).

On the other hand, the 2014-2015 MECP drinking water report indicated that there were 17 SDWA prosecutions leading to convictions, involving 20 regulated drinking water systems totalling $\$ 161,000$ in fines. Out of the 17 convictions, eight were against systems serving "designated facilities", and seven were against non-municipal year-round residential drinking water systems. All these cases involve private owners of camps, trailers, resorts, and numbered companies. ${ }^{32}$ Most offences involved operators without licensed certificates, improper documentation of records, samples not taken, failing to comply with training requirements, failing to report adverse water quality incidents, and timing for required reports. No municipality was involved in any of these convictions (MECP, 2016).

\footnotetext{
32 MECP (2016) Chief Drinking Water Inspector Annual Report 2014-2015, [Online]: www.ontario.ca/page/chiefdrinking-water-inspector-annual-report-2014-2015 [12 Oct 2018]
} 
All this having been said, it should be noted that Ontario First Nations, with a population of approximately $242,000,33$ are not subject to the Ontario DWQMS governance regime and continue to be subject to regular boil water advisories (CTV, 2018). Under the Constitution Act, 1867, First Nations are a federal constitutional responsibility. The Ontario Ministry of Health and Long-Term Care reported 473 active boil water advisories in Ontario First Nation communities during the month of October 2011 (CELA, 2011). Water quality for First Nation communities is a subject that warrants further attention by federal, provincial and indigenous governments, and others, but is beyond the scope of this dissertation.

Post-Walkerton, the drinking water regulatory regime involved a transfer of responsibilities from the province to municipalities. It includes regulations for financial planning, minimum design requirements for drinking water treatment and distribution, pipe cleaning and CCPs, among others. The holistic approach saw the replacement of the old piecemeal approach of provincial approvals (e.g. one subdivision, one approval), with a consolidated Municipal Drinking Water licence and permit for the entire water system, and a pre-authorization of low risk activities (e.g. expansions with new subdivisions, system modifications, etc.). On the whole, this approach ensures increased accountability, transparency and public confidence in municipal drinking water.

\section{Provincial Role - Municipal Wastewater and Stormwater}

Municipal wastewater and stormwater are governed by site-specific rule instruments (environmental compliance approvals or ECAs), issued by authority of the province under the EPA and the OWRA. An ECA is issued on a site-specific basis. Generally, every new subdivision has one ECA, and every urban stormwater discharge to the environment has one ECA. This results in any given medium-sized municipality having thousands of ECA for its sanitary infrastructure. Also, there are a number of voluntary provincially developed guidelines governing municipal wastewater and stormwater, the more relevant to this study are: the Provincial Water Quality Objectives (PWQO) (1994); the Ontario Sewer Bylaw Guidelines (1998); the Stormwater Plan and Design Manual (2003); the Sewer Design Guidelines (2008). The PWQO are a set of water quality criteria considered to represent the minimum standards

\footnotetext{
${ }^{33}$ Indigenous and Northern Affairs Canada, [Online]: www.aadncaandc.gc.ca/eng/1100100020284/1100100020288 [12 Oct 2018]
} 
necessary for the protection of aquatic life and recreational water use (MECP 1994). The Ontario Sewer Bylaw Guideline assisted municipalities to develop their own bylaws, which by 2004, saw 60 per cent of Ontario municipalities adopting their own sewer use bylaws modeled on the provincial guideline, and the 2006 CCME Model Sewer Use Bylaw, also prompted many municipalities to update their own sewer bylaws in subsequent years (Lukasik, 2003; Saxe, 2013; ECO, 2004). In the late 1980's and early 1990's the province developed the Municipal Industrial Strategy for Abatement (MISA) regulations. The objectives of MISA were to regulate “... the increasing presence of toxic contaminants in the lakes, rivers and streams" (MISA, 1992). While the province enacted regulations for eight industrial sectors: metal mining; electric power generation; pulp and paper; petroleum refining; organic and inorganic chemicals; iron \& steel; and industrial minerals, the municipal regulation was never enacted, leaving the municipal wastewater and stormwater sectors relying on site-specific regulatory approvals only.

Post-Walkerton, there have been only marginal regulatory improvements directed at municipal wastewater systems. The promulgation of O. Reg. 129/04, under the OWRA, provided licensing and training requirements for wastewater operators. However, the wastewater and stormwater sectors did not directly benefit from the new provincial risk-based approach to drinking water. The municipal wastewater and stormwater sectors remained with basically the same governance structure that had been established in the 1950s for wastewater, and in the 1970s for stormwater management (Tovilla and Webb, 2017). While there was no equivalent legislated MSS established for Ontario municipal wastewater and stormwater sectors, there were valuable policy tools developed post-Walkerton including: the Ontario Stormwater Management Planning and Design Manual (MECP 2003), and the Ontario Design Guidelines for Sewer Works (MECP 2008). These guidelines are voluntary rather than mandatory.

In relation to stormwater management (SWM), as noted by Bradford and Gharabaghi (2004: 343), stormwater has been managed in Ontario for flood control purposes since the 1970's, and for quality treatment since 1994 through provincial design guidelines. Although the guidelines are voluntary with no regulatory requirements, the SWM manual has been widely accepted and its design criteria are sometimes required through site-specific approvals. The 2003 SWM 
design manual incorporated an evolution of design criteria including erosion control and water balance objectives (in addition to flood and water quality objectives), which at the time were recognized as leading approaches in North America (Bradford and Gharabaghi, 2004). It also integrated a treatment-train approach with lot-level-controls, conveyance and end-of-pipe facilities. More recent developments in SWM involve the use of Low-Impact-Development (LID) technologies, as an evolution of lot-level-controls, with more sophisticated infiltration and retention technologies. LID has been driven by research and development of new technologies to imitate pre-development hydrology and provide additional levels of quality treatment, among other environmental benefits (Bhatt, Bradford, and Abbassi, 2019).

Since 2010, the province has been gradually adopting a risk-based management approach to municipal wastewater and stormwater systems similar to that already in place for municipal drinking water. The Open for Business Act (2010), amending the EPA, enabled the province to streamline their piecemeal approval regime to some extent, and to introduce certain preauthorized environmental approvals (Tovilla and Webb, 2017a). On a case-by-case basis, since 2013 the province has issued four wastewater system-wide Environmental Compliance Approvals (ECAs) in Ontario (Halton Region, Sudbury, Barrie, and Peel Region), and one systemwide ECA for stormwater management (Barrie) (Tovilla, Duong and Benkovich, 2014; Tovilla, $\left.2018^{34}\right)$. This pre-authorization regime covers wastewater and stormwater systems owned by municipalities; it does not cover new expansions and extensions of infrastructure, which are typically owned by developers or the private sector.

In the context of policy convergence and the calibration of rule instruments, these systemwide permits calibrate the site-specific rule instrument for wastewater and stormwater to resemble the drinking water permit regime in that there is one single approval covering the entire municipal system. In effect, this holistic licencing approach replaces thousands of individual approvals but is limited to pre-authorizations of infrastructure owned by municipalities. As noted by a MECP representative at a February 2019 stakeholder consultation

\footnotetext{
34 Tovilla, E. (2018) Experience on System-wide ECAs for Wastewater Collection by Ontario Municipalities, WEAO, MECP $11^{\text {th }}$ Engineer's Professional Development Day, May 2018, [Online]: https://d3n8a8pro7vhmx.cloudfront.net/weao/pages/43/attachments/original/1530822909/20180509 Experienc e of Wastewater System Wide ECA by Ontario.pdf?1530822909. [12 Oct 2018]
} 
working group in Toronto, "it is anticipated that with the new O. Reg. 208/19 [enacted in June 2019], it will allow the province to pre-authorize not only system improvements and expansions owned by municipalities, but also those owned by prescribed persons, i.e. developers and private entities".

To transfer responsibilities to municipalities, the province developed two additional programs that resemble aspects of the drinking water governance licencing regime: the Environmental Activity and Sector Registry (EASR) 35 in 2012; and the 2016 pilot project for "selfinspection" of municipal water and wastewater systems. The EASR created a streamlined approval process for businesses to self-register less complex operations, whereby activities to be registered in the EASR must be undertaken subject to a particular regulation (such as $\mathrm{O}$. Reg. $346 / 12$ for heating systems and standby power systems). This permit-by-rule approach is consistent with the federal ${ }^{36}$ and provincial trend of developing and implementing a more riskmanagement oriented approach (O'Connor, 2002b). In his recommendations (2002b), Justice O'Connor stated:

[r]isk assessment and management have become increasingly common features in public policy in recent decades [....] The management of risks to public health is a valuedriven exercise that must be informed by and must respond to the views of the public [....] (O'Connor, 2002b: Chapter 3, pp.76).

Another example of this approach is the 2016 pilot project for "self-inspection" of low risk water and wastewater activities, implemented in York Region. This project applied selfinspections of drinking water systems based on the principles of Behavioral Insights (BI), a school of thought in behavioural science developed in the UK to support self-governance of public and private entities (Halpern, 2015). The results of this York Region pilot (Khemai, 2016) raised concerns about downloading more comprehensive responsibilities to municipalities without a clear policy of accountability, revenue generation and potential liabilities.

\footnotetext{
${ }^{35}$ MECP, Environmental Activity and Sector Registry, [Online]: www.ontario.ca/page/environmental-activity-andsector-registry [12 Oct 2018]

${ }^{36}$ O'Connor (2002b: 75) refers to risk management policy published by the federal government in 1994 and 2001. More recent policy was published in 2010. See Canada, Treasury Board Secretariat, 2010, Framework for the Management of Risk, [Online]: www.tbs-sct.gc.ca/pol/doc-eng.aspx?id=19422 [27 Jul 19].
} 
Although there are no EASR activities for Ontario municipal wastewater or stormwater activities, the adoption of this permit-by-rule process through legislation since 2012, and the self-inspection pilot (2015), can be considered indicators that the province is shifting its approvals program toward more of a risk-based approach, and downloading more responsibilities to municipalities.

Some municipalities have been adopting non-state EMS standards like ISO 14001 in an apparent attempt to increase their ability to meet their duty of care, to exercise due diligence and to ensure accountability. For example, in Ontario: York Region (2000), Elgin Area/Lake Huron (2003), Durham Region (2004), Richmond Hill (2006), Collingwood (2007); and in other Canadian provinces: City of Calgary (2002), City of Edmonton (2004), City of Winnipeg (2004), Nanaimo (2005), Regina (2014), and Halifax Water (2015). It can be seen from this list that the adoption of EMS by Canadian municipalities is not a phenomenon limited to Ontario.

In summary, the post-2010 provincial initiatives noted above are indicative of the province's efforts to calibrate (or align) its rule instruments across the drinking water, wastewater and stormwater sectors, moving towards management system standards for all three sectors. This points to a policy convergence where lessons learned from the drinking water regulatory framework are being applied to the municipal wastewater and stormwater sectors.

This calibration of rule instruments in the wastewater and stormwater regulatory regime under a risk-based approach (e.g. the recent O. Reg. 208/19, system-wide ECAs, EASR, selfinspections) has a direct effect on municipalities and private developers in terms of enhancing their ability to design and build wastewater and stormwater infrastructure in a timely manner, thereby assisting them in their efforts to replace aging infrastructure, upgrade treatment systems and build new areas to be serviced, while protecting the environment, and reducing the likelihood of flooding and adverse effects on human health.

The references in provincial laws to EMS, specifically to ISO 14001, and the alignment of rule instruments provide evidence of provincial recognition of the value of EMS standards in combination with ensuring low-risk infrastructure is built in a timely fashion. Table 8 summarizes all the federal, provincial, and municipal regulations that in one way or another are relevant to MSS, and specifically to ISO 14001 and the ISO 14000 family of standards. 
Table 8. Federal, Provincial, Municipal Regulatory Framework Relevant to ISO 14001

\begin{tabular}{|c|c|c|}
\hline & Rule Instrument & Significance \\
\hline \multirow{5}{*}{$\begin{array}{l}\overline{\frac{T}{U}} \\
\frac{\mathrm{O}}{\mathrm{d}} \\
\stackrel{4}{4}\end{array}$} & \multirow[t]{2}{*}{ Fisheries Act, 1985} & $\begin{array}{l}\text { s. } 79.2 \text { (b) and (i) of the Act gives courts the authority to exersice in } \\
\text { creative sentencing powers to order actions to "avoid any harm [...] } \\
\text { and secure good conduct". Courts have used this authority to order } \\
\text { organizations to obtain ISO } 14001 \text { certification. }\end{array}$ \\
\hline & & 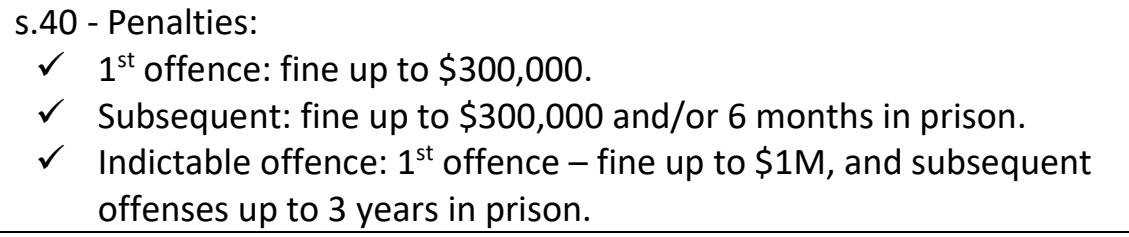 \\
\hline & CEPA, 1999 & $\begin{array}{l}\text { s. 209.1.a of the Act has provisions to allow for development of regs. for } \\
\text { "the establishment of environmental management systems." }\end{array}$ \\
\hline & $\begin{array}{l}\text { Environmental } \\
\text { Enforcement Act, } 2010\end{array}$ & $\begin{array}{l}\text { Passed in 2010, the Act introduces enforcement tools that allow for } \\
\text { directing the offender "to implement an EMS" and might entail } \\
\text { "requiring periodic environmental audits" }\end{array}$ \\
\hline & $\begin{array}{l}\text { A protocol guide for an } \\
\text { EMS Audit. } 2001\end{array}$ & $\begin{array}{l}\text { An Environment Canada publication based on the ISO } 14001 \\
\text { (Environment Canada, 2001). }\end{array}$ \\
\hline \multirow{7}{*}{ 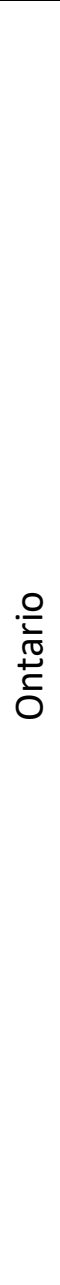 } & $\begin{array}{l}\text { Ontario Water } \\
\text { Resources Act (OWRA) }\end{array}$ & $\begin{array}{l}\text { Section } 106(18) \text { provides for a reduction of an environmental penalty if } \\
\text { the person had in place "an environmental management system" } \\
\text { specified by regulations. } \\
\text { Penalties: s. } 108 \text { (1) and s. 109(2), specify fines of up to } \$ 10 \text { million on } \\
\text { second offenses and subsequent convictions and can include up to one- } \\
\text { year imprisonment. }\end{array}$ \\
\hline & $\begin{array}{l}\text { Safe Drinking Water } \\
\text { Act, Part IV - DWQMS }\end{array}$ & $\begin{array}{l}\text { Requires a quality management standard for drinking water systems. It } \\
\text { is primarily based on ISO } 9001 \text { and HACCP and takes much of its } \\
\text { foundation from ISO } 14001 \text {. } \\
\text { Penalties, s. } 141 \text { to } 143 \text { set out large fines of up to } \$ 10 \text { million and up to } \\
\text { five-year imprisonment. }\end{array}$ \\
\hline & $\begin{array}{l}\text { Env. Penalties, } \\
\text { O. Reg. } 222 / 07\end{array}$ & $\begin{array}{l}\text { Encourages regulated persons to implement EMSs, and reduces } \\
\text { penalties for entities having a valid "ISO } 14001 \text { certification". }\end{array}$ \\
\hline & $\begin{array}{l}\text { Licensing of operators } \\
\text { - O. Reg. } 129 / 04\end{array}$ & $\begin{array}{l}\text { Requires certification of operators with minimum training } \\
\text { requirements. [Note: indirect link to ISO } 9001 \& \text { ISO } 14001 \text { competence } \\
\text { requirements.] }\end{array}$ \\
\hline & Municipal Act & $\begin{array}{l}2006 \text { amendments recognized possibility for municipalities to adopt } \\
\text { voluntary measures for accountability and transparency including an } \\
\text { ombudsman role. } \\
\text { [Note: indirect link to ISO } 14001 \mathrm{sec} .5 .1 \text { and } 5.2 \text { for accountability and } \\
\text { sec. } 9.1 \text { for internal audits.] }\end{array}$ \\
\hline & $\begin{array}{l}\text { Infrastructure for Jobs } \\
\text { and Prosperity Act, } \\
2015\end{array}$ & $\begin{array}{l}\text { s.3 (11) requires consideration of ecological biodiversity and } \\
\text { infrastructure to be "resilient to the impacts of climate change" } \\
\text { s. } 6 \text { (1) requires infrastructure asset management plans. } \\
\text { [Note: indirect link to ISO } 14006: 2011 \text {, for eco-design, to ISO } 14044 \text { for } \\
\text { life cycle assessments, and to ISO } 55000 \text { for asset management.] }\end{array}$ \\
\hline & Development Charges & 2015 amendments require municipalities to have an asset management \\
\hline
\end{tabular}




\begin{tabular}{|c|c|c|}
\hline & Act, 1997 & $\begin{array}{l}\text { plan prior to passing any development charge bylaws. } \\
\text { [Note: indirect link to ISO } 14001 \text { competence requirements.] }\end{array}$ \\
\hline & $\begin{array}{l}\text { Asset Management } \\
\text { Reg (O. Reg. 588/17) }\end{array}$ & $\begin{array}{l}\text { s.3 (1) requires an asset management policy, including "approach to } \\
\text { continuous improvement", and consideration of "levels of service and } \\
\text { lifecycle management [... and] mitigation approaches to climate } \\
\text { change". } \\
\text { [Note: indirect link to ISO } 14001 \mathrm{sec} .10 .1 \text { and } 10.2 \text { for continual } \\
\text { improvement, to ISO } 14044 \text { for life cycle assessments, and to ISO } 55000 \\
\text { for asset management.] }\end{array}$ \\
\hline \multirow{4}{*}{ 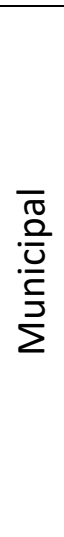 } & $\begin{array}{l}\text { EMS for Municipal } \\
\text { Infrastructure - Env. } \\
\text { Protocols, } 2005\end{array}$ & $\begin{array}{l}\text { Guidance document based on ISO 14001, by the Federation of Canadian } \\
\text { Municipalities and the Canadian National Research Council. }\end{array}$ \\
\hline & \multirow{3}{*}{$\begin{array}{l}\text { Adoption of ISO } 14001 \\
\text { standard for } \\
\text { wastewater systems }\end{array}$} & $\begin{array}{l}\text { Mandated via court decisions: Calgary, Winnipeg, Alberta Capital Region } \\
\text { Wastewater Commission. }\end{array}$ \\
\hline & & $\begin{array}{l}\text { Voluntary } \\
\checkmark \quad \text { Certified: York Region, Quebec City, Durham Region, Halifax, Elgin } \\
\text { Area Water, Lake Huron Area, Nanaimo, Richmond Hill, Regina } \\
\checkmark \quad \text { Conformance }^{37} \text { : Collingwood, Ottawa, Hamilton. }\end{array}$ \\
\hline & & $\begin{array}{l}\text { Under development: Toronto, Halton Region, Metro Vancouver, Barrie, } \\
\text { Winnipeg, Vaughan and Peel Region. }\end{array}$ \\
\hline
\end{tabular}

\subsubsection{Municipal Governance Role}

Ontario's municipalities are government entities created by the provincial government and therefore are subordinate to provincial legislative and regulatory requirements. The Municipal Act is the main provincial statute governing the creation, administration and governance of municipalities in the province. There are many rules concerning what municipalities may do, and how they may do it. Municipalities are required to comply with minimum requirements set by the province, but municipalities may adopt higher than minimum standards. Like other entities, municipalities may choose to meet these "beyond the law" standards for a variety of reasons that have been discussed in Chapter 2.1.4, and illustrated in Figure 3.

As regulatory actors, municipalities are in a unique position in the sense that they are subject to regulation by two other levels of government, while at the same time they are public entities that regulate others. As governmental bodies, municipalities are subject to particular public accountability, transparency and related responsibility requirements that are different

\footnotetext{
37 The term "conformance" in this context means meeting non-regulatory requirements such as those that organizations voluntarily adopt when following ISO-type requirements. This term is used for self-declaration when adopting ISO-type standards with a lesser degree of commitment (i.e. not-certified by a third party).
} 
from those applying to for-profit companies. Given their unique position of being both regulated and regulators, their activities may reveal particular regulatory gaps and limitations in existing regimes. This is particularly evident for public services, as municipalities have the mandate to provide drinking water, wastewater and stormwater services to citizens, as well as to commercial, industrial, and non-governmental users within their boundaries.

Under provincial legislation (i.e. SDWA, EPA, and OWRA), municipalities are "owners" of the water, wastewater and stormwater infrastructure, with the key responsibilities for planning, developing and implementing drinking water, wastewater and stormwater infrastructure and services. Through municipal bylaws, they can also impose additional requirements within their boundaries. It is standard practice for municipalities to adopt international, Canadian and provincial standards relevant to their own bylaws. ${ }^{38}$ Examples of international standards are referred to in Chapter 2.1.8 (non-state MSSs in the Water Sectors), and include: ISO standards, HACCP, CSA Group standards, AWWA standards and the Blue Flag Beach Program, among others.

Municipalities are particularly sensitive to residents' concerns about reliable and safe drinking water, flooding, sewer back-ups in resident's basements, and their ability to use rivers and lakes for recreational purposes. Given the mandatory DWQMS requirements for all municipalities, there seems to be a community of practice among Ontario municipalities and others who are growing more knowledgeable about and drawing on MSSs to incentivize ongoing improvements in environmental performance.

At the national level, in 2005 the Federation of Canadian Municipalities (FCM) noted in their "Environmental Management Systems for Municipal Infrastructure - Environmental Protocols" (FCM/NRC, 2005), which is based on ISO 14001, that eight municipalities across Canada had been ISO 14001 certified, and nine were actively working toward certification. The FCM is an advocacy group at the national level representing more than 2,000 municipalities in Canada, which collectively represent more than $90 \%$ of the Canadian population. ${ }^{39}$

After the water crises in Milwaukee (1993), Walkerton (2000), and Flint (2014), the number of municipalities (and private municipal water operators) adopting some form of EMS has

\footnotetext{
${ }^{38}$ Municipal Act, 2015. Part II, Sec. 10 (2), (Online): www.ontario.ca/laws/statute/01m25 [09 Jan 2016]

${ }^{39}$ Federation of Canadian Municipalities [Online]: https://fcm.ca/en/about-fcm [09 Jan 2016]
} 
increased, with early Canadian municipal ISO 14001 adopters including: York Region (2000), Quebec City (2001), City of Calgary (2002), Elgin Area/Lake Huron - water supply to the City of London (2003), Durham Region (2004), City of Edmonton (2004), City of Winnipeg (2004), Nanaimo (2005), Richmond Hill (2006), Collingwood (2007), ${ }^{40}$ Alberta Capital Region Wastewater Commission (2014), Regina (2014), and Halifax Water (2015).

In the cases of the City of Ottawa (2010), and the City of Hamilton (2012), although they decided not to seek ISO 14001 certification for their wastewater systems, they formally implemented significant components of the ISO 14001 (Table 10). The seven Ontario municipalities that have adopted significant components of ISO 14001 collectively represent approximately 4.3 million people, which is approximately $30 \%$ of the province's population, estimated at 14.2 million (2017 estimate ${ }^{41}$ ).

In comparison, only three municipalities adopted ISO 9001 (QMS) for their drinking water and/or wastewater systems, and two of these, York Region and Durham Region, have since dropped it, as it is seen as a duplication of the mandatory DWQMS for drinking water, and of little value for wastewater systems (this will be discussed in detail in Chapter 5.0). Only the Elgin Area/Lake Huron system continues to use ISO 9001 for their drinking water system (see Appendix $\mathrm{F}$ for more detailed description).

As reported at a 2016 Municipal Water and Wastewater Regulatory Committee (MWWRC) seminar, ${ }^{42}$ there are currently five Ontario municipalities developing EMS standards pursuant to ISO 14001: Halton Region, Toronto, Region of Peel, Vaughan, and Barrie. These municipalities account for an estimated 5.1 million people or $36 \%$ of Ontario's population. The combined populations of municipalities with some form of ISO 14001 in place (30\%) and those developing EMS (36\%) amounts to $66 \%$ of Ontario's total population, and therefore the adoption of EMSs by all these municipalities is likely to influence the remaining municipalities and other provinces in the near future. Canada-wide, the combined population of municipalities with some form of

\footnotetext{
${ }^{40}$ Collingwood, obtained ISO 14001 certification in 2007, but abandoned the external auditing in 2015, while continuing to maintain the underlying EMS standard (see Appendix F).

${ }^{41}$ Statistics Canada [Online]: www150.statcan.gc.ca/n1/pub/12-581-x/2018000/pop-eng.htm?HPA=1 [09 Jan 2016]

${ }^{42} \mathrm{NWWRC}$ is an independent forum formed in 2007 by Ontario municipalities on a voluntary basis with the purposes of data exchange and mutual support for the implementation of the DWQMS and water and wastewater regulatory compliance.
} 
EMS in place is estimated at approximately $47 \%$ of the national total (Figure 9). However, the trend of adopting ISO 9001 for wastewater is declining. Short summaries from these municipalities that have adopted some form of EMSs is included in Appendix F.

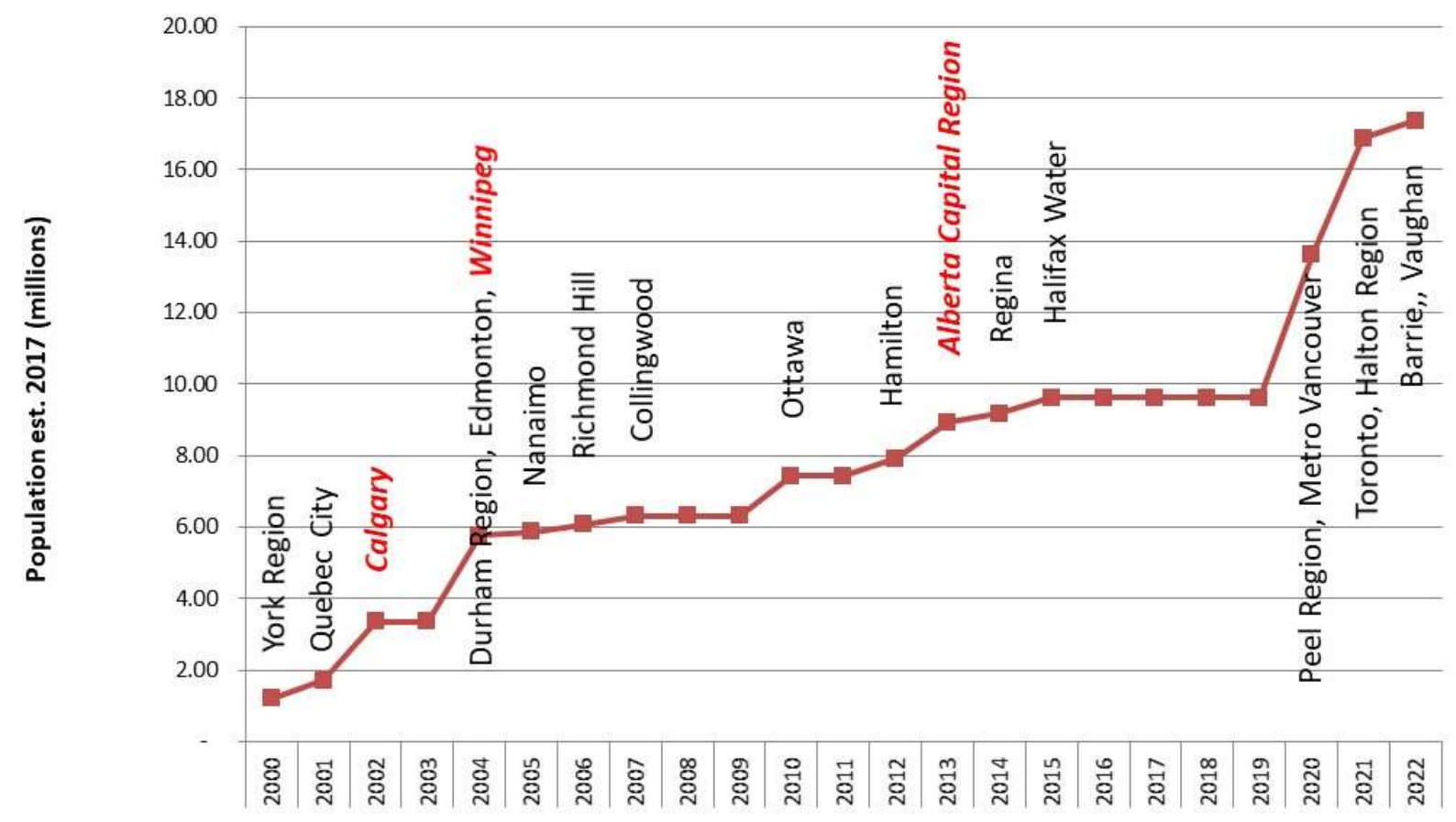

Figure 9. Growth of EMS for Water and Wastewater System Components in Canada

Notes:

1. Calgary's and the Alberta Capital Region's decisions to adopt ISO 14001 were the result of court decisions; while Winnipeg and Ottawa adopted it in response to public opinion and hearing recommendations.

2. Cities noted for 2019 and 2020 are projections based on reports from the MWWRC 2018 report, and publicly available information.

While there has been an increase in uptake of ISO 14001 and EMS by Canadian municipalities for wastewater and stormwater activities, this has not been the case with respect to municipal application of ISO 9001 or QMS for wastewater and stormwater activity. As noted in this section, the two municipalities that had adopted ISO 9001 certification for some wastewater activities, have since decided to drop it, in apparent recognition that it does not provide any additional value (Chapter 5.0). 
As noted earlier, private corporations and government entities can use their contracting and procurement powers to require supply chain partners to meet certain standards (Webb, 2012a). Municipalities can also use their contracting power to require their suppliers to meet a particular code or standard. There are thus cases of MSSs being imposed as contractual obligations by municipalities, for example:

- Since 2014, the City of Calgary, a city of 1.4 million (2017), has mandated as part of its Environmental Policy that its service providers must comply with environmental performance protocols and contractual responsibilities in adherence to EnviroSystem (the City's EMS, which is aligned with ISO 14001) (Appendix F).

- The Regional District of Nanaimo, a city of 10,000 on Vancouver Island, requires its contractors and/or suppliers to follow environmental procedures outlined in EMS ${ }^{43}$ (Table 25).

- Halifax Water is a water utility providing water, wastewater, and stormwater services to the City of Halifax (with a 2015 population of 420,000). Since 2015, its facilities have been operated as ISO 14001 certified treatment plants. Furthermore, its subcontractors are required to comply with Halifax Water's EMS as a condition of tender compliance for water and wastewater services (Halifax Water, 2016) (Table 25).

- The Region of Peel, a municipality of 1.4 million people, developed a new 10-year contract with the Ontario Clean Water Agency (OCWA) in 2018 that requires OCWA, which operates the GE Booth and Clarkson wastewater treatment plants (among the largest municipal wastewater treatment plants in Canada), to comply with an EMS based on ISO 14001, a QMS based on the DWQMS, and a health and safety management standard (H\&SMS) based on the CSA Z-1000, all by 2021 . The terms of the contract require OCWA to develop and implement an EMS, QMS and H\&SMS in adherence with the management systems that Peel Region is currently developing (according to a municipal representative familiar with this contract, M-18).

\footnotetext{
${ }^{43}$ Regional District of Nanaimo - EMS, [Online]: www.rdn.bc.ca/environmental-management-system [18 Jan 2019]
} 


\section{Municipal Water/Wastewater Prosecutions}

According to Province of Ontario's Court Bulletin, in the period from 2012 to 2014 there were a total of 11 convictions ${ }^{44}$ under the SDWA (drinking water) and OWRA (sewage) involving municipalities, with most being for drinking water offences. An argument can be made that the ability of Canadian courts to levy large fines and even imprisonment for water pollution offences creates an incentive for municipalities and other regulated entities to engage in preventative activity that decreases the likelihood of problems arising and therefore of convictions, like those noted in Table 8. The potential for fines and imprisonment constitutes an incentive to decrease the likelihood of prosecution, and to have measures in place that will make a defence of due diligence possible if court action does arise. The publicity associated with having an ISO certification (or working towards it) can be seen as another incentive for regulated actors to prevent pollution, as it publicly positions the municipality or entity in a positive light. There is evidence that several municipalities issue public announcements to this effect (e.g. York Region, ${ }^{45}$ Richmond Hill, ${ }^{46}$ Elgin Area/Lake Huron Area, ${ }^{47}$ Durham Region, ${ }^{48}$ City of Calgary, ${ }^{49}$ City of Edmonton/EPCOR, ${ }^{50}$ Metro Vancouver, ${ }^{51}$ City of Ottawa, ${ }^{52}$ Alberta Capital Region Wastewater Commission, ${ }^{53}$ City of Winnipeg, ${ }^{54}$ Yukon, ${ }^{55}$ Regina/EPCOR, ${ }^{56}$ Kingston $^{57}$ ).

\footnotetext{
${ }^{44}$ Province of Ontario - Court Bulletin, [Online]: www.downloads.ene.gov.on.ca/files/court bulletins/en/news/convictions/index.html [09 Jan 2016] ${ }^{45}$ York Region, Wastewater Collection \& Treatment - ISO 14001 EMS [Online]: www.york.ca/wps/portal/yorkhome/environment/yr/waterandwastewater/wastewatercollectionandtreatment/ [09 Jan 2018]

${ }^{46}$ Richmond Hill EMS [Online]: www.richmondhill.ca/en/find-or-learn-about/Environmental-ManagementSystem.aspx [09 Jan 2019]

${ }^{47}$ Elgin Area/Lake Huron EMS [Online]: https://huronelginwater.ca/about-us/management-systems/ [09 Jan 2019]

${ }^{48}$ Durham Region, IMS [Online]: www.durham.ca/en/living-here/wastewater-and-sewers.aspx [09 Jan 2019]

${ }^{49}$ City of Calgary, EMS [Online]: www.calgary.ca/UEP/ESM/Pages/Our-Environmental-ManagementSystem/EnviroSystem.aspx [09 Jan 2019]

${ }^{50}$ EPCOR 2014 Financial Results (EPCOR, 2015)

${ }^{51}$ Metro Vancouver [Online]: www.metrovancouver.org/services/solidwaste/SolidWastePublications/MetroVancouverWastetoEnergyFacilityOperationalCertificate107051.pdf [09 Jan 2019]

${ }^{52}$ City of Ottawa - Biosolids Program [Online]: http://app06.ottawa.ca/calendar/ottawa/citycouncil/riac/2009/0721/03\%20-\%20Biosolids\%20-\%20Participant\%20Letter\%20of\%20Introduction.htm [09 Jan 2019]

${ }^{53}$ Darbyshire, M., 2016

${ }^{54}$ City of Winnipeg - RFP [Online]: www.winnipeg.ca/finance/findata/matmgt/documents/2018/749-2018/7492018 Request for Proposal.pdf [09 Jan 2019]

${ }^{55}$ Yukon Government [Online]: www.eco.gov.yk.ca/pdf/environment act 2000-2003.pdf [09 Jan 2019]

${ }^{56}$ Regina - WWTP - EPCOR [Online]: www.epcor.com/about/news-announcements/notices/Pages/isocertification.aspx [09 Jan 2019]
} 
Such publicity can be interpreted as an attempt by the municipalities to publicly communicate to their citizens and others that they are meeting high standards that go above and beyond the minimum requirements set by the federal and provincial/territorial governments.

In addition to the financial penalties flowing from convictions for environmental offences, other costs are those associated with legal representation and environmental remediation. In a report prepared for Engineers Canada with funding from the Standards Council of Canada, some examples are offered of lawsuits in Canada that involve astronomical dollar figures (Engineers Canada, 2018). The more prominent cases (Table 9) include:

- Cerra v. City of Thunder Bay (2013), an ongoing \$300 million class action lawsuit seeking remediation for flooding damages due to pollution caused by a wastewater treatment plant in a May 2012 storm event.

- McLaren v. Stratford (City) (2005), a court-certified class-action lawsuit against the city, following a 2005 storm event in which municipal CSOs flooded basements of residents. In 2010, Stratford reached a \$7.7 million settlement after already spending \$1.3 million in emergency relief and wastewater system upgrades.

- Lissack v Toronto, (2008), a case brought by a private resident for a storm sewer back-up that flooded his basement, leading to a court finding that the City had breached its duty of care by failing to maintain and improve stormwater management systems (Engineers Canada, 2018: 10). Typically, remediation costs for single-family residences suffering from sewage flooding may range from $\$ 20,000$ up to $\$ 100,000$, depending on sitespecific circumstances (according to a loss management specialist from a large Ontario municipality, interview respondent M-20).

Even in cases where municipalities may not be at fault, they may still incur in significant costs. In the Kawartha Lakes (City) v. Ontario (Environment) case, the City had to cover the clean-up and remediation costs of approximately $\$ 500,000$ for a 2008 oil spill (Willms, 2013). The clean-up was caused by a 500-litre oil spill into the basement of a private resident, when the oil migrated through the storm sewers under the adjoining

\footnotetext{
${ }^{57}$ Kingston Environment \& Sustainability [Online]: www.cityofkingston.ca/residents/environment-sustainability [09 Jan 2019]
} 
city road and into nearby Sturgeon Lake. Under the EPA, the MECP issued a Provincial Officer Order, requiring the city to undertake the remediation for any oil remaining in the culverts and sewers that could re-contaminate Sturgeon Lake (Willms, 2013). Moreover, in subsequent actions associated with this case, in Gendron v. Thompson Fuels, 2017, an Ontario provincial court ruled that Thompson Fuels (the oil supplier) had to cover $40 \%$ of the total damages of $\$ 2.16$ million, with the remaining $60 \%$ of liability to be covered by Gendron (the home owner) (Lombardi, 2018).

\begin{tabular}{|c|c|c|}
\hline Case/Year & Associated Remedial Costs & Status \\
\hline Fletcher vs. Kingston (City), 1998 & $\$ 120,000$, fines & $\begin{array}{l}\text { Case appealed and charges } \\
\text { were overturned in } 2013\end{array}$ \\
\hline R. v City of Hamilton, 2000 & $\$ 450,000$, fines & City entered a guilty plea \\
\hline $\begin{array}{l}\text { R. v City of Calgary, 2000; and } \\
2014\end{array}$ & $\begin{array}{l}\text { Two cases with a combined } \\
\$ 400,000 \text { in remediation } \\
\text { costs }\end{array}$ & $\begin{array}{l}\text { In both cases the city } \\
\text { entered a guilty plea }\end{array}$ \\
\hline $\begin{array}{l}\text { McLaren v. Stratford (City), } 2005 \\
\text { (Class Action) }\end{array}$ & $\begin{array}{l}\$ 7.7 \text { million settlement, plus } \\
\$ 1.3 \text { million in emergency } \\
\text { relief }\end{array}$ & $\begin{array}{l}\text { In } 2008 \text {, the case was } \\
\text { settled }\end{array}$ \\
\hline R. $v$ City of Ottawa, 2008 & $\begin{array}{l}\$ 562,000 \text { in fines and } \\
\text { remediation costs }\end{array}$ & City entered a guilty plea \\
\hline Lissack v Toronto, 2008 & Est. $\$ 20,000$ to $\$ 100,000$ & Court found city guilty \\
\hline $\begin{array}{l}\text { Kawartha Lakes (City) v. Ontario } \\
\text { (Environment), } 2008 \\
\& \\
\text { Gendron v. Thompson Fuels, } \\
2017\end{array}$ & $\begin{array}{l}\$ 500,000 \text { in remediation } \\
\text { costs }\end{array}$ & $\begin{array}{l}\text { In 2013, an appeal court } \\
\text { ruled against the city, and in } \\
2017 \text {, the Ontario Superior } \\
\text { Court ruled against the } \\
\text { home owner and oil firm }\end{array}$ \\
\hline $\begin{array}{l}\text { Cerra v. City of Thunder Bay, } \\
2013\end{array}$ & $\begin{array}{l}\text { \$300 million class action } \\
\text { lawsuit }\end{array}$ & $\begin{array}{l}\text { Trial expecting resolution in } \\
2019\end{array}$ \\
\hline $\begin{array}{l}\text { R. v Alberta Capital Region } \\
\text { Wastewater Comm., } 2014\end{array}$ & $\$ 200,000$ in fines & City entered a guilty plea \\
\hline $\begin{array}{l}\text { R. v Greater Vancouver } \\
\text { Sewerage and Drainage District, } \\
2014\end{array}$ & $\begin{array}{l}\$ 110,000 \text { in fines plus } \\
\text { remediation costs }\end{array}$ & City entered a guilty plea \\
\hline
\end{tabular}

Note: This is an adaptation of the table published in Engineers Canada (2018), with additional cases and data. 


\section{Court Decisions Ordering EMSs}

Two judicial cases involving water utilities provide examples where Canadian courts at various levels are drawing on EMS standards in their decisions as applied to municipal governments and firms, with the courts thereby acting as "facilitators" in the application of federal and provincial environmental laws applying to municipal governments and other organizations. First, the City of Calgary, with three judicial cases (2000, 2005 and 2014); and the Alberta Capital Region Wastewater Commission (ACRWC) case in 2014. In these instances, both entities entered guilty pleas under the Fisheries Act, sec.36 and Alberta's Environmental Protection and Enhancement Act and were sentenced to commit to obtaining ISO 14001 certification for the operation of its facilities and/or enhanced their EMS in adherence to the ISO 14001. A more detailed narrative of these two cases is included in Appendix F.

Courts have also used ISO MSS certification with respect to private firms. In the R. $v$. Prospec Chemicals Ltd. (1996) case, the sentence under the Fisheries Act included a requirement to implement an EMS (Gibson, 1999).

\section{Court Decisions Leading Municipalities to Adopt EMS-type Corrective Actions Water}

Seven court decisions involving municipalities are described in this section. In these cases, it can be seen that the court actions influenced the municipalities to improve management of the system and to develop some form of EMS. Although two of these cases did not include water services, they involved leaking contaminants from municipal waste management services, where lessons learned migrated to the provision of drinking water and wastewater services.

It can be argued that in these cases, it was the municipalities who determined that the management of their water systems needed improvement and voluntarily adopted forms of MSS. Short summaries of cases where Canadian courts have led municipalities to voluntarily adopt EMS-type corrective actions are included in Appendix F. A synopsis of the relevance of those cases in included in Table 10. Examples of other jurisdictions that have adopted ISO 14001 or EMAS (the European equivalent of ISO 14001) are noted in Table 11. 
Table 10. Lessons from Canadian Municipalities Led by Court's Decisions to Adopt MSS

\begin{tabular}{|c|c|c|}
\hline & Municipality & Relevance to the voluntary adoption of ISO 14001 and MSSs \\
\hline 1 & $\begin{array}{l}\text { City of Kingston / } \\
\text { Utilities Kingston }\end{array}$ & $\begin{array}{l}\text { In the } 1998 \text { Fletcher } v \text {. Kingston, a private prosecution case (with Ecojustice } \\
\text { support), the City was convicted under the Fisheries Act. This prompted the } \\
\text { City to adopt an environmental MSS aligned with ISO } 14001 \text { (not certified). } \\
\text { Their goals were to assist in building a due diligence defence and reducing } \\
\text { penalties in cases of convictions. This illustrates the concept of sustainable } \\
\text { governance, where non-state actors (such as citizens and NGOs) add a check } \\
\text { and balance dynamic to hold municipalities accountable for env. violations. }\end{array}$ \\
\hline 2 & City of Hamilton & $\begin{array}{l}\text { In 2000, a private prosecution under OWRA re: Landfill contamination, the } \\
\text { City entered into a guilty plea. In 2005, top management leadership began } \\
\text { working on an EMS for the city. This case highlights both, the influence of } \\
\text { judicial prosecutions (fines for environmental violations), external factors } \\
\text { and city's leadership role to develop EMSs for wastewater operations. }\end{array}$ \\
\hline 3 & $\begin{array}{l}\text { EPCOR - City of } \\
\text { Edmonton }\end{array}$ & $\begin{array}{l}\text { In } 2003 \text {, the City was charged under the Alberta EPA (potential penalties of } \\
\$ 4.5 \text { million). In } 2004 \text {, City adopted ISO } 14001 \text { for most public work areas } \\
\text { This supports the recognition of the value of adopting ISO } 14001 \text { to improve } \\
\text { regulatory compliance and to assist in addressing environmental risks. This is } \\
\text { evidence in support of vertical and horizontal convergence concerning the } \\
\text { use of non-state EMS standards, between state actors (provincial and } \\
\text { municipal) drawing on non-state rule instruments such as ISO standards. }\end{array}$ \\
\hline 4 & City of Ottawa & $\begin{array}{l}\text { From } 2006 \text { through } 2008 \text {, spills to the Ottawa River triggered public reaction } \\
\text { (a.k.a. in the media as "Sewergate"). In 2008, the City pleaded guilty to } \\
\text { charges under OWRA - following an internal investigation. City of developed } \\
\text { an EMS based on the ISO } 14001 \text { (not certified). This case supports the } \\
\text { concept of sustainable governance, and horizontal convergence, whereby } \\
\text { non-state actors (such as citizens and public opinion) assist in holding cities } \\
\text { accountable for water violations and also drawing on non-state EMSs. }\end{array}$ \\
\hline 5 & Metro Vancouver & $\begin{array}{l}\text { In 2014, the City pleaded guilty for charges under the Fisheries Act. It } \\
\text { recognized the value of ISO } 14001 \text { to improve regulatory compliance. In } \\
2014, \text { Vancouver began developing an EMS as per ISO } 14001 \text {. This illustrates } \\
\text { evidence in support of vertical and horizontal convergence with the use of } \\
\text { non-state EMS standards, between state actors (three levels of government) } \\
\text { drawing on non-state rule instruments such as ISO standards. }\end{array}$ \\
\hline 6 & City of Timmins & $\begin{array}{l}\text { In } 2012 \text {, the MECP issued a Provincial Officer Order, which led the City to } \\
\text { adopt elements of EMS, such as monitoring and reporting, risk assessment, } \\
\text { and continual improvement. Although the City of Timmins has not adopted } \\
\text { an EMS, it has implemented many important elements of ISO } 14001 .\end{array}$ \\
\hline 7 & City of Winnipeg & $\begin{array}{l}\text { After a } 2002 \text { Provincial Hearing due to sewage overflow at a WWTP, it led } \\
\text { the City to proactively implement the recommendations of the hearing } \\
\text { report without waiting to be prosecuted. Even though there was no litigation } \\
\text { involved, this case shows multi-stakeholder support for use of non-state MSS } \\
\text { standards, in keeping with the sustainable governance approach. }\end{array}$ \\
\hline
\end{tabular}


Table 11. Private Companies with ISO 14001 or EMAS

Company

EPCOR Water (Edmonton)

Toronto Hydro

Suez (Global)

Veolia Water Technologies

(Global)

Southern Water (UK)

Aguas de Barcelona (Spain)
System ISO 14001 Certified

Adopted ISO 14001 and CSR policy (Canada and USA)

Adopted ISO 14001 and OHSAS

Adopted ISO 14001/EMAS on some sites worldwide

Adopted ISO 14001/EMAS, for some sites and ISO 9001 for some technology equipment

All operations certified worldwide to ISO 14001 / EMAS

Expanded ISO 14001 for all wastewater operations (2016)

Tovilla and Webb, 2017a

\subsubsection{Mapping the Sustainable Governance Model - Municipal Water Sectors}

Figure 10 and Figure 11 offer an illustration of the complex map of relationships shaping governance as it applies to the Ontario municipal water sectors. A brief description of the maps is given here and more details are provided in later chapters of this dissertation. These maps recognize the dynamic configuration of the key components of governance and the linkages between them. It reveals the complex relationships between international, federal, provincial, and municipal actors and institutions surrounding a municipal water utility. These relationships are formed with direct/indirect links between conventional and innovative actors and institutions with state and non-state rule instruments.

Figure 11 illustrates how municipalities, and specifically the water/wastewater/stormwater utility structures, are at the centre of a complex constellation of state-based governance, which includes non-state governance components with innovative connections with state-based components (e.g. MEA, MCEA, DWQMS). Figure 11 illustrates the addition of non-state governance components including their innovative inter-connections (e.g. ISO, HACCP, NGOs, CSA, Ten State Standards, industry associations, insurance companies and consultants and suppliers). On both illustrations, the municipalities (and their utilities) are in charge of designing, building, operating and maintaining drinking water, wastewater and stormwater systems, and are at the centre of multiple processes connecting rule instruments, actors and institutions. Relevant state-based voluntary standards for municipalities include: the Ontario Provincial Water Quality Objectives (1994), the Sewer Bylaw Guidelines (1999), the Stormwater Management Planning and Design Manual (2003), the Sewer 
Design Guidelines (2008), the EMS Protocol for Municipal Infrastructure (FCM, 2005), and the Protocol Guide for EMS Audits (2001).

More relevant for the purpose of this study is the role of non-state actors: civil society with numerous organizations (e.g. NGOs, CSA, ISO, CCME) influencing state-based rule instruments with their own guidelines and standards, which are adopted by the provincial and municipal governments (e.g. ISO 14001, Ten State Standards, the CCME Environmental Quality Guidelines, MCEA, OPSS, HACCP). This recognizes that non-state actors and their rule instruments cannot be characterized as supplanting or substituting conventional state-based decision making. As an example, the CSA Group played an indirect innovative governance role in the creation of the DWQMS (as the CSA Group partnered with the MECP to help create the DWQMS in 2006).

\section{$\underline{\text { Non-state Actors }}$}

Important in this mapping exercise is the role of non-state actors, described by some scholars as epistemic communities, "a knowledge-based community with shared worldviews, values, causal knowledge and policy prescriptions" (Harrison, 2002 citing Haas, 1992). This study does not examine epistemic communities, but it is important to highlight how they play a significant role in actively commenting on government initiatives, participating and collaborating with state actors, and therefore influencing the decision-making process for state-based and non-state water, wastewater and stormwater standards.

Non-state actors also play an important role in disseminating information and influencing other non-state actors that share similar interests. This involves both active non-governmental organizations and professional organizations. Some of the relevant NGOs include:

- Blue Flag Beach Program: an international program owned by the Foundation for Environmental Education and administered in Canada by Environmental Defence ${ }^{58}$. This program has a partnership with the City of Toronto to monitor 8 of its 11 swimming beaches (Table 25).

- Canadian Environmental Law Association (CELA): created in 1970, CELA is a non-profit organization established to use existing laws to protect the environment and to advocate environmental law reforms (www.cela.ca). CELA was an active participant in both the post-

\footnotetext{
${ }^{58} \mathrm{CDE}$ - Blue Flag program, [Online]: Blue Flag website [10 Jan 2019]
} 
Walkerton discussions with the provincial government (Chapter 2.3.2) and the City of Kingston case (Table 10).

- Ottawa Riverkeeper: a non-profit organization with the mandate to protect the Ottawa River and reduce combined sewer overflows ${ }^{59}$. Ottawa Riverkeeper played a key role in exposing the 2006-2007 City of Ottawa raw sewage spill known as "Sewergate" (Table 10).

- Swim Drink Fish (previously known as Lake Ontario Waterkeeper): a Canadian non-profit NGO with a goal to safeguard, restore, and protect the lake's natural resources ${ }^{60}$. Swim Drink Fish played a significant role in exposing the 1998 City of Kingston case of pollution of Lake Ontario tributaries, discussed in (Table 25).

In addition, there is a network of professional associations in Ontario that actively exchange information, liaise with the provincial government and hold discussion forums that provide feedback and advice to provincial regulators. In the Ontario context, relevant non-state actors participating at this level include:

- Ontario Municipal Engineers Association (MEA): an association of public sector Professional Engineers in the full-time employment of Ontario municipalities and provincial agencies performing municipal engineering duties. Consultants acting as the engineer-of-record on behalf of a municipality are also eligible for membership. MEA develops, maintains and distributes best practice technical documentation for use by both private and public sector municipal engineering practitioners. MEA holds joint ownership with the Ministry of Transportation (MTO) of the Ontario Provincial Standards Specification (OPSS) system as the provincially recognized authority for the design and construction of infrastructure. In addition, MEA is the proponent of the Municipal Class Environmental Assessment (MCEA) process. Both the OPSS and the MCEA are hybrid rule instruments (co-owned by state and non-state agencies); however, while the OPSS is only a guideline, the MCEA is mandatory under the Ontario Environmental Assessment Act (1990). The MCEA is a provincially required procedure for planning and evaluating environmental impacts of publicly funded infrastructure. The

\footnotetext{
${ }^{59}$ Ottawa Riverkeeper, [Online]: www.ottawariverkeeper.ca/[10 Jan 2019]

${ }^{60}$ Swim Drink Fish, [Online]: www.waterkeeper.ca/[10 Jan 2019]
} 
MCEA was first approved by Cabinet in 2000, and then amended in 2007, 2011 and 2015. It is currently under review, with an amended version expected in $2019^{61}$.

- Water Environment Association of Ontario (WEAO): a non-profit association of 1,300 individual professional members that include government employees, consultants, suppliers, technology developers, academics and students. WEAO is the Ontario chapter of the Water Environment Federation (WEF), a US-based association founded in 1928, with approximately 34,000 members worldwide. In 2018, WEAO completed a survey of municipal perceptions of provincial environmental compliance approvals (ECA). The report's recommendations to the MECP (Tovilla, 2018; WEAO, 2018a) focused on making wastewater and stormwater ECAs more aligned with a system-wide approach (similar to that of drinking water). ${ }^{62}$

- Wastewater Practitioners Group: a formal partnership established in 2012 between the WEAO and the MECP to discuss and share information among practitioners. This group meets 3-4 times per year to discuss technical aspects associated with wastewater and stormwater regulatory matters. ${ }^{63}$

- Ontario Water Works Association (OWWA): a non-profit association with approximately 1,400 members dedicated to sharing knowledge on drinking water systems in Ontario. The OWWA is the Ontario chapter of the US-based American Water Works Association (AWWA), ${ }^{64}$ founded in 1881, which has about 51,000 members worldwide. The 2009 AWWA Standard G400, Utility Management System, provides water utility managers with best management practices for everyday utility operations (AWWA, 2009).

- Ontario Municipal Water Association (OMWA): a non-profit association made up of individual elected, appointed and management representatives from more than 180 municipalities in Ontario. The OMWA acts as an advocacy group "to provide direction and leadership on policy, legislative and regulatory issues for drinking water, wastewater and stormwater." 65

- Municipal Finance Officers' Association (MFOA): established in 1989, the professional association of municipal finance officers, with more than 2,300 individual members. MFOA

\footnotetext{
61 MEA, [Online]: www.municipalengineers.on.ca/, [10 Jan 2019]

62 WEAO, [Online]: www.weao.org/about, [10 Jan 2019]

${ }^{63}$ WWPC, [Online]: www.weao.org/wastewater practitioners group page, [10 Jan 2019]

${ }^{64}$ OWWA, [Online]: www.owwa.ca/, [10 Jan 2019]

65 OMWA, [Online]: www.omwa.org/water3/, [10 Jan 2019]
} 
represents individuals who are responsible for handling the financial affairs of municipalities and who are key advisors to councils on matters of finance policy. ${ }^{66}$

- Ontario Public Works Association (OPWA): a non-profit organization of professional public works practitioners, with 630 members employed by the federal and provincial governments, municipalities, consulting engineers, utility companies, contractors and suppliers. The OPWA is the Ontario Chapter of the American Public Works Association (APWA), which has about 28,000 members throughout North America, making it the largest and oldest organization of its kind in the world. ${ }^{67}$

- Asset Management Ontario (AMONTario): a non-profit organization focused on innovation for public sector asset management, working with multi-disciplinary communities of practice to strengthen asset management capabilities and achieve levels of service aligned with international standards, regulatory requirements, and best practices to optimize public services. $^{68}$

- Ontario Coalition for Sustainable Infrastructure ${ }^{69}$ (OCSI): a non-profit partnership founded in 2006, bringing together seven associations involved with Ontario's infrastructure to form a united association to speak and advocate for sustainable infrastructure. The partner associations are: MEA, WEAO, OMWA, OPWA, the Ontario Pollution Control Equipment Association (OPCEA), the Ontario Good Roads Association (OGRA), and MFOA.

Some of these organizations have advocacy mandates. OCSI and OMWA bring policy issues identified by other organizations for discussion with provincial and federal elected officials. Other industrial organizations have more profit-driven member representation such as the Ontario Sewer and Watermain Construction Association (OSWCA), and the Building Industry and Land Development Association (BUILD), among others. Although they have similar mandates to those noted above, their primary distinction of these organizations is that their individual members are profit-driven.

\footnotetext{
${ }^{66}$ MFOA, [Online]: www.mfoa.on.ca/mfoa/main, [10 Jan 2019]

67 OPWA, [Online]: https://opwa.ca/about-us/, [10 Jan 2019]

${ }^{68}$ AMONTario, [Online]: https://amontario.ca/[10 Jan 2019]

69 OCSI [Online]: www.on-csi.ca/ [10 Jan 2019]
} 


\section{Innovative Relationships}

Direct and indirect innovative relationships in the Ontario's water, wastewater and stormwater sectors are shown in Figure 11. A relevant example of direct innovative governance is the DWQMS, a rule instrument developed by state actors (the MECP) not only drawing from non-state standards (the ISO and HACCP), but also with the direct participation of the CSA Group and a couple of municipalities piloting the new standard. A quality management system standard became a legislated requirement under the Safe Drinking Water Act (O. Reg. 170/03). The DWQMS was developed in 2005-2006, with phased accreditation under O. Reg. 188/07 for the licensing of all municipal water systems in Ontario from January 2009 to June 2010.

Another example of innovative governance is the role played by federal and provincial courts when they make decisions involving the adoption of an environmental management system (indirect relationship), and in some cases with direct reference to requirements for the ISO 14001 (Table 8). Provincial laws and legislation (Chapter 2.3.2) are also having direct relationship to ISO 14001, such as the Environmental Penalties Regulation (O. Reg. 222/07) under the Ontario EPA, which has a provision for the reduction of environmental penalties if an ISO 14001 certification is documented by a third-party audit.

Another example of an indirect innovative relationship is that between the Blue Flag Program and municipalities, where an international rule instrument (Blue Flag certification) and monitoring processes are implemented to continue accreditation. Another indirect innovative relationship is that between the MECP and non-state actors like WEAO and OWWA. In addition to its annual meetings with the MECP (WEAO, 2018b), a 2018 WEAO report to the Ministry concerning municipalities' perceptions on system-wide ECAs (WEAO, 2018a), might have been a contributor for the MECP to support the O. Reg. 208/19, enacted in June 2019 under the Environmental Protection Act (this new regulation supports the concept and further adoption of the system-wide ECAs and in particular its pre-authorization regime, similar to the drinking water permit). In parallel to this new regulation, the MECP commenced the development of a wastewater collection system design criteria, which was also noted as a needed element to allow the MECP to implement system-wide ECAs, which will mimic the holistic city-wide approach already existing in the municipal drinking water sector (WEAO, 2019). 
The above may offer a response to the research sub-question one (Chapter 1.3), as it suggests that the governance model that best aligns with the current state of affairs with the Ontario municipal water sectors is the sustainable governance model as defined by Webb (2005: 242-249), whereby the concentric approach of water utilities (municipalities) surrounded by a constellation of state and non-state actors generates a competitive dynamic, and this model seem to be occurring simultaneously in alignment with policy convergence theory. 


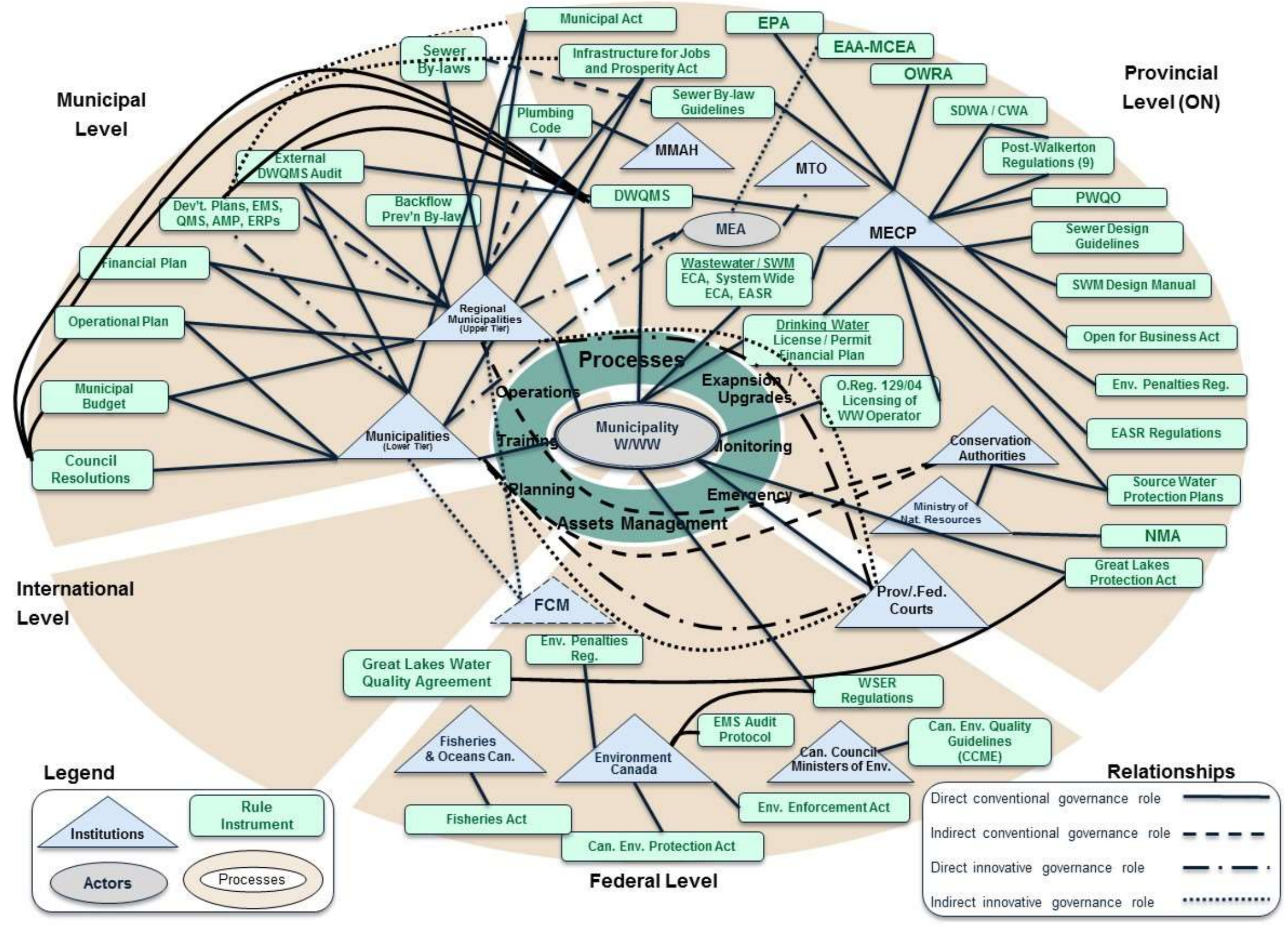

Figure 10 Sustainable Governance Map for the Municipal Water Sectors (State-based Governance Components)

This graph is an adaptation from Martin and Webb (forthcoming) 


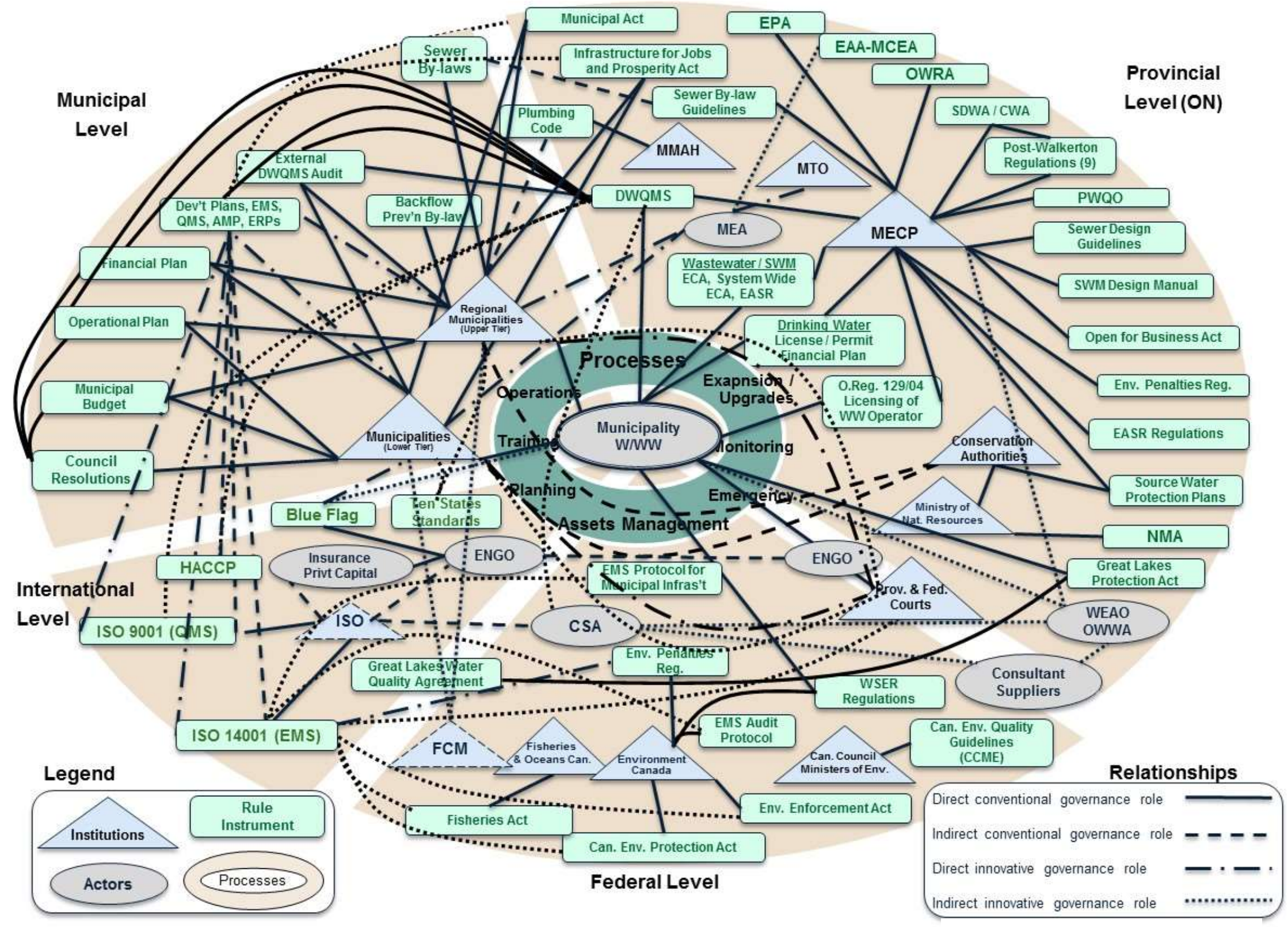

Figure 11. Sustainable Governance Map for the Municipal Water Sectors (State and Non-state Governance Components)

This graph is an adaptation from Martin and Webb (forthcoming) 


\subsection{Synthesis of the Literature Review - State-based Sources}

Based on the foregoing review, there is considerable evidence of Canadian federal, provincial and municipal entities and environmental laws, regulations and policies drawing on environmental management systems in support of public policy objectives. Federal and provincial legislation (Table 8), illustrates the use of environmental and quality MSSs (e.g. Canadian Environmental Protection Act, the Environmental Enforcement Act, the Ontario Safe Drinking Water Act, the Ontario Penalties Regulation). Ontario laws also reference critical elements associated with MSSs (e.g. the Infrastructure for Jobs and Prosperity Act, the Development Charges Act, the Asset Management Regulation and O. Reg. 129/04). Finally, Canadian and Ontario laws use language that has allowed Canadian courts to exercise their authority to order organizations to obtain MSSs (e.g. the Fisheries Act, the Ontario Water Resources Act, and the Municipal Act).

National municipal organizations like the Federation of Canadian Municipalities (FCM), have developed guidelines based on ISO 14001 for municipal services including water, wastewater, and stormwater. Federal nuclear agencies (e.g. CNSC), as well as municipalities (e.g. Halifax Water, the Regional District of Nanaimo, the City of Calgary and the Region of Peel), are also using their contracting power to impose MSS conditions on suppliers.

At the provincial level, in Ontario, there is an increasing trend toward the adoption of EMSs, with an estimated $63 \%$ of the provincial population now covered by to some form of EMS for wastewater and stormwater. At the national level, about $47 \%$ of the Canadian population are covered by some form of EMS for municipal wastewater and stormwater (Figure 9). It is important to note however, that it is mostly large municipalities that have taken this step, either proactively or as a result of some form of court process or public pressure. Smaller municipalities, even if they were subject to prosecution due to environmental violations, have not adopted MSSs, e.g. Kawartha Lakes (pop. 75,000), Belleville (pop. 50,000), City of Timmins (pop. 42,000), City of Stratford (pop. 31,500), Atikokan (pop. 3,000). In the case of the City of Kawartha Lakes (Table 9), although there is no evidence of the city pursuing an MSS, the city is in the process of developing the Kawartha Lakes Healthy Environmental Plan, as a 
comprehensive strategy for climate change mitigation and adaptation. ${ }^{70}$ This suggests support for the proposition that even small municipalities (with fewer resources to develop an EMS) can take steps towards enhancing environmental stewardship and due diligence with planning rule instruments, similar to the structural pillars of the ISO management system's "plan-do-checkact" model (Figure 5).

Since the Walkerton tragedy (2000), the Ontario municipal water sectors have undergone a significant transformation. Before the tragedy, all drinking water wastewater and stormwater sectors were governed by the Ontario EPA and OWRA under a piecemeal approach where the province approved any construction work proposed by municipalities or its agents (i.e. developers).

In the post-Walkerton era, the drinking water regulatory framework has evolved into a riskbased and multi-barrier approach with source water protection, controls for water treatment, testing, monitoring and reporting using a specialized management system standard. This approach followed a holistic risk-based management process with regulatory requirements for operator licensing, financial planning and minimum design requirements for drinking water treatment and distribution and pipe cleaning. This came with the transfer of some responsibilities to the municipalities - mainly infrastructure planning and pre-authorization for construction (provided they met minimum design criteria and CCPs). This holistic approach replaced the old piecemeal project-by-project provincial approval process, which was transformed into a consolidated permit for the entire drinking water system and a preauthorization for low risk activities (i.e. subdivision expansions, system modifications, etc.).

The post-Walkerton regulatory framework for the drinking water sector in Ontario (the holistic risk-based and multi-barrier approach) is designed to reduce the likelihood of human health hazards due to unsafe drinking water (CELA 2011; MECP, 2016). Although there were a number of enforcement actions reported in 2014 to 2015, most were for non-municipal systems (MECP, 2016). However, while the post-Walkerton risk-based approach for drinking water systems seems to be accomplishing its policy goals of human health protection, there is not a parallel approach in place for First Nations communities in Ontario.

\footnotetext{
${ }^{70}$ City of Kawartha Lakes - Healthy Environmental Plan, [Online]: www.kawarthalakes.ca/en/living-here/kawarthalakes-healthy-environment-plan.aspx [29 Mar 2017]
} 
Unlike the municipal drinking water sector, for the wastewater and stormwater sectors, although there have been some small improvements to the regulatory regime (e.g. licensing of operators and training), the overall legal framework has remained largely unchanged. However, it is important to note that since 2010 there has been a shift at both the provincial and municipal levels towards a holistic and risk-based approach similar to that in place with respect to drinking water. Examples of these initiatives include:

- provincial: the Open for Business Act (2010), which has given the EPA and OWRA flexibility to calibrate approval (a type of regulatory rule instrument), leading to the development of the Environmental Activity and Sector Registry (EASR, 2012); plus selfinspection pilot programs (e.g. York Region in 2015); and area-wide pilot environmental compliance approvals (ECAs).

- municipal: a number of municipalities have adopted ISO 14001 EMSs, which suggests policy learning and policy convergence, from non-state MSSs and from their drinking water systems to their wastewater and stormwater systems.

Also, as noted earlier, some Ontario municipalities have been independently adopting nonstate MSS, in an apparent effort to meet their duty of care, exercise due diligence and public accountability. This knowledge transfer has been more evident among large municipalities, which have the capacity to exceed the minimum requirements set by provincial legislation and address management needs (e.g. adoption of environmental, quality, and health \& safety MSSs, to name a few). There is evidence however, that smaller and rural municipalities and First Nation communities lack the resources and capacity that would enable them to follow the same path. It is unlikely that smaller and rural communities would divert their limited resources from competing priorities (e.g. roads, housing, emergency services, etc.) into voluntary programs for environmental protection, even if they risk liability should environmental violations occur.

A conclusion drawn from combining the academic and government sources literature reviews is the apparent recognition of the important role of having both state and non state actors involved in the governance of the Ontario water management sectors. From the discussion of governance (Chapter 2.1), what the academic literature seems to downplay is the extent to which state actors appear to be adopting non-state actors' rule instruments and 
processes in their state-based rule instruments and processes, through both collaborative and checks and balance approaches.

Based on the discussion of the Ontario provincial and municipal water management sector (Chapters 2.3.2 and 2.3.3), and from the analysis of Figure 11, it is possible to respond to the research sub-question 2 posed in Section 1.3 by concluding that the governance model that best aligns with the current state of affairs in the Ontario municipal water sectors is the sustainable governance model as defined by Webb (2005). An analysis of Figure 11, which shows that the concentric approach of water utilities (municipalities) surrounded by a constellation of state and non-state actors generates a competitive dynamic, seems to support the claim that a sustainable governance model is being adopted in Ontario's water sectors. For the purposes of this dissertation, Webb's conception of sustainable governance (2005) will be applied as it seems to align well with the combination of state and non-state rule instruments, institutions, processes and actors involved in governance, sometimes operating collaboratively, sometimes operating in a more check-and-balance manner. Examples of these inter-connection or bridging between state (government-based) and non-state forms of regulation includes new and innovative policy instruments, tools and institutions such as MCEA, OPSS, OFWAT, DWQMS, Source Water Protection Committees, ${ }^{71}$ HACCP, ${ }^{72}$ Blue Flag Program. ${ }^{73}$

A preliminary conclusion appears to be that the Ontario water management activity appears to align well with policy convergence theory as characterized by Holzinger and Knill (2005), Knill (2005), Lenschow et al. (2005). This policy convergence appears to occur in two dimensions:

- Horizontal dimension, between state actors (three levels of government) drawing on non-state rule instruments such as ISO standards. This works in both directions, as nonstate actors also draw from government learning to develop sector-specific standards.

- Vertical dimension, between the three levels of government (federal, provincial, and municipal) creating policy tools for management system standards (e.g. DWQMS, federal protocol guide for EMS audit), including a quasi-vertical dimension recognizing

\footnotetext{
${ }^{71}$ Source Water Protection Committees - see Chapter 2.3.2

72 HACCP - see Chapter 2.1.6.

${ }^{73}$ Blue Flag Program - see Appendix F.
} 
the distinctive role of Canadian courts as facilitators in resolving issues of federal and provincial jurisdiction with municipalities.

A subsequent conclusion drawn from this literature review of government sources is that there is also an increasing trend in legislation, judicial sentencing, and administrative enforcement, with a focus on enhancing the due diligence in protecting the environment and human health. This trend is marked by increasing adoption of and reference of MSSs (e.g. the DWQMS, ISO 14001-EMS). Moreover, the cases noted in this section and the increase of use of MSSs in wastewater system components in Canada (Figure 9) suggest that municipalities, which are at the centre of sustainable governance systems (Figure 11), are regularly drawing on nonstate MSSs and other standards to reduce the likelihood of environmental violation and legal liabilities.

Another preliminary conclusion derived from this section is that the province of Ontario is moving towards a certain degree of calibration (alignment) of its rule instruments for the wastewater and stormwater sectors and exploring ways of shifting these sectors to a similar holistic and risk-based approach similar to that of drinking water. There is also evidence of a cumulative effect of laws, precedent cases, lessons learned and administrative decisions, particularly in the post-Walkerton era, that is driving municipalities to voluntarily adopt EMS components in order to fill regulatory gaps and reduce the risk of liability should environmental violations occur. This points to policy learning and policy convergence, where lessons learned from the drinking water regulatory framework are being adapted and transferred to the municipal wastewater and stormwater sectors. The overall impression gained from this review is that the federal government, provinces, municipalities, NGOs and courts are all recognizing the value of municipal use of ISO 14001 and other MSSs in furtherance of legislative environmental objectives pertaining to the water sectors.

An additional preliminary conclusion that can be drawn from the above involves the court decisions associated with EMSs. Taken together, the discussion of the courts either ordering EMSs or leading to municipalities adopting EMS constitute support for the proposition that courts and other oversight entities like the Manitoba Clean Environment Commission (MCEC) are finding value in drawing on non-state MSSs in their environmental decisions concerning 
municipalities and other entities. A number of large municipalities that have been subject to some sort of enforcement or administrative actions due to environmental violations have moved to adopt EMS (e.g. Calgary, Alberta Capital Region Wastewater Commission, Edmonton, Ottawa, Metro Vancouver, and Kingston). There have also been four cases involving small municipalities, that have been prosecuted or subject to administrative enforcement for environmental violations where the municipalities have not moved to adopt an EMS: City of Kawartha Lakes (2008), ${ }^{74}$ City of Belleville (2013), ${ }^{75}$ City of Timmins (2012), ${ }^{76}$ and the Town of Atikokan (2013), ${ }^{77}$ a First Nation community. A search by the author of the websites of small municipalities did not reveal evidence of adopting EMS or ISO 14001. In each of these cases, the size of the municipality (and its reduced tax base, i.e. income) may have been a factor.

Here, it is possible to respond to the first research sub-question: how do academic conceptions of governance, policy convergence and management systems standards assist in understanding Ontario's evolving approach to municipal water regulation. Based on the review of the literature and government sources it appears that a sustainable governance model is simultaneously occurring through the calibration of rule instruments with governments directly transferring and learning from the actions of other governments (vertical dimension) and from non-state rule instruments (horizontal dimension) such as MSSs (e.g. ISO 14001, ISO 9001, HACCP, and others). In this context, a policy convergence is evidently occurring in both vertical and horizontal dimensions, in an effort to ensure compliance with environmental obligations, reduce the risk of legal liability, reduce reputational risks and enhance the duty of care in the provision of municipal water services.

\footnotetext{
${ }^{74}$ Engineers Canada, 2018; Willms, 2013; and idem as Footnote No. 44

75 See Footnote No. 44

${ }^{76}$ ECO Report, 2018; and idem as Footnote No. 44

${ }^{77}$ See Footnote No. 44
} 


\subsection{METHODS}

\subsection{Research Design}

For this study, a multi-method approach was followed using non-experimental methods, applying descriptive and qualitative research components (semi-structured interviews, a focus group, and case studies) in a "staged" or sequential approach. The multi-method research approach will allow for what Cresswell et al., referencing Hossler and Vesper, refer to as a "concurrent triangulation method design" (2007: 162), indicating a triangulation of data collection, separate data analysis, and the integration of databases at the interpretation or discussion stage of the report, and a way to test validity (Carter et al, 2014: 545).

Figure 2 outlines the multi method approach applied in this study using three different data collection techniques: semi-structured interviews, a case study method, and a focus group. The proposed methods are considered "applied science" as they are focused on immediate application.

Drawing on the arguments of scholars such as Sutton and Staw (1995: 379) in relation to maintaining a balance between theory and methodology, and on Salkind's multi-method approach (2012: 125-127), this research has been structured in an effort to ensure reliability and validity, by means of the following steps:

a) An attempt was made to explore the underlying theoretical aspects of the study and existing law and policy frameworks.

b) An attempt was made to triangulate information through collection via multiple methodologies, and by integrating a diversity of state and non-state perspectives.

c) A certain amount of redundancy was included in the questions to validate other questions.

d) Presentations of some of the research findings were made at professional conferences in Ontario and throughout Canada.

Prior to undertaking this research approval was obtained from the Ryerson Candidacy Examination Committee in April 2016, and the proposed methodology and ethical procedures 
were approved by the Ryerson Ethics Review Board in August 2016, with extensions provided to cover up to 2020 if needed.

\subsection{Interviews}

The interview method is undertaken with a view to addressing the following research subquestions:

3. Are management system standards likely to have neutral, positive, or negative effects on the performance of Ontario municipal water management activity?

4. Which MSS standards relevant to the water sectors (ISO 9001 - QMS, ISO 14001 - EMS and HACCP) are best suited to address municipal water, wastewater and stormwater activity?

The interview method also allowed the author an opportunity to address the central research question: is there value in creating a provincially mandated municipal wastewater environmental management system standard, and a stormwater environmental management system standard?

A total of 25 interviews with respondents from government, the private sector and civil society were conducted for this study, using semi-structured, open-ended questions (the list of questions is included in Appendix A). The semi-structured, open-ended approach provided interviewees with the opportunity to elaborate on points of interest and thus increased the value of data. Interviews were conducted from September 2016 through July 2019. The interviews were conducted in compliance with Ryerson University's Review Ethics Board approval received in August 2016 (Appendix G), and valid through August 2019. When combined with the research from government sources and academic sources, as well as the case studies and focus groups, the interviews provided the author with many useful insights that contributed to the dissertation analysis, conclusions and recommendations concerning the use of an MSS standard to contribute to municipal wastewater and stormwater management. The analysis and results drawn from the interviews, outlining the interview respondents' recommendations for preferred options for a potential wastewater and stormwater MSS are presented in Chapter 4.0. 


\subsubsection{Purpose and Scope}

A list of interview questions was developed related to challenges and opportunities that an MSS for municipal water, wastewater and stormwater systems should take into account. The objective of the interviews was to collect information in order to better understand the governance context within which MSSs operate from a municipal view-point, the challenges and opportunities associated with using MSSs as part of a municipality's approach to its water systems, and some of the theoretical aspects discussed in Chapter 2.0 of this dissertation. Consent forms and a letter of information about the study were provided two weeks in advance to all interviewees. Specific insights were sought concerning:

a) enablers and barriers for the adoption of management system standards;

b) perceptions in relation to selecting a QMS and EMS;

c) perceptions in relation to the positive, neutral, or negative effects of an EMS;

d) governance interactions;

e) the value of creating a provincially required EMS for municipal wastewater and stormwater systems; and

f) rival propositions for the use of MSSs.

Although the interview questions focused on water MSSs and governance approaches, they were also designed to provide opportunities for comment by interview respondents on related issues, such as policy convergence and future regulatory paths for further analysis.

\subsubsection{Methodology}

Potential respondents were identified via organizational websites, publications in journals, and articles from magazines associated with organizations, such as the Ontario Municipal Water Wastewater Regulatory Committee (MWWRC), the Water Environment Association of Ontario (WEAO) and the Ontario Water Works Association (OWWA).

All municipalities that have an ISO 9001 and/or ISO 14001 certification were targeted for interviews (Table 13). The directory of the Municipal Water Wastewater Regulatory Committee (MWWRC) provided access to the contact information of more than 150 municipal officials in Ontario. An attempt was made to interview federal regulators from Environment and Climate Change Canada, but they responded that municipal water management is a provincial 
responsibility and no interviews were secured. Requests were also made for interviews of provincial regulators (MECP officials), but they were not accepted on the basis that the MECP has no regulatory requirements for MSSs for municipal wastewater and stormwater systems. Provincial regulators were, however, included in the Focus Group method (Chapter 6.0).

Potential respondents were initially contacted by the author, who attempted to ensure that a broad range of perspectives were elicited from: municipal officials from small and large municipalities, consultants, ENGOs, and non-state regulators (e.g. standards bodies). From a total of 32 professionals contacted, 25 respondents accepted the invitation. This represented a rate of response of $75 \%$.

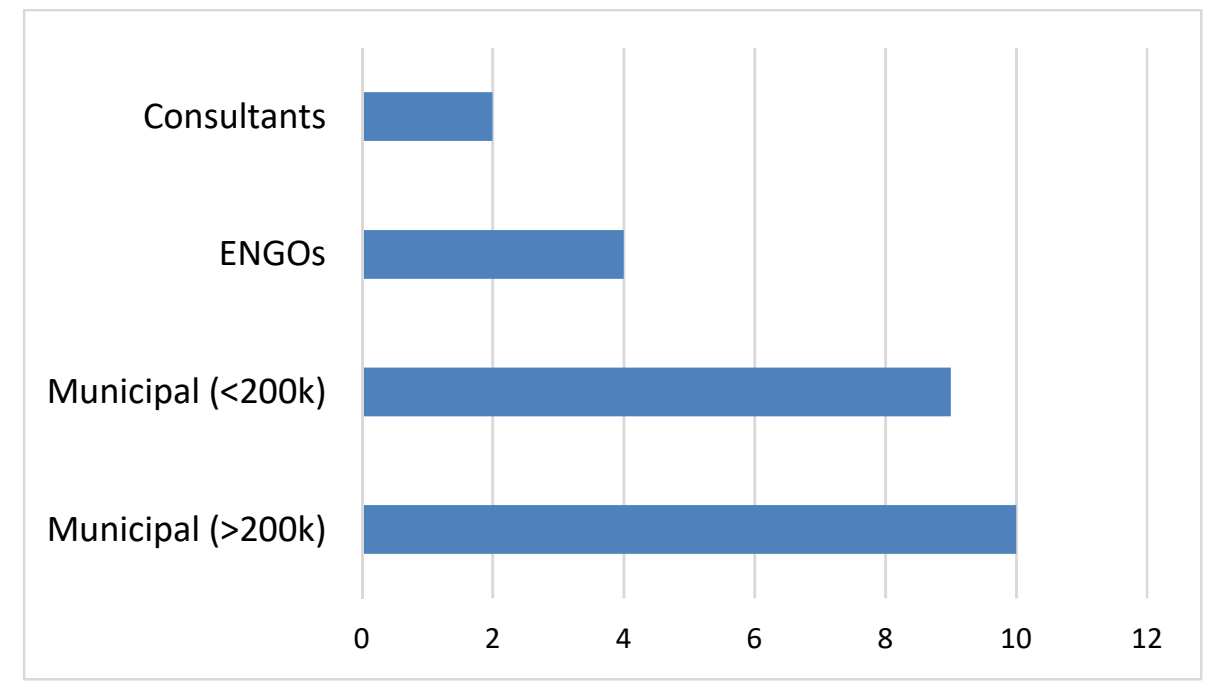

Figure 12. Interview Respondent Distribution

The interviews were conducted by the author using a face-to-face approach. All respondents had experience in one capacity or another concerning municipal drinking water, wastewater and stormwater systems, and/or some form of environmental governance in Ontario. All were involved in drinking water, wastewater, and stormwater systems, and/or some form of environmental governance in Ontario. Figure 12 shows interview respondent roles within their organizations. 


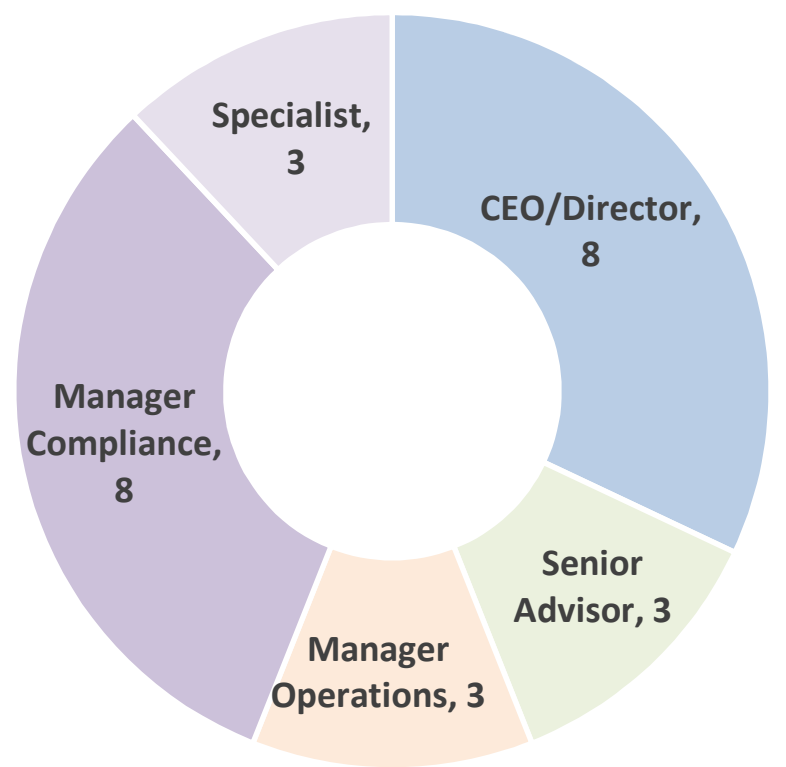

Figure 13. Interview Respondent Roles

Figure 14 shows the experience and expertise of interview respondents with management systems (including DWQMS, ISO 9001 and ISO 14001).

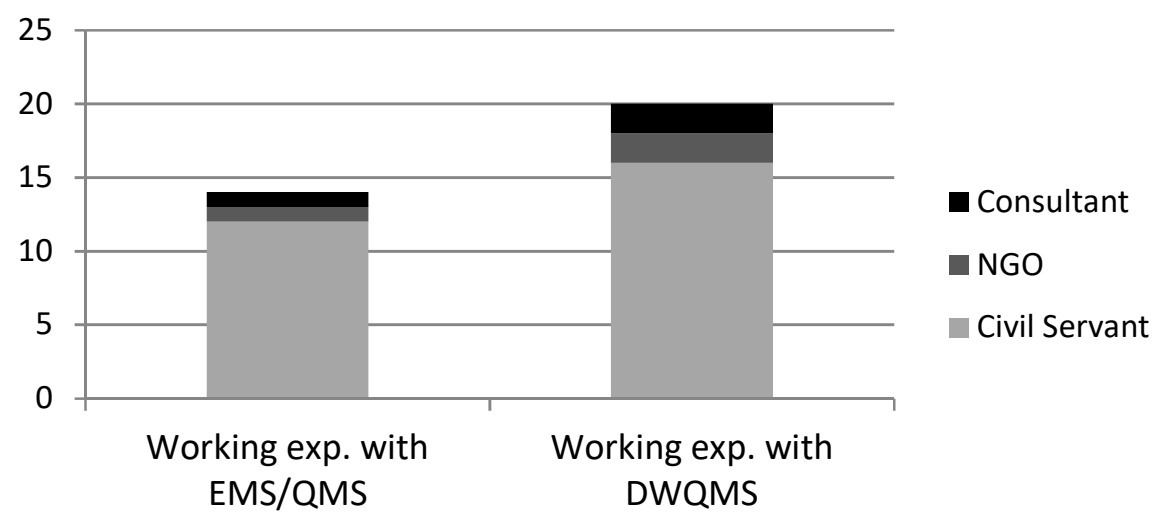

Figure 14. Interview Respondents' MSS Expertise (DWQMS, ISO 9001 \& 14001)

The questions were grouped into the following topics: General questions about DWQMS and EMS, planning/development/implementation of their management systems; policy and governance, rival propositions, and desires for future regulatory paths. An attempt was made to organize the information collected into the categories of enablers and barriers, governance, structure, and procedural aspects. This approach enhanced the ability of the author to identify 
key differences and similarities concerning programs/policies, and program implementation (Yin, 2003: 32).

Most interviews were conducted between 2016 and 2018, and preceded the development of the case studies, and the focus group (Chapters 5 and 6 respectively). The interviews with the four representatives of ENGOs were conducted in 2018. Questions for the ENGOs representatives were more focused and condensed. The interview analysis consolidates all 25 interviews.

\subsection{Case Studies}

For the case study's interview respondents, the central research question was addressed. In addition, the data obtained from respondents, publicly available information and data facilitated by interview respondents was used to address the following research sub-questions:

5. Why are municipalities in Ontario and other jurisdictions adopting quality and environmental management system standards, such as those set out in ISO 9001 and ISO 14001?

6. How (if at all) has the voluntary adoption of MSSs (in the form of ISO 9001 and/or ISO 14001) evolved over time, for the municipal water, wastewater and stormwater sectors?

Three case studies of Ontario municipalities that have adopted ISO 14001 is included here: York Region, Richmond Hill and Durham Region. These three municipalities were early voluntary adopters of ISO 9001, ISO 14001 and HACCP. The criteria used to select these municipalities included: Ontario municipalities that have voluntarily adopted ISO 9001, ISO 14001 and/or HACCP for their wastewater and/or stormwater systems; and municipalities of diverse sizes, allowing for a better understanding of any differences in usage of MSSs based on the size of their wastewater and stormwater systems.

In Ontario there are only six municipalities that have at some point adopted ISO 9001, ISO 14001, and/or HACCP. Five of them involve drinking water systems (York Region, Durham Region, Collingwood, Elgin Area and Lake Huron Water Systems), while three involve wastewater systems (York Region, Durham Region and Richmond Hill). One municipality has an 
ISO 14001 that covers the stormwater system (Richmond Hill), and only one municipality's experience involves HACCP certification for a drinking water system (Durham Region). A selection matrix is included in Table 13 identifying Durham Region, York Region and Richmond Hill as the only Ontario municipalities that have adopted voluntary MSSs for wastewater and stormwater systems.

Among other things, the three case studies are opportunities to explore questions concerning policy governance, policy transfer, and municipal use of MSSs, particularly as applied to drinking water, wastewater and stormwater systems. At an operational level, the case studies also allowed for explorations of questions such as why certain Ontario municipalities sought MSS certification before there was any provincial law requiring them to do so (e.g. the DWQMS), and why certain Ontario municipalities abandoned the application of particular MSSs or expanded their application within their organization. In addition, the experiences of seven other Canadian municipalities with MSSs are considered (Table 25).

The three case studies' analysis and results are included in Chapter 5.0, including conclusions and answers to research sub-questions 5 and 6 . Short summaries of seven relevant Canadian municipalities are referenced in Appendix F.

\subsubsection{Purpose and Scope}

In keeping with the recommendations of leading case study scholars, such as Stake (2000), Yin (2009) and Eisenhardt (1989; 2007), the case study method was selected for this dissertation in an effort to better understand how and why municipalities implement management system standards, and to test theoretical constructs and propositions associated with MSSs, drawing on the empirical evidence associated with the real-life contexts of municipalities. As Eisenhardt (2007) has noted, case studies are typically used to attempt to answer research questions that address questions of how and why in emerging research areas. The case study is used in this dissertation to assist in understanding possible causal factors behind the use of MSSs, and particularly to help answer two of the sub-questions:

- Why are quality and environmental management systems, such as those set out in ISO 9001 and ISO 14001, being adopted by Ontario municipalities? 
- How (if at all) has the voluntary adoption of MSSs (in the form of ISO 9001 and/or ISO 14001) evolved over time, for the municipal water, wastewater and stormwater sectors?

Clearer understanding is also sought concerning:

a) the possible perceived policy convergence aspects associated with MSSs in the wastewater and stormwater sectors;

b) the perceptions of interview respondents concerning the value of selecting QMS as opposed to EMS approaches;

c) the perceptions of interview respondents concerning drivers for municipal adoption of MSS (enablers and barriers);

d) the value and strengths and weaknesses of creating a provincially required MSS for municipal wastewater and stormwater systems, as perceived by interview respondents; and

e) possible alternative propositions explaining the use of MSSs by municipalities, as posited by interview respondents.

To mitigate against the bias associated with interview data, three case studies are undertaken, drawing on the perspectives of a diverse group of interview respondents who can potentially offer a variety of perspectives on issues, in an effort to triangulate observations and findings with the focus group and other research undertaken for this dissertation.

\subsubsection{Methodology}

To better understand the situation concerning the three municipalities that are the subject of the three case studies, the author reviewed a wide range of publicly available documents (e.g. council meeting minutes, municipal reports and press releases found on municipal websites, media accounts, scholarly articles), and interviews with 10 respondents with particular knowledge about MSSs in municipal contexts, as well as additional information identified during the interviews. The interviews were conducted in accordance with Ryerson University's Research Ethics Board approval. Two weeks prior to meeting with the interview respondents, general information about the study objectives, risks, mitigation and a preview of the type of questions to be discussed was provided. 


\subsubsection{Rationale for Selected Cases}

The rationale for selecting municipalities for the case study was based on the following criteria:

- actual experience in the application of ISO 14001, ISO 9001, and HACCP management approaches for their wastewater/stormwater sectors, having undergone the ISO certification process.

- population size, to capture both large (more than 500,000$)$ and small to medium municipalities (lesser than 200,000).

Municipalities that have experience with ISO 14001 and ISO 9001, were identified through the following sources:

1. The literature review process, particularly of the following publications:

a. The National Sewage Report Card - Grading the sewage treatment of 22 Canadian cities, Report No. 3 (SLDF, 2004), which identified the following municipalities as having an EMS in place: Edmonton and Quebec City.

b. Environmental management systems for municipal infrastructure, (FCM / NRC, 2005), which identified the following municipalities: Montreal, Halifax, Winnipeg, St. John's, Calgary, Ottawa and Vancouver.

c. "Environmental Penalty Regulations." Getting to K(No)w, ECO Annual Report, 2007-08, (Environmental Commissioner of Ontario, 2008), which identified the City of Timmins as having committed environmental offences under the EPA.

d. Government of Ontario - Court Bulletins 2012-2014, ${ }^{78}$ which identified municipalities with convictions due to environmental offences under the EPA and OWRA: Brockville, Atikokan, Bellville, London, Ottawa, Newmarket, Cornwall, and West Elgin.

2. Interviews with respondents, which identified the following municipalities as having some sort of EMS in place or ISO 14001 certification: City of Hamilton, City of Ottawa, City of Windsor, Richmond Hill, Regina, EPCOR, Nanaimo, Collingwood, Halifax, Elgin Area and Lake Huron.

${ }^{78}$ Government of Ontario - Court Bulletin, [Online]:

http://www.downloads.ene.gov.on.ca/files/court bulletins/en/news/convictions/index2013.html [29 Mar 2019] 
3. Conversations with other attendees while attending conferences in 2016 and 2017 to present the literature review for this dissertation, which identified the following municipalities as having undergone or seeking any form of EMS for their wastewater and stormwater systems: Toronto, Vaughan, Alberta Capital Region Wastewater Commission, Barrie, Halton Region and Peel Region. Conferences attended to present the literature review included:

a. Ontario Water Works Association Conference, Windsor, ON, May 2016;

b. Canadian Water \& Wastewater Association Conference, Toronto, ON, Nov. 2016;

c. $52^{\text {nd }}$ Central Canadian Symposium on Water Quality Research - Canadian Association of Water Quality Conference, Toronto, ON, Feb. 2017;

d. Water Environment Association of Ontario Conference, Ottawa, ON, Apr. 2017;

e. Canadian Environmental Conference and Tradeshow (CANECT 2017) Conference, Mississauga, ON, May 2017.

4. Publicly available information on municipalities' websites; entities with EMS or ISO 14001 were screened and other relevant cases selected.

In addition, in 2016 the author had the opportunity to present the objectives and methodology of this research at the Municipal Water and Wastewater Regulatory Committee (NWWRC) Spring Workshop. The NWWRC is an independent forum of Ontario municipalities formed in 2007 on a voluntary basis with the purpose of information exchange and mutual support related to regulatory compliance issues. NWWRC members meet on quarterly basis. At the 2016 Spring Workshop, members of the NWWRC confirmed that there are six municipalities in Ontario that have ISO 9001 and/or ISO 14001 certification for water and/or wastewater systems (although Collingwood dropped their certification in 2015); five that are in the development and/or implementation process; and two that have implemented partial elements of ISO 14001 (Table 12). 
Table 12. Municipalities with ISO 9001, ISO 14001, OR HACCP

\begin{tabular}{|c|c|c|c|c|c|}
\hline \multicolumn{2}{|r|}{ Municipality } & ISO 9001 & ISO 14001 & HACCP & Comments \\
\hline \multirow{6}{*}{ 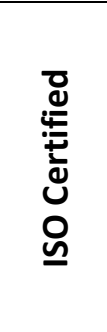 } & York Region & $\checkmark$ & $\checkmark$ & & Since $2000^{*}$ \\
\hline & Elgin Area Water & & $\checkmark$ & & Since 2002 \\
\hline & Lake Huron Water & & $\checkmark$ & & Since 2003 \\
\hline & Richmond Hill & $\checkmark$ & $\checkmark$ & & Since 2006 \\
\hline & Durham Region & $\checkmark$ & $\checkmark$ & $\checkmark$ & Since 2006 \\
\hline & Collingwood & & $\checkmark$ & & From 2007 to 2015 \\
\hline \multirow{5}{*}{ 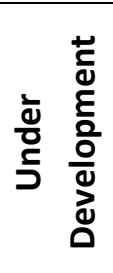 } & Region of Peel & $\checkmark$ & $\checkmark$ & & Estimated for 2020 \\
\hline & City of Toronto & & $\checkmark$ & & Estimated for 2021 \\
\hline & Halton Region & $\checkmark$ & $\checkmark$ & & Estimated for 2021 \\
\hline & City of Vaughan & & $\checkmark$ & & Estimated for 2022 \\
\hline & City of Barrie & & $\checkmark$ & & Estimated for 2022 \\
\hline \multirow{2}{*}{ 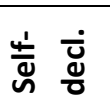 } & City of Ottawa & & $\checkmark$ & & Since 2010 \\
\hline & City of Hamilton & & $\checkmark$ & & Since 2012 \\
\hline
\end{tabular}

(*) Adopted ISO 14001 for wastewater only in 2000, and ISO 9001 for drinking water in 2001

Of these six municipalities with an ISO 14001 EMS in place, only three met the criteria established for this dissertation. They are York Region, Durham Region and Richmond Hill. Table 13 shows the application of the criteria to each of the six municipalities identified.

Table 13. Selection of Municipalities for the Case Study Method

\begin{tabular}{|l|c|c|c|c|}
\hline \multicolumn{1}{|c|}{ Ontario municipality } & $\begin{array}{c}\text { MSS in } \\
\text { Stormwater }\end{array}$ & $\begin{array}{c}\text { MSS in } \\
\text { Wastewater }\end{array}$ & $\begin{array}{c}\text { Population } \\
<\mathbf{2 0 0 , 0 0 0}\end{array}$ & $\begin{array}{c}\text { Population } \\
\mathbf{5 0 0 , 0 0 0 +}\end{array}$ \\
\hline York Region & & $\checkmark$ & & $\checkmark$ \\
\hline Richmond Hill & $\checkmark$ & $\checkmark$ & $\checkmark$ & \\
\hline Durham Region & & $\checkmark$ & & $\checkmark$ \\
\hline Collingwood $\left(^{*}\right)$ & & & $\checkmark$ & \\
\hline Elgin Area Water & & & $\checkmark$ & \\
\hline Lake Huron Water & & & $\checkmark$ & \\
\hline
\end{tabular}

* Collingwood dropped ISO 14001 in 2015 (Table 25).

On applying the criteria, no municipality met the first criterion of having all three ISO 9001, ISO 14001 and HACCP for both wastewater and stormwater systems. The criteria for each municipality are as follows: 
1. York Region has a current ISO 14001 certification for its wastewater system but not for stormwater. It is considered a large municipality with a population larger than 500,000 .

2. Richmond Hill has ISO 14001 certification for both wastewater and stormwater systems. It is considered a small to medium municipality with fewer than 200,000 residents.

3. Durham Region has ISO 14001 for its wastewater treatment plant (with shared ownership with York Region). At one point it had ISO 9001 and HACCP as well, but it abandoned the certification while maintaining the management practices. It is considered a large municipality, having a population of more than 500,000 . It is the only municipality that has obtained HACCP certification.

4. Collingwood had ISO 14001 for its wastewater operations from 2007 until 2015, when it decided to abandon the certification while continuing the management practices. It is considered a small to medium municipality, with a population of less than 200,000 .

5. The Elgin Area and Lake Huron Water have an ISO 14001 for their drinking water systems. They do not own or operate wastewater or stormwater systems.

Based on the above, Richmond Hill was selected for the small to medium category as it was the only municipality in Ontario with ISO 14001 for its stormwater system. Durham Region was selected for the large size category, being the only municipality that has obtained HACCP certification.

However, given that York Region shares ownership of Durham Region's wastewater treatment plant and also shares ownership of the wastewater system for Richmond Hill (York and Richmond Hill wastewater systems are intertwined, as York provides bulk supply and trunk wastewater collection and Richmond Hill handles the distribution of drinking water and operates its local wastewater collection for its residents). York Region was included as third case study. Each of these three municipalities is examined starting with York Region.

\subsection{Focus Group}

The focus group method was planned as the last thread to tie everything together and obtain feedback and criticism from expert practitioners. Its purpose was to build on the preliminary results of the literature review, the semi-structured interviews and the case studies. It also 
assisted in corroborating and triangulating the research process and all research questions, particularly the main research question. For this focus group, the author moderated the session and the PhD Supervisor acted as a participant observer. Two graduate students were recruited as recorders of conversations and to facilitate the planned breakout sessions.

The key research question for the focus group was: is there value in creating and establishing a provincially required municipal wastewater and stormwater environmental management standard similar to ISO 14001? This question was explored with a group of professional experts in the provincial-municipal water, wastewater, and stormwater regulatory sectors on February 15, 2018, in Toronto. The focus group session was preceded by the literature review, interviews, and case studies (2015 and 2017).

Triangulating with the preliminary findings drawn from the research undertaken earlier for this dissertation, a key purpose of the focus group was to obtain expert feedback and criticism on the value of a provincially mandated EMS standard for municipal wastewater and stormwater. It was also hoped that the focus group discussions would provide an opportunity to develop a better understanding of the strengths and weaknesses of possible approaches to municipal water issues, and the sort of factors and considerations affecting decision making. While consensus was not a goal, there was a certain amount of coalescence among the experts around certain ideas. A review by the focus group members of transcripts/summaries of the session provided further opportunity for participants to comment on the issues and confirm the accuracy of the focus group summary. In this section sub-questions 3 to 6 are addressed including the central research question (Chapter 1.3).

\subsubsection{Participants}

A representative balance of participants was sought to ensure a broad representation of state and non-state actors in the governance structure of water systems. The focus group had 14 participants including representatives from Ontario and international experts on environmental regulations, EMS, small and large water utilities (municipal and non-municipal), and the private sector. The focus group participants comprised:

1. provincial government regulators from the MECP directly involved with all municipal water, wastewater, and stormwater systems (4 participants); 
2. large municipalities (1+ million residents) with EMS systems in place or in the process of being implemented (3 participants);

3. medium to small municipalities, including representation of the Ontario Clean Water Agency (OCWA) (3 participants);

4. international private sector regulators and registrars, with representation of the CSA Group, including the two registrars designated to conduct DWQMS external audits for all municipal water systems in Ontario (3 participants); and

5. a consultant with ample experience in ISO management systems and with the operation and compliance of municipal water systems (1 participant).

To address the challenge of ensuring meaningful representation of small municipalities, ${ }^{79}$ the focus group included three senior officials from the Ontario Clean Water Agency (OCWA). OCWA manages and operates 180 municipal, non-municipal and First Nation water and wastewater systems across Ontario, most of which are in municipalities with fewer than 50,000 people $^{80}$. These officials provided significant insights from smaller municipalities in Ontario.

All 14 focus group participants were recruited by means of emails and telephone calls by the author. All participants were based in Ontario, except for one consultant/ registrar who is based in Quebec. Participation was by invitation only. The focus group session was organized by the author and PhD supervisor, with the support of Ryerson University - Ted Rogers School of Management. As recommended by relevant literature concerning how to conduct focus groups (e.g. Krueger and Casey, 2015; Liamputtong, 2011) and by the Ryerson University Research Ethics Board, all participants were offered a gift certificate valued at $\$ 50$ to cover costs of travel and parking, and in consideration of the time they dedicated to the half-day session (although the civil servants declined it).

\subsubsection{Procedure and Protocol}

All participants received the key research question and the two sub-questions in advance, along with brief contextual information. The contextual information shared with the participants prior

\footnotetext{
79 There are 444 municipalities in Ontario, who own and/or operate 630 licensed drinking water systems with a similar distribution for wastewater systems. A total of 10 municipalities cover $75 \%$ of the population in Ontario. ${ }^{80}$ OCWA 2017 Annual Report, [Online]: www.ocwa.com/sites/default/files/ocwa-ar2018-eng-tagged.pdf [15 Sep 2019]
} 
to the focus group is included in the Introduction section of this dissertation. The key research questions and sub-questions provided in advance were:

- Is there value in creating a provincially mandated municipal wastewater environmental management system standard, and a stormwater environmental management system standard?

- Are management system standards likely to have neutral, positive, or negative effects on the performance of Ontario municipal water management activity?

- How (if at all) has the voluntary adoption of MSSs (in the form of ISO 9001 and/or ISO 14001) evolved over time, for the municipal water, wastewater and stormwater sectors?

Two Ryerson graduate students were recruited, with the assistance of the PhD supervisor, to take notes during the session. The students were paid for their time at standard Ryerson University hourly rates for graduate students. No video or voice recording was allowed. The focus group began on time at 8:30 a.m. with all participants present. In the introductory remarks by Tovilla and Webb, participants were reminded of the purpose of the focus group, the risks to participants and how those risks were mitigated. All participants confirmed that they understood and also confirmed their assent on the Consent Form signed prior to the start of the session.

After the introductory remarks, the author provided a presentation that highlighted the preliminary observations and initial findings of the research. Notes on the discussions were taken by the graduate students and the author, with the latter moderating the discussion. All participants engaged actively in the discussion. Instead of dividing the group into breakout sessions as originally planned, given the manageable number of participants, and noting the active engagement of all participants in the dialogue, the organizers suggested continuing the discussion in a single group to keep the momentum going. The participants agreed.

\subsubsection{Strategy}

The points for which there appeared to be consensus were summarized and noted at the halfway point in the focus group session, and an opportunity was provided for focus group participants to confirm their veracity, to corroborate, elaborate or disagree, after which the remaining questions were discussed. When the focus group session concluded, the author 
reviewed and consolidated the notes taken by the two recorders. The summary of transcripts was shared with each individual participant to obtain their feedback. All participants were given the opportunity to review the summary to clarify, comment, or confirm their insights. Based on the revised transcripts, all recorded discussions were reviewed and classified. The confirmed transcripts of the 14 participants were coded and then analyzed. A draft report of the conclusions was prepared and provided to participants for comment.

Although consensus was not sought by the organizers, there was a certain degree of agreement expressed by the focus group participants. New assertions not originally considered in the design of the focus group were also recorded, and divergent opinions noted. By reviewing the transcripts, a coding framework with topics based on the key research question, and sub-questions and categories was developed. 


\subsection{INTERVIEWS - ANALISIS AND RESULTS}

\subsection{Analysis of Interviews}

This analysis is presented in three sections. First, five key questions and the responses to them are reviewed quantitatively to analyze the respondents' perceptions concerning MSSs for municipal water systems. This is followed by a classification of qualitative data in terms of enablers and barriers, governance, structure, and procedural aspects in relation to MSSs. Finally, the qualitative data is examined with a focus on the relevant position taken by the respondents, and particularly on the:

A. relevance to municipalities of voluntarily adopting non-state regulatory standards, such as ISO 14001 or ISO 9001;

B. regulatory barriers to modernizing the Ontario municipal wastewater and stormwater regulatory framework; and

C. provincial regulatory priorities associated with improving the protection of freshwater quality from potential contamination from municipal wastewater and stormwater.

The interviews took place at a time when the province was conducting a public consultation through the Ontario Environmental Registry ${ }^{81}$ (2016-2017) regarding proposed updates to the Drinking Water Quality Management System. This meant that most respondents had developed considerable familiarity with the DWQMS and proposed amendments to its original 2007 version.

\subsection{Key Interview Questions}

Five key questions were included for the interviews:

1. Do you consider an MSS to have neutral, positive, or negative effects for the Ontario water sectors?

2. Should Ontario municipalities have a voluntary or mandatory wastewater and/or stormwater management system standard based on ISO 14001 ?

3. In terms of MSSs, are ISO 14001 and/or ISO 9001 the best fit for drinking water, wastewater, and stormwater systems, or is there something better that should be used?

${ }^{81}$ Ontario Environmental Registry No. 012-5530, [Online]: www.ebr.gov.on.ca/ERS-WEB-

External/displaynoticecontent.do?noticeld=MTI2Mzky\&statusld=MTk5Nzk1\&language=en [29 Mar 2019] 
4. Does an MSS that is not regularly revised and updated pose an organizational risk because it does not encourage ongoing innovation and instead rewards "going by the book" behaviour?

5. Do you have any ideas as to why only a subset of Ontario municipalities have voluntarily adopted ISO 14001 as of 2016 ?

For Question No. 1: a total of $\mathbf{8 8 \%}$ of respondents (22/25) answered that implementing an MSS would have positive effects for the municipal water sectors.

For the Question No. 2, the responses can be grouped as follows:

- $\mathbf{7 7 \%}$ considered that EMS should be a regulatory requirement.

- $15 \%$ considered that EMS should be either a voluntary or regulatory requirement.

- $10 \%$ considered that EMS should be a voluntary requirement.

For Question No. 3, the response breakdown as follows:

- $100 \%$ considered ISO 9001 -QMS best fit for drinking water systems.

- $\quad 95 \%$ considered ISO 9001 redundant for drinking water systems as DWQMS addresses water quality controls.

- $\mathbf{9 5 \%}$ considered ISO 14001 -EMS the best fit for wastewater and stormwater systems.

- $60 \%$ considered that ISO 14001 -EMS could address the environmental protection regulatory gaps for drinking water systems.

One respondent to this question highlighted the possibility of mirroring the DWQMS for the wastewater and stormwater sectors; however, the remaining 19 respondents concurred on the need for a sector-specific EMS for wastewater and for stormwater and recommended integration with the ISO family of MSSs in order to avoid duplication. Three respondents noted that their municipality has also adopted ISO for health and safety, and the recent 2015 version of ISO standards makes them easy to integrate.

For Question No. 4, a total of 5 respondents answered affirmatively, and 20 did not. Three quarters of respondents noted the importance of MSS in promoting innovation throughout the organization. This was characterized as occurring through the ISO 14001 continual improvement process, and its associated root cause analysis (RCA). RCA is a procedural participative process applying investigative techniques to resolve problems/issues at the root 
cause, so as to prevent similar issues from happening again. Techniques noted by one of the respondents include the fishbone diagram, ${ }^{82}$ the 5 -Ws process (i.e. asking 'why' five times or until reaching the root cause of an issue) (Strong, $n / d$ ), and the failure more analysis ${ }^{83}$. While RCA is not a requirement under ISO 9001 or ISO 14001, some type of investigation mechanism is. Most registrars and ISO consultants include these RCAs as techniques to implement the ISO requirement for a continual improvement process (Strong, $n / d$ ).

With respect to Question No. 5, all respondents noted that the primary driver for adoption of the standard was the desire to anticipate upcoming provincial regulations as recommended in the Walkerton Inquiry (2002), and also the support it received from upper management and city councillors in light of the tragedy. However, after the DWQMS guide was published and the implementation calendar was legislated (O. Reg. 188/07), all municipalities concentrated their efforts on developing, implementing and complying with the DWQMS.

\subsection{Enablers, Barriers, Governance, Structure and Procedural Aspects}

The schematics presented in this section are an adaptation of the schematics developed by Rosenberg and Yates (2007) to illustrate the descriptive analysis resulting from the semistructured interviews. Respondents' answers are classified under enablers or barriers, and each concept is identified in terms of governance and policy aspects, and also in terms of structure and process. First, Table 14 shows the enablers and barriers classified in two areas: governance; and structure and process. This classification makes it possible to screen the qualitative data obtained to focus on governance (and policy) separately from implementation (structure and process).

In addition, qualitative data was coded into multiple topics to illustrate the distribution of the most frequently cited topics. The data is presented in separate graphs: two for MSS enablers (Figure 15, and Figure 16), and two for MSS barriers (Figure 17 and Figure 18).

According to Figure 15, the most common topic in support of the use of MSSs is compliance, and the reduced likelihood of environmental violations, followed by the ability to enhance the municipality's due diligence defence in the event of violations. Complementarity with existing

\footnotetext{
${ }^{82}$ A fishbone diagram is a cause and effect diagram also known as the Ishikawa diagram (Wong, 2011).

${ }^{83} \mathrm{~A}$ failure mode analysis is a methodology to minimize risk with reliability and statistical analysis (Stamatis, 2003).
} 
state regulations, risk management and management accountability were also prominent as

points in support for adopting MSSs.

Table 14. Governance, Structure, and Process - Enablers and Barriers Enablers

Barriers

- $\quad$ Reduced likelihood of environmental violations (improved compliance)

- Support for due diligence defence in case of noncompliance

- $\quad$ EMS complements the MECP inspections and audits (MECP cannot keep up with their 3-year inspection standard)

- Increased accountability for management

- A risk-based approach aligning with water regulations, e.g. system-wide ECA, EASR, selfinspections

- Risk mitigation and environmental protection

- If regulated, it should be flexible and scalable for implementation (the way ISO 14001 is)

- $\quad$ CSA and ISO are great partners to develop sectorspecific standards

- If regulated, easy to get Council's support

- Continual improvement is tied to EMS

- EMS improves standard of care, provides checks and balances, and professionalism

- $\quad$ No need to mirror the DWQMS for WW, an EMS is a better fit for WW \& SWM; ISO 14001 not meant for drinking water

- It provides a holistic approach to innovations "you have to come up with stuff" (improvements)

- ISO 14001 is a good model

- Having provincial guidelines would help

- Added value to governance, either voluntary or mandatory

- $\quad$ EMS is good for performance tracking KPIs: energy consumption, emissions, water conservation, etc.

- Public acceptance: transparency, reputation and brand value

- Elected officials' support due to public benefits

- Critical mass balance of knowledge available

- MSS holds municipalities to a higher standard

- Many QMS elements already in place across sectors

- It prepared municipalities to meet more stringent env. protection requirements by the province

- Having a pilot project, or program would help

- Improvement of communications (int.\& external)

- Uncertainty of regulations

- Need for a sector specific standard (like the DWQMS for water)

- On-going costs to keep/maintain an MMS are high (resource intensive process)

- $\quad$ Risk-based processes such as EASR \& selfinspections need oversight

- $\quad$ MECP needs to see benefits and take the lead for development of some tools

- Municipal councillors are not familiar with MSS

- Council approval for funding every year

- After adopting international standards, and going through "stagnant" audits with no improvement, then the certification can be dropped, while maintaining the MSS

- Obsolete regulations continue to be a barrier

- Buy-in from elected officials

- Complex for small municipalities

- Difficult to maintain

- Reacting to tragedy seems to be a waiting game ("why wait if we can be proactive")

- Cultural change among WW and Stormwater staff needed (like that which occurred in water)

- Public work areas work in silos (need crossdivisional activities to ensure consistency)

- Extensive consultation needed

- Political risk

- Municipalities afraid of vulnerability-public scrutiny for open records

- Need for cost benefit analysis

- MSS are duplicative as regulations cover everything

- No additional ISO standards needed; it is better to work with the DWQMS for more integrated standards

- The ISO banner does not say much to residents, who are more concerned about costs 


\begin{tabular}{|c|c|c|}
\hline & 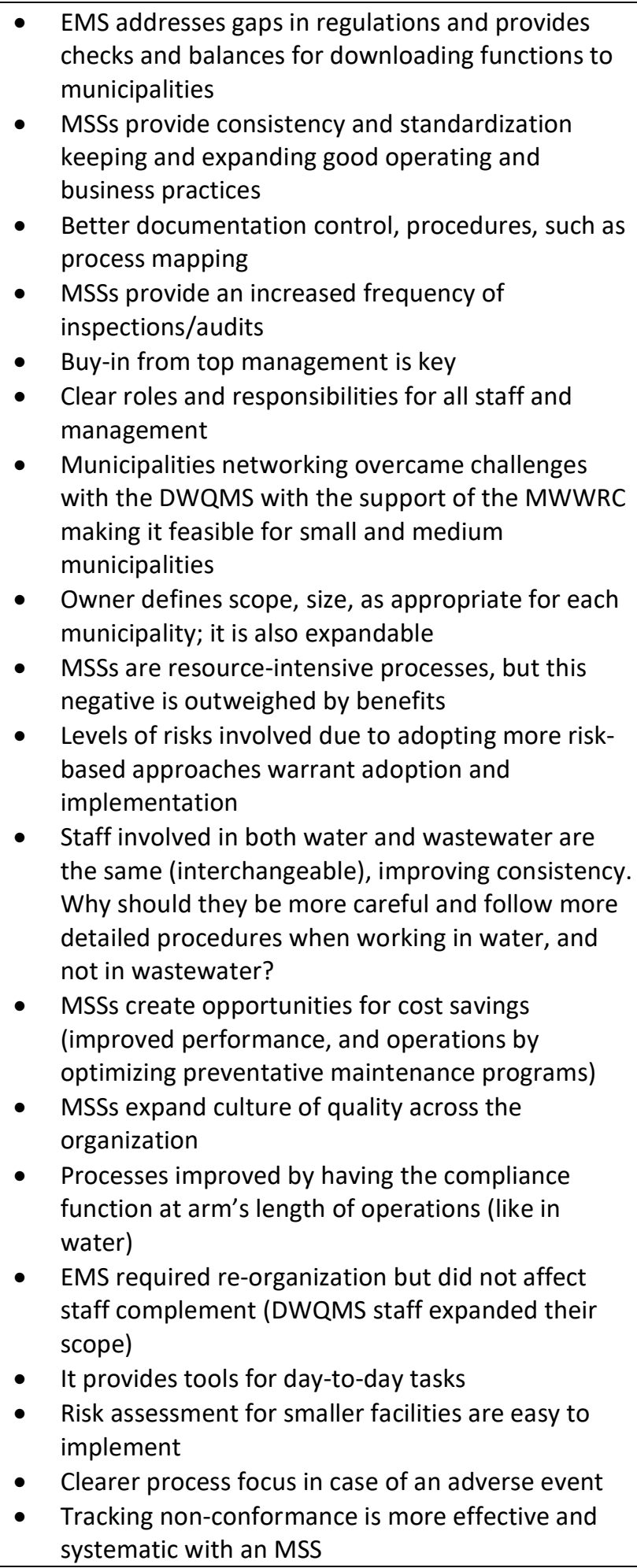 & $\begin{array}{l}\text { - } \text { MSS development and implementation is resource } \\
\text { intensive } \\
\text { - } \quad \text { There is a perception of additional work } \\
\text { - } \text { documentation) } \\
\text { - } \text { Buy-in from operators } \\
\text { - } \quad \text { Aftder a few years, DWQMS audits are less justifiable } \\
\text { - } \quad \text { since there are fewer findings } \\
\text { - } \quad \text { Risk analysis more complex for large systems } \\
\text { - Re-organization makes it challenging } \\
\text { - } \quad \text { Different mindset needed for people to understand } \\
\text { - } \quad \text { purpose of audits } \\
\text { - } \quad \text { projects } \\
\text { Staff need to understand why it is important }\end{array}$ \\
\hline
\end{tabular}




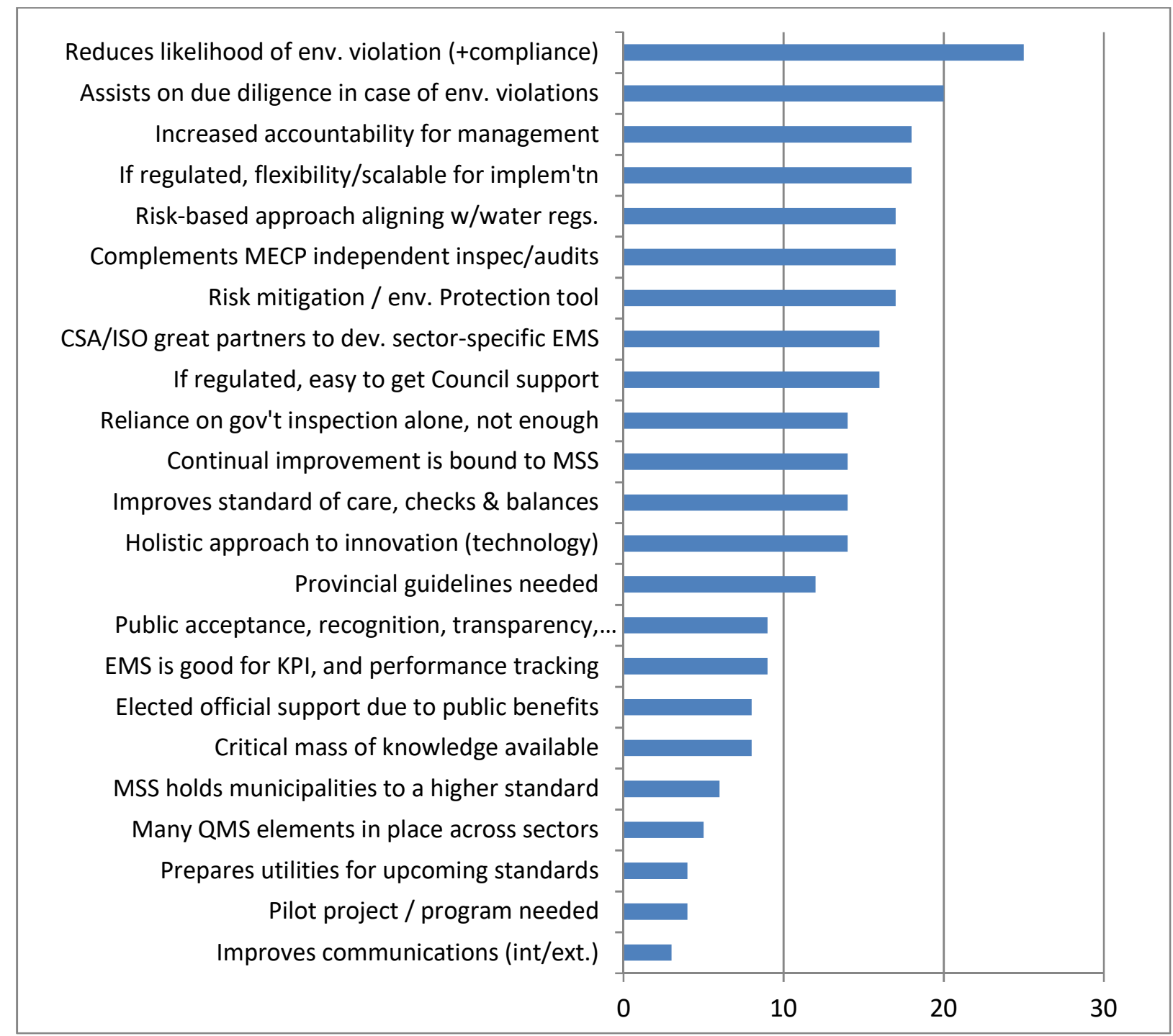

Figure 15. MSS Enablers - Governance and Policy Aspects

As for implementation of these kinds of systems, Figure 16, reflects that positions in support of MSSs include the ability to address regulatory gaps in state legislation by adding checks and balances to reduce risks. This aspect is significant as some respondents noted that provincial inspections of wastewater systems were infrequent (and basically non-existent for stormwater systems). 


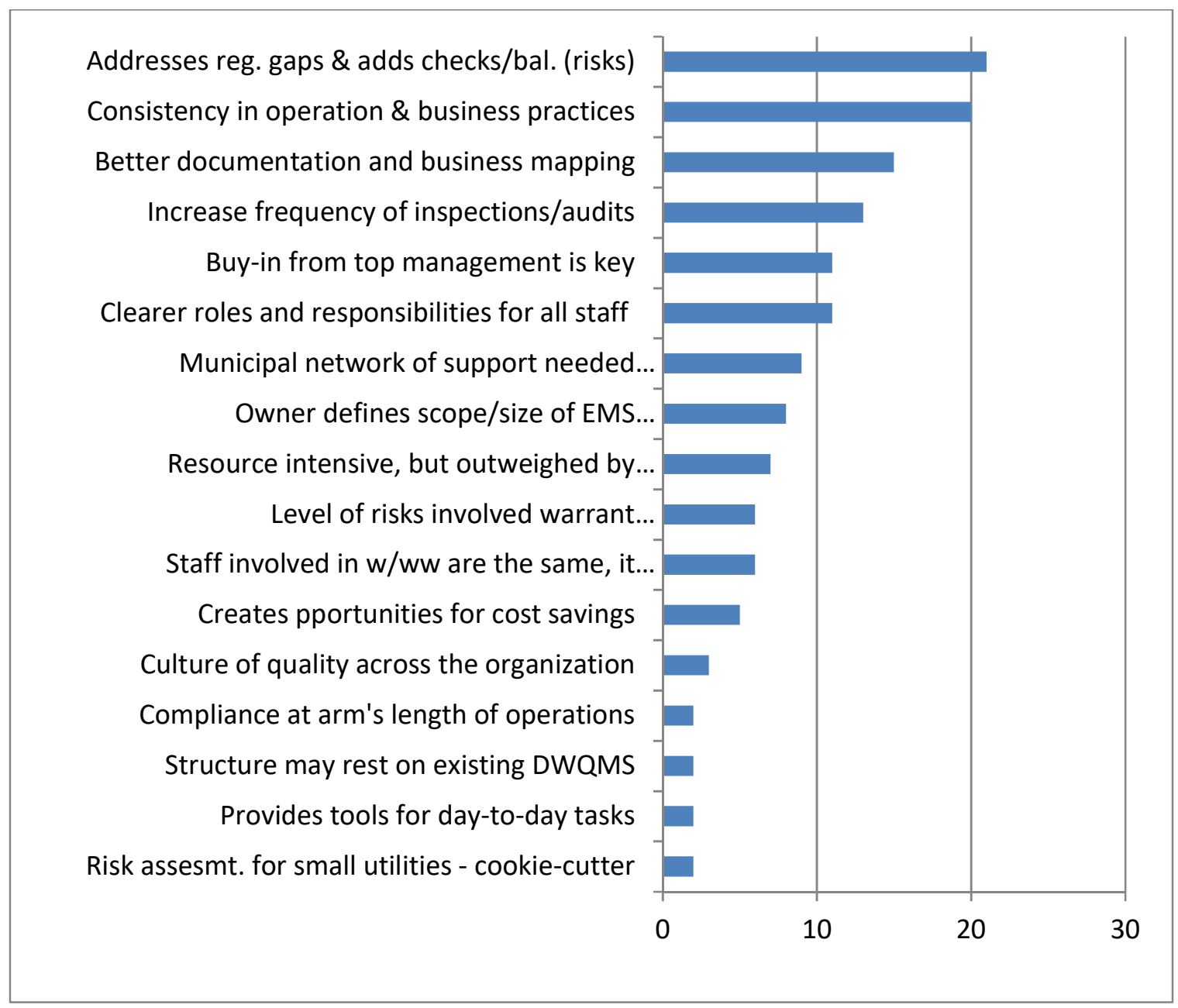

Figure 16. MSS Enablers - Structure and Process Aspects

When discussing the different propositions, most respondents identified similar regulatory gaps in current legislation as the primary barriers to MSS implementation. Other MSS barriers included: uncertainty of regulations, development and implementation costs, and on-going cost implications. The following figures illustrate the distribution of the most frequently cited topics in responses about MSS barriers. 


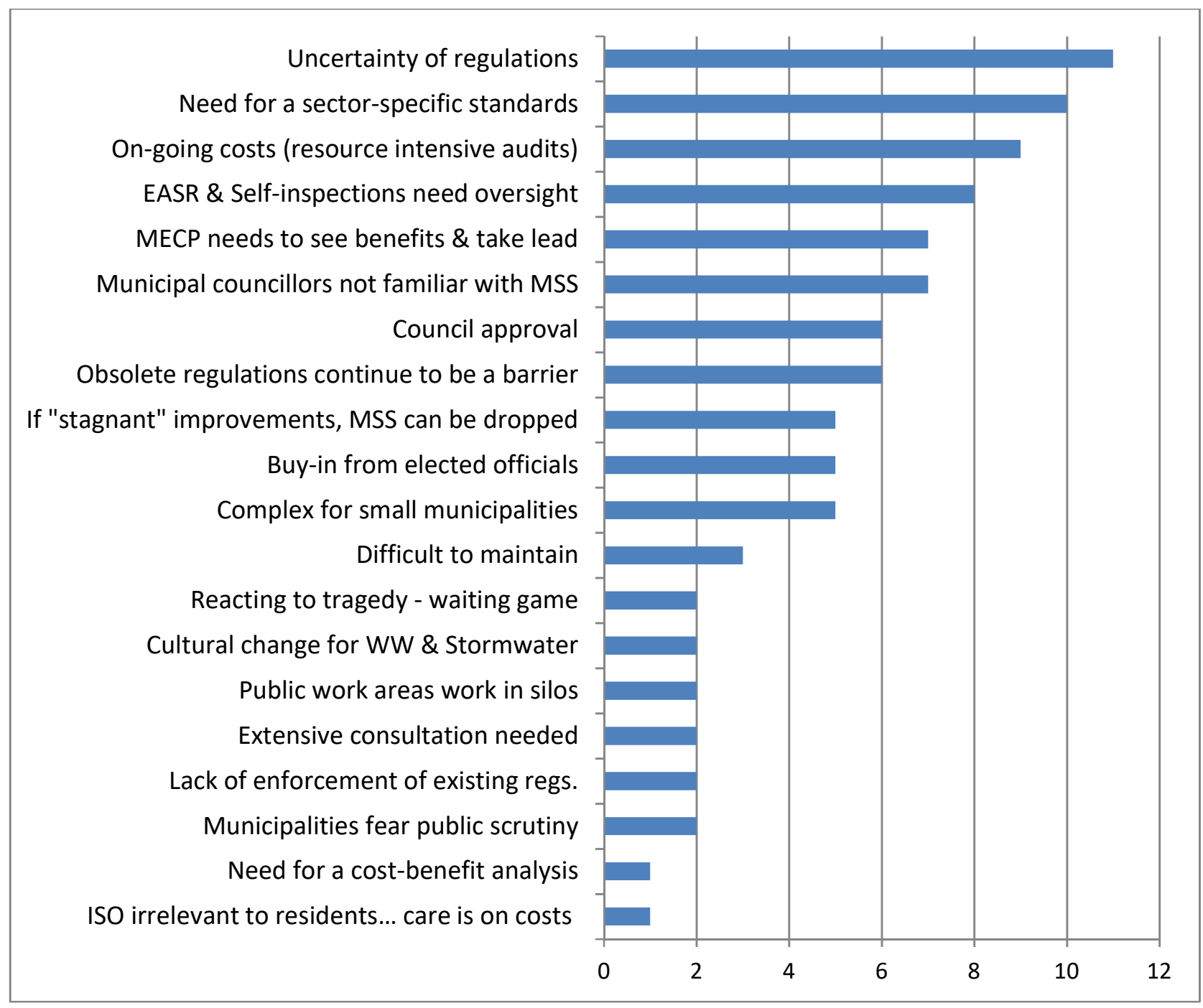

Figure 17. MSS Barriers - Governance and Policy Aspects

The recurring interviewees' responses included the uncertainty of regulations for the wastewater and stormwater (given that it heavily relies on guidelines, voluntary codes and best municipal practices). It was also noted that any MSS requires a significant amount of resources for implementation, and the expressed need for a sector-specific standard tailored to the wastewater and the stormwater sectors (similar to that of the DWQMS for the drinking water sector). 


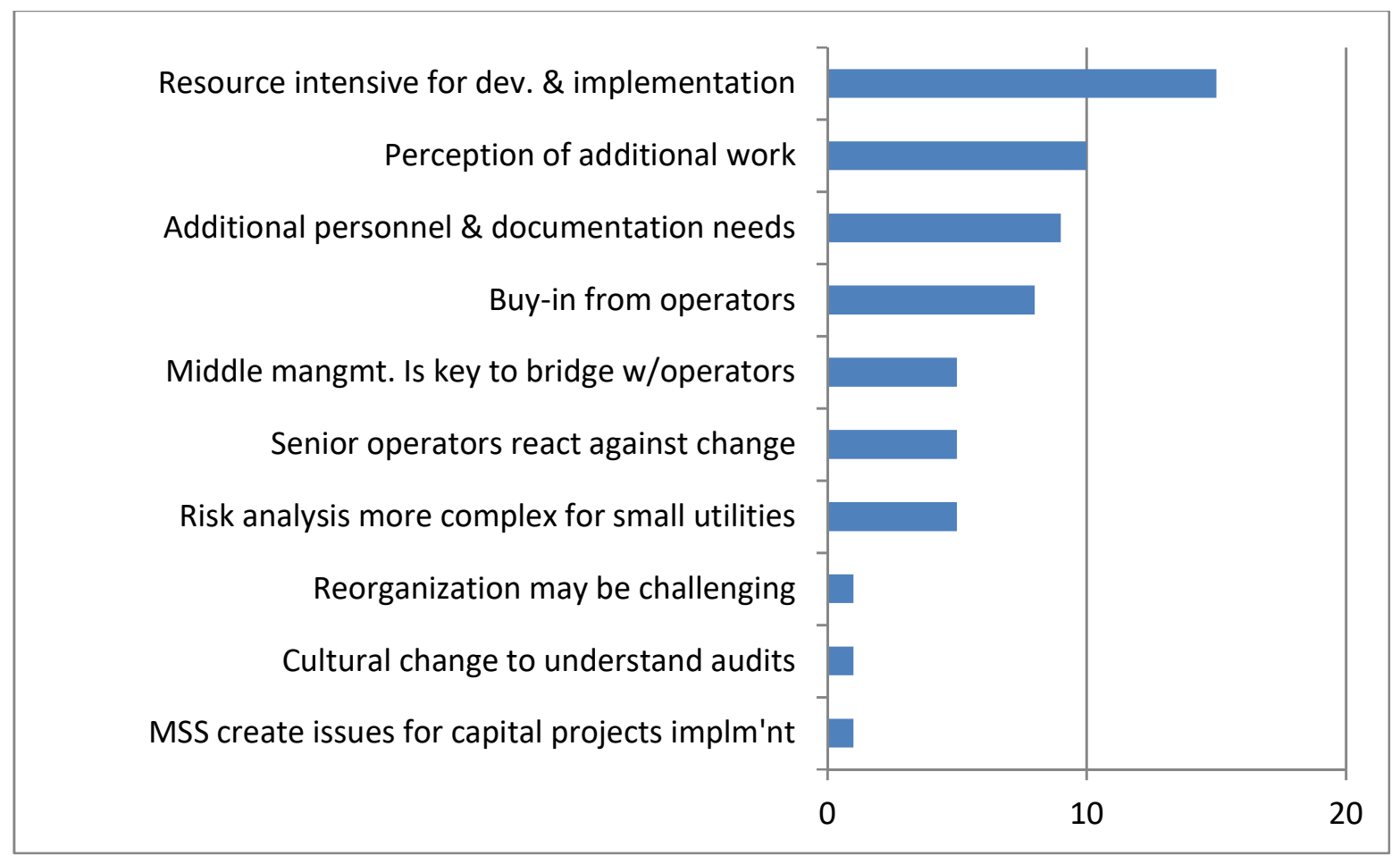

Figure 18. MSS Barriers - Structural and Process Aspects

\subsection{Relevant Positions by Sector (municipal, consultants and ENGOs)}

A total of 19 municipal representatives participated in the interview process. A sampling of statements by respondents are included in Table 15. In addition to the codification in the previous section, information was examined concerning the following topics:

A. relevance for municipalities of voluntarily adopting non-state regulatory standards, such as ISO 14001 or ISO 9001;

B. regulatory barriers to modernizing the Ontario municipal wastewater and stormwater regulatory framework; and

C. provincial regulatory priorities associated with improving the protection of freshwater quality from potential contamination from municipal wastewater and stormwater. 
Table 15. Municipalities' Specific View-points

\begin{tabular}{|c|c|}
\hline & ses Class \\
\hline 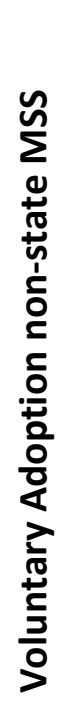 & $\begin{array}{l}\text { - "for managers [MSSs] are a great tool to ensure due diligence, and for staff it } \\
\text { provides the day-to-day tools [SOPs, documentation] for completing tasks, and for } \\
\text { training" M1 } \\
\text { - " } \text { - "MSS] is of great value as it provides a professional approach [to operations]" M1 } \\
\text { environment, audits" M2 } \\
\text { - "operations are focused on operations. A holistic approach is needed, a big picture" } \\
\text { - "for small municipalities [the DWQMS] was challenging. It became easier, once } \\
\text { - "municipalities networked through the MWWRC" M5 } \\
\text { because they are familiar with them and see the benefits" M14 }\end{array}$ \\
\hline 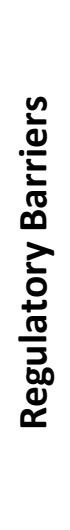 & $\begin{array}{l}\text { - "[the EMS] implementation is challenging. It is better to go in stages, by department } \\
\text { - "for by facility" M2 } \\
\text { - "how to do corrective actions was weak in the first DWQMS, now it is better } \\
\text { - "hnderstood" M10 } \\
\text { - } \text { line staff is paramount" M12 } \\
\text { "A cost-benefit analysis would assist municipalities before they embark on such an } \\
\text { undertaking [....] it is better to wait and see what the province decides to do" M13 }\end{array}$ \\
\hline 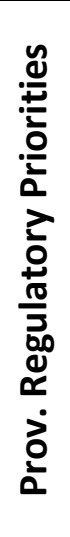 & $\begin{array}{l}\text { - "the MECP should develop a wastewater EMS, the ISO } 14001 \text { is a better approach" } \\
\text { - M5 "If an EMS is mandatory, it would be easier for municipalities to obtain funding and } \\
\text { support from Council" M6 } \\
\text { - "there should not be designated registrars; this would make it easier and more } \\
\text { affordable to obtain ISO } 14001 \text { certification" M14 } \\
\text { - "it is a matter of time for the province to require an EMS for wastewater" M15 } \\
\text { - "if [an EMS is] left voluntary, then it will not fare well over time. [An EMS] needs a } \\
\text { stick. [Having a system registered under ISO 14001] is required" M16 }\end{array}$ \\
\hline
\end{tabular}

Municipal respondents had a significant number of positive and negative responses concerning the use of an MSS for wastewater and stormwater systems. There was generally recognition of the value and benefits, as well as the procedural aspects for implementation (e.g. 
MWWRC networking), including the critical mass of knowledge, as has happened with the DWQMS. Based on the responses provided, it was apparent that respondents had a good familiarity with ISO 14001 and the differences between it and the DWQMS. As noted earlier, these interviews occurred at the time the MECP had released a Draft DWQMS (2015) for public comment. This is an indicator of the awareness needed not only to improve the standard, but also of the acceptance by municipalities of the beneficial use of the standard.

Two consultants who participated in the interview process were specialists in MSS. In addition to the codification in the previous section, information was examined focusing on arguments A, B, and C. Representative arguments are included in Table 16.

Table 16. Consultants' Specific View-points

\begin{tabular}{|c|c|}
\hline $\mathbf{Q}$ & Classified under Topics A, B and C \\
\hline & $\begin{array}{l}\text { - "the DWQMS was strategically designed for drinking water, and very limited to } \\
\text { address environmental issues [....] [ISO } 14001 \text { is necessary] to effectively manage } \\
\text { impacts to the environment" C1. } \\
\text { - "ISO } 14001 \text { is a big deal, and [a] great response to environmental groups and public } \\
\text { pressure" C1 } \\
\text { - "[large] municipalities are already cloning their management systems, [i.e. } \\
\text { transferring their drinking water management systems approach to wastewater] [....] } \\
\text { the body of knowledge created by the DWQMS is paying dividends" C2 } \\
\text { - "the operators had no identity [....] [and then] after Walkerton, they were the focus. } \\
\text { Now, they are licensed, are responsible [....] the MECP professionalized the } \\
\text { operation" C2 } \\
\text { "EMS will never be the fine screen to catch everything, but will likely catch the big } \\
\text { stuff. Like anchors in the system" C2 }\end{array}$ \\
\hline & $\begin{array}{l}\text { - "top management's on-going commitment is an issue [....] there is always the risk of } \\
\text { political change in elections [....] and the change of leadership" C1 } \\
\text { - "ISO standards are always seen as a cost of doing business. But it keeps people safe, } \\
\text { protects the environment, and keeps everyone out of jail" C1 } \\
\text { - "The implementation of the DWQMS was too onerous [....] for smaller municipalities } \\
\text { [....]. They will find [an EMS or ISO 14001] really hard to afford" C2 }\end{array}$ \\
\hline
\end{tabular}




\begin{tabular}{|c|c|}
\hline 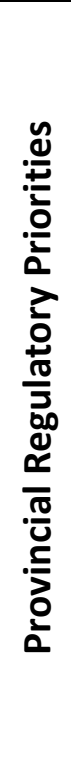 & $\begin{array}{l}\text { - "the new thing is to have sector specific standards; as an example, the ISO } 14001 \text { was } \\
\text { criticized because it was not deep enough for energy. [So then ISO came up] with ISO } \\
50001 \text { for energy" C1 } \\
\text { - "the MECP should address EMS as part of the DWQMS, and also should have a } \\
\text { sector-specific EMS for wastewater. Also, they should leave it to the CSA and/or ISO } \\
\text { to develop the standard - leave it to the hands of the experts" C1 } \\
\text { - "For wastewater systems, the core structure should be ISO 14001, then add } \\
\text { - "the MECP should not enforce a wastewater management standard. They will be } \\
\text { better off to let it evolve for some more years" C2 } \\
\text { "If MECP decides to support it, then they need to make it flexible enough for small } \\
\text { municipalities [....] and create a repository of SOPs and BMPs, so municipalities could } \\
\text { use them" C2 }\end{array}$ \\
\hline
\end{tabular}

A consistent message from consultants was that if a wastewater management standard was mandated, it should be scalable, flexible, and with support mechanisms to allow smaller municipalities to comply with it. Furthermore, there was also a consistent message in that larger municipalities are already implementing it or cloning it. Finally, consultants recognized the body of knowledge created by the DWQMS, and the professionalization of the operation, as benefits transferable to the wastewater sector.

Four ENGOs representatives participated in the interview process. The participating ENGOs were selected based on having a good governance structure, engaging in relevant activities in Ontario (with water management as a priority) and operating water programs and projects. The four ENGOs were:

- One focused on Ontario rivers and lakes water quality and its users;

- One focused on environmental laws and enforcement;

- One focused on new technologies and innovation in the Ontario municipal water sectors; and

- One focused on North American wetlands and the habitats they provide to wildlife. The questions posed to the ENGOs representatives covered topics A, B and C, and their responses are summarized in Table 17. 
Table 17. ENGOs Specific View-points

\begin{tabular}{|c|c|}
\hline $\mathbf{Q}$ & ENGOs Interview Responses Classified under Topics A, B and C \\
\hline 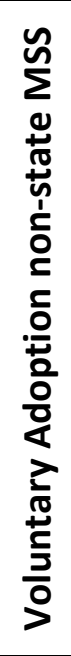 & $\begin{array}{l}\text { - "Municipalities need to enforce international management systems, and the } \\
\text { province needs to act as a leader. Wastewater is not regulated and managed in an } \\
\text { effective way right now" NG24 } \\
\text { - "The voluntary adoption of ISO 14001, or any other EMS for that matter, could be of } \\
\text { assistance for sure, but not a replacement of regulations" NG23 } \\
\text { - "It is hard to regulate/mandate a continual improvement process. This is more of a } \\
\text { cultural change, [for] which typically management standards are effective" NG23 } \\
\text { "The political question becomes whether a wastewater management standard } \\
\text { - "Phould be optional. If it remains optional, then it takes a back seat" NG23 } \\
\text { officials and the public. The ISO certification has resonance and it should help" NG22 }\end{array}$ \\
\hline & $\begin{array}{l}\text { - "If minimum wastewater regulatory requirements were addressed and identified, } \\
\text { then this will lead to intelligent standards, which will be able to be reviewed over } \\
\text { time" NG23 } \\
\text { "A big gap is the enforcement of the law by federal and provincial governments" } \\
\text { NG24 } \\
\text { "[if there was] generic minimum criteria for wastewater [....] we can advise on how } \\
\text { municipalities are meeting the minimum requirements" NG23 } \\
\text { "the current regulatory framework [for wastewater] continues to be a barrier for } \\
\text { promoting innovation and new clean water technologies. The province needs to } \\
\text { support risk-based and holistic approaches. Having an EMS in place will help } \\
\text { municipalities to ensure they are balancing such risks" NG22 } \\
\text { "If the province is promoting risk-based approaches, we need management tools for } \\
\text { checks and balances such as MSS" NG21 } \\
\text { "smaller municipalities are at the mercy of what the province is going to do for them } \\
\text { [....] example: make it scalable, not so comprehensive for small municipalities [....] it } \\
\text { is like a treatment process: smaller municipalities prefer lagoon systems rather than } \\
\text { mechanical plants" NG21 }\end{array}$ \\
\hline
\end{tabular}




\begin{tabular}{|c|c|}
\hline & $\begin{array}{l}\text { - "civil society cares about environmental outcomes, although they may not care 'how' } \\
\text { [....] Having a sector-specific standard is OK, but a conversation is needed to } \\
\text { understand its value against competing interests. Making it mandatory without this } \\
\text { conversation might be risky" NG22 } \\
\text { - "Smaller municipalities have challenges in dealing with collection and haulage of } \\
\text { septage, its treatment and/or disposal [....] Small municipalities need the capital to } \\
\text { support haulage to proper treatment and disposal" NG24 } \\
\text { - "the stormwater management fees [....] [are] the correct approach for municipalities } \\
\text { to obtain funding to deal with SWM [....] [provincial guidelines such as] the sewer } \\
\text { bylaw approach can help smaller municipalities" NG24 } \\
\text { "[the province] has to provide subsidies for green infrastructure, such as SWM } \\
\text { retention practices. This is not as expensive and it is easy to implement" NG23 } \\
\text { "There should be a more concerted effort by feds, province, and municipalities to } \\
\text { enforce water protection and fisheries legislation" NG23 } \\
\text { "The province needs to articulate how they can achieve those [MSS] goals and } \\
\text { objectives. Is that the only solution? If the goal is to reduce sewer system overflows } \\
\text { or sewer bypass, then they need a multi-barrier approach [....] The cumulative effect } \\
\text { of such multi-barrier approach should reduce or eliminate sewers overflows" NG24 } \\
\text { "there are bi-national [i.e. Canada-USA] implications. [....] If we are going to manage } \\
\text { Lake Erie we need to standardize management approaches, so we can quantify and } \\
\text { document how we are doing" NG21 } \\
\text { to have some latitude to comply with it" NG } 21\end{array}$ \\
\hline
\end{tabular}

In general, all ENGO representatives found common ground in affirming that MSSs are very useful for top management as they provide a sort of peer review through audits, monitoring, and other protocols. It was noted that typically, standards require objectives and processes, and their effectiveness depends on how ambitious those objectives and processes are.

One specific aspect noted by one ENGO representative was the gap in financial planning for wastewater and stormwater systems. The ENGO representative noted that during the development of the financial regulation [O. Reg. 453/07, for financial plans of municipal drinking water] to address recommendations by Justice O'Connor (2002b), there were arguments for and against, including wastewater as part of the regulation:

[w] relied on the municipal accounting standard, so we didn't have to re-invent the wheel. The inclusion of wastewater on this regulation had widespread support, sound 
basis and it had a strong consensus, but in the end the arguments to leave it as a BMP [best management practice] prevailed. So, we ended up with the financial plan requirements only for drinking water, and it was a BMP for wastewater (NG24).

Moreover, as noted by Abouchar et al. (2010: 8), and by the OSWCA ${ }^{84}$ (2016), even with O. Reg. 453/07, financial plans for drinking water licensing (containing details on financial position, operations, cash receipts, and a consideration of financial impacts for a period of at least six years), would not require a full cost recovery model and as a result do not provide clear detail on system sustainability, which continues to be a gap for both drinking water and wastewater. Referring to the Walkerton Inquiry (O'Connor, 2002), Abouchar et al. observe:

[j] ustice O'Connor recognized that full cost accounting and full cost recovery were key components to ensuring the sustainability of water and wastewater systems, and that financial plans should be prepared based on these components [....] The Provincial government's role would be to set standards for full cost recovery and to determine the degree to which the government would review and approve these plans (2010: 8).

Although there are mandatory requirements for municipal accounting derived from standards and guidelines from the Public Sector Accounting Board (PSAB) of the Canadian Institute of Chartered Accountants (CICA), they do not address details of water utilities and their financial sustainability. This is in large part accomplished on a voluntary basis by municipalities in accordance with PSAB guidelines and standards (MMA, 2016).

\subsection{Synthesis and Preliminary Conclusions of Chapter}

The interview questions were designed to obtain a broad range of perspectives about the role of MSS in the water, wastewater and stormwater sectors, drawing on the 10 years of provincialmunicipal experience with the DWQMS in drinking water, and similar experiences of a handful of municipalities that have voluntarily adopted additional standards such as ISO 14001, ISO 9001, HACCP and the OHSA (CSA Z-1000).

${ }^{84}$ Ontario Sewer and Watermain Construction Association, [Online]: https://www.oswca.org/ [29 Mar 2019] 
In addressing the research sub-question No. 3: are management system standards likely to have neutral, positive, or negative effects on the performance of Ontario municipal water management activity?

Having a risk-based management approach similar to that for drinking water using a management system standard, resonated with many respondents. This would mean that while the province is advancing with some policies to allow for a holistic and risk-based management approach to wastewater and stormwater (downloading responsibilities to municipalities), the operational risks are not balanced in a similar way to the approach taken to drinking water with the DWQMS. Four important elements were identified by respondents as needed to balance this risk-management approach (and to download it to municipalities):

1. a provincial wastewater and stormwater design criteria with minimum requirements;

2. a pre-identified set of critical control points to address technical risks and hazards;

3. a financial full cost recovery model in accordance with PSAB guidelines and standards (or at a minimum the more relaxed requirements under O. Reg. 453/07); and

4. a sector-specific MSS for wastewater and stormwater.

The qualitative analysis of the interviews revealed that the majority of respondents identified the MSS as an enabler for risk-based management approaches to water, wastewater and stormwater. Specifically, the interview respondents highlighted the following objectives in favour of MSS:

- to reduce the likelihood of potential environmental violations;

- to improve compliance and accountability;

- to align with the risk-based approaches of the post-Walkerton drinking water regulations; and

- to complement the regular (and less frequent) MECP inspections with independent ( $3^{\text {rd }}$ party) inspections and audits.

In terms of perceptions of MSSs having neutral, positive or negative effects on municipal water systems, $\mathbf{9 6 \%}$ of respondents (24/25) concluded that implementing an EMS would have positive effects for the municipal water sectors. 
A total of 304 responses discussed enabling aspects of MSSs for the water sectors, and 119 identified barriers to adopting MSSs. This means that nearly three quarters of respondent arguments supported the adoption of MSSs for wastewater and stormwater systems. One of the most popular discussions concerned the need to have a similar risk-based approach for wastewater and stormwater aligned to the existing drinking water regulatory framework. This idea suggests the consistent perception towards a policy convergence occurring in the adoption of MSSs in municipal water sectors, as part of a risk-based approach to wastewater and stormwater management.

In addressing the research sub-question No. 4: which MSS standards relevant to the water sectors (ISO 9001 -QMS, ISO 14001 - EMS and HACCP) are best suited to address municipal water, wastewater and stormwater activity?

There was widespread agreement among respondents that the ISO 9001 was the correct standard on which to base the DWQMS, as it was the best fit for the drinking water system, but that securing ISO 9001 certification for drinking water in addition to implementing the DWQMS would be redundant as DWQMS already addresses water quality controls. There was recognition however that the investigative, continual improvement, and audit aspects of the DWQMS were weak, and that any ISO-type of MSS would address those items more effectively. There was also widespread agreement among respondents that ISO 14001 would work well as a management system for the wastewater and stormwater sectors.

The new DWQMS (September 2017) publication addressed two regulatory gaps identified in the research undertaken for this dissertation: namely (1) the value of including a continual improvement process for the DWQMS; and (2) a documented investigative process for corrective actions (e.g. root cause analysis). However, at the present time there is no equivalent incorporation of any MSSs with respect to the municipal wastewater and stormwater sectors.

The value of having more than just provincial inspections/audits to foster compliance was noted, such as those provided through third-party MSS certification:

[....] having the one- or two-day provincial inspection every two or three years is not enough for our systems; we need the more frequent annual internal and external inspections required by ISO 14001 (interview respondent, M-6). 
$80 \%$ of respondents identified the CSA Group and ISO as organizations well suited for the development of quality and environmental MSS for the drinking water, wastewater and stormwater sectors. Not all respondents were aware that the CSA Group was a partner organization with the MECP in the development of the initial DWQMS along with a handful of municipalities that carried out pilot testing.

The central research question was around the value in creating a provincially mandated municipal wastewater environmental management system standard, and a stormwater environmental management system standard.

The interview respondents clearly acknowledged the value of EMS for reducing the likelihood of environmental violations, enhancing compliance and improving due diligence and accountability for water systems. MSSs are perceived as having a positive impact on the management of water/wastewater/stormwater systems as they serve as a catalyst for continual improvement, innovation, compliance, conformance and better communication with stakeholders, elected officials, and the public. At the same time MSSs are challenging for smaller municipalities, whether they are voluntary or mandatory standards, as their implementation is resource intensive. Respondents from large municipalities were supportive of voluntarily adopting EMS in anticipation of future regulatory requirements, whereas it was suggested that there would be reluctance by small municipalities to increase their costs by implementing a voluntary EMS with no direct provincial regulatory guidance. Based on the interview responses, ISO standards are perceived by many smaller organizations as onerous, and there was a clear preference among smaller municipalities to wait for a sector-specific standard made in Ontario with some built-in flexibility that would allow smaller and rural municipalities to implement it more effectively.

Based on the results of the interviews, there appears to be considerable support for the provincial regulator to adopt risk-based management approaches to wastewater and stormwater management, that align with recent provincial regulatory activity such as the DWQMS (2006), the Open for Business Act (2010), EASR regulations (2012), area-wide ECAs (since 2013), and the York Region self-inspection pilot (York Region, 2015). A perceived move 
toward downloading provincial regulatory environmental responsibilities to municipalities (e.g. pre-authorization of low-risk wastewater and stormwater activities, reduced provincial inspections) seems to have been offset by certain medium to large municipalities voluntarily and proactively adopting or moving toward adopting non-state MSSs or elements thereof for their wastewater and stormwater systems.

Contrary positions taken by some respondents included:

- the uncertainty of provincial regulations (e.g. one interview respondent asked: "why bother to adopt standards if the province will come up with something really different down the road?");

- the need for sector-specific standards (i.e. ISO standards are perceived as onerous, so there is a preference to have a sector-specific standard developed in Ontario that all municipalities, large and small, could adopt);

- the amount of resources needed to develop, implement, and maintain any MSS;

- the lack of leadership, as the MECP needs to see the benefit and take the lead (i.e. it is hard for small municipalities to take on such an undertaking due to competing priorities and their limited resources); and

- Municipal Council approval for non-essential costs (i.e. management standards "are perceived as the cost of doing business, with minimum tangible benefits").

Most respondents were positively disposed towards having a mandatory wastewater and/or stormwater sector-specific standard based on ISO 14001 . Only 10\% identified a preference for having a voluntary standard (status quo). The ENGO respondents all supported the adoption of a multi-barrier approach in some form. It is worth noting that no other class-type of respondent identified specific requirements (apart from a sector-specific MSS for wastewater) for developing a multi-barrier approach; however, about $50 \%$ of municipal respondents come from municipalities that have their own sewer design requirements, and do financial planning for water and wastewater with a six year planning horizon (in adherence to O. Reg. 453/07 for drinking water systems). Only the very large municipalities have design criteria requirements and financial planning for stormwater infrastructure. 
A specific question posed was whether interview respondents preferred a voluntary or mandated requirement for a sector-specific standard for wastewater and stormwater. The following options, drawn from the interview responses, merit further study:

1. A provincially-endorsed, voluntary EMS standard. This involves developing a new sector-specific, provincially-endorsed MSS (voluntary). This standard could be based on a customized version of ISO 14001, DWQMS and other standards.

2. Mandated ISO 14001. This involves a provincial requirement to implement an EMS based on ISO 14001.

Fundamental to both options is the central role municipalities are playing in the governance of water management (Figure 1 and Figure 11), applying a sustainable governance approach to address current perceived regulatory gaps, system needs for consistent approaches, and the challenges of uncertainty due to changes to provincial regulations, population growth, urbanization, aging infrastructure and an aging workforce.

The Municipal Water Wastewater Regulatory Committee (MWWRC) could play an important role in securing widespread adoption of EMS by municipalities: the MWWRC is a voluntary, municipally-driven network of professionals that originally enabled the implementation of the DWQMS, and more recently facilitated a centre for sharing information, experiences, and procedural aspects on how to implement the BMPs that the wastewater and stormwater sectors are increasingly adopting.

Furthermore, the interviews conducted for this dissertation contain clear manifestations of sustainable governance as defined by Webb (2005), involving state and non-state actors, rule instruments, and policy learning networks (e.g. references to the NWWRC, industry associations, CSA \& ISO standards, ENGOs and court cases). These manifestations support previous findings that support the argument that policy convergence and policy learning are occurring simultaneously through network forums, information sharing, and government action in migrating policies and policy approaches from the drinking water sector to the wastewater and stormwater sectors, and from the non-state sector to the government sector. 


\subsection{CASE STUDIES - ANALYSIS AND RESULTS}

\subsection{York Region}

York Region is an upper-tier municipality located in the GTA, north of Toronto (Figure 8Figure 19), with a population in 2016 of $1,176,000 .{ }^{85}$ It encompasses nine lower-tier municipalities: ${ }^{86}$ the City of Richmond Hill, Town of Aurora, Town of East Gwillimbury, Town of Georgina, Township of King, City of Markham, Town of Newmarket, City of Vaughan, and Town of Whitchurch-Stouffville.

York Region was created in 1971 under Bill 102, An Act to Establish the Regional Municipality of York. The Act included the formation of the nine area municipalities. Municipal services are provided by both York Region and the lower tier municipalities. York Region owns and operates the bulk water supply for all nine lower-tier municipalities. The lower-tier entities own and operate the local distribution system to deliver the water to their users and are also responsible for water metering and water billing to individual residents.

The wastewater trunk system is owned and operated by York, while the local sewer system is owned and operated by the lower-tier municipality. Wastewater generated in York Region is conveyed through the York Durham Sewage System, a trunk system that conveys all wastewater from the Southern area municipalities in York Region to the Duffin Creek Water Pollution Control Plant (WPCP) for treatment and final discharge to Lake Ontario. The Duffin Creek WPCP, located in Pickering and discharging its treated wastewater to Lake Ontario, is jointly owned and operated by York and Durham. ${ }^{87}$ Moreover, portions of the wastewater collected to the east of York Region is delivered to wastewater treatment plants owned by neighbouring municipalities: Toronto and Peel Region. There are other wastewater treatment plants that are locally operated by other lower-tier municipalities. York Region also owns the

\footnotetext{
${ }^{85}$ Key Findings and Directions Report, Town of Richmond Hill Economic Development Strategy Update, November 7, 2016, [Online]: www.richmondhill.ca/en/resources/Landing-Pages/Economic-Development/Key-Findings-andDirections-Report---Nov-8.pdf [20 Jan 2017]

${ }^{86}$ An upper tier municipality provides regional services such as drinking water, wastewater, solid waste collection, transit systems, regional roads, public safety (police), housing, paramedics, among other services, while lower tier municipalities typically provide local services to their residents such as stormwater management, local roads, community centres, water distribution, local sewers, parks and recreation, among others.

${ }^{87}$ Richmond Hill -Water Services, water and wastewater [Online]: www.richmondhill.ca/en/our-services/WaterServices.aspx? mid =628 [20 Jan 2017]
} 
storm drainage infrastructure for highways and major regional roads, which accounts for about $5 \%$ of the stormwater infrastructure in the area (interview respondent $M-6)$, and the remaining stormwater infrastructure is owned by the lower tier municipalities.

After the Walkerton tragedy in 2000, York Region voluntarily accredited its wastewater system to ISO 14001, and in 2001 adopted ISO 9001 for its drinking water system (Table 18). As noted by a Regional official, "[t]he main drivers were:

- to address the upcoming Walkerton Inquiry Report recommendations;

- to anticipate new regulatory requirements; and

- to mitigate liabilities from potential future environmental violations" (interview respondent, M-6).

Table 18. York Region and Richmond Hill - Management System Standards

\begin{tabular}{|c|c|c|c|c|}
\hline \multicolumn{2}{|r|}{ System Component } & DWQMS & ISO 9001 & ISO 14001 \\
\hline \multirow{4}{*}{ 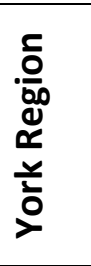 } & Water supply system & $\checkmark$ & $\checkmark$ & \\
\hline & $\begin{array}{l}\text { Wastewater trunk sewer system } \\
\text { (facilities + PM) }\end{array}$ & & & $\checkmark$ \\
\hline & Duffin Creek WPCP & & & $\checkmark$ \\
\hline & Stormwater system ( 10\%) & & & \\
\hline \multirow{4}{*}{ 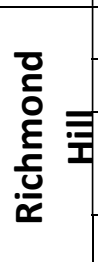 } & Water distribution system & $\checkmark$ & & $\checkmark$ \\
\hline & Wastewater collection-facilities & & & $\checkmark$ \\
\hline & $\begin{array}{l}\text { Wastewater collection- preventative } \\
\text { maintenance }\end{array}$ & & & \\
\hline & Stormwater system ( 90\%) & & & $\checkmark$ \\
\hline
\end{tabular}

York Region's ISO 14001 includes all wastewater facilities and its preventative maintenance programs. Preventative maintenance involves: sewer system inspections, pipe flushing, manhole inspections and sewer repairs. Table 18 shows the scope of the management standards for York and Richmond Hill's water, wastewater and stormwater systems.

In a 2015 staff report to York Region Council, the section referencing the IMS update for Water, Wastewater and Waste Management, stated:

[b]y voluntarily adopting an Environmental Management System for wastewater operations [....] [t]his standard helps York Region minimize operational impacts on the environment, comply with applicable laws, regulations and other environmental 
requirements, while continually improving environmental management (York Region, 2015: 1-2).

After the publication of the provincial DWQMS guidelines (2006), York Regional Council authorized implementation of a single Integrated Management System (IMS) Policy in 2009. In 2010, the existing ISO 14001 (EMS) certification was expanded to include waste management operations. The scope of the EMS was expanded again in 2014 to include the sewer use bylaw unit (Table 19).

According to information on its website, York Region is "committed to achieving ISO 9001 and ISO 14001 standards." ISO 9001 is maintained for water facilities, and ISO 14001 for wastewater and waste management facilities, to demonstrate "its commitment to provide safe water, wastewater and waste management services." 88

After the Open for Business Act (2010), York Region and many other municipalities also adopted the Environmental Activity and Sector Registry (EASR) (i.e. the permit-by-rule process for self-registration) for stand-by power equipment at their water and wastewater facilities. In 2016, York Region partnered with the MECP in a pilot project for "self-inspections" for low-risk activities. This project involved self-inspections of drinking water systems based on the principles of Behavioural Insights. ${ }^{89}$ According to interviews conducted for this case study, the pilot project results (Khemai, 2016) were looked upon favourably by York Region officials, with a preference for relying on third party audits to maintain checks and balances for accountability and reducing the risk of liability.

In a 2015 evaluation of the York Region MSS conducted by independent consultants, it was recommended not to pursue ISO 9001 for wastewater systems since additional risk mitigation would not warrant the effort of implementing ISO 9001 for wastewater systems (Spitzig, 2016). However, ISO 9001 was recommended to be maintained for drinking water and expand it for solid waste management. This was despite the perceived duplication between the DWQMS and ISO 9001 for drinking water. Therefore, the following decisions were made:

\footnotetext{
${ }^{88}$ York Region -Environment / Water and Wastewater [Online]: www.york.ca/wps/portal/yorkhome/environment/yr/waterandwastewater/ [20 Jan 2017]

${ }^{89}$ Behavioural Insights is a school of thought in behavioral science developed in the UK to support self-governance of public and private entities (Halpern, 2015), [Online]: www.ontario.ca/page/behavioural-insights-pilot-projectlicense-plate-sticker-renewal [29 Mar 2017]
} 
1. to maintain ISO 9001 for drinking water;

2. to expand ISO 9001 for solid waste management;

3. not to expand ISO 9001 for wastewater;

4. to maintain ISO 14001 for wastewater and waste management; and

5. not to expand ISO 14001 for drinking water.

The report also identified evidence that the use of management standards was proving to be of value to the municipality, including the ability to document operational procedures and investigate root causes in order to address non-conformities (Spitzig, 2016: 8-11):

- there was a $32 \%$ reduction in the average time taken to close non-conformities in 2015 (this is a year-over-year improvement in tracking non-conformities, a process inherent to ISO 9001 and ISO 14001).

- 16 root cause analysis (RCA) workshops were conducted by the municipality to improve practices with 74 findings (the RCA is a popular management tool and part of the investigative requirements of ISO 9001 and ISO 14001).

- 269 document change requests to strengthen procedural documentation (having an MSS makes this a systematic process to close non-conformities resulting from RCA workshops, and record such documentation for audits. As noted by an interview respondent: "[s]trengthening procedural documentation occurs on systems without an MSSs, but it is not systematic and it is not tracked, it normally occurs by priorities, and since there are no audits, there is no need to document root cause analyses or non-conformities," M14).

The study noted that 108 regular internal inspections were completed by municipal staff in 2015, which found 30 non-conformities; 52 internal compliance audits that found 10 nonconformities; and two external audits completed by third parties to confirm registration and accreditation, which identified seven non-conformities (Spitzig, 2016). The number of regular internal inspections and internal and external compliance audits are about the same every year (interview respondent M-6). From these RCA findings, 70 corrective actions addressed problems that otherwise could have become potential compliance issues; these findings would likely not have been made without an MSS in place (interview respondent M-6). 
Table 19. Chronology for York Region

\begin{tabular}{|l|l|}
\hline Year & \multicolumn{1}{|c|}{ Chronology of Events } \\
\hline 2000 & Walkerton tragedy \\
\cline { 2 - 3 } & York Region adopts ISO 14001 for wastewater system \\
\hline 2001 & York Region adopts ISO 9001 for water operations \\
\hline 2002 & Walkerton Inquiry report \\
\hline 2006 & MECP publishes DWQMS in October \\
\hline 2007 & O. Reg. 188/07 - Phased Compliance with DWQMS \\
\hline 2009 & Compliance with DWQMS for water operations \\
\hline 2010 & ISO 14001 certification of waste management depot operations \\
\hline 2014 & ISO 14001 is expanded to include sewer use bylaw operations \\
\hline \multirow{2}{*}{2015} & $\begin{array}{l}\text { Independent report recommends maintaining: ISO 9001 for drinking water, but not } \\
\text { expanding it to wastewater and solid waste; and maintaining ISO 14001 for } \\
\text { Wastewater and expanding it to solid waste management. }\end{array}$ \\
\cline { 2 - 3 } & MECP announces DWQMS updates, open for public comment \\
\hline 2016 & MECP-York Region pilot self-inspection project (for low risk activities) \\
\hline 2017 & MECP publishes Version 2.0 of DWQMS on February 2017 \\
\hline
\end{tabular}

One interview respondent who works for the municipality stated that "[w]e see value in maintaining [....] duplication [of QMS and DWQMS for drinking water] because of the complementarity of the investigative function of the ISO 9001, and the value of frequency of internal and external inspections" (interview respondent M-7). This suggests recognition of the value of different types of MSSs being used by municipalities for their water systems, depending on whether a citizen-based, water quality objective or an ecosystem-based environmental objective was the focal point of concern.

MECP Inspection Ratings for York Region drinking water systems are consistently very high as documented in the Chief Drinking Water Inspector Annual Reports for 2013-2015. Ratings for $2015-2016$ are $100 \%$. The percentage of test results that met the standard was $99.66 \%$ for 2014-2015 (MECP, 2015, 2016). There is no provincial report for municipal wastewater or stormwater systems. 


\subsection{Richmond Hill}

The City of Richmond Hill is located in the GTA and is a lower-tier municipality within York Region (Figure 19). It is the third most populous of the nine municipalities in York Region, with an estimated population of 195,000 in 2016. Richmond Hill was created in 1971 under Bill 102, An Act to Establish the Regional Municipality of York, which included the formation of the nine area municipalities. Known as the Town of Richmond Hill, it became a "City" by Council approval in March 2019.90

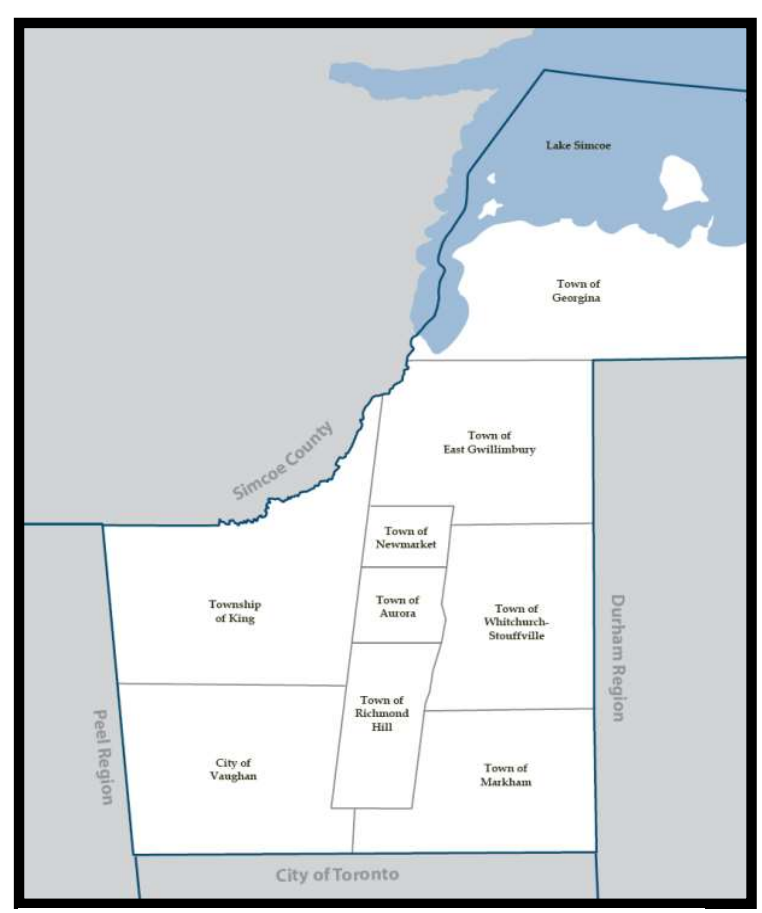

Figure 19. York Region and Richmond Hill Location

Richmond Hill delivers municipal drinking water services and is also responsible for water metering to individual residents, and water billing. Richmond Hill's drinking water system is a hybrid that involves components of the system owned by four municipalities: Richmond Hill owns the distribution system; York Region owns and operates the bulk supply for Richmond Hill; the City of Toronto and Peel Region own and operate their water taking from Lake Ontario and treatment (Richmond Hill, 2016a: 23).

Richmond Hill is responsible for the wastewater collection system, which includes all local sewers and six sewage pumping stations up to its delivery to the York Durham Sewage System, and to the Toronto and Peel Region collection system. The York Durham Sewage System is a trunk sewer that conveys all wastewater from the Southern area municipalities in York Region to the Duffin Creek WPCP for treatment and final discharge to Lake Ontario. The Richmond Hill stormwater management (SWM) system involves the operation of more than 70 stormwater ponds, 620 kilometers of storm sewers, 17,000 catch basins and an increasing number of green infrastructure primarily formed by Low Impact Development (LID) or lot-level

\footnotetext{
${ }^{90}$ City of Richmond Hill announcement March 26, 2019 [Online]: www.richmondhill.ca/Modules/News/index.aspx?feedld=5988c08a-c0f5-4d51-91e09691f68738f4\&newsld=f3bad5ae-0601-4bc0-9d2b-48aee687489f [1 Jun 2019]
} 
controls (e.g. green roofs, infiltration swales, exfiltration systems, underground parking lot storage, etc.). The stormwater infrastructure is meant to manage storm runoff to prevent flooding and erosion and improve the water quality of streams and rivers in order to protect aquatic habitat.

According to the research undertaken for this case study, the two main drivers for Richmond Hill to adopt ISO 9001 and ISO 14001 were:

1. the Walkerton tragedy (2000) and Inquiry (2002); and

2. the leadership shown by York Region officials in deciding to adopt the ISO standards (2000) prior to the completion of the Inquiry.

Table 20. Chronology for Richmond Hill EMS

\begin{tabular}{|c|c|}
\hline Year & Chronology of Events \\
\hline 2000 & Walkerton tragedy \\
\hline 2001 & York Region adopts ISO 14001 for Wastewater system \\
\hline \multirow[t]{2}{*}{2002} & Walkerton Inquiry report \\
\hline & RH commences development \& design of ISO 14001 \\
\hline \multirow[b]{2}{*}{2006} & MECP publishes DWQMS in October 2006 \\
\hline & RH Obtains ISO 14001 for W/WW (1 ${ }^{\text {st }}$ in ON to cover multiple departments) \\
\hline 2007 & O. Reg. 188/07 - Phased Compliance with DWQMS \\
\hline 2009 & Compliance with DWQMS for water operations \\
\hline 2010 & $\begin{array}{l}\text { Due to re-organization, EMS expanded to include Env. Services (Waste, stormwater), but } \\
\text { excludes: finance and planning, in what is "more of a practical decision rather than } \\
\text { reduced value". Maintained for areas with potential for greatest environmental impact }\end{array}$ \\
\hline 2013 & Fire and Emergency Departments added to the scope of ISO 14001 \\
\hline 2014 & EMS scope expansion multi-year plan; 2014 includes Parks Operations \\
\hline 2015 & MECP announces DWQMS updates, open for public comment \\
\hline 2016 & EMS scope is expanded to include Recreation and Culture \\
\hline
\end{tabular}

In 2006, after a two-year development process, Richmond Hill obtained ISO 14001 certification for its water and wastewater departments (interview respondent M-2). In the same year, Richmond Hill reported that it "[b]ecame the first municipality in Ontario to have 
multiple departments registered to the ISO 14001." ${ }^{91}$ Fire and Emergency Services were added to the scope of the ISO 14001 in 2013. Its website also notes that Richmond Hill was "[t]he first [municipality] in the province to register Fire and Emergency Services to the ISO 14001 Standard. Our EMS shows that Richmond Hill is a leader in corporate environmental management and sustainability."92

After an internal re-organization, the EMS was expanded in 2010 to include stormwater and waste management. This expansion of the scope of the ISO 14001 included an evaluation of a multi-department approach in a multi-year plan. The final plan excluded the departments of finance and planning as "more of a practical decision rather than to reduce value" (interview respondent, M-3). The ISO 14001 certification dated October 2015 includes the following nine departments: Water and Wastewater, Stormwater and Roads, Parks, Solid Waste Management, Fire and Emergency, Buildings and Fleet Management, Capital Works, Development and Transportation, and Engineering and Infrastructure (NSF, 2015). In a 2016 staff report to Council, Richmond Hill staff observed that "among Canadian municipalities with an EMS, only Calgary and Edmonton had EMS scopes comparable or larger than Richmond Hill" (Richmond Hill, 2016b: 25).

Richmond Hill does not have ISO 9001 for any of its facilities. As stated in its DWQMS Operational Plan, the DWQMS is defined as "a provincially developed management standard based on ISO 9001 and HACCP standards. It was created in response to the Walkerton Report's recommendations for quality management in municipal drinking water systems, and was first released in 2006" (Richmond Hill, 2016a: 16). As noted by an interview respondent who works for the City of Richmond Hill: "ISO 9001 is a duplication if you have the DWQMS" (interview respondent M-4). The DWQMS is audited by a third party annually, and while the ISO 14001 standard is externally audited every three years (interview respondent M-5).

The scope of the Richmond Hill ISO 14001 wastewater system covers wastewater collection system facilities such as pumping stations, valve chambers, and overflow structures, as well as responses to spills and overflows (interview respondent M-5). Preventative maintenance (PM)

\footnotetext{
${ }^{91}$ Richmond Hill -Environmental Management System, [Online]: www.richmondhill.ca/en/find-or-learnabout/Environmental-Management-System.aspx [20 Jan 2017]

${ }^{92}$ See Footnote No. 91
} 
activities are not part of the scope of ISO 14001 (PM activities include system inspections, sewer CCTV, ${ }^{93}$ flushing, manhole inspections and repairs). This is in contrast with the scope of ISO 14001 for York Region, which includes PM as part of the EMS program. As noted by a Richmond Hill interview respondent: "[b]y focusing on the response to spills and overflows, it makes implementation of the standard easier" (interview respondent M-5). Richmond Hill's EMS Policy complies with the ISO 14001 standard with the following commitments:

[t]he Town commits to pollution prevention and continual improvement through our EMS, together with our Environmental Strategy, Greening the Hill: Our Community Our Future. The Town further commits to act in good faith in complying with all applicable legal and other requirements to which our organization subscribes (Richmond Hill, 2016b).

In interviews conducted for this case study, Richmond Hill officials noted that management systems such as the EMS are easier to implement when there is a mandatory requirement, and they are in favour of MSS:

[....] it allows the resources to be approved without too much questioning by the elected officials, like when the Ontario One Call regulation was implemented [for locating buried infrastructure] (interview respondent M-2).

[....] examples such as mandatory self-inspections, such as those required by the DWQMS, help to apply corrective actions a lot quicker, and make you build a system of checks and balances (interview respondent $\mathrm{M}-3$ ).

According to interviews with Richmond Hill officials conducted for this dissertation, the Rumble Pond Stormwater project, won the 2014 Project of the Year Award from the Ontario Public Works Association (OPWA) in the Environment category for its excellent project management and partnerships. ${ }^{94}$ This was partly because of the expansion of its EMS to include SWM in 2010 (interview respondent $\mathrm{M}-3$ ).

Distinctive aspects of the Richmond Hill case include the expansion of the scope of ISO 14001 in 2010, the recognition by its officials of practicalities in implementation in certain areas

\footnotetext{
${ }^{93}$ CCTV in wastewater refers to Closed-Circuit Television in the form of camera inspection by robots travelling through sewers.

${ }^{94}$ Richmond Hill -Stormwater Management [Online]: www.richmondhill.ca/en/our-services/StormwaterManagement.aspx [20 Jan 2017]
} 
(excluding finance and planning) in 2010, recognition of the duplication between DWQMS and QMS for drinking water systems, the policy learning Richmond Hill officials gained from their upper-tier partner (York Region in adopting the ISO 14001 in 2000), and the fact that the focus of Richmond Hill's EMS is on facilities and emergencies (i.e. spills and overflows) rather than operations. This suggests (as in the case of York Region) a recognition of the value of different types of MSSs being used by municipalities for their water systems, depending on what their human health or environmental objectives are.

MECP Inspection Ratings for Richmond Hill drinking water systems are consistently among the highest in the Chief Drinking Water Inspector Annual Reports for 2013-2015. Ratings for 2015-2016 are $100 \%$. The percentage of test results that met the standard was $99.66 \%$ for 2014-2015 (MECP, 2015, 2016). There is no provincial report for municipal wastewater or stormwater systems. Richmond Hill has several dozen EASR registrations for its water, wastewater and stormwater systems for stand-by power equipment in pumping facilities.

\subsection{Durham Region}

Durham Region is located in the GTA, on the upper shores of Lake Ontario to the east of Toronto (Figure 8). It is an upper tier regional municipality providing services to eight lower-tier cities and towns: Ajax, Brock, Clarington, Oshawa, Pickering, Scugog, Uxbridge, and Whitby. The 2016 estimated population was 663,000 residents. ${ }^{95}$

Durham Region was created in 1974 under The Regional Municipality of Durham Act (1973). The Act provided for the formation of eight area cities and towns by the annexation and amalgamation of 21 local municipalities. Durham Region provides all water services except for stormwater management, which is provided by individual cities and towns. The water services provided by the Region include water supply and distribution, wastewater collection and treatment, and biosolids management. The water and wastewater systems are owned and operated by Durham Region. Durham Region also provides waste management, roads and transportation services. Other services provided by the Region include police and paramedics. The lower-tier municipalities do not provide any water or wastewater services to their

\footnotetext{
${ }^{95}$ Durham Region. Commissioner of Planning and Economic Development Report. Monitoring Growth Trends, [Online]: www.durham.ca/departments/planed/planning/stats-n-facts/2016-INFO-33.pdf [30 Dec 2016]
} 
communities, only stormwater services. The lower-tier municipalities have not adopted any ISO standard for any drinking water or wastewater systems; however, Ajax has adopted ISO 9001 for its engineering department (interview respondent $\mathrm{M}-10$ ).

The Region of Durham's drinking water system includes nine well systems, six water treatment plants, and a number of reservoirs, towers and pumping stations, including a drinking water distribution system. The wastewater system includes 11 wastewater treatment plants, 57 pumping stations, one odour control facility, and a large network of sewer pipes.

In the wastewater sector, of particular interest is the Duffin Creek WPCP. This treatment facility is part of the York-Durham Sewage System and services approximately $90 \%$ of the population of York Region, as well as the sewage from Pickering and Ajax. The Duffin Creek WPCP is located in the City of Pickering near the shores of Lake Ontario. Ownership of this facility was transferred to the Regions in 1997 from the Province of Ontario. Both Regions own and operate the facility and are also responsible for its planning and expansion.

The lower tier municipalities in Durham Region (Ajax, Brock, Clarington, Oshawa, Pickering, Scugog, Uxbridge, and Whitby) do not own or operate water or wastewater facilities. These facilities are operated by Durham Region (interview respondent $\mathrm{M}-10$ ). The Region also owns the storm drainage infrastructure for highways and major regional roads, which accounts for about $10 \%$ of the stormwater infrastructure in the area (interview respondent $M-10$ ), and the remaining stormwater infrastructure is owned by the lower tier municipalities.

Durham Region adopted a combination of the ISO 9001, ISO14001 and HACCP standards in 2006, collectively referred to by Durham Region as the integrated management standard (IMS) (Durham Region, 2009: 2-3). The Region obtained ISO standards and HACCP certifications prior to the enactment in 2007 of O. Reg. 188/07 (requiring certification under the DWQMS). The IMS applies to the Durham Region drinking water system; however, the scope of the IMS for the wastewater system applies only to ISO 14001 (EMS) for the Duffin Creek WPCP. The QMS and HACCP do not apply to Duffin Creek WPCP. Neither Durham Region nor the lower tier municipalities have ISO standards for stormwater management (SWM).

The research undertaken for this case study has identified three significant drivers for Durham Region to adopt ISO 9001, ISO 14001 and HACCP: 
- The political importance and function of the Duffin Creek WPCP, which serves a large population base shared between Durham and York Regions. York Region was an early adopter of ISO 9001 and ISO 14001 in the early 2000's, and there are contractual obligations between the two Regions to maintain ISO 14001 for Duffin Creek WPCP.

- The implications of the Walkerton Inquiry (2002), which included a recommendation to establish a provincially required QMS (O'Connor, 2002b).

- A 2002 Fisheries and Oceans Canada Letter of Advice, pursuant to the Fisheries Act, which stated that Durham Region had to address and eliminate discharges of chlorinated wastewater to Lake Ontario (interview respondent M-10).

Table 21. Durham Region - Integrated Management System (2006-2016)

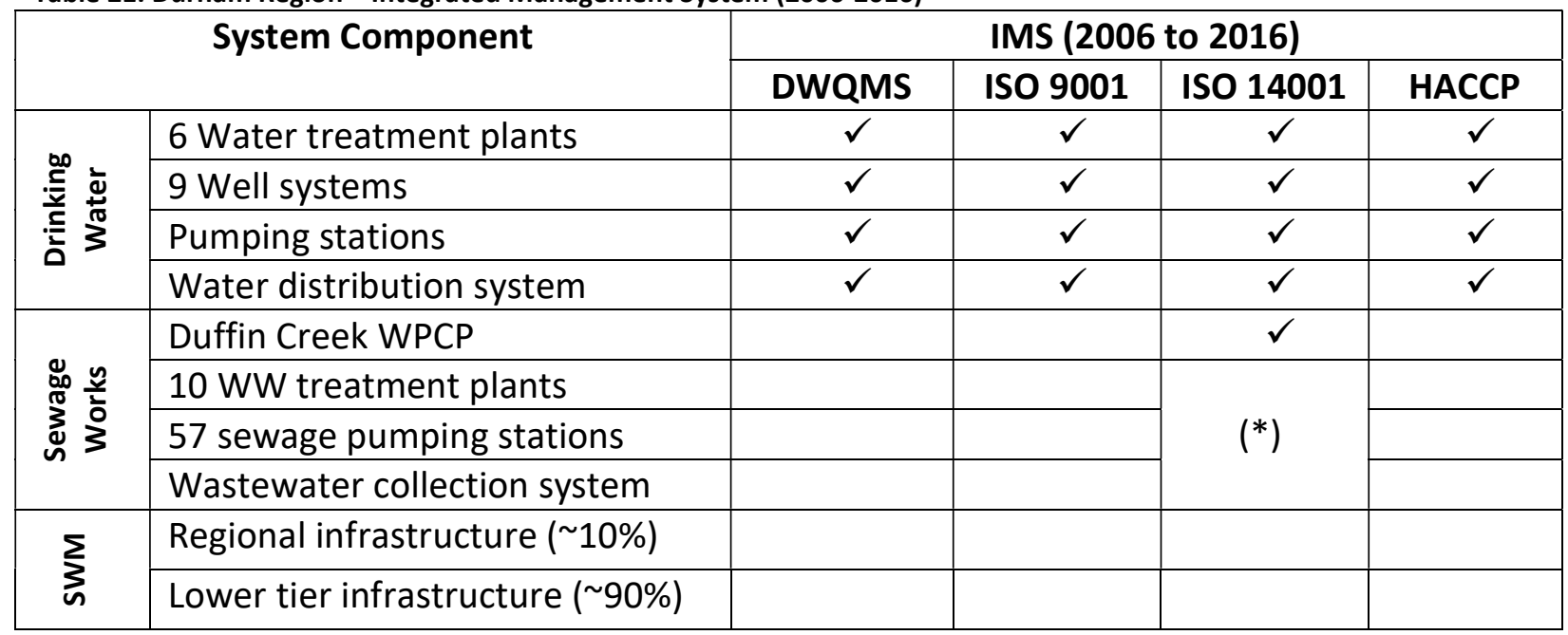

$\left(^{*}\right)$ Since 2014, Durham Region started a process to expand ISO 14001 for all wastewater facilities but has not achieved certification at the time of writing.

Research for this case study also suggests that municipal elected officials in Durham Region played a large role in the decision to adopt voluntary standards (interview respondent M-10). Based on interviews with Durham Region officials, ISO standards are very well known in industrial settings but are not very familiar to most municipal officials. Interview respondents suggested that perhaps because the Durham Region is a location with numerous car manufacturing facilities, an industry in which the application of ISO standards is well known, there was a higher level of familiarity with ISO among local politicians: 
[t]hese standards are here to stay, there is no way [of] going back [....] our municipal councillors from Oshawa, are very familiar with the ISO standards, because of the GM Oshawa plant, which employs close to 3,000 persons (interview respondent M-10).

The Durham Region IMS policy statement is structured around 20 policies, which address everything from the DWQMS and HACCP to ISO 14001 requirements. Policy IMS-01 establishes the following commitments for eligible water and wastewater systems (Durham, 2009):

Durham Region shall establish an Integrated Management System (IMS) that consists of an ISO 14001:2004 compliant environmental management system, and ISO 9001:2008 compliant quality management system, a HACCP compliant system and a Drinking Water Quality Management System compliant system.

[....] [the objective is] to ensure the IMS is established and communicated to the Plant Operations and Maintenance Operations Divisions of the Regional Municipality of Durham and to improve operational and environmental performance.

[w] hile document controls, and other elements have already been implemented, internal audits started in 2016 [....] It is estimated that by 2019 all wastewater systems will be part of Durham Region's IMS (Durham, 2009).

One part of the Durham Region IMS is an Environmental Policy. According to one respondent, this policy "forces you to come up with new ideas, innovation, and improvements" (interview respondent M-11). According to officials interviewed for this dissertation, Durham Region looks favorably on provincial risk-based approaches to wastewater management. This suggests that there is a link between risk taking and the IMS, which can be interpreted as a causal connection between managing risks associated with operating facilities that may pose a risk to the environment and the peace of mind that comes from the checks-and-balances inherent in MSSs. The downloading of provincial approvals to the municipalities for certain environmental equipment and facilities under the provincial EASR regulations (2012) was interpreted by one respondent as a form of risk taking:

[t]he EASR targets proven technologies and it is supported with a regulation, [....] however I would not advocate for self-registrations, since there is great value in having a third party coming to say how the system is operating, and [it] helps to justify training, documentation, and SOPs (interview respondent $\mathrm{M}-10$ ). 
After a 2013 internal assessment of value and benefits conducted by Durham Region, it was decided to abandon the HACCP certification for drinking water systems while maintaining its procedures, in view of the fact that: "year after year we noted no significant benefits in identifying room for improvement, aside of some improvements on the ultra violet (UV) disinfection lamps in case of rupture noted in 2006-2007; we did not find any additional improvements in our drinking water treatment processes" (interview respondent M-10).

With the introduction of the new DWQMS version published in 2017, Durham Region made the decision to drop ISO 9001 and ISO 14001 for all drinking water "because the investigative function and continual improvement [were] now addressed in the new DWQMS" (interview respondent M-10). As part of this 2017 decision, Durham Region confirmed that it would expand ISO 14001 to all wastewater systems (interview respondent M-10). The IMS has thus been reconfigured as shown in Table 22 .

Table 22. Durham Region - Integrated Management System (2017- Onwards)

\begin{tabular}{|c|c|c|c|c|}
\hline \multicolumn{2}{|r|}{ System Component } & \multicolumn{3}{|c|}{ IMS (2017 - onwards) } \\
\hline & & DWQMS & ISO 9001 & ISO 14001 \\
\hline \multirow{4}{*}{ 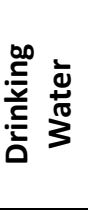 } & 6 Water treatment plants & $\checkmark$ & & \\
\hline & 9 Well systems & $\checkmark$ & & \\
\hline & Pumping stations & $\checkmark$ & & \\
\hline & Water distribution system & $\checkmark$ & & \\
\hline \multirow{5}{*}{ 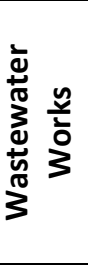 } & Duffin Creek WPCP & & & $\checkmark$ \\
\hline & $10 \mathrm{WW}$ treatment plants & & & $\checkmark$ \\
\hline & 57 sewage pumping stations & & & $\checkmark$ \\
\hline & Wastewater collection system & & & $\checkmark$ \\
\hline & Odour Control facility & & & $\checkmark$ \\
\hline \multirow{2}{*}{$\sum_{n}$} & Regional infrastructure ( 10\%) & & & \\
\hline & Lower tier infrastructure ( 90\%) & & & \\
\hline
\end{tabular}

As one Durham Region representative observed: "we continue not to have [any provincial] inspections [of our] wastewater system. The Ministry of the Environment, Conservation and Parks simply does not have staff to inspect [it]. We have sought out Environment Canada [for their assistance] and they have completed two inspections at our wastewater plants [....] As for drinking water, every single one of our water systems is inspected annually by the MECP as per the regulation" (interview respondent $\mathrm{M}-10$ ). 
Durham Region was a pioneer in the adoption of many of the risk-based approaches launched by the MECP as a result of the Open for Business Act (2010) (Tovilla, Duong and Benkovich, 2014: 2). In 2010, Durham Region's Harmony Creek WPCP became the first wastewater facility in Ontario to obtain an ECA with Limited Operational Flexibility (LOF) for sewage works (Tovilla, Duong and Benkovich, 2014: 2). The LOF allowed for pre-authorization of low-risk construction activities, such as system modifications and expansions, similar to the SDWA drinking water permits (Tovilla, Duong and Benkovich, 2014: 7). In addition, Durham Region has over 100 EASR self-registrations for stand-by power equipment at wastewater facilities (interview respondent $\mathrm{M}-11$ ).

This suggests an appetite among Ontario municipalities for a similar risk-based management approach as that adopted for drinking water systems. An important element of such approach is the MSS, such as the DWQMS for drinking water, which establishes a number of requirements for self-inspections, internal and external audits, and the critical control points (from the HACCP) which address major risk factors for drinking water systems (Table 4). This question will be further analyzed in this dissertation, considering how MSSs can fill these gaps (such as through critical control points) for wastewater and stormwater systems (Chapter 7.3.2).

Table 23. Chronology for Durham Region IMS

\begin{tabular}{|l|l|}
\hline Year & \multicolumn{1}{|c|}{ Chronology of Events } \\
\hline 2000 & DFO Letter of Advice, re: discharge of chlorinated WW to Lake Ontario \\
\cline { 2 - 3 } & Walkerton tragedy \\
\hline 2001 & Durham explores privatization, causing concern in the Union \\
\hline 2002 & Walkerton Inquiry report \\
\hline \multirow{2}{*}{2006} & $\mathbf{1}^{\text {st }}$ municipality in North America with ISO 9001, 14001 \&HACCP) for water operations \\
\cline { 2 - 3 } & MECP publishes DWQMS in October 2006 \\
\cline { 2 - 3 } & ISO 14001 certification of Duffin Creek WPCP \\
\hline 2007 & O. Reg. 188/07 - Phased Compliance with DWQMS \\
\hline 2009 & Compliance with DWQMS for water operations \\
\hline 2010 & Harmony Creek WPCP - 1 ${ }^{\text {st }}$ ECA for WW with pre-approval ( $\approx$ SDWA) \\
\hline 2013 & HACCP certification is dropped \\
\cline { 2 - 2 } & Durham decides to expand the scope of ISO 14001 for all sewage works \\
\hline
\end{tabular}




\begin{tabular}{|l|l|}
\hline 2015 & MECP announces DWQMS updates, open for public comment \\
\hline \multirow{2}{*}{2016} & Plans expansion of ISO 14001 elements to all wastewater facilities (audits) \\
\cline { 2 - 3 } & Reduced MECP inspections for water and wastewater facilities \\
\hline 2017 & Durham drops ISO standards (9001 \& 14001) for all drinking water facilities \\
\hline 2018 & $\begin{array}{l}\text { Durham reaffirms selected elements of EMS moving forward for all wastewater } \\
\text { facilities (will not pursue accreditation) }\end{array}$ \\
\hline
\end{tabular}

The significance of this case can be summarized in three points:

a) Initially, Durham decided to maintain the duplication between the DWQMS and the ISO 9001 for drinking water, citing similar reasons as those cited by York Region. However, in 2017, Durham decided to drop ISO 9001 and ISO 14001 for all drinking water facilities. This was after the MECP released the new 2017 DWQMS, which has a more rigorous requirement for continual improvement, with investigative processes for nonconformances.

b) The existing EMS applies only to Duffin Creek WPCP, as part of a contractual commitment with York Region (co-owner of the facility). A concern noted by a Region representative was the lack of Ministry oversight of the wastewater system: "in the past four years, Durham Region has not received any MECP inspection for wastewater systems" (interview respondent M-10). Durham Region has plans to expand the ISO 14001 to all its wastewater facilities and operations, and it was remarked that this decision is driven by the need for systematic oversight.

c) The Region decided to abandon the HACCP certification in 2013. This decision was taken because year over year the inspection and audits had offered little value in terms of improving maintenance procedures and CPPs. As noted by a Regional official, "we decided to keep the procedures and methodology, but drop the hassle and expense of going through certification every three years" (interview respondent M-10).

MECP Inspection Ratings for Durham Region's municipal drinking water systems are consistently very high according to the MECP Chief Drinking Water Inspector Annual Reports for 2013-2015. Ratings for 2015-2016 for all 13 municipal drinking water systems are above 98\%, with only one system in Scugog with a 95\% rating. 99.6\% of drinking water quality tests for all 13 municipalities met the provincial standard. All ratings and test result percentages are even 
higher, with many $100 \%$ ratings for $2014-2015$ (MECP, 2015, 2016). A province-wide report does not exist for municipal wastewater or stormwater systems.

\subsection{Chronological analysis}

This chronology describes the sequence of events in order to map out a predicted explanatory rationale. The objective is to outline a plausible anticipation of some events, time intervals, and classes of events, including lessons learned. Potential patterns will be identified as a way to predict and evaluate predominant trends, rival trends, and any other trend. Table 19, Table 20, and Table 23 show the chronology for York Region, Richmond Hill, and Durham Region respectively, and the path leading to the implementation and evolution of the MSS. Table 24 consolidates those events into one single chronology.

Table 24. Consolidated chronology (York Region, Richmond Hill, Durham Region)

\begin{tabular}{|c|c|c|c|}
\hline Year & York Region & Richmond Hill & Durham Region \\
\hline \multirow[t]{2}{*}{2000} & $\begin{array}{l}\text { Adopts ISO } 14001 \text { for } \\
\text { wastewater (ww) system }\end{array}$ & & $\begin{array}{l}\text { DFO Letter of Advice (warning } \\
\text { to take action) }\end{array}$ \\
\hline & \multicolumn{3}{|c|}{ Walkerton tragedy } \\
\hline 2001 & Adopts ISO 9001 for water ops & & Union concerns w/privatization \\
\hline \multirow[t]{2}{*}{2002} & \multicolumn{3}{|c|}{ Walkerton Inquiry report } \\
\hline & & $\begin{array}{l}\text { Starts development and } \\
\text { design of the ISO } 14001\end{array}$ & \\
\hline 2004 & & & $\begin{array}{l}1^{\text {st }} \text { North American entity to } \\
\text { have an integrated MSS (i.e. } \\
9001,14001, \text { HACCP) }\end{array}$ \\
\hline \multicolumn{4}{|c|}{ MECP publishes DWQMS on October 2006} \\
\hline 2006 & & $\begin{array}{l}1^{\text {st }} \text { ON entity } w / m u l t i p l e ~ I S O \\
14001 \text { - water/ ww }\end{array}$ & $\begin{array}{l}\text { ISO } 14001 \text { certification of } \\
\text { Duffin Creek WPCP }\end{array}$ \\
\hline 2007 & \multicolumn{3}{|c|}{ O. Reg. 188/07 - Phased Compliance with DWQMS } \\
\hline 2009 & \multicolumn{3}{|c|}{ Compliance with DWQMS for water operations } \\
\hline 2010 & $\begin{array}{l}\text { ISO } 14001 \text { for solid waste } \\
\text { management operations }\end{array}$ & $\begin{array}{l}\text { Internal study: EMS expands } \\
\text { to solid waste and SWM }\end{array}$ & $\begin{array}{l}\text { Harmony Creek WWTP }-1^{\text {st }} \\
\text { ECA w/pre-approval }(\approx \text { SDWA) }\end{array}$ \\
\hline \multirow[t]{2}{*}{2013} & & $\begin{array}{l}\text { Fire \& Emergency added to } \\
\text { ISO } 14001\end{array}$ & HACCP certification dropped \\
\hline & & & $\begin{array}{l}\text { Decision to expand the ISO } \\
14001 \text { for all sewage works }\end{array}$ \\
\hline 2014 & $\begin{array}{l}\text { Expands ISO } 14001 \text { to Sewer } \\
\text { User Bylaw operations }\end{array}$ & $\begin{array}{l}\text { EMS expanded in a multi-year } \\
\text { plan, to incl. Parks Operations }\end{array}$ & \\
\hline \multirow[t]{2}{*}{2015} & \multicolumn{3}{|c|}{ MECP announces DWQMS updates, open for public comment } \\
\hline & Study: cancels ISO 9001 for & & \\
\hline
\end{tabular}




\begin{tabular}{|c|c|c|c|}
\hline & $\begin{array}{l}\text { water, \& integrates ISO } 9001 \\
\& 14001 \text { for solid waste }\end{array}$ & & \\
\hline \multirow[t]{2}{*}{2016} & $\begin{array}{l}\text { Reduced MECP inspections for } \\
\text { water and ww facilities }\end{array}$ & $\begin{array}{l}\text { EMS expands to include } \\
\text { Recreation and Culture }\end{array}$ & $\begin{array}{l}\text { Reduced MECP inspections for } \\
\text { water and ww systems }\end{array}$ \\
\hline & $\begin{array}{l}\text { MECP-York Region pilot self- } \\
\text { inspection project (water syst.) }\end{array}$ & & $\begin{array}{l}\text { Begins internal audits for ww } \\
\text { systems, applying ISO } 14001\end{array}$ \\
\hline \multirow[t]{2}{*}{2017} & \multicolumn{3}{|c|}{ MECP publishes DWQMS Version 2.0 on February 2017} \\
\hline & & & Drops ISO for drinking water \\
\hline 2018 & & & $\begin{array}{l}\text { Confirms expansion of } 14001 \\
\text { for all sewage works }\end{array}$ \\
\hline
\end{tabular}

\subsection{Analysis of Data}

Both Richmond Hill and York Region municipalities conducted independent studies, in 2010 (Richmond Hill), and in 2015 (York Region), leading to the following decisions:

1. To expand the scope of the EMS to multiple sectors and multiple departments associated with the likelihood of greatest environmental impact, e.g. Richmond Hill's Waste, Stormwater Management, Fire \& Emergency, Parks \& Recreation.

2. To reduce the scope of Richmond Hill's EMS for "office-oriented" departments such as Finance and Planning.

3. To consider the reduction of the scope of York Region's ISO 9001 (QMS) for the drinking water system by making it selective to areas where benefits are already built into the structures of their systems, and to abandon the certification.

Interview respondents from both York Region and Durham Region acknowledged duplication between their DWQMS and ISO 9001 certifications as both are quality management systems. They nevertheless concluded it was good to have both, noting the additional value of ISO 9001 beyond the original DWQMS requirement in terms of investigative processes/continual improvement (root cause analysis) and external audits (Durham Region 2013 internal report, and York Region 2015 independent report). After the publication in 2017 of the new DWQMS, which has a more rigorous requirement for continual improvement with investigative processes for non-conformances, Durham Region decided to drop ISO 9001 for drinking water.

For Durham Region, which adopted HACCP for drinking water systems prior to the DWQMS becoming a provincial requirement, duplication was acknowledged, however, after ISO 9001:2000 was updated to ISO 9001:2008, where risk assessments became more easily 
integrated, this contributed to Durham Region's decision to drop HACCP certification in 2010, although they would be maintaining HACCP procedures. According to one municipal official, the HACCP:

[....] was seen as a duplication with the ISO 9001:2008, which made it easier to integrate with risk assessments, and after a few years of maintaining the HACCP and noting no opportunity for improvement, [the HACCP] was abandoned in 2012 but keeping the procedures, in particular the maintenance management system (interview respondent M-10).

With more than 10 years of experience in applying ISO 14001 to selected wastewater facilities (i.e. Duffin Creek WPCP and Richmond Hill's wastewater collection facilities), municipal officials acknowledged the value of the standard and the decision to keep it and expand it: "[....] it provides extra motivation to comply with regulatory requirements and ensures confidence on staff and support from elected officials" (interview respondent M-11).

Municipal officials interviewed for this dissertation identified benefits to expanding the ISO 14001 to more wastewater facilities, including: consistency with their water and wastewater groups, and transference of the benefits seen in the management of drinking water systems to other water systems (e.g. systematic assessment of risks and liabilities, and mitigation actions; clearer roles and responsibilities for management and union employees; better awareness of continual improvement; consistent asset management protocols -which are now required under the Asset Management Regulation - O. Reg. 588/17).

Based on these observations, it is suggested that the combined experience of the municipalities identified with DWQMS, QMS and EMS has stimulated the adoption of a multiMSS-consistent approach, with the EMS offering tangible benefits. One municipal official remarked that the:

[....] ISO 14001 requirement to set goals for improvement supports innovation, it helps to set large scale objectives to be reported quarterly to senior management (interview respondent $\mathrm{M}-3$ ).

[....] the small budget required for ISO 14001 [helped to] keep Council engaged [....] [it is] seen as a good thing (interview respondent $\mathrm{M}-3$ ). 
The municipal officials interviewed for this dissertation view ISO 14001 certification as effective in improving compliance with environmental regulations, although regulatory requirements already address some key issues. For municipalities that have implemented ISO 9001 and ISO 14001 for both water and wastewater systems, officials interviewed for this dissertation have found ISO 14001 to be more appropriate for wastewater and stormwater systems:

[....] ISO 14001 is better aligned to wastewater impacts to the environment (interview respondent $\mathrm{M}-7)$.

[....] the new ISO 14001:2015 broadens thinking to a lifecycle perspective (interview respondent $\mathrm{M}-8)$.

There was consensus among the officials interviewed from all three municipalities that there is a lack of design standards, and insufficient inspections and enforcement for wastewater and stormwater systems. In contrast to the DWQMS legal requirements, the wastewater and stormwater sectors rely on guidelines, BMPs, and designers' approaches to infrastructure planning. Moreover, interview respondents noted that while the province issues a thorough annual report concerning drinking water performance, there is no such province-wide report for municipal wastewater or stormwater systems. The interview respondents also suggested that there is a lack of provincial inspections for municipal wastewater and stormwater activity. The lack of inspections (and consequent potential reduction in enforcement activity) can be interpreted as a regulatory gap, for which an EMS certified by a third party, and subject to regular audits, could be considered a parallel non-state environmental protection implementation mechanism. The interviews with municipal officials conducted for this dissertation suggest that a consistent approach by the provincial regulator is needed to ensure compliance of all three water management systems.

Municipal interview respondents suggested that risk-based approaches are positively received by municipalities when supported by provincial regulations; reliance on selfinspections and self-audits alone is not preferred as officials pointed to the many benefits associated with third-party inspections (e.g. a more persuasive justification for obtaining municipal council approval for resources, additional staff and training). 
Based on interviews with municipal officials, there appears to be support for the introduction of provincially required wastewater and stormwater management standards that are based on and/or aligned with ISO 14001, similar to the provincially required DWQMS standard based primarily on ISO 9001. Municipal interview respondents noted:

[....] it's very hard to obtain additional resources from city council to implement these standards and have self-inspections/audits unless there is a provincial regulation (interview respondent $\mathrm{M}-2$ ).

[....] the use and application of ISO standards continues to evolve, while the DWQMS has not been able to maintain the same momentum [....] Rather than creating a new standard, the MECP should consider mandating ISO 14001 for key elements in municipal wastewater systems (interview respondent M-6).

[....] [having mandatory management systems] provides great value to have a third party coming to say how the system is operating, and helps to justify training, documentation, and SOPs (interview respondent $\mathrm{M}-10$ ).

In contrast, another municipal interview respondent was of the opinion that there is little to no benefit associated with the use of MSSs for municipalities, because after several years of good conformance, they are unlikely to promote constant improvement unless they are modified over time to make the applicable standards stricter. If this stated opinion is well founded, it suggests that the value of a state or non-state MSS drops off with time unless it is constantly revised. ISO standards are reviewed every three to five years to establish whether a formal revision is required to keep it current and relevant to the marketplace (ISO, 2015). This is also consistent with the DWQMS, first introduced in 2006, and then updated in 2017. The updated 2017 DWQMS contributed to the decision by Durham Region to abandon ISO 9001 for its drinking water system.

The case study interviews with municipal officials conducted for this dissertation, reflect widespread agreement that the adoption of voluntary non-state MSS standards such as ISO 14001 increases the likelihood of municipal compliance with government regulations, and such standards typically go above and beyond strict compliance with additional voluntary requirements. Voluntary non-state MSS standards were found to enhance environmental 
performance and compliance with provincial regulatory requirements, although they are not viewed as a replacement of state regulations.

The author also explored additional cases (Table 25) concerning other Canadian municipal experiences with MSSs, drawing on publicly available information and interviews with municipal officials met at water conferences from 2016 to 2019 attended by the author. The short summaries with additional information of those cases are included in Appendix F.

Table 25. Lessons from Other Canadian Municipalities' Experience with MSSs

\begin{tabular}{|c|c|c|}
\hline & Municipality & Relevance to the voluntary adoption of ISO 14001 and MSSs \\
\hline 1 & $\begin{array}{l}\text { Lake Huron and Elgin Area } \\
\text { Water Supply systems }\end{array}$ & $\begin{array}{l}\text { Since } 2016 \text { maintain ISO } 14001 \text { and ISO } 9001 \text { certification for its } \\
\text { drinking water systems. In addition to the DWQMS, this case shows } \\
\text { the value of adopting ISO } 14001 \text { and an Emergency Management } \\
\text { System to supplement existing state-based requirements. }\end{array}$ \\
\hline 2 & City of Collingwood & $\begin{array}{l}\text { Its ISO } 14001 \text { certification (2009) for its drinking water treatment } \\
\text { plant was maintained until 2015, when a change in senior leadership } \\
\text { decided to keep practices but not its certification. This case suggests } \\
\text { that leadership play a role in municipal decisions to adopt MSS. }\end{array}$ \\
\hline 3 & Halton Region & $\begin{array}{l}\text { In 2014, new senior management started implementing ISO } 14001 \text { for } \\
\text { all water sectors. This case provides support for the proposition that } \\
\text { senior municipal leadership staff can play a key role in deciding } \\
\text { whether to adopt (and the extent of the scope of) a voluntary MSS. }\end{array}$ \\
\hline 4 & $\begin{array}{l}\text { Regional District of } \\
\text { Nanaimo }\end{array}$ & $\begin{array}{l}\text { Since } 2005 \text { its wastewater services are ISO } 14001 \text { certified. This case } \\
\text { supports the idea that not only large municipalities, but also smaller } \\
\text { municipalities perceive value in adopting ISO 14001, and in being able } \\
\text { to impose contractual obligations on third-parties. }\end{array}$ \\
\hline 5 & Quebec City & $\begin{array}{l}\text { In } 2004 \text { it was reported that one WWTP was ISO } 14001 \text { certified. It } \\
\text { provides support for the proposition that ENGOs can play an } \\
\text { important role in monitoring and providing checks-and-balances to } \\
\text { ensure compliance and going above and beyond. }\end{array}$ \\
\hline 6 & Halifax Water & $\begin{array}{l}\text { Since } 2003 \text { all drinking water facilities are ISO } 14001 \text { certified. The } \\
\text { wastewater facilities were added in } 2016 \text { and required third parties } \\
\text { to comply with EMS policies. It supports the recognition of the value } \\
\text { of adopting ISO } 14001 \text { to increase compliance, to address risks of } \\
\text { system operations with a culture of continuous improvement. }\end{array}$ \\
\hline 7 & City of Toronto & $\begin{array}{l}\text { In this case, the non-state Blue Flag certification could be interpreted } \\
\text { as representing an additional rule system in support of municipal } \\
\text { (state) water protection, building on federal and provincial regulatory } \\
\text { requirements and ISO certifications. }\end{array}$ \\
\hline
\end{tabular}




\subsection{Synthesis and Preliminary Conclusions of Chapter}

In this chapter, the author applied the case study research method particularly to answer questions of why and how MSSs have been applied by Ontario municipalities in relation to the adoption of non-state MSSs. Three municipalities were examined in detail including the review of publicly available information, interviews with municipal officials, a chronology analysis and the correlation of data and analysis. Additionally, seven short summaries were presented with relevant experiences in the adoption of MSSs.

As can be seen from the case studies and summary examples provided in this chapter, there is considerable experience in municipalities in Ontario and around Canada with environmental management systems, and as a result an increasing number of municipal staff have become more knowledgeable about the value of management systems in support of environmental performance. In keeping with the sustainable governance theory discussed earlier in the dissertation, the case studies and examples provided in this chapter also support the idea that non-state rule instruments (e.g. ISO 14001 and Blue Flag), processes (e.g. certification), institutions (e.g. ISO, CSA, Blue Flag Foundation), and actors (e.g. elected officials, municipal staff, auditors, members of ENGOs) can support governmental environmental objectives and activities. Below is a summary of the findings of the case studies in relation to the "why" and "how" of municipal use of MSSs (research sub-questions 5 and 6):

1. Why are quality and environmental management systems, such as those set out in ISO 9001 and ISO 14001, being adopted by Ontario municipalities?

Based on the research undertaken for this chapter, the reasons for the adoption of nonstate MSS standards are:

- to anticipate upcoming regulations as a result of provincial activity;

- to complement state-based regulations - regulatory gaps - and in so doing reduce the likelihood of environmental violations. Examples of these gaps include: a lack of design standards, a lack of inspections and enforcement for wastewater and stormwater systems, and a lack of holistic performance reporting on wastewater and stormwater systems;

- to avoid liability in case of environmental violations; 
- to motivate staff and ensure compliance with regulatory requirements and conformance with more stringent standards, increasing the due diligence;

- to ensure consistency in the management and operation of water, wastewater, and stormwater systems;

- to capitalize on MSS benefits from one sector once those benefits are identified, and transfer those benefits to other system components, or other public work sectors; and

- to ensure compatibility and synergies with other provincial regulations.

There appears to be a growing number of provincial and municipal officials developing an understanding of the value of MSSs in support of their own work as evidenced by: (i) Ontario municipalities adopting ISO 9001 and ISO 14001 prior to the mandated DWQMS (York Region and Durham Region); (ii) the recognition by the provincial government of the need to update the original DWQMS (2006) (original version published in 2007; version 2 published in 2017); (iii) the quarterly meetings of municipal officials participating in the MWWRC discussion forum; and (4) the selective approach to expand the ISO 14001 to other municipal public work areas (Richmond Hill, Durham Region, York Region).

It also appears that executive leadership can play a significant role in whether municipalities adopt non-state MSS as evidenced by: (1) York Region and Durham Region deciding to adopt non-state MSSs in anticipation of the Walkerton Inquiry; and (2) the decision by many other Canadian municipalities to adopt MSSs and particularly ISO 14001, for their wastewater systems (Halton Region, Collingwood).

Finally, there appears to be evidence of municipalities transferring the requirement to adopt and comply with MSSs, and particularly of EMS to their third-party service providers as evidenced by the City of Calgary, the Regional District of Nanaimo, Halifax Water and Peel Region all requiring third-party compliance with their own EMS in their contractual documents.

Using Alcantara's concept of policy learning, and the definition offered by Lenschow et al. of policy convergence, the case studies support the argument that both concepts are occurring simultaneously in the context of Ontario's water sectors. Policy learning and convergence involves policy officials, policy networks, policy communities and policies themselves. 


\section{How (if at all) has the voluntary adoption of MSSs (in the form of ISO 9001 and/or ISO}

14001) evolved over time, for the municipal water, wastewater and stormwater sectors?

The research conducted for this dissertation suggests that initial municipal adoption of MSSs in Ontario was both voluntary for some municipalities in anticipation of government action after the Walkerton tragedy (2000), and then subsequently became mandatory as a provincial regulatory requirement through the DWQMS for drinking water systems (2007). A phased-in approach was used for DWQMS implementation as per O. Reg. 188, allowing all 444 Ontario municipalities to become accredited under the new regime over the period from January 2009 (larger municipalities), to June 2010 (smaller municipalities). Some municipal councils approved proactive MSS measures in advance of the new regulations being adopted (e.g. York Region, Richmond Hill, Durham Region, London, and Collingwood), and all 444 municipal councils approved funding for the implementation of the DWQMS as a regulatory requirement.

Since then, based on an examination of voluntary EMS implementation by municipalities in Ontario and elsewhere, a number of implementation variations are evident:

- Certification / Accreditation - This option requires municipal Council approval of the EMS. This option does not involve a municipal bylaw, but a council resolution to work towards obtaining and keeping certification (e.g. York Region, Richmond Hill, Durham Region, London, and Collingwood pre-2012).

- Self-declaration / Conformance - This option indicates a lesser degree of commitment and enforceability, involving a decision by senior management to work towards a standard, but without actually obtaining the certification associated with that standard. This option may be adopted because it is not possible to secure the approval of elected officials (political climate), or because of a lack of resources to develop and implement specific elements of the standard; or lack of willingness to report to the public.

- Cherry-picking -This is a subset of the self-declaration, where only certain elements of the MSS are selected for development and implementation (e.g. Hamilton).

Based on the case studies presented in this chapter, there appears to be considerable support at the municipal level for the proposition that non-state EMSs can assist in meeting municipal wastewater and stormwater objectives. 


\subsection{FOCUS GROUP - ANALYSIS AND RESULTS \\ 6.1 Analysis of Data}

The participants appeared to have a common understanding that the governance structure for the wastewater and stormwater sector relies on a provincial regulatory framework but also on proactive action by municipalities in adopting best management practices (BMPs) derived from non-state actors that have developed useful tools such as non-state management system standards and protocols (e.g. ISO and CSA Group standards, FCM 2005 Protocols). In other words, the participants confirmed that a sustainable governance-type of decision-making and action framework was in place, involving both state and non-state instruments, institutions, processes and actors. The data from the focus group generated the following topics:

1. Perceptions of the effects of EMS on managing municipal wastewater and stormwater systems (positive, negative, neutral);

2. Role of the provincial government in adopting standards for EMS (legislated/ mandatory vs. voluntary adoption of EMS);

3. Role of municipalities in adopting non-state standards for EMS (peer-to-peer support, lessons learned);

4. Role of non-state actors supplementing state-based regulations (risk assessment, standards development processes); and

5. Drivers for EMS in the municipal wastewater sector (motivators, barriers).

Table 26 presents the frequency and distribution of each of the five topics across the five participant categories. The data indicates that all 5 participant classes had a good knowledge and understanding of the subject, its challenges, risks, and opportunities. It also notes that both state and non-state regulators generated and received arguments associated with their role as an agent of change and call for action (topics 2 and 4 ) with the greatest frequency. 
Table 26. Focus Group Participant Categories and Argument Counts by Topic

\begin{tabular}{|l|c|c|c|c|c|c|}
\hline \multirow{2}{*}{ Participant category } & & \multicolumn{6}{c|}{ Participants' topic count } \\
\cline { 2 - 7 } & $\#$ & $\begin{array}{c}\text { Topic 1 } \\
(+/-)\end{array}$ & $\begin{array}{c}\text { Topic 2 } \\
\text { (Prov. role) }\end{array}$ & $\begin{array}{c}\text { Topic 3 } \\
\text { (Mpal. role) }\end{array}$ & $\begin{array}{c}\text { Topic 4 } \\
\text { (Privt. role) }\end{array}$ & $\begin{array}{c}\text { Topic 5 } \\
\text { (Drivers) }\end{array}$ \\
\hline Provincial regulator & 4 & 11 & 4 & 4 & 5 & 6 \\
\hline Large municipality & 3 & 8 & 9 & 3 & 5 & 6 \\
\hline Small/medium municipality & 3 & 6 & 12 & 3 & 2 & 2 \\
\hline Private regulator & 3 & 6 & 6 & 4 & 7 & 3 \\
\hline Consultant & 1 & 2 & 2 & 1 & 3 & 0 \\
\hline \multicolumn{1}{|c}{ Total } & $\mathbf{1 4}$ & $\mathbf{3 3}$ & $\mathbf{3 3}$ & $\mathbf{1 5}$ & $\mathbf{2 7}$ & $\mathbf{1 7}$ \\
\hline
\end{tabular}

\section{Topic 1 - Perceptions of EMS effects on managing wastewater systems}

There seemed to be agreement that environmental management systems would have positive environmental and regulatory effects on Ontario's municipal wastewater and stormwater sectors. Participants referenced the success of the QMS for the drinking water systems, but highlighted how challenging it was to implement it for smaller municipalities:

[t]he Walkerton Inquiry identified major governance deficiencies with respect to water treatment, which led to the formalization and standardization of water operations (Fp1).

The phased-in approach set out in O. Reg. 188/07 allowed municipalities classified as small municipalities an 18-month window to comply with the QMS requirement. A non-state regulator emphasized that an EMS is "a well-established way of demonstrating due diligence in case of risks being underestimated" (Fp2). In a concluding remark, a provincial official remarked "Do we need ISO or an EMS for wastewater management? Absolutely" (Fp3). There was no disagreement with this assertion from other focus group participants. This particular topic was noted by the research team to confirm what is taken to be a consensus on the positive effects of the EMS in wastewater systems, where all participants nodded their assent, or added additional arguments:

[....] having the ISO 14001 certification for our wastewater systems translates into municipal council's confidence in our operations, building credibility, legitimacy, and reputation (Fp6). 
[....] implementing an EMS is a good information "cleanup" exercise that can help turn operational data into meaningful information (Fp7).

Representatives from all groups expressed the idea that management systems can provide a standardized and systematic approach that enables consistent compliance with regulatory requirements on a long-term basis. Some divergence of opinion emerged on the effectiveness of an EMS, given that management system effectiveness would be dependent on many factors that would vary on a case-by-case basis; nevertheless, EMS was generally seen as having positive effects:

[....] in a worst-case scenario, our EMS has provided staff with baseline literacy around environmental issues that they may not otherwise have (Fp8).

[....] implementing an EMS is an opportunity to "remove cobwebs" and to focus on what makes an organization successful (Fp12).

These arguments were commented on by several members of different representative groups up to a point that it appeared to be a consensus in the understanding of benefits of the MSSs.

\section{Topic 2 - Role of the provincial government in adopting standards for EMS}

For this topic, there appeared to be a consensus among focus group participants that EMSs would have to be a provincially regulated requirement in order to ensure that municipalities would adopt it. There appeared to be a consensus that medium to large municipalities would likely have the resources to develop and implement EMS on their own, but for smaller municipalities, compliance would be more of a challenge. Medium to large municipalities represent approximately $70 \%$ of Ontario's population (Figure 9).

All participants recognized the lead role the province would need to play in making such a standard a mandatory requirement. One provincial regulator noted that in the context of the drinking water regulatory overhaul following the Walkerton Inquiry, "the QMS requirement is part of an ecosystem of regulations that the ministry established" (Fp1). It was further noted that:

[....] we would need to change legislation to make EMS mandatory for wastewater systems (Fp1). 
[....] the [municipalities] that need help typically will not speak up, which is why a management standard should be made mandatory (Fp4).

The term "ecosystem of regulations" was used to describe the array of regulations introduced after the Walkerton Inquiry, which formed the multi-barrier approach (i.e. regulations for: source water protection, disinfection, management of the water treatment-distribution systems and monitoring of drinking water) with multiple regulations for drinking water.

There also seemed to be agreement among the focus group participants that legislative/regulatory requirements would not be immediately feasible because they would require an understanding of the different operating contexts and necessitate significant consultation efforts before the appropriate regulations were crafted and then moved through the legislative process. A distinction was also noted between "legislated" and "mandatory" requirements. A legislated process begins with a bill introduced to the Legislative Assembly and concludes with Royal Assent, when it typically comes into force (Kaye, 2011), with significant timelines involved. Conversely, a mandatory requirement could be accomplished through provincial administrative tools such as Ministry Abatement Orders, Minister's conditions for approval, site-specific approvals, or even by referencing specific rule instruments (e.g. guidelines, standards) on permits, licenses or orders. A mandatory requirement can thus be imposed in a fraction of the time needed for a legislative reform. As noted by another provincial official: "I can go back to my office and push a button [in order to require an EMS]" (Fp3).

One point that emerged on multiple occasions in the focus group was the idea of having a risk-based approach by developing a standard that would be scalable, flexible, and with gradual or phased implementation. It was recognized by one of the non-state regulators that "in the municipal sector, if it is not required, the uptake is generally poor" (Fp11), a position that was supported by the medium and small municipal representatives.

There appeared to be a consensus among focus group participants in favour of an EMS type of requirement needed to accommodate municipalities that have limited resources, by having a scalable, adaptable, and risk-based standard that could be implemented gradually, drawing on the lessons learned from the DWQMS experience regarding drinking water and its phased 
approach through O. Reg. 188/07. It was suggested that: “.... an economic analysis (costs vs. benefits) needs to be conducted for the application and implementation of a wastewater/stormwater EMS" (Fp2).

In terms of risk assessment, there appeared to be recognition among focus group participants in relation to the DWQMS that the risk assessment element was addressed by having: (1) the required Critical Control Points (for water quality verification) embedded into the Act and regulations; and (2) risk assessments undertaken pursuant to O. Reg. 284/07 (for source water protection areas), and O. Reg. 288/07 (for source water protection committees). To address the risk aspect of EMS for wastewater and stormwater systems, focus group participants proposed a similar approach to those for source water protection:

[....] by having a similar approach of pre-identifying risks - with identified control measures to mitigate these risks - and using the existing source water protection policy tools, we could potentially avoid smaller municipalities having to undertake costly risk assessments (Fp14).

[....] addressing wastewater and stormwater in one single standard would be complex since for the most part risks are different and have different drivers [....] there are [also] some cross-over issues between wastewater and stormwater that it would be necessary to address [....] in a different management standard (Fp11).

In discussions of the need for a wastewater and stormwater management standard there appeared to be a consensus that smaller municipalities do not necessarily have less risk, and that any risk assessment involves equating magnitude of consequences (or severity) with the likelihood of the occurrence of the risk event. Given that one of the purposes of regulations is to mitigate risks, two alternatives were suggested by one provincial regulator:

[....] [an EMS] could be required for all municipalities; or on a case-by-case basis, if some municipalities are not performing well in the area of wastewater management, then the province could require them to implement an EMS as a compliance response (Fp2).

The idea that a "one-size-fits-all" standard may not be adequate for the wastewater and stormwater sectors was shared by the focus group participants representing municipalities. Provincial officials observed that wastewater and stormwater management is more complex than drinking water management, as site considerations affect the quality of influent 
wastewater quality, and lakes and rivers have different assimilative capacities, that in turn determine pollutant loadings and corresponding technology. It was also argued that a gradual approach offered advantages for sound implementation:

[....] any path forward for EMS in municipal wastewater needs to follow a gradual/phased, risk-based approach that has to allow for contextual factors such as available resources, risk, size, geography, industrial waste output, etc., and options for scalable and adaptable EMS scope (Fp3).

Other participants emphasized having MECP coordinated timelines for both water and wastewater inspections and licence renewals; and having a wastewater and a stormwater management standard compatible with the DWQMS and/or ISO 14001: "we need to have a partial or incremental implementation to allow for a flexible approach that is mindful of the different risk-based factors" (Fp3).

Assuming a standard was established, additional roles were suggested for the provincial regulator. Some of these roles included using ISO 14001 as a model to develop a sector-specific standard and/or guidelines for the municipal wastewater sector. This should reduce the work of the municipalities, allowing them simply to complete the details and implement it. Finally, it was suggested that either provincial or private regulators should have a shared role in regularly maintaining and updating the standard to reflect changes to approaches in technology, new expectations and new concerns:

[....] it is not enough to develop and implement a standard. It must be regularly maintained and updated; reflecting process updates and changes and change management must be built into a standard (Fp11).

\section{Topic 3 - Role of municipalities adopting non-state standards for EMS}

There was a consensus among participants that a relatively informal peer-to-peer learning network of municipalities to share best practices would be useful and could enhance performance. As one non-state registrar noted:

[....] assuming there is provincial authority behind a standard's implementation, a steering committee composed of representatives from interested parties would be beneficial... identifying subject matter experts and sharing that expertise will eventually lead to a collective rise in performance (Fp12). 
At the focus group session, the role of municipalities in voluntarily adopting an EMS (across Canada) for wastewater was pointed out by the author. It was observed that Richmond Hill, York Region, and Durham Region, which implemented an EMS approach certified to ISO 14001, are now expanding the scope of their management system to other public works areas. Participants from larger municipalities noted the value of the decision to keep expanding the EMS to their wastewater systems:

[....] an EMS approach for municipal wastewater systems could be developed in consultation with municipalities to ensure core requirements are captured (Fp3).

[....] compatibility and consistency to manage both water and wastewater systems would strengthen the case for a voluntary wastewater standard (Fp5).

[....] [municipalities] would benefit by having the DWQMS synchronized with the ISO family of standards (Fp7).

[....] this means that the DWQMS would be significantly improved if the methodology closely followed that of the ISO management standards (Fp8).

Nevertheless, focus group participants for municipalities remarked that obtaining council support to fund voluntary programs is challenging. Having guidance and clear direction from the provincial government would facilitate efforts to secure municipal funding:

[....] a mandatory EMS would make it easier for municipalities to obtain council support and funding. If left voluntary, then [funding] would be dependent on leadership (Fp5).

From the perspective of small municipalities and operators, participants noted the challenges not only in securing funding, but also regarding capacity-building, and long-term sustainability:

[....] in order to determine whether a wastewater EMS should be mandatory, a conversation around funding must occur. Small and remote townships and municipalities in particular face challenges:

- they do not have the same manpower as larger ones,

- they face [a] lack of resources at the local level,

- they have a knowledge challenge (Fp9). 
[....] it is possible for a wastewater management standard (potentially based on ISO 14001) to align with DWQMS so that there are fewer new requirements for municipalities to tackle, as most municipalities have transferred generic requirements of the DWQMS to their wastewater system operations (Fp10).

Another important observation noted by focus group participants representing municipalities experienced in ISO 14001, was that with an EMS, the investigative role of municipalities, when conducting their own root cause analysis, can reduce the need for provincial resources for investigation and abatement:

[....] when a municipality identifies an issue, [it] completes its own investigation and advises the provincial regulator. In some cases the investigative role of the MECP can be reduced (Fp6).

[....] there are benefits with the annual inspections required by Management Systems, which complement the provincial inspections every five years (Fp5).

The focus group's municipal representatives identified the EMS as a management tool for the risk assessment process: "We are identifying areas that we inaccurately predicted were low risk that in fact turned out to be higher risk" (Fp5) noted one municipal official. It was pointed out that an ISO 14001 does not have built-in Critical Control Points the same way the DWQMS has for drinking water, but "that can be addressed with customization" (Fp6). Finally, as pointed out by a non-state regulator, "municipalities should not wait for a disaster to happen before taking necessary measures to demonstrate due diligence in order to avoid penalties, clean-up costs, and legal action" (Fp6).

While discussing the proactive approach of municipalities in adopting an MSS for wastewater and stormwater systems, with reference to the experience on the drinking water side with the DWQMS, a provincial representative noted that "[t]here was a balancing act [....] We gave municipalities the keys of the car, but we required them to follow a robust driving manual [DWQMS], street maps, driving test, monitoring and reporting" (Fp4). 


\section{$\underline{\text { Topic } 4 \text { - Role of non-state actors supplementing state-based regulations }}$}

A point made by several participants was that standards are a well-established way of demonstrating due diligence. A non-state regulator noted that:

[....] increasingly, standards are being developed for particular sectors. More and more, they are not using ISO 14001, they are using something based on ISO 14001 that is sector-specific (Fp11).

[....] another advantage is that the non-government standards [such as CSA/ISO standards] have a mandatory review every three to five years, so they stay up to date and relevant (Fp11).

It was also suggested that either provincial or private regulators should share in the task of developing a sector-specific standard:

[....] we could develop an "upper and lower tier" of the standard for larger, and smaller and/or less risky municipalities to adopt (Fp11).

[....] if, like in Walkerton, you cannot show due diligence, then you are exposing yourself to significant operational and legal risk. In the event that a risk has been underestimated, standards are [a] useful way of showing that you've done your due diligence (Fp11).

[....] it is not necessary to have another Walkerton-type incident to provide the motivation for change. With an EMS, municipalities and businesses have the opportunity to identify smaller scale issues themselves before they become too big to manage effectively. These issues can then be brought to the ministry to be addressed, rather than waiting for the ministry to investigate when a serious risk arises; this is a risk-based approach vs. preventive approach (Fp6).

A clear role identified for non-state actors was the third-party auditing process. Large municipality representatives had divergent points of view with regards to the quality of the third-party audits between those conducted by the MECP's accredited registrars, and those conducted under their voluntary ISO 14001. One participant noted that they dropped ISO 9001, as it was duplicative of the DWQMS, and after maintaining it for several years it was found to provide minimal benefits or added value for continual improvement. However, the business 
perspective associated with the ISO-type audit was also noted, as "it covers different aspects than those covered by the ministry" (Fp12). Finally, it was pointed out that non-state regulators have placed an emphasis on integrating standards and making them compatible in order to facilitate their implementation:

[....] there needs to be an integrated approach to drafting, budgeting, implementing and running any management system. In addition, given that approximately $40 \%$ of ISO 9000 and 14000 requirements are similar, audits need to be integrated to reduce duplication (Fp13).

[....] based on the 2015 new versions of the ISO management system standards, similarities [in the structure of the standard itself, which would assist adoption of multiple standards] for integration [of multiple standards] may be more than $70 \%$ [of the standard table of contents] (Fp14).

[....] municipalities we work with, they would be willing to implement [a management system standard for municipal wastewater] right away (Fp13).

\section{Topic 5 - Drivers for EMS in the municipal wastewater sector}

Participants discussed EMS motivators and barriers in wastewater and stormwater, both if adopted on a voluntary basis and if mandated by the provincial regulator. One relevant question raised in the discussion was: "do we have a clear understanding of what problem [it] is necessary to solve with MSS? The management of the system, or the infrastructure design principles of the infrastructure, or investing in capacity size increase - this is particularly relevant as the design of municipal wastewater and stormwater systems is based on BMPs and guidelines, with no minimum requirements. The question is what we need to fix first" (Fp6).

This topic became one of the most debated points by the focus group participants during the second half of the session. As one municipal representative put it, "before thinking about making EMS a provincial requirement, we need to define what problem we are trying to solve, and how solving the problem will benefit the province" (Fp7). A provincial regulator also pointed out that:

[....] phasing in a new requirement such as an EMS is relatively straightforward, we did that with the DWQMS. But what is more challenging is getting to the stage where you are ready for making it a requirement (Fp1). 
There was agreement that the three problems noted above - management of the system, the infrastructure design principles, and investing in increasing capacity - need to be addressed, but there was no agreement as to which to look into first. There was a general understanding that MSS and design standards would assist in achieving the ultimate goal: to improve the levels of service to citizens and the community by reducing floods, spills and CSOs, flooding of people's basement, inflow/infiltration, and environmental degradation. Having management standards and adequate design standards would certainly help to achieve this objective. However, in terms of economic resources the question is where to spend tax-payer money: e.g. on an MSS or on increasing infrastructure capacity.

Another important driver noted was that the existing wastewater and stormwater regulations are very old, with the regulatory framework for the stormwater sector being particularly out of date. Specifically, it was pointed out that:

[....] policies and procedures [for wastewater and stormwater] can be quite old, with some still using the same ones they did in the 1950s and 70s (Fp8).

[....] the obsolete state of stormwater regulatory framework is more dramatic, in that it relies only on guidelines, and there are no legislative requirements (Fp3).

[....] [since Walkerton,] municipalities have been exploring the applicability, fit, and transferability of the drinking water management standard for the purposes of wastewater management (Fp4).

Towards the end of the focus group session, and considering the consensus reached on the positive environmental and regulatory effects of an EMS on Ontario's municipal wastewater and stormwater sectors, the debate concentrated on "how" to persuade politicians, council members, the public, and the medium to small municipalities of the need to implement EMS. To answer this question, several participants remarked that hopefully it would not be necessary to have another Walkerton-type incident to provide the motivation for change. Building on the need to manage risk, it was noted that an EMS approach can assist in demonstrating due diligence, which is beneficial in case of environmental violations, and acts as an incentive for 
general managers and owners to adopt EMS: “.... a precautionary approach should be followed instead of regulation by disaster" (Fp3).

A provincial regulator commented that the 2015 amendments to the Ministry of Infrastructure Act (2011), and the 2015 enactment of the Infrastructure for Jobs and Prosperity Act, provides new impetus for the province to encourage evidence-based and strategic longterm infrastructure planning, including the construction, and operation of municipal infrastructure. This was perceived as a catalyst for the MECP to take intermediate steps:

[....] this can support the development of targeted operational guidelines for user class, risk assessments, and use of mandatory requirements with built-in flexibility for adoption and implementation (Fp3).

Another point of consensus was the need for a larger risk assessment to determine overall risks to be addressed with a potentially provincially mandated EMS, along with an economic assessment to evaluate the cost and benefits for different classes of municipalities before mandating a wastewater or stormwater EMS.

\subsection{Synthesis and Preliminary Conclusions of Chapter}

In keeping with the concept of governance, there was widespread support among the state and non-state focus group participants for a regulatory governance approach involving a combination of state and non-state instruments, institutions, processes and actors. All participants appeared visibly comfortable discussing the diverse policy issues, even when challenging issues such as political will were discussed. There was also widespread agreement that municipalities were adopting non-state regulatory approaches to assist in bridging the current gaps and deficiencies associated with existing state-based regulations. Both state and non-state participants saw roles for both to act as agents of change with respect to the adoption of wastewater and stormwater EMS standards (topics 2 and 4).

The analysis of topic 1 (perceptions of EMS effectiveness) suggests a consensus that an EMS could have positive environmental and regulatory effects on Ontario's municipal water, wastewater and stormwater sectors. The concept of "standardization of operations" was generally acknowledged as one of the primary benefits of the new array of regulations for 
drinking water. An EMS-based approach was also noted as a safety net in the event of environmental risks being underestimated and as an enabler for consistent compliance with regulatory requirements and making municipalities more efficient (in removing cob-webs).

The analysis of topic 2 (provincial role) suggests a consensus that an EMS approach would best be achieved through a provincially regulated requirement. There was consensus that medium to large municipalities would likely have the resources to develop and implement EMS, but that there would be significant implementation challenges for small to medium municipalities (i.e. lack of resources for development and operationalization, complexity and capacity). A scalable, adaptable, and risk-based approach for gradual implementation was seen as preferable.

There appeared to be general agreement that legislative and regulatory EMS requirements for municipalities would require an understanding of the different operating contexts, and significant consultation efforts before they are crafted and go through the legislative process. The following observations were also made:

- Addressing wastewater and stormwater environmental management in a single standard would be complex since for the most part risks are different and have different drivers.

- Smaller municipalities do not necessarily have less risk, and that any risk assessment involves equating magnitude of consequence (or severity) with the likelihood of the occurrence of the risk event.

- Once a sector-specific standard is available it could be used for enforcement activity on a case-by-case basis if some municipalities are not performing well, or when more flexibility of regulatory approvals are considered for one municipality.

- The idea of a "one-size-fits-all" standard for wastewater and stormwater sectors was probably not feasible.

- Consistency among standards is desirable.

A clear opportunity was identified for the provincial regulator and non-state actors to work together, similarly to what occurred for the development of the DWQMS for drinking water, to develop and endorse a sector-specific standard for wastewater, and for stormwater. 
The analysis of topic 3 (municipal role) suggests a consensus among participants that municipalities have a big role to play in creating a relatively informal peer-to-peer learning network for sharing best management practices (BMP) and enhancing their environmental protection. The importance of consultation with municipalities for the development of a sector-specific standard was emphasized. Furthermore, while it was noted that obtaining council support to fund voluntary programs is challenging for municipalities, having guidance and provincial direction would facilitate such efforts. However, for small municipalities, in addition of funding support, challenges would include capacity building, training, and manpower. It was noted that an EMS was an excellent risk management tool, but for smaller municipalities it would be too onerous to implement. In this context, the transfer of the concepts of CCPs would assist smaller municipalities to avoid resource-intensive risk assessments and apply their scarce resources more efficiently.

The analysis of topic 4 (private regulator role) identified the following relevant arguments: (1) the increasing trend toward standards being developed for particular sectors; (2) the benefit of having a mandatory review of standards every three to five years to ensure their continued relevance; (3) the possibility of developing upper- and lower-tier standards for large and small municipalities, respectively; (4) the value of third-party audits to fill current gaps in provincial regulation; and (5) the existence of a market for clients willing to implement an MSS for municipal wastewater (noted by private registrars).

The analysis of topic 5 (EMS drivers) identified the following additional drivers not already identified in this study: (1) the obsolescence of the state-regulatory framework for stormwater is in a more dramatic state of disrepair than the municipal wastewater regulatory framework (i.e. there are significantly more guidelines and non-mandatory design standards for municipal wastewater); (2) a clear understanding is needed of the problem that we are seeking to solve with an MSS: management of the system, infrastructure design principles, or increasing infrastructure capacity (this point is particularly relevant as the design of municipal wastewater and stormwater systems is based on BMPs and guidelines but there are no minimum requirements). Targeting all three: management system standards, design standards, and investing in infrastructure capacity will address the main goals of human health and 
environmental protection (reducing flooding, spills, CSOs, flooding of people's basements, inflow/infiltration, and environmental degradation). The question is what is what we need to address first. There was agreement that all three problems need addressing, but there was no agreement as to which to tackle first. The problems identified were:

a. to increase acceptance of an MSS for municipal wastewater and stormwater systems;

b. to improve design standards for sewers and treatment infrastructure; and

c. to ensure resources are available to build a larger infrastructure.

The discussion about "how" to persuade politicians, council members, the public, and the small municipalities of the need to implement an EMS led to a number of conclusions: (1) a precautionary approach should be followed instead of regulation by disaster; (2) there is an increasing need for a risk-based and holistic approach to water management; (3) it is important to reduce the likelihood of environmental violations and ensure appropriate due diligence; and (4) there is an increasing number of provincial and federal regulations that have already created a new impetus for evidence-based and strategic long-term infrastructure planning, including the construction and operation of municipal infrastructure that relies on risk-based approaches. Finally, it was suggested that sector-specific standards with a 2-tier implementation could facilitate risk assessments, together with the use of mandatory requirements for built-in flexibility on a case-by-case basis.

Relevant to this study, one of the focus group participants remarked that around 2009, the MECP tried to draft a model of an EMS standard for wastewater and to make it consistent with the existing DWQMS, but the initiative was shelved as there was no political appetite or will to move forward with it at the time. A reflection by the author is that in recent years, and in light of the evidence from this study, the appetite that was lacking at the provincial level about 10 years ago, has found synergies primarily in municipalities, but also in civil society. Examples of these synergies include the Engineers Canada 2018 report on stormwater QMS (an independent study with findings that align with this dissertation); formal plans by large GTA municipalities to actively seek ISO 14001 certification (e.g. Toronto, Peel, Halton, Vancouver, Vaughan); and new provincial regulations focusing on specific elements of ISO 14001 such as life cycle and climate resilience considerations, asset management plans (e.g. Infrastructure for 
Jobs and Prosperity Act, 2015, Asset Management O. Reg. 588/17, and the Development Charges Act, 2015 - for the significance of this legislation, see Table 8).

Based on the foregoing analysis, the following options would appear to be available:

1) A provincially endorsed, voluntary EMS standard. This represents an enhanced status quo scenario, where existing non-state activity continues to drive the uptake of MSSs for wastewater and stormwater systems. However, provincially-endorsed sector-specific standards for wastewater and for stormwater could constitute a catalyst to boost voluntary uptake of MSSs by municipalities. These standards should streamline municipal efforts and reduce the difficulties involved in the adoption of an ISO 14001-type standard. Having the collaboration and endorsement of the provincial regulator would likely lead to more municipalities, large and small, to adopting the standard. A provincial endorsement, potentially together with referencing of the standard in certain policy tools (guidelines and municipal practices), would send the message that a provincially mandated standard is likely to be introduced in the future, especially since there is evidence of municipalities trying to anticipate future provincial legislation to develop a new sector-specific, provincially endorsed (voluntary) MSS. This standard could be based on a customized variation of ISO 14001, DWQMS and other standards to address the regulatory gaps noted in Chapter 7.3 (i.e. financial planning, minimum design criteria, critical control points [CCPs], performance reporting and inspections/audits). This could be developed in a participatory approach between state and non-state actors to enable and assist municipalities to voluntarily adopt a standard for EMS in municipal wastewater and stormwater systems.

2) Mandated ISO 14001. For site-specific case-by-case situations (e.g. abatement action), the MECP could mandate the ISO standard for abatement processes and also for built-in flexibility for adoption and implementation (e.g. pre-authorization of low risk activities). This option could open the door for a systematic move toward area-wide approvals on a case-by-case basis. 


\subsection{DISCUSSION}

The goal of this chapter is to offer a synthesis discussion of some of the key findings and elements discussed in Chapter 2.0 (theoretical aspects of the study, involving the examination of scholarly conceptions of regulatory governance, policy convergence and the academic literature on management system standards as they relate to water systems; as well as the legal and policy framework within which municipal water governance operates, including federal, provincial and municipal laws and regulations and court decisions). It also offers a synthesis of Chapter 3.0 (the research methods), Chapter 4.0 (semi-structured interviews), Chapter 5.0 (case studies of three Ontario municipalities and summaries of seven other municipal experiences), and Chapter 6.0 (focus group). This discussion focuses on:

- establishing connections between the theoretical concepts and insights derived from the research undertaken in this dissertation;

- identifying evolving factors for and against the use of MSS standards to the municipal wastewater and stormwater sectors; and

- exploring the regulatory gaps in the current regime and the complementarity of MSSs in addressing those gaps, as well as some of the considerations involved in selecting the appropriate MSSs for the wastewater and stormwater activities.

\subsection{Connecting the Theoretical Concepts with the Research Findings}

In order to better understand the role that management system standards might be able to play in municipal water governance, Chapter 2 started with a review of different academic conceptions of regulatory governance, in an effort to determine which model could best accommodate a situation where non-state rule instruments, processes, institutions and actors were playing important roles in state regulatory regimes. The concept of multi-level governance, was noted as originally developed to describe the situation of EU integration, where there is continuous negotiation among governments and the recognition of multiple centres of authority within governments (Hooghe and Marks, 2003: 234; Cairney, 2015: 30). However, there is no particular acknowledgement of non-state/state interactions as integral parts of governance. The concept of adaptive governance emphasizes decentralization of 
policy-making, and evolving consensus building among actors to address challenges (Ostrom, 1994: 3; Dietz et al, 2003; Nagendra \& Ostrom, 2012: 104; Hatfield-Dodds, 2007: 9). The recognition of the value of an adaptive, decentralized approach to governance aligns well with the municipal water governance situation in Ontario, but the concept does not elaborate on the different state and non-state rule instruments, institutions, processes and actors involved in governance, and the varying nature of the interactions.

The concept of participatory governance emphasizes the role that non-state actors can play in state governance (Kohler-Koch, 2010: 105; Hogl et al., 2012: 8; Newig, 2012: 48) but does not recognize the possibility that non-state actors can independently develop and implement rule instruments that can then be incorporated into state regulatory approaches (e.g. ISO 14001). The concept of collaborative governance places a strong emphasis on the value of cooperative arrangements between governance actors (Ansell and Gash, 2007: 543; Rosenbloom and Gong, 2013: 545), but fails to acknowledge the positive role that a more "check-and-balance" dynamic can play, as is the case with elements of the state/non-state municipal water governance situation.

The concept of network governance emphasizes the value of involving a wide range of participants as legitimate members of the governance decision-making process (Stoker, 2006: 41), but does not elaborate on different types of state and non-state rule instruments, or on the complex nature of the interactions between participants, like those in the municipal water governance context. The concept of sustainable governance recognizes that the private sector and civil society can work collaboratively on regulatory governance with state actors, but these non-state actors can also initiate, develop and implement valuable regulatory governance instruments and approaches independently of government, so that there can be both collaboration and "check-and-balance" dynamics at play (Webb, 2005: 243).

The review of government laws in Chapter 2.3, provided a better understanding of the legal framework and the role of state and non-state elements in the governance of the Ontario water management sectors. The evolving municipal approach to water governance in Ontario can be characterized by an increasing level of involvement of non-state actors in policy decisionmaking elements (Chapter 2.4), moving from state-centric approaches towards approaches that 
recognize the value of non-state governance components, whereby divergent perspectives are reflected in new and innovative policy instruments, tools and institutions.

Based on the discussion in Chapter 3 about the Ontario federal, provincial and municipal regulatory framework for water management activity and the complex array of state and nonstate actors, rule instruments, institutions and processes, this seems to align well with the concept of sustainable governance as defined by Webb (2005:243). Figure 11 provides a mapping exercise of such relationships showing both state and non-state elements in the sense that all three levels of Canadian governments and at the international level, are involved to one extent or another in municipal water governance, creating checks-and-balances dynamics among them. The combination of state and non-state rule instruments (e.g. OPSS, MCEA, DWQMS, ISO 14001, HACCP and Blue Flag), processes (e.g. certification, adjudication, enforcement), institutions (e.g. Source Water Protection Committees, ISO, CSA, Blue Flag), and actors (e.g. elected officials, municipal staff, auditors, members of ENGOs) that can support governmental environmental objectives and activities.

The foregoing examination of interviews, case studies and findings from the focus group in the municipal drinking water, wastewater and stormwater context highlights the role of laws, courts, and civil society organizations in recognizing the value of non-state rule instruments such as MSSs in municipal regulatory governance, particularly the use of EMSs for their wastewater and stormwater systems and of QMSs and HACCP for their drinking water systems.

The use of MSSs by Ontario municipalities can be described as an innovative example of sustainable governance in which the state adopts non-state approaches, involving rule instruments, processes, institutions, and actors, with both horizontal and vertical policy convergence. This spectrum of inter-connections and relationships occurring in Ontario's municipal water sectors aligns best with the concept of sustainable governance (Webb, 2005: 277-279), where state and non-state actors operate sometimes collaboratively, and sometimes in more of a check-and-balance manner.

It is also possible to draw connections between the theoretical concepts of policy convergence, policy transfer and associated terms discussed earlier, and the concept of sustainable governance as applied to municipal water management in Ontario. In particular, it 
is possible to identify instances of policy transfer (Dolowitz, Marsh, 2000: 5; Stone, 1999: 51), policy diffusion (Strang et al., 1993: 487), policy learning and policy convergence (Lenschow et al., 2005: 297; Holzinger et al., 2005: 775; Alcantara et al., 2012: 119).

As noted earlier in the dissertation, these inter-related terms are associated with policy innovation in so far as it is directly linked with diffusion and convergence processes whereby organizations try to improve their performance by imitating successful peers (Rogers, 1983; 2003; Strang \& Meyer, 1993: 491; Strang \& Macy, 2001: 147). The role that causal factors play in addressing environmental issues was also identified, with policy transfer, diffusion and learning sometimes occurring independently and sometimes leading to convergence (Holzinger, et al., 2011: 20; and Jörgens, et al., 2014: 1).

The analysis above of the laws and regulations, interviews, case studies and the focus group, points to the existence of a relationship between the approach to common environmental issues (sustainable governance) and a trend of policy convergence in the transfer of provincial risk-management approaches from the drinking water sector to the wastewater and stormwater sectors. This policy convergence operates with the interaction of all three levels of government, with rule instruments and processes being transferred by means of regulations (e.g. Open for Business Act, EASR regulations, O. Reg. 208/19 [the prescribed person regulation downloading of provincial functions to municipalities], pre-authorization of works and self-inspections), and by the voluntary action of municipal governments (e.g. adoption of ISO, CSA, HACCP standards). Table 3 highlights public and private regulations of relevance to the context of this study.

In this respect, as noted earlier, this research contributes to literature on policy convergence by proposing the idea of two dimensions, horizontal and vertical, of policy convergence (Tovilla and Webb, 2017a: 211), with the horizontal dimension referring to multiple same level governance institutions adopting a particular non-state approach (e.g. municipalities using EMSs in their operations), while the vertical dimension refers to the adoption by multiple levels of governance institutions of a particular non-state approach (e.g. federal, provincial and municipal governments all drawing on EMSs), including a quasi-vertical 
dimension recognizing the role of the courts as facilitators in resolving issues of federal, provincial and other law as applied to municipalities, including their use of MSSs.

Based on the theoretical conceptions of management system standards (MSSs) synthetized below, it is possible to draw connections between MSSs and the sustainable governance approach currently being adopted in the Ontario water sectors. Particularly notable in this respect are the following theoretical conceptions of MSSs:

a) State and non-state standards. MSSs are being developed in response to public concerns, human tragedy, environmental crisis or as precautionary measures, but also strongly rooted in market forces and profit-driven goals (Kollman et al., 2002: 52), with non-state MSSs being more stringent than state-based MSSs (Fulponi 2006: 10; Delmas et al., 2008: 75). Examples of triggers include new policy goals, uncertainty, stricter policies, new scientific insights, disasters, disease, market forces, fair practices, tragedies and catastrophic events (Figure 3).

b) Voluntary codes and management systems standards. Voluntary codes are commitments not required by legislation or regulations, agreed to by one or more individuals or organizations, intended to influence or control behaviour, to be applied in a consistent manner or to achieve a consistent outcome (Webb, 2004: 97). MSSs constitute a network of codes typically established by consensus, which could be either mandatory (e.g. DWQMS) or voluntary (e.g. ISO, CSA, HACCP).

c) Objectives of QMS, EMS and HACCP standards. The QMS, originally designed for the manufacturing and defence industries, closely aligns with the objectives of human health protection in the municipal drinking water sector (regardless of the source, technology to be used or location). Similarly, the HACCP, a standard for the food industry, clearly aligns with the objectives of producing drinking water of the desired quality to protect human health. The EMS, a standard designed to increase environmental performance, compliance and operational due diligence, appears to be more suited to reducing the likelihood of environmental and property damage risks. Nonetheless, the selection of a QMS or EMS should be based on a purposive consideration of the objectives to be accomplished. 
d) North American context. While the focus of this study is on Ontario, there are valuable experiences in other Canadian provinces (e.g. Edmonton/EPCOR, Metro Vancouver, City of Nanaimo, Halifax Water, the Alberta Capital Region Wastewater Commission) and in the United States where environmental emergencies have triggered government action to adopt elements of ISO 14001 (e.g. Wisconsin's Green Tier program, based on ISO 14001 certification for regulatory incentives; and the Michigan Guide to Environmental, Health and Safety Regulations, Michigan State [2018], containing a chapter with specific references to ISO 14001).

Specifically, non-state MSSs such as ISO 9001, ISO 14001 and HACCP are being transferred vertically and horizontally between multiple levels of state and non-state governance institutions (e.g. all three levels of government, private water operators). Reflecting on the above, there appears to be evidence of both vertical and horizontal adoption by multiple governance institutions of a particular non-state approach that draws on MSSs, and particularly on ISO 9001, ISO 14001 and HACCP.

In summary, based on the research undertaken in this study, the suggestion is that there is a connection between the sustainable governance model (Webb, 2005: 277-279) with a policy convergence taking place in the municipal drinking water, wastewater and stormwater sectors in Ontario (and to some extent, throughout Canada), and the use of non-state MSSs, specifically ISO 9001, ISO 14001 and HACCP. Figure 11 shows the four key components of a sustainable governance model: rule instruments (e.g. laws and regulations, inter-governmental arrangements, non-state standards, certification programs and self-regulatory codes); governance institutions (e.g. government regulatory agencies, inter-governmental bodies, private standards bodies, industry self-regulatory bodies); processes (e.g. enforcement of laws, certification and auditing of private rule systems); and actors (e.g. government, the private sector, and civil society ENGOs). 


\subsection{Factors For and Against the Use of MSS Standards for Wastewater and Stormwater}

Based on the research undertaken in this study (literature review, interviews, case studies and focus group), the claims that support the application of some form of non-state EMS standards to the wastewater and stormwater sectors include:

- the general support among interview respondents and focus group participants for the development and implementation of a provincial MSS for wastewater and stormwater, with medium to large municipalities likely having the resources to develop and implement MSSs, while smaller municipalities may not;

- a perception among interview respondents and focus group participants that an MSS standard for wastewater and stormwater would likely reduce the possibility of environmental violations occurring, and if they did, adherence to an MSS could provide a strong basis for a due diligence defence and may reduce the fines and remediation costs (Table 9, Figure 15);

- the recognition by federal and provincial governments and courts, based on the analysis of federal and provincial laws and court decisions, of the legal value of ISO 14001, in court cases and administrative decisions establishing abatement processes and penalties (Table 8, Table 10);

- a perception among many interview respondents and focus group participants that the adoption of MSS standards would have positive environmental and regulatory effects on Ontario's municipal water, wastewater and stormwater sectors, including standardization across operations as a primary benefit for upper management, as well as checks-and-balances to ensure environmental risks are not underestimated;

- the suggestion by some interview respondents and focus group participants that having MSS standards for the wastewater and stormwater sectors would likely make it easier for management to obtain council approval for funding for support staff, documentation, inspections and audits;

- a perception among some interview respondents and focus group participants that EMS standards assist in meeting growing state and non-state pressure for accountability, 
transparency and related responsibility for municipal water, wastewater and stormwater utilities (Figure 9 and Figure 11);

- a perception among many interview respondents and focus group participants that an MSS standard for the wastewater and stormwater sectors could assist in addressing regulatory gaps (e.g. inspections, audits, financial planning, performance reporting - see Table 27);

- a perception among many interview respondents and focus group participants that an MSS for the wastewater and stormwater sectors could encourage municipalities to adopt more self-initiated, evidence-based and strategic long-term infrastructure planning (with considerations for life-cycle assessments and climate change implications), which appears to align well with the provincial government trend towards self-inspections, external audits, and self-regulation (e.g. EASR, pre-authorization for low risk construction activities, O. Reg. 208/19 [the prescribed person regulation]);

- an observed increasing trend toward the adoption of customized MSSs standards for specific sectors, such as: ISO 29001, a QMS standard developed for the petroleum, petrochemical and natural gas industries; ISO 50001 for energy management, a hybrid combining elements of QMS, EMS and other standards; the made-in-Ontario DWQMS, a standard for municipal drinking water systems based on ISO 9001 and the HACCP (for the food industry); and ISO 14006 for incorporating eco-design into EMS.

- an observed increase in knowledge and experience among municipal officials with MSSs, and peer-to-peer sharing of that knowledge through inter-municipal bodies (e.g. MWWRC, Wastewater Practitioners Group) that can enhance the ability for policy convergence and policy transfer on these subjects;

- the potential for an MSS for the wastewater and stormwater sectors to bring government regulatory incentives (e.g. Ontario Ministry of Labour evaluating to help create a voluntary accreditation program for health and safety based on ISO 45001, which may recognize employers who go above and beyond to promote best practices see Chapter 2.1.8). 
- a perception among interview respondents and focus group participants that smaller municipalities have different capabilities for adoption of MSSs than do larger municipalities.

An important recent development is the Standards Council of Canada (SCC) and Engineers Canada (EC) 2018 Report advocating for an MSS for the stormwater sector. This report provides additional support for the sustainable governance approach and vertical and horizontal policy convergence in the adoption of non-state MSSs. The report's findings were published at the time the first draft of this research dissertation was completed in December 2018. Moreover, the sources of data and methods used in the SCC-EC 2018 Report are different (based on a literature review). Most importantly, the report's main recommendation is consistent with one of the major findings of this research, thus supporting the soundness, validity and reliability of these conclusions.

Furthermore, following a presentation by the author at the National Water and Wastewater Conference (November 2018), the CSA Group approached representatives of the Ontario Ministry of the Environment (MECP) and the author to start discussions that may lead to the development of a wastewater management standard (WWMS). At the time of writing this dissertation, a CSA Advisory Group had been formed and there were plans to establish a technical committee by the end of 2019 to develop the new standard for municipal wastewater systems (CSA Group, 2019).

On the other hand, some interview respondents and focus group participants made some suggestions concerning work that should be undertaken before developing and implementing an MSS for the wastewater and stormwater sectors, including:

- the value of conducting a cost-benefit and economic impact analysis to better understand the differential impacts, particularly for small municipalities. It was noted that there are 444 municipalities in Ontario, approximately $90 \%$ of which have a population of 50,000 or less and approximately $78 \%$ of which have a population of 10,000 or less. ${ }^{96}$ Based on this, there were suggestions concerning the value of

\footnotetext{
${ }^{96}$ Statistics Canada, 2016 Census data.
} 
guidelines, phased approaches, scalable scopes, and support networks to facilitate MSS compliance;

- the value of developing a better understanding of how MSS standards can assist in addressing issues such as flooding, spills, and environmental degradation, and so that elements of the MSS could focus on the environmental objectives it is trying to achieve (i.e. regulatory gaps - see Chapter 7.3.2); and

- the value of developing a better understanding about whether different types of MSS standards are needed for different municipalities, and a better understanding of the problems associated with a "one size fits all" approach to MSS standards.

To sum up some of the key findings of the research in relation to the arguments for and against the application of MSSs to wastewater and stormwater activities, there appears to be a perception among most state and non-state actors who participated in the study that the adoption of MSS standards have positive environmental and regulatory effects in governing Ontario's municipal wastewater and stormwater sectors. Government officials, ENGO, consultants and private regulators recognize the value of the DWQMS for the drinking water sector, and the transferability of that value to the wastewater and stormwater sectors. The findings also suggest that consideration should be given to properly assess the feasibility of implementing MSSs in small to medium size municipalities.

Summarizing examples of evidence and recognition of the value of EMS in municipal wastewater and stormwater systems include: academic research (such as this dissertation); awareness of consequences (i.e. environmental damage such as flood, spills, as well as economic impacts such as fines, court orders, legal fees, and reputation); private regulators willing to develop sector specific MSSs for municipal water sectors; provincial government endorsing a sector-specific EMS; and government enforcement activity. An indicator of this municipal reaction to provincially endorsed voluntary standards is the Ontario Sewer Use Bylaw Guidelines (1998), which in a span of five years had 60 percent of municipalities develop their own based on the provincial model. The voluntary adoption of a sector-specific EMS for wastewater and for stormwater is likely to increase with government-sponsored activity. The actions by the CSA Group to start in 2019 the development of a sector-specific wastewater 
management standard and the Standard Council of Canada's 2018 Report recommending a management system standard for municipal stormwater management are promising.

\subsection{Regulatory Gaps and Complementarity of an MSS in the Ontario Water Sectors}

This section considers the basis for selecting the appropriate MSS for the municipal drinking water, wastewater and stormwater sectors, followed by a discussion of the regulatory gaps in the water sectors and how those gaps are being addressed to establish the critical control points for drinking water and for wastewater and stormwater.

\subsubsection{Considerations for Selecting an MSS for the Water Sectors}

This section examines the differences in objectives of each of the relevant standards for the municipal water, wastewater and stormwater sectors (ISO 9001, ISO 14001 and HACCP). Based on a synthesis of the previous sections, risks and hazards associated with the provision of water/wastewater/stormwater services can be grouped in:

- Risks to human health, i.e. water borne disease.

- Environmental risks, such as contamination of soil, rivers and lakes, e.g., combined sewer overflows ${ }^{97}$ (CSOs - from combined sewer systems ${ }^{98}$ ) or sewer system overflows $^{99}$ (SSOs - from separate sewer systems ${ }^{100}$ ).

- Harm to public or private property, such as sewer back-ups, basement flooding.

In response to the Walkerton Inquiry (2002), the Ontario government connected the dots to address the health hazards associated with the provision of drinking water, designing the DWQMS to reduce the likelihood of health hazards affecting Ontario's residents.

As confirmed through interviews, case studies and focus group methods, most respondents and participants identified the EMS as the most suitable MSS for municipal wastewater and stormwater activities, and the QMS most suitable for drinking water. As shown in Table 4, the

\footnotetext{
${ }^{97}$ Combined sewer overflow (CSO) refers to a discharge to the environment from a combined sewer system (CSS) that usually occurs as a result of a rainfall event when the capacity of sewers are exceeded (MECP, 2019).

${ }^{98}$ Combined sewer system (CSS) refers to a collection system that contain sanitary sewers and stormwater sewers within the same sewer collection system (adapted from MECP, 2019).

${ }^{99}$ Sewer System Overflow (SSO) refers to an overflow when additional flows enter the sewer system due to rainwater, groundwater rise or emergency situations (blockage such as grease build-up, tree roots in pipes, or accumulation of "unflushables") overloading the system capacity (sewer pipes) (WEAO, 2019).

100 Separate sewer system (SSS) refers to collection systems that contain separate sanitary sewers, and separate stormwater, making them two separate collection systems (adapted from MECP, 2019).
} 
risks and hazards are different for wastewater and stormwater, and as a result an EMS standard would seem to be a more appropriate approach to address the environmental and public/private property damage risks.

As discussed in the case studies (Chapter 5.0), some municipalities that had adopted a quality MSS for their wastewater issues subsequently decided to drop it because of a perceived lack of value. If the objective is to ensure that the design, construction and operation of wastewater and stormwater infrastructure to address environmental and property damage risks, then a quality management system approach would appear adequate. Figure 20 represents an attempt to illustrate the QMS approach with controlled inputs and outputs, similar to a manufacturing facility, where an organization can control all inputs and have a quality product (outputs).

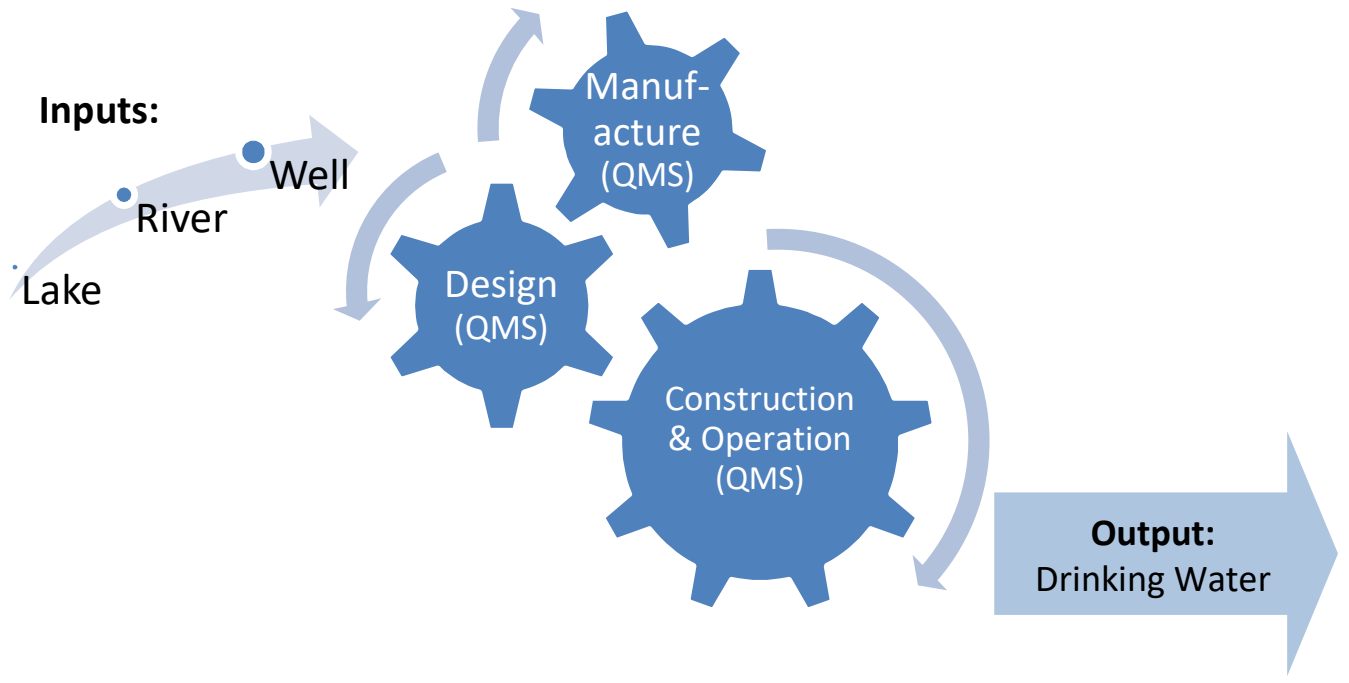

Figure 20. DWQMS Single Inputs \& Outputs (Controls: QMS Process)

A QMS is designed to ensure that a product is manufactured at the same level of quality regardless of where it is manufactured. Manufacturing a beverage like drinking water requires a QMS/HACCP approach to ensure it is delivered (output) with the same level of quality regardless of the water source used (lake, river or wells). This is controlled through strict standards for design, as well as manufacturing (or construction of the infrastructure that will distribute water). In the drinking water context, the MECP accomplished an effective DWQMS 
with the support of regulated design standards and pipe disinfection, mandatory source water protection and mandatory CCPs to ensure continual water pressure, testing and disinfection.

In contrast, an EMS standard is intended to ensure that there are procedures in place to reduce impacts on the environment, including addressing the impacts of the broader infrastructure in both design capacity and performance. Figure 21 illustrates the EMS approach with uncontrolled inputs and outputs. The objective here is to minimize undesired outputs considering the uncertainty of multiple inputs to the system.

Thus, regardless of how the manufacturing process was designed and built or what shape it is in, in the context of wastewater and stormwater the primary objective of the EMS is to have systems in place that would reduce the risk of impacts on the environment, taking into consideration that there is limited control of inputs (i.e. inputs are heavily dependent on weather, rain, inflow and infiltration (multiple non-controlled catchbasins, cross-connections) and fewer opportunities to ensure quality.

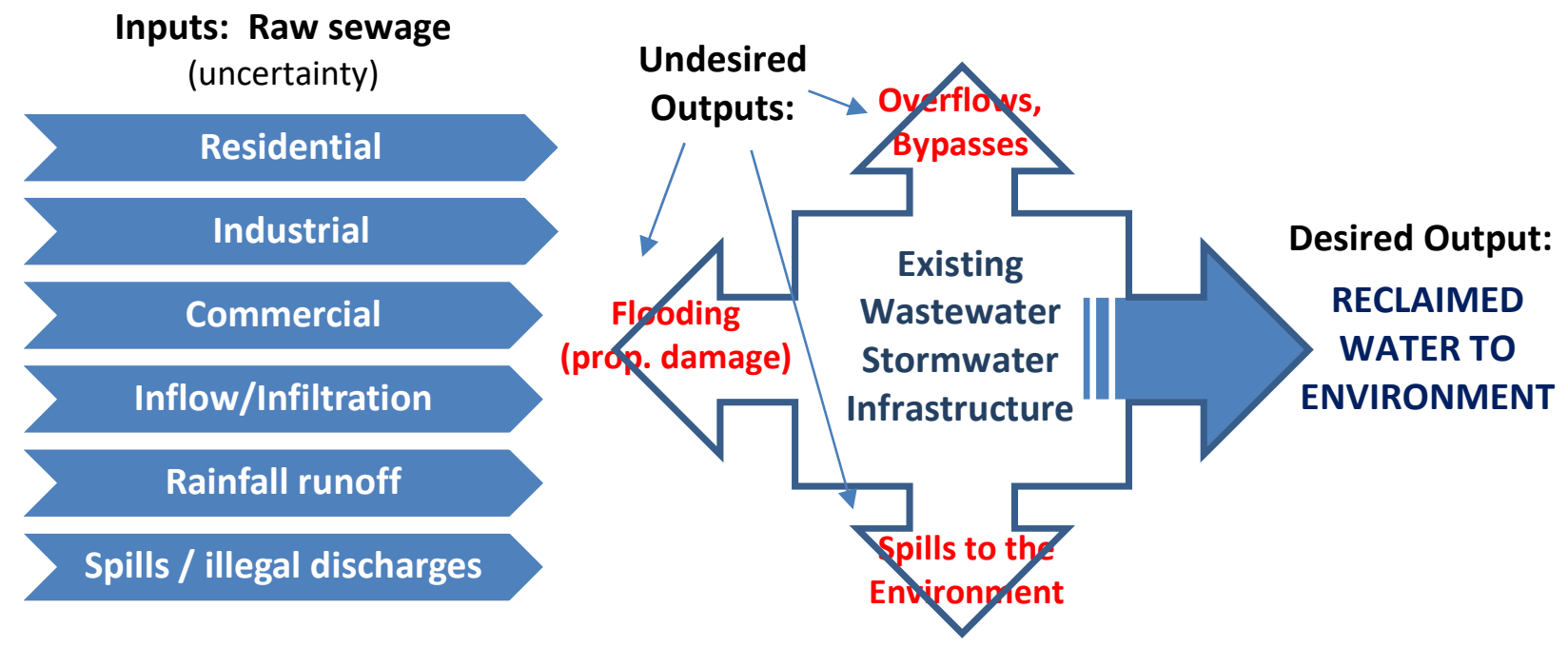

Figure 21. EMS Wastewater - Multiple Inputs \& Outputs (Controls: EMS Process)

Some of the key EMS objectives are to reduce impacts on the environment and ensure the capacity to respond to the uncertainty and unforeseen emergencies. In terms of wastewater and stormwater infrastructure, the key question in selecting between a QMS and an EMS is how far the organization is prepared to go to ensure that "inputs" and "outputs" are 
adequately controlled. This means selecting between "ensuring" and "influencing" the design and construction of infrastructure to certain minimum criteria.

While the QMS requires ensuring infrastructure is designed, built and delivered, the EMS requires influencing the delivery of such quality infrastructure. Influencing is easier to document and achieve than ensuring. The EMS objective of environmental protection at a minimum should involve ensuring that the wastewater/ stormwater infrastructure in place is well operated and well maintained, and that when disasters do occur municipalities have effective response procedures to reduce risks of environmental and property damage. Involving design and construction of wastewater and stormwater infrastructure brings two separate dimensions, and likely the reason why most entities (public or private) adopting ISO 14001 focus only on operations rather than design and construction. The two complexities if involving design and construction in the scope of the MSS involve: First, the application of appropriate treatment technologies and design options (i.e. equipment selection, capacities, redundancies) to achieve desirable environmental goals; and second, the use of appropriate methods for construction to reduce likelihood of environmental risks during construction.

\subsubsection{Addressing the Gaps}

Based on the research conducted for this study, the legally mandated DWQMS 2.0 (2017) addresses the health hazard risks (Table 6) for drinking water and the critical control points (CCPs) designed to ensure a systematic approach to accountability, documentation control, updating of operational procedures, internal and external audits, with effective checks and balances according to the plan-do-check-act cycle of the ISO management structure model.

A summary of the regulatory gaps for drinking water, wastewater and stormwater is presented in Table 27. For the municipal drinking water gaps include: financial and cost recovery and environmental protection (in the form of regulating the discharge of contaminants to the environment). The cost recovery concept was a recommendation in the Walkerton Inquiry report. While the province required a financial plan (O. Reg. 453/07), the scope of this regulation did not go as far as having full accounting recovery. As noted by Abouchar et al. (2010), the difference between O. Reg. 453/07 and full cost recovery is that the regulation "merely requires that the system be financially viable" (2010: 8) covering long-term 
capital investment planning, asset management, and approaches for the development of financial plans. Full cost recovery would have required the revenues needed to provide full service, covering source protection costs, operating costs, financing costs, renewal and improvement costs. In this context, having adequate revenue is the key difference. Under the current regulation as it stands now, municipalities are required to financially plan what they can do (with current revenues adjusted annually by inflation), rather than what they should do. In terms of environmental protection as noted in this dissertation section 2.3.2, while there was consideration of ISO 14001 when the DWQMS was being developed (City of London, 2008), a review by the author of the original 2006 DWQMS found it did not contain the word "environment" or any clause pointing to "environmental protection". Questioned by the author about this during the MWWRC 2017 Annual Workshop, an MECP representative in charge of the DWQMS noted that such environmental protection was left for municipalities to determine as part of Element 21 (continual improvement) of the DWQMS.

As for the regulatory gaps in the wastewater and stormwater sectors, where environmental risks are the main concern, an EMS standard can assist with financial planning, minimum engineering design criteria, performance reporting, and inspections/audits. Table 27 identifies those with a red circle; and a white circle those gaps where the MECP is actively working to address through mandatory requirements (WEAO, 2019). One element to consider that constitutes a significant difference with drinking water is the reliance of the wastewater/ stormwater systems on design guidelines and best management practices (Table 3).

Table 27 reveals how the DWQMS is positioned in drinking water governance to address many policy goals identified through the Walkerton Inquiry Recommendations. One example is the reporting requirements. Typically, site-specific approvals (ECAs) require municipalities to report annual performance in treatment, but there are no requirements to report the performance of the collection system (network of sewer pipes and pumping stations). Prioritizing all identified gaps would require a different type of analysis (with an extensive stakeholder consultation process), which is not within the scope of this research. 
Table 27. Gaps in Legislation and How the DWQMS Fills Them in Drinking Water

\begin{tabular}{|c|c|c|c|}
\hline Barrier / Protection & Drinking Water & Wastewater & Stormwater \\
\hline Source water protection & CWA, NMA ${ }^{101}$ & CWA, NMA & CWA, NMA \\
\hline \multirow[t]{2}{*}{ Financial planning } & \multirow[t]{2}{*}{ O. Reg. 453/07 } & G A P & \multirow{2}{*}{ G A P } \\
\hline & & PSAB Standards & \\
\hline \multirow{2}{*}{$\begin{array}{l}\text { Financial full cost } \\
\text { recovery }\end{array}$} & G A P $\mathbf{P}^{102}$ & G A P & G A P \\
\hline & PSAB Standards ${ }^{103}$ & PSAB Standards & PSAB Std, SWM fees ${ }^{104}$ \\
\hline Effective treatment & $\begin{array}{l}\text { CPP (treatment), } \\
\text { SDWA }{ }^{105}\end{array}$ & ECA & $\begin{array}{l}\text { ECA, SWM design } \\
\text { guidelines }\end{array}$ \\
\hline \multirow{2}{*}{$\begin{array}{l}\text { Minimum design } \\
\text { criteria }\end{array}$} & \multirow{2}{*}{$\begin{array}{l}\text { SDWA, Design criteria, } \\
\& \text { area-wide permits }\end{array}$} & G A P & G A P \\
\hline & & Design Guidelines & SWM design guidelines \\
\hline \multirow[t]{2}{*}{ Testing \& monitoring } & \multirow{2}{*}{$\begin{array}{l}\text { O. Reg. 248/03, } \\
\text { 243/07, DWQMS }\end{array}$} & G A P (collection) & \multirow{2}{*}{ G A P } \\
\hline & & ECA (treatment) & \\
\hline \multirow[t]{2}{*}{ Reporting performance } & \multirow[t]{2}{*}{ SDWA, DWQMS } & G A P (collection) & \multirow[b]{2}{*}{ G A P } \\
\hline & & $\begin{array}{l}\text { ECA (treatment), } \\
\text { PPCP }\end{array}$ & \\
\hline Operator training & $\begin{array}{l}\text { O. Reg 128/04, } \\
\text { DWQMS }\end{array}$ & O.Reg 129/04 & G A P \\
\hline \multirow{2}{*}{$\begin{array}{l}\text { Secured distribution } \\
\text { (or) collection system }\end{array}$} & \multirow{2}{*}{$\begin{array}{c}\text { SDWA, CPP (disinfect) } \\
\text { O. Reg. } 243 / 07\end{array}$} & G A P & G A P \\
\hline & & MTO-OPSD Stds ${ }^{107}$ & SWM design guidelines \\
\hline Emergency Response & Permit, DWQMS & ECA/Permit & G A P \\
\hline $\begin{array}{l}\text { Inspections / audits } \\
\text { (internal/external) }\end{array}$ & DWQMS & G A P & G A P \\
\hline Env. Prot'n/discharges & G A P & OWRA/ ECA & OWRA/ECA \\
\hline
\end{tabular}

Prioritizing all identified gaps would require a different type of analysis (more engineeringbased with a strong stakeholder consultation process), which is not part of the scope of this research. In the context of this study, special attention is directed at gaps associated with the critical control points (CCPs, see chapter 2.3.2). The CCPs, as pre-identified mitigation factors on drinking water systems, are listed in Table 28 , and is associated with system functionality (and corresponding legislation).

101 Clean Water Act (O.Reg. 284/07, O.Reg. 288/07), Nutrient Management Act (O. Reg. 267/03, AgriSuite BMP).

102 O. Reg. 453/07 does not include full cost recovery. FCR was a recommendation by Justice O'Connor

103 See Section 4.4.

${ }^{104}$ About a dozen Ontario municipalities have established bylaws for stormwater management (SWM) fees.

105 Safe Drinking Water Act (O.Reg. 170/03, O. Reg. 169/03.

106 Ontario Policy F-5-1 for combined sewer systems requires Pollution Prevention Control Plans (PPCP).

${ }^{107}$ Ministry of Transportation (voluntary) ON Provincial Standard Drawings for sewer systems. 
Table 28. Critical Control Points for Municipal Drinking Water Systems (DWQMS)

\begin{tabular}{|c|c|c|}
\hline CCPs - Risk assessment & Functionality & Specific Regulation \\
\hline \multirow{7}{*}{$\begin{array}{ll}\text { - } & \text { Source water protection } \\
\text { - } & \text { Disinfection, treatment plant } \\
\text { - } & \text { Water treatment processes } \\
\text { - } & \text { Disinfection - storage } \\
\text { - } & \text { Disinfection - distribution } \\
\text { - } & \text { Water treatment processes } \\
\text { - } & \text { Water storage levels }\end{array}$} & Minimum design criteria & O. Reg. 170/03, Permits \\
\hline & Management framework & O. Reg. 170/03 (DWQMS) \\
\hline & Certification of operators & O. Reg. 128/04 \\
\hline & Financial plans & O. Reg. 453/07 \\
\hline & Drinking water testing & O. Reg. $248 / 03$ \\
\hline & Drinking water quality standards & O. Reg. $169 / 03$ \\
\hline & Flushing for lead & O. Reg. $243 / 07$ \\
\hline
\end{tabular}

The idea of having CCP has been identified through the survey-interviews, and the focus group, as necessary to assist in the implementation of costly risk assessments for MSS in wastewater and stormwater systems. Table 29 Table 29attempts to draw parallels for wastewater and stormwater systems based on a simplified regulatory functional framework proposed by the author. This table identifies some proposed CCPs for municipal wastewater and stormwater systems.

Table 29. CPPs Proposed for Wastewater / Stormwater Systems

\begin{tabular}{|l|l|l|}
\hline CCPs - Risk assessment & Functionality & Specific regulations \\
\hline \multirow{4}{*}{$\begin{array}{l}\text { SONE - TBD } \\
\text { Suggested CCPs relevant to } \\
\text { wastewater: }\end{array}$} & Minimum design criteria & None / ISO 14001 \\
\cline { 2 - 3 } - Spills and overflows & Management framework & None / ISO 14001 \\
\cline { 2 - 3 } - Infiltration and inflow (I/I) & Certification of operators & O. Reg. 129/04 \\
\cline { 2 - 3 } - By-passes \& overflows & Wastewater quality standards & Site specific ECAs \\
\cline { 2 - 3 } - Reporting to public & Wastewater testing & Site specific ECAs \\
\cline { 2 - 3 } - Flushing / cleaning & Collection system integrity & None/ ISO 14001 \\
\cline { 2 - 3 } - Biosolids management & Sludge treatment and disposal & Site specific ECAs, \\
- Odour controls & Nutrient Mangmt. Act \\
\cline { 2 - 3 } & System performance & None / ISO 14001 \\
\cline { 2 - 3 } & Continual improvement / root causes & None / ISO 14001 \\
\hline
\end{tabular}


Table 29 reveals that while there is some sort of regulatory requirements for the certification of operators, testing, and wastewater quality standards, there is nothing on: minimum design criteria, EMS (at the provincial level), financial planning, and sewer inspection and cleaning requirements. The proposed CCPs on Table 29, identifies the risk factors likely to be addressed if there was a sector-specific wastewater management standard. The risk factors, functionality and "self-regulation" noted under the "specific regulations" column, illustrates the risks that could be mitigated by having an ISO 14001, EMS-type of MSS. There are five (5) major gaps where a sector-specific MSS could address:

- generic wastewater municipal design criteria

- management framework

- $\quad$ performance reporting

- $\quad$ CCP to ensure collection system integrity

- $\quad$ CCP to ensure system performance (flushing, cleaning, biosolids management and odour controls)

This chapter has offered a synthesis of some of the key findings emerging from the research undertaken for this research concerning the application of management system standards to municipal water activities. First, the municipal drinking water, wastewater and stormwater sectors in Ontario (and to some extent the rest of Canada) have a clear connection with the sustainable governance model, and also with the use of non-state MSSs, in what seems a policy convergence occurring both vertically and horizontally. Second, there appears to be a positive perception among most study participants (state and non-state actors) of the use of MSS standards to govern Ontario's municipal wastewater and stormwater sectors. Lastly, there is evidence that the DWQMS successfully addresses the government's regulatory and environmental objectives (e.g. CELA 2011, MECP, 2016), and there is a perception that regulatory gaps in wastewater and stormwater noted in Table 27 would likely be addressed by an EMS-type standard. 


\subsection{CONCLUSIONS AND RECOMMENDATIONS}

The key question that this research has sought to answer is: is there value in creating a provincially mandated municipal wastewater environmental management system standard, and a stormwater environmental management system standard? Additionally, there are six subquestions that this study has analyzed, which are addressed in this chapter.

\subsection{Answer to Research Sub-questions}

The first sub-question revolved around an investigation of how academic conceptions of governance, policy convergence and management systems standards could assist in understanding Ontario's evolving approach to municipal water regulation.

This research examined the evolving conceptualization of governance since the 1980 s and how it has moved from a government-centric model toward a sustainable governance model (Webb, 2005), whereby non-state actors are significant drivers of policy development and implementation in a dynamic that is collaborative in some cases and rivalrous and adversarial in others. It has also examined how policy convergence has evolved from its initial conceptualization in the context of globalization and trade competition, into an array of factors influencing how policy goals are achieved. Lastly, this dissertation reviewed the evolving application of management systems standards as they relate to ISO 9001 (1987) and ISO 14001 (1996) from the original conceptualization as a means to addressing corporate profit-driven concerns to its current condition as a large family of standards expanding both in scope and in use, due to the increasing adoption by the government sector of elements to fill state-based regulatory gaps.

Based on research undertaken in this research, there appears to be a policy convergence occurring in terms of government use of non-state management system standards in support of government objectives, occurring in two dimensions:

- a horizontal dimension (i.e. with multiple governance institutions at a single level adopting non-state approaches, e.g., municipalities using EMSs). 
- $\quad$ a vertical dimension (i.e. between federal, provincial and municipal levels of governments), including a quasi-vertical dimension recognizing the distinctive role of Canadian courts as facilitators in resolving issues of federal and provincial jurisdiction with respect to use by municipalities of MSSs;

The research suggests that state actors are drawing on non-state rule instruments and are also working in collaboration with non-state actors in developing rule instruments and processes, leading to an apparent calibration of state and non-state rule instruments among policy officials, policy networks, and policy communities. There is an apparent policy learning and transfer of policy approaches from the drinking water sector to the wastewater and stormwater sectors, and from the non-state sector to the government sector (e.g. Open for Business Act, EASR regulations, O. Reg. 208/19 [prescribed person regulation, downloading of provincial functions to municipalities], pre-authorization of works and self-inspections - see Table 3). Policy convergence is also evident in the voluntary adoption by some municipal governments of MSSs for their water activities. The criteria used for assessing the policy convergence included:

$\checkmark$ Explicit use of non-state rule instruments (e.g. ISO 14001, ISO 9001, Blue Flag beach certification).

$\checkmark$ Explicit use of non-state processes (e.g. third-party auditing/certification).

$\checkmark$ Explicit use of non-state institutions (e.g. using CSA, a non-state standards body, to develop a DWQMS or customized wastewater or stormwater EMS standard; Environmental Defence, the body in administering the Blue Flag program).

$\checkmark$ Explicit use of non-state actors (e.g. MECP-accredited registrars such as BSI and SAI Global, to obtain third-party certification under the DWQMS, Swim Drink Fish).

Laws and court decisions analyzed as part of this research suggest that governments and courts are drawing on MSSs to address municipal environmental water issues, and as such they represent further evidence of the state use of non-state MSSs in support of public policy objectives. This governmental use of MSSs appears to be intended to improve accountability, establish the necessary duty of care, and better protect against hazards to human health and the environment. 
The responses of interview participants, the insights from the case studies and the discussions of the focus group participants provide further support for the proposition that a form of sustainable governance (Webb, 2005: 277-279) seems to be operating in the establishment of state and non-state rule instruments, processes, institutions and actors variously supporting the achievement of municipal water management objectives, constituting both horizontal and vertical policy convergence.

The second sub-question explored scholarly conceptions of governance, to determine which one best aligns with Ontario's evolving approach to municipal water regulation.

This dissertation used the definition of governance offered by the Commission of Global Governance, as the ".... sum of the ways in which individuals and institutions, in public and private spheres, manage their common affairs in order to accommodate diverse and conflictual views" (Boas, 1998: 119). The examination of different characterizations of governance included in this study covered: multi-level governance, adaptive governance, participatory governance, collaborative governance, network governance and sustainable governance, which observed an evolution from a government-centric prior to the 1980 s, to different levels of participation observed since the 1990s (Figure 7).

Based on research conducted for this dissertation, it was observed that the particular combination of state/non-state rule instruments, institutions, processes and actors seems to align best with the concept of sustainable governance as defined by Webb (2005), whereby state and non-state rule instruments, processes, institutions and actors operate collaboratively in some cases, and in more of a check-and-balance manner in others. While the other conceptions of governance examined in this dissertation all acknowledge a non-state role in environmental regulation, they do not consider the rule instrument/process/institution/actor taxonomy offered by the sustainable governance model. Also, unlike the sustainable governance model, these other models do not acknowledge that non-state governance approaches can be developed and implemented independently of state approaches, nor do they consider the collaborative/check-and-balance dynamic. 
The sustainable governance model best aligns with this research because in the context of the Ontario municipal drinking water, wastewater and stormwater experience there are significant state and non-state actors drawing on a combination of state and non-state governance rule instruments (e.g. laws, ISO standards, HACCP and Blue Flag), processes (e.g. adjudication, enforcement and certification), institutions (e.g., federal, provincial, and municipal governments, courts, ISO and CSA standards bodies, Environmental Defence [Blue Flag]), and actors (e.g. elected officials, municipal staff, auditors, members of ENGOs) that variously support government environmental objectives and policy goals.

The dynamic state and non-state interactions and linkages are mapped in greater detail in Figure 11. Sustainable Governance Map for the Municipal Water SectorsFigure 11. The mapping reveals the complex relationships and interactions among international, federal, provincial, and municipal actors and institutions involved in a municipal water utility. These relationships are formed by conventional and innovative direct and indirect links connecting actors and institutions with state and non-state rule instruments. Municipalities (and their utilities) are responsible for designing, building, operating and maintaining drinking water, wastewater and stormwater systems, at the centre of multiple processes in which rule instruments, actors and institutions are intertwined.

The third sub-question focused on whether management system standards are likely to have neutral, positive, or negative effects on the performance of Ontario municipal water management activity.

A total of 1.1 million ISO 9001 certifications have been provided since 1987, and close to 350,000 EMS certifications since 1996 (ISO, 2017). Most of these are registered by private corporations. Only $1 \%$ of QMS and $0.9 \%$ of EMS certifications are associated with "water supply" entities and/or "public administration" combined (ISO, 2017).

Drawing on management standards literature, scholars have observed positive views in both government and industry of the brand value of MSSs, stakeholders recognizing positive influence on corporate social responsibility (Webb, 2015a: 30; Darnall et al., 2010: 288; Delmas et al., 2011: 103), to effectively address evolving needs, societal expectations and market 
demand (Henriques et al., 2008: 162), and to increase organizations' internal efficiency, external legitimacy, as well as to help organizations respond to stricter regulations (Hart \& Milstein, 2003: 56; Delmas et al, 2011: 111).

There is also literature critically assessing and debating the benefits of voluntary MSS initiatives. Kollman \& Prakash (2002: 43), Chatterji \& Toffel (2010: 936) and Simpson \& Sroufe (2014: 830) suggest that reporting and validation are deflectors of attention rather than performance and process improvements. The risk posed by a stagnant EMS, whether statebased or non-state, is the lack of incentive for innovation, and some authors suggest that MSSs may inadvertently discourage diversity of environmental management practices and innovation by encouraging "going by the book" compliant behaviour (Chatterji \& Toffel 2010: 934; Simpson \& Sroufe, 2014: 831; Dahlström et al., 2003: 187; Alvarez-Garcia et al., 2016: 1). Nonetheless, Arimura et al., (2008: 293) argues this also applies to command and control regulations. The ISO 14001 does not require third-party audits be publicly disclosed, which is noted as a weakness (Darnall et al., 2008: 95; Searcy et al., 2012: 278).

However, these criticisms are outweighed by arguments in support of MSSs that underscore their value and benefits, positive impacts on performance (for EMS), opportunities for innovation, enhanced cost efficiency, improved stakeholder relations, external legitimacy, and positive influence on stakeholders (Hart \& Milstein, 2003: 56; Henriques and Sadorsky, 2008: 162; Delmas et al., 2011: 103; Searcy et al., 2012: 278), and others who have critically assessed EMSs have noted the positive environmental performance impact from government sponsored voluntary environmental MSSs (Darnall et al., 2010: 303; Alvarez-Garcia et al,, 2016: 1).

The fact that Ontario has developed and adopted a mandatory QMS for water quality is indicative of a perceived positive impact of such a standard on water quality. The fact that Canadian laws and court decisions draw on management system standards suggests recognition of their value by legislators and courts.

Concerning the efficacy of the quality management system standard for Ontario drinking water, a 2011 report by the Canadian Environmental Law Association ${ }^{108}$ noted that "based on monitoring results collected by the Ontario MECP, it appears that municipally treated drinking

\footnotetext{
${ }^{108}$ See Footnote No. 31
} 
water usually meets Ontario's drinking water quality standards." This report noted that the ministry's stringent drinking water standards were met in (CELA, 2011: 2):

- $99.88 \%$ of drinking water tests on municipal residential systems,

- $99.51 \%$ of drinking water tests on non-municipal year-round residential systems, such as mobile home parks, and

- $99.49 \%$ of drinking water tests on non-residential and seasonal residential systems serving designated facilities such as day nurseries, schools and health centres.

More recent information from the MECP Chief Drinking Water Inspector Annual Reports from 2012-2015 indicate that province-wide $99.8 \%$ of all drinking water test results meet Ontario's drinking water quality standards, and there is 98 to $99 \%$ compliance of non-municipal systems from the periods 2012 to 2015 (MECP, 2016). Furthermore, the 2014-2015 MECP drinking water report indicated that there were 17 SDWA prosecutions leading to convictions, with no municipality involved in any of these convictions (MECP, 2016).

In the interviews conducted for this dissertation, $95 \%$ of respondents concluded that implementing an MSS and particularly an EMS, would have positive effects on the municipal water, wastewater and stormwater sectors. Of the total of 423 responses coded in arguments supporting MSSs and arguments raising concerns about challenges posed by MSSs, nearly $75 \%$ included arguments inclined to support the adoption of MSSs for wastewater and stormwater systems.

According to the case study findings (Chapter 5.0), York Region, Richmond Hill and Durham Region all have ratings above $95 \%$, with $99 \%$ or more of the drinking water quality tests on most of their subsystems meeting the provincial standard. All ratings and test result percentages were even higher for 2014-2015, with many $100 \%$ ratings (MECP, 2015; 2016). In summary, the available evidence suggests that the application by municipalities of quality and environmental management system standards has a positive effect.

The fourth sub-question explores which MSS standards are best suited to address municipal water, wastewater and stormwater activity.

The research findings have revealed an apparent over-simplification of the reasons why most standards draw on EMSs rather than QMSs for wastewater and stormwater. This research 
identified empirical and documented evidence of the municipal use of MSSs (legislated or voluntary) as follows:

- ISO 9001 (QMS) more suited for drinking water systems;

- ISO 14001 (EMS) more suited for wastewater and stormwater systems; and

- HACCP more suited for drinking water systems.

This proposition is based on the nature of the inputs and outputs in the management of MSS processes in water, wastewater and stormwater systems, and the environmental, health and property risks associated with them (Table 4). Increasingly, federal, provincial and municipal laws, as well as the courts, are referencing ISO 14001 as a policy tool for environmental protection. In addition, the semi-structured interviews and case studies provide experiences and documented evidence pointing to MSSs, and particularly ISO 14001, as the model best suited to wastewater and stormwater systems.

The combined effect of the DWQMS and its regulatory framework as observed in this study appears to have a track record of achieving its policy objective of human health protection. While it would be erroneous to credit the achievement of this objective to the DWQMS alone, as this policy tool works in tandem with a dozen regulations created since the Walkerton tragedy, there appears to be widespread agreement on the benefits and value of the DWQMS (95\% respondents). An overwhelming 100\% of respondents noted that the ISO 9001 was the correct standard on which to base the DWQMS for drinking water, and almost all respondents agreed that ISO 14001 was the best fit for the wastewater and stormwater sectors. There was also recognition of the value of the DWQMS in professionalizing the operation of water systems, the value of support networks such as the MWWRC, and the transferability of its benefits to the wastewater and stormwater sectors.

This study found that an increasing number of Ontario municipalities are adopting MSSs for their water sector systems. There are currently six Ontario municipalities that have voluntarily adopted non-state MSSs (Durham Region, York Region, Elgin Area and Lake Huron Drinking Water Systems, and Collingwood). In addition, there are five Ontario municipalities developing EMS standards pursuant to ISO 14001 (Halton Region, Toronto, Region of Peel, Vaughan, and Barrie). The combined populations of municipalities with some form of ISO 14001 in place (30\% 
of Ontario's population) and those developing EMSs (est. 5.1 million people or 36\%) represents $66 \%$ of Ontario's total population. Canada-wide, municipalities representing approximately $47 \%$ of the country's total population have some form of EMS in place (Figure 9).

The fifth sub-question explored why Ontario and other municipalities are adopting quality and environmental management system standards, such as those set out in ISO 9001 and ISO 14001.

Research undertaken for this dissertation suggests that municipalities are adopting MSS standards to fill regulatory gaps and supplement state-based regulation (e.g. inspections/audits, operational documentation, management controls - see Table 27), to anticipate and address regulatory uncertainty from provincial activity, to reduce potential liabilities, enhance accountability, to motivate staff to ensure compliance and increase consistency/compatibility in the operation of water and wastewater systems, to capitalize on MSS benefits from one sector to another and to ensure effective system performance. MSS standards have also been adopted to improve consistency in drinking water, wastewater and stormwater system management and to reduce the likelihood of flooding, spills, overflows and contamination. It has been shown that federal and provincial laws, policies and court decisions provide an additional impetus for municipalities to adopt management system standards.

The sixth sub-question focused on: how (if at all) the voluntary adoption of MSSs (in the form of ISO 9001 and/or ISO 14001) have evolved over time, for the municipal water, wastewater and stormwater sectors.

First, we have seen that initially only a legally mandated water QMS was developed for the municipal sector, while the use of EMS standards for the municipal wastewater and stormwater sectors has not been legislatively mandated. Over time, a number of municipalities have adopted EMS approaches based on the ISO 14001 standard, and this has been reinforced by court decisions, and positive references to EMSs standards in laws and related documents. Among the 21 Canadian municipalities identified as having some form of EMS (Figure 9), 10 are ISO 14001 certified, five are self-declared, and six are under development. The argument here 
is that some municipalities knowingly or sometimes inadvertently improve their management practices aligned with elements of ISO-type of standards.

The failed attempt by the MECP in 2009 to create a sector-specific MSS for wastewater is of relevance to this study. The initiative was apparently shelved in light of a lack of political will to move forward with it at the time. The focus group participants were on the whole supportive of having (voluntary or mandatory) sector-specific MSSs for wastewater and stormwater management. Evidence of increasing support for municipal EMSs can also be found in the Standards Council of Canada (SCC) and Engineers Canada 2018 Report, which advocates for an MSS for the stormwater sector, and the growing trend of municipalities actively seeking ISO 14001 certification (e.g. Toronto, Peel, Halton, Barrie, Vancouver and Vaughan).

\subsection{Answer to Key Research Question}

The key research question underlying this study is whether there is value in creating a provincially mandated municipal wastewater management system standard, and a stormwater management system standard.

Reflecting on the insights gained from the review of the academic literature, laws and court decisions, the semi-structured interviews, the case studies, and the focus group, there appears to be a good basis of support for the establishment of a provincially required Wastewater and Stormwater Environmental Management System Standard aligned with the ISO 14001 EMS standard. This proposition was directly addressed in the focus group, where participants were supportive of the use of some form of EMS, as part of a broader sustainable conception of governance.

Taken together this research finds evidence in support of and wide recognition of the practical value of MSS by assisting municipalities in meeting their environmental objectives, addressing environmental and property damage risks, providing an additional mechanism of public accountability and transparency, and improving alignment with the existing legal structure. It was also apparent that there is no political appetite in the provincial government to embark on a mandated MSS, so the preferred option at this time appears to take the form of a provincially-endorsed, voluntary sector-specific standard for wastewater and also for 
stormwater, which could constitute a catalyst to boost voluntary uptake of MSSs by small to medium municipalities (as it is already occurring with large municipalities). This standard could be based on a customized variation of the ISO 14001, DWQMS and other standards to address existing regulatory gaps. More specifically:

1) if an EMS for wastewater and stormwater is to be widely adopted, the most effective approach would likely be a provincially regulated requirement, similar to the DWQMS. It was noted by most participants that medium to large municipalities are more likely to have the resources to be able to develop and implement an EMS, but smaller ones will have significant challenges (in terms of capacity building, training, and manpower). A recommendation arising from this discussion was that a mandated MSS should be scalable, flexible, adaptable, risk-based and implemented gradually. There was agreement that legislative/regulatory requirements may not be immediately feasible until consultations have taken place. However, there was also support for the development first of a sectorspecific standard, and then of a mandatory requirement of application afterward. Related to this, there was interest in having separate MSSs for wastewater and for stormwater.

2) peer-to-peer learning networks between municipalities could be a valuable method for sharing best practices and related information (similar to the Municipal Water Wastewater Regulatory Committee for DWQMS implementation in drinking water).

3) a clear opportunity was identified for the provincial and private regulators to work together, similar to the process to develop the DWQMS for drinking water. Specifically, on this, there was support for the involvement of non-state standards development bodies like ISO or CSA Group in the development of the EMS standard, working with government officials and others. This would be similar to the DWQMS development process.

\subsection{Contributions of Study}

The following aspects are identified as key contributions of this research:

1. Governments' use of independently developed non-state rule instruments, processes, institutions and actors in support of environmental public policy (e.g. ISO 14001, third party audits, Blue Flag program) 
2. Governments' directly and indirectly incorporating non-state rule instruments (i.e. EMS and/or ISO 14001) into laws, policies, guidance documents and court decisions (e.g. CEPA, Environmental Enforcement Act, OWRA, DWQMS, Ontario Environmental Penalties Regulation-O. Reg. 222/07 - see Table 8).

3. Policy convergence happening in the Ontario municipal wastewater and stormwater sectors by adopting and/or transferring elements from the drinking water regulatory regime in two dimensions: horizontal (i.e. multiple governance institutions at a single level adopting non-state approaches, e.g. municipalities using environmental management system standards -EMSs) and vertical (i.e. adoption by multiple levels of governance institutions, including a quasi-vertical dimension with the courts adopting non-state approaches, e.g. 3-levels of government drawing on EMSs).

4. Individual municipalities (voluntarily) being "regulated" by non-state rule instruments, processes, institutions and actors in support of public policy environmental objectives and doing so in advance of formal governmental laws and policies incorporating nonstate rule instruments (this shows how non-state initiatives contribute to long-term sustainability, even when state action is not yet forthcoming).

5. The sustainable governance approach aligns well with theoretical concepts of policy convergence. This is reflected in the Ontario municipal regulatory framework with increasing dynamics at play to bring consistency with the wastewater and stormwater sectors at the same level playing field with that of the drinking water governance model (e.g. Open for Business Act, System-wide ECAs, EASR, O. Reg. 208/19 - see Chapter 2.3.2). Additional policy conceptions such as policy transfer (e.g. ISO standards, CSA Group, Self-inspection pilot, Blue Flag program) and policy learning (e.g. MWWRC, WEAO 2018 report - see Table 25) are apparent with increasing roles of non-state regulatory support.

6. The recognition of the value in the use of MSSs in the Ontario municipal water sectors. Since the 2000 Walkerton tragedy and the 2007 mandatory DWQMS, there is evidence of a growing critical mass of knowledge by municipal officials, practitioners and elected officials voluntarily adopting elements primarily from the DWQMS and ISO 14001 and 
being selective about MSSs, for the wastewater sector. Scholars also recognize the value of non-state MSS and their benefits in terms of transparency, legitimacy, sustainability, accountability, effectiveness and efficient public policy and public administration, in what Hatfield-Dodds (2007: 9) refers to as a license to operate.

7. This dissertation provides insights into motives, perceptions and experiences related to the use of MSSs in the context of municipal water, wastewater and stormwater in Ontario. While there is a significant volume of literature on MSSs and ISO standards applied in private sector contexts concerning multiple industries, their motives, performance and evolution, there appears to be very little literature on MSSs in municipal water, wastewater and stormwater contexts. This dissertation interconnects existing literature on MSSs with the legal system establishing requirements to quality management for water sectors (e.g. DWQMS, CMOM, AWWA-G400, Wisconsin's Green Tier Program, Michigan EMS Guide, O’Connor, 2002), and with direct experiences involving EMS in the municipal water sectors (see Canadian laws in Table 8 and Appendix E; judicial cases on Chapter 2.3.3; and U.S. cases in Chapter 2.1.7).

8. This dissertation, through literature, interviews, case studies and focus group identified clear evidence pointing to ISO 14001 as the best suited MSS for wastewater and stormwater systems. Reflecting on this, there appears to be an over simplification of the reasons why most standards draw on EMSs rather than QMSs for wastewater and stormwater management. Analysis in Chapter 7.3.1 examines the nature of the inputs and outputs in MSS processes and prominent risks (environmental, health and property damage) (Table 4), which further substantiate findings. This research makes a contribution to the literature on MSSs by documenting the perception, use and reasons why municipalities (legislated or voluntary) adopt the following standards:

- ISO 9001 (QMS) more suited for drinking water systems;

- ISO 14001 (EMS) more suited for wastewater and stormwater systems; and

- HACCP more suited for drinking water systems.

9. Based on this research there appears to be good basis of support for the establishment of a provincially required Wastewater and Stormwater Environmental Management 
System Standard aligned with the ISO 14001 EMS. While a mandated standard may not appear viable at this time, an alternative option is to have a provincially endorsed, voluntary EMS standard, which may be a catalyst to boost voluntary uptake of MSSs by municipalities.

10. This research makes a contribution to understanding the governance of the Ontario municipal wastewater and stormwater, in contrast to much of the academic literature that concentrates on drinking water quality and governance in a post-Walkerton environment.

The research methods applied in this study followed a somewhat unconventional approach. The interviews, case studies and focus group followed both a "staged" or sequential process and triangulation of data. The staged approach consisted in using the coding of data from the interview respondents to confirm municipalities selected for the case studies. Subsequently, the case studies were analyzed and summarized to provide a preamble or introduction to facilitate the discussion during the focus group session. At each stage, presentations were given at provincial and national conferences to obtain commentary and feedback from attendees. These learning stages assisted the author to move on to subsequent stages. Triangulation of data was applied also in a sequential approach in order to confirm the coding completed at the first stage. The codification and thematic analysis were subsequently re-done after the case studies interviews were completed as to confirm trends and outcome from the initial interview respondent data coding. The triangulation further continued with data observed from the literature review process, case studies and focus group.

In summary, the key contributions noted above, are intended to assist academics, government and non-state actors to have a better understanding of the value of MSSs for the municipal drinking water, wastewater and stormwater sectors in Ontario. This will also assist to understand the distinctive willingness of governments and courts to draw on non-state rule instruments, processes, institutions and actors in support of achieving government and societal environmental goals, while keeping with the sustainable governance approach (with both collaborative and check and balance ways). 


\subsection{Areas of Future Research}

This dissertation has identified three areas of possible future research. One concerns the possible adoption of QMS and EMS-type standards by First Nation communities, another involves the application of a mandatory EMS approach to municipal wastewater and stormwater similar to that proposed for Ontario in other parts of Canada; and the third pertains to further exploration addressing the gaps noted under section 7.3.2 and identifying the potential critical control points for both municipal wastewater and stormwater systems.

\subsection{Limitations of Study}

The study focuses on the Ontario experience, drawing on interviews with Ontario-based respondents and Ontario-based focus group participants. The multi-method and sequential approach used for this research provide some level of triangulation to validate the information obtained through interviews, then case studies and finally through the focus group, which try to articulate reliability into this study findings. While short summaries provided in Table 10 , Table 25 and Appendix F, which may offer some findings and insights of use to other contexts and jurisdictions, it should be noted that this study does not generalize its findings to other geographic areas in Canada nor in North America. Any generalization of observations and findings should be cautiously considered, and more research would be required. 


\section{APPENDIX A - INTERVIEW QUESTIONS}

1. What is your position in your organization, and for how long have you been working with management system standards or operation of municipal water, wastewater, and/or stormwater systems?

2. What are the primary distinctions between ISO 9001 and 14001 ?

3. How easy/difficult was the implementation of the DWQMS or other standards?

4. What benefits/burdens you see with the DWQMS or other standards?

5. What you see as the barriers for continual adoption of ISO 14001?

6. What you see as the prominent challenges in implementing ISO 14001?

7. Are management system standards likely to have neutral, positive, or negative effects on the performance of Ontario municipal water management activity?

8. Can municipalities adopt ISO 14001 for WW and not for DW?

9. Has DWQMS leveraged decisions to adopt ISO 14001 or other standards?

10. What are the cost implications... Any significant costs in adopting ISO 14001?

11. How municipalities are addressing the perceived gaps in DWQMS?

12. What do you perceive as the primary drivers for implementation?

13. Have you experienced compliance issues that resulted in Provincial or Federal abatement actions over the past 10 years?

14. Has there been any prosecution due to environmental offenses in your places of employment / clients over the past 10 years?

15. How prevalent is iso 14001 in North America?

16. Is it relevant to adopt ISO 9001 in addition to DWQMS?

17. Is it relevant to adopt ISO 14001 in addition to DWQMS?

18. In terms of MSSs, are the ISO 14001 and/or ISO 9001 the best fit for drinking water, wastewater, and stormwater systems or is there something better that should be used?

19. Why are Ontario and other municipalities adopting quality and environmental management system standards, such as those set out in ISO 9001 and ISO 14001?

20. Impression of proposed changes to DWQMS (2015)? 
21. What specific elements of ISO 14001:2015 can be included in the proposed revision of the DWQMS?

22. How feasible would be to implement ISO 14001 for small, medium and large municipalities?

23. Which MSS standards relevant to the water sectors (ISO 9001 - QMS, ISO 14001 - EMS and HACCP) are best suited to address municipal water, wastewater and stormwater activity

24. Can the same balance achieved in DW, be adopted for WW sectors w/o a management system?

25. Does an MSS that is not regularly revised and updated poses an organizational risk because it does not encourage ongoing innovation and instead rewards "going by the book" behaviour?

26. Do you have any ideas why only a subset of Ontario municipalities have voluntarily adopted ISO 14001 as of 2016?

27. Should Ontario municipalities have a voluntary or mandatory wastewater and/or stormwater management system standard based on the ISO 14001?

28. Why municipalities are adopting ISO 14001 or BMPs from EMS?

29. What the MECP should be doing about this? 


\section{APPENDIX B - GOVERNANCE CONCEPTIONS}

\section{1) Multi-Level Governance}

The topic of governance received significant attention in the context of the European integration (1992), globalization and international trade in the early 1990s with a focus on different conceptions of state and non-state governance (Rhodes and Marsh, 1992: 194; Resenau and Czempiel, 1992: 32; Marks, 1993: 392; Stephenson, 2013: 817-818). The term Multi-Level Governance (MLG) was first defined by Marks as: "[....] a system of continuous negotiation among nested governments at several territorial tiers" (1993: 392).

In his study, Marks describes the emphasis on transparency and the new role of subnational governments creating vertical linkages with the European Commission "that bypass member states and challenge their traditional roles as sole intermediary between subnational and supranational levels of government" (1993: 403). Marks describes this phenomenon as a partnership with a notion of transparency where decisions are "taken as closely as possible to the citizen" (1993: 406).

Bache and Flinders (2004: abstract), identify the increased participation of non-state actors in "complex overlapping networks", while Rhodes (2007: 1243) refers to policy networks, pointing to analysis based on beliefs, practices, traditions and dilemmas. MLG can in some ways be contrasted with the Westminster model (concentration of power in central government), given the increased role of non-state actors, complex overlapping networks and democratic accountability (Cairney, 2012: 24-25). Building on the multi-level approach to governing in "a rejection of top-down control", Cairney notes that "there are multiple centres of authority and strong central government is increasingly replaced by bargaining government and the type of mutual adjustments associated with incrementalism" (2015: 28, 32). In this conception, incrementalism, is described by Cairney as a trial and error strategy in policymaking, recognizing that new policies only achieve part of what was originally intended and will "produce unanticipated [not desired] consequences" (2015: 31-32, citing from Lindblom). In the North American context, in his comprehensive overview of MLG, Stephenson argues that the concept of MLG is "especially tricky" when examined outside the EU, and in particular with the 
North American Free Trade Agreement (NAFTA), given the "ironclad commitment to avoid institutionalization and institution-building" (2013: 830, citing from Sbragia), which is such a particular feature of the EU context. In his study of the evolution of multi-level-governance, Stephenson suggests that the conceptualization of MLG no longer operates as an Eurocentric, three-layered approach, "but acknowledges external actors in global governance" (2013: 829). This evolution recognizes trans-governmental networks in a "governance matrix", with the example of Public-Private-Partnerships (PPP) "whereby non-state actors co-govern along with state actors for the provision of collective goods and adopt governance functions that have formerly been the sole authority of sovereign states" (Stephenson, 2013: 829).

In summary, the conceptualization of MLG recognizes phenomena occurring among different levels of government interacting and bypassing traditional government-centric models and moving towards increasing institutional complexity. Within the North American context, as represented by the example of NAFTA, MLG has placed more emphasis on non-state actors (rather than subnational governments). Under this conceptualization, MLG involves a trial and error process that recognizes a more complex constellation of actors, evolving towards a dynamic of transparency and the incrementalism noted by Cairney (2015: 31-32), where nonstate actors are increasingly relevant in the formation of a governance matrix.

\section{2) Adaptive Governance}

The term adaptive governance is associated with the polycentric governance or decentralization of policy making through self-governing institutions (Ostrom, 1994: 3, 6-9; Dietz et al, 2003 : 1908-1909; Nagendra and Ostrom, 2012: 117). These early conceptualizations of governance focused on conflict resolution, sustainable development, capacity building, policy networks, regulatory processes and self-governing arrangements, however, delegation of power or power sharing was not part of this concept.

Hatfield-Dodds (2007: 9) further describes the concept of adaptive governance as a consensus building tool based on the necessity for political efficiencies on contentious issues in order to obtain a "license to operate", and as an economic tool for market success. 


\section{3) Participatory Governance}

Fung and Wright (2001: 5-7; 12-13) conceptualize participatory governance as ameans of harnessing the energy and influence of ordinary people for the solution of problems (e.g. Chicago's Neighborhood Governance Council to address inner city concerns, or the US Endangered Species Act empowering stakeholders to develop governance arrangements). Participatory governance thus has an empowering dimension, giving civil society a role in the development of both inputs and outcome strategies.

Lindgren and Persson (2011: 12-18) describe participatory governance from the perspective of the decline in the effectiveness of democratic institutions in direct relationship with the complexity and size of the they face. Hogl et al. (2012: 18-19) describe participatory governance as the granting by the state to non-state actors of enhanced modes of participation in governmental activity. In the analysis by Newig (2012: 57), a review of North American cases (2002-2006) noted the use of participatory governance in watershed management and its effects on outcomes (e.g. 76 watershed partnerships in California and Washington measuring merits of collaboration and participation).

In a different definition, in the context of the European Union 2000s debates, Kohler-Koch characterize participatory governance as a way to "promote societal self-participation" (2010: 105) that fulfills multiple functions: a performative function (through discourse and interaction in the public sphere); and a representative function (providing societal interests with a voice).

In summary, the conceptualization of participatory governance, while recognizing the influence of non-state actors and the complexity of effective democratic processes, ultimately refers to the state allowing others (non-state actors) to be involved in decision-making policy, and is thus still a government-centric paradigm.

\section{4) Collaborative Governance}

In the late 1990 s and 2000 s, the term collaborative governance was widely used by scholars with no clear consensus on its definition (Rosembloom, 2013: 544; Amsler, 2016: 700). Ansell and Gash (2007: 544) define collaborative governance as a system where:

[....] one or more public agencies directly engage non-state stakeholders in a collective [state-based] decision-making process that is formal, consensus-oriented, and 
deliberative and that aims to make or implement public policy or manage public programs or assets.

This definition recognized the institutionalization of collective decision making and how public and private actors work collectively in distinctive ways, using particular processes to establish laws and rules for the provision of public goods. In collaborative governance, the role of public and private sector actors are intertwined to carry out society's decisions, achieving society's goals and taking part in policy implementation.

In their analysis of "clean" collaborative governance, Rosenbloom and Gong (2013: 557) study it in the context of increased privatization and PPP and the consequent potential for increased corruption as public funds flow to private organizations in the form of contracts and grant payments. They find public value in "clean" collaborative governance as it gives private individuals and community organizations incentives to combat corruption.

Rosenbloom and Gong (2013: 546) provide an analysis of collaborative governance in terms of the role of private companies taking control of traditional public enterprises and the potential risk of corruption that it entails. Referencing work by Van Slyke (2003: 544), Rosenbloom and Gong offer three considerations related to this type of collaborative governance:

- Government functions can often be performed more cost-effectively by market-driven or specialized non-governmental entities.

- Governments can leverage their administrative capacity by relying on networks of nongovernmental and other governmental organizations to accomplish their missions.

- There may be political benefits to downsizing government workforces and distributing contracts regionally, socioeconomically, and on other strategic bases.

\section{5) Network Governance}

Stoker (2006: 41) defines network governance as:

[....] a particular framing of collective decision-making that is characterized by a trend for a wider range of participants to be seen as legitimate members of the decisionmaking process in the context of considerable uncertainty and complexity [...] it requires public managers to manage through networks, to be open to learning in different ways 
and to draw in resources from a range of sources [....] under a new public value management paradigm.

In this definition Stoker describes a new public value management paradigm with a marketoriented vision, which offers a broader framework in which to comprehend the management challenge posed by an open range of networks (2006: 42). The concept of network governance brings motivational elements to the governance model, whereby governments benefit from their involvement in networks and partnerships with others formed in the context of mutual respect and shared learning. Bevir (2011: 8) speaks of "hybrid organizations" stakeholders, recognizing complex processes and interactions involving "multi-jurisdictional and plural stakeholders working together in networks" (2011: 2). He posits mixed public-private or entirely private forms of regulation, and multijurisdictional governance intertwining "people and institutions across different policy sectors and different levels of government (local, regional, national and international)" (2011: 2).

In summary, the evolution of governance has changed significantly, shifting from a government-centric paradigm (Peters and Pierre, 1998) to more modern definitions. Rhodes (2000) refers to governance as a "new 'process' or method of governing" (cited by Wellington, 2010: 3). Wellington refers to this new process as involving actors that "exercise control and influence and that are themselves subjects of control and influence" (2010: 3). In this definition the term "actors" includes not only government, but also non-state actors such as private sector, international organizations and other non-government organizations (NGOs). As described by Bevir, the new conceptualization of governance "refers to changes in the nature and role of the state since the last quarter of the twentieth century. The state has become increasingly dependent on organizations in civil society and more constrained by international linkages" (2011: 15). 


\section{APPENDIX C - POLICY CONVERGENCE CONCEPTIONS}

\section{1) Policy Diffusion}

One of the most widely cited definitions of policy diffusion is by Rogers (1983), who describes it as occurring: "[....] when an innovation is communicated through certain channels over time among the members of a social system" (as cited by Strang and Meyer, 1993: 487-488).

In their description of diffusion, Strang and Meyer (1993: 488) point to rational choices and "rapid" diffusion dependent on the active role of government actors, "rational actors" and "social actors" (networks of individuals and rationalized organizations). Bennett (1991) viewed to diffusion as a phenomenon of increasing interest due to European market integration and globalization in the early 1990s. Bennett also highlights emulation as a process where state officials copy the actions of other state officials in different jurisdictions. Strang and Meyer consider diffusion to be critical for the "flow of social practices among actors within some larger system"... and describe it as "importantly shaped and accelerated" by cultural similarities between actors, with information "communicated through certain channels" (1993: 487).

After European integration and the movement towards globalization among Western societies, Strang and Soule (1998: 268) described what they referred to as "macro diffusion", focusing on "accelerators" of diffusion. These accelerators could be cultural homogeneity (Lenschow, 2005); the role of international institutions (Holzinger and Knill, 2005: 777) or the participation of different actors (Strang and Meyer, 1993: 488), such as industries, social movements or communities of experts on the political and business scenes, who shift the attention to non-state actors as influencers and adopters.

The above description compares with that of Rogers in the fifth edition of his book on "Diffusion of innovation" (2003), with its emphasis on diffusion as a process for overcoming uncertainty:

[....] seeking others like themselves who have already adopted a new idea [....]. The diffusion process, then, is most often shaped by a few individuals who spread the word amongst their circle of acquaintances, a process that typically takes months or years. But there are exceptions: use of the Internet in the 1990s, for instance, may have spread more rapidly than any other innovation in human history - and it continues to influence 
the very nature of diffusion by decreasing the significance of physical distance between people. As thought-provoking as it is instructive, this fully updated, widely acclaimed work of scholarship is itself a great idea that continues to spread (2003: 1).

Rogers statement above is consistent with most examples of policy diffusion which reflect the need for state-based rule instruments and mandatory processes to remove barriers to policy diffusion (Giacomini et al., 2018). Lenschow (2005) identifies cultural differences between Latin American and European countries to underline the limitations between policy diffusion and degrees of human equality versus authority, noting the preference for enforceable rules (Latin America) or participatory approaches (Europe). A different example can be found in the effectiveness of policy diffusion on transnational policy issues (DeLeon \& Resnick-Terry, 1999), such as those noted by Knill (2005), where the United Nations Framework Convention on Climate Change (UNFCCC) brought reporting requirements and non-binding guidelines to many nations around the world. This example reflects the influence of non-state actors (UNFCCC), in influencing and shaping state rule instruments (climate change policy) and processes (carbon accounting and certification).

In the context of river basin management, examples of policy diffusion abound especially in the area of integrated water resources management (IWRM), including institutional capacity building (Johns, 2014a: ; Bouckaert, et al 2018). In the example of the Rhine River basin and micropollutants monitoring (Metz \& Fischer, 2016), policy diffusion depends on the exchange of monitoring data and governance structures from governments within this watershed. Another example is the water quality protection of the Canada-U.S. Great Lakes, where state and nonstate actors, their rule instruments, processes and institutions have been mapped out by Martin and Webb (forthcoming), highlighting their intertwined relationships. On the Great Lakes, the international Blue Flag program, a voluntary eco-label program operated by a European non-profit, involves local beaches being audited and certified after meeting a rigorous set of criteria (rule instruments). This program represents an example of a non-state rule instrument endorsed and supported by local governments. In section 7), the Blue Flag Program is described in terms of its influence on the City of Toronto's environmental protection stewardship. 


\section{2) Policy Transfer}

Policy transfer was described by Stone as a process "on the increase in an era of globalization [....] as some governments and international organizations are proactive in promoting harmonization and convergence or exporting policy lessons" (1999: 51). Stone uses a commonly cited definition of policy transfer, citing Dolowitz and Marsh (2000):

[....] [a] process in which knowledge about policies, administrative arrangements, institutions, and ideas in one political setting (past or present) is used in the development of policies, administrative arrangements, institutions and ideas in another political setting (2000: 5).

Stone understands policy transfer and policy learning as contributors to innovation, improving policy making by helping to effectively respond to crises (1999: 52). He also views the "agents of transfer" as passive while others are more actively engaged in spreading ideas and approaches to understand "how self-conscious and reflective about this process we should be" (1999: 55-56). Stone's ideas are important because they highlight the proactive approach of actors and institutions to innovation, equipping them to respond more effectively.

However, other leading scholars define policy transfer in relation to mechanisms of coercion and multi-lateral cooperation, where policies may be imposed as conditions for economic incentives (Dolowitz and Mash, 2000: 8). This notion is expanded by Holzinger and Knill, who characterize it as "coercive and voluntary policy transfer" (2005: 779). In their analysis, Dolowitz and Mash identify international government organizations such as the OECD, IMF and the UN and their various agencies, as well as NGOs, as agents of coercive transfer, but also as agents of voluntary transfer. Dolowitz and Mash conceptualize policy transfer (or borrowing) on a spectrum ranging from "lesson-drawing to the direct imposition of a program, policy or institutional arrangement on one political system by another"(2000: 11-13).

In the evolution of policy convergence theory, an aspect accepted by some scholars is that policy diffusion and policy transfer are policy processes that do not automatically lead to convergence (DeLeon \& Resnick-Terry 1999; Knill, 2005). In his study, Harrison (2002) characterizes policy divergence as a situation where despite consensus on the area of study, very different policy goals are reached due in part to the combined effect of domestic interests, 
different institutional contexts for decision-making, politics, and state jurisdictional differences (Botcheva and Martin, 2001).

Examples of policy transfer include: the Western monetary policy transferred to Third World countries, "driven by conditionalities that accompanied loans by the World Bank" (Holzinger and Knill, 2005) or the "International Monetary Fund" (Dolowitz and Mash, 2000: 7). Another example is the reference to private product standards by Hozinger and Knill, involving private industries in low and high regulating countries, where there is a common interest in harmonization of product standards to avoid market segmentation. In this situation, high regulating countries could in effect be imposing stricter standards on low regulating countries by "erect[ing] exceptional trade barriers, for example for health or environmental reasons under World Trade Organization rules" (2005), trade tariffs or other trade barriers. If competitive pressure proves ineffective, then pressure would induce high regulating countries to lower their standards (Holzinger and Knill, 2005). This last example is relevant as it illustrates the influence of state actors on the imposition of rule instruments and processes on non-state actors (private product standards).

\section{3) Policy Learning}

Holzinger and Knill (2005) define policy learning as a voluntary policy transfer that can emerge from government learning, lesson-drawing and social learning, taken from state actors and policy networks. In this conception, policy learning occurs when:

[....] governments rationally utilize available experience elsewhere in order to solve domestic problems. According to Rose (1991), who introduced the concept, lessondrawing is based on a voluntaristic process whereby government $A$ learns from government B's solution to a common problem what to do ('positive lessons') or what not to do ("negative lessons") (2005: 783).

In Holzinger and Knill's conception, in policy learning state actors are interested in "solving domestic problems", as opposed to emulation, which is driven by conformity rather than the search for effective solutions. In the original conception of lesson-drawing established by Rose, policy learning may include the creation of new programs rater than those merely copied from other policies in many different forms, "reaching from hybrids of transferred and domestically 
developed components to completely new models" (Holzinger and Knill, 2005: 783). In Rose's depiction of policy learning policies may not require changes, as learning also involves evaluating programs negatively, resulting in their abandonment, and not necessarily leading to policy convergence.

In the study by Yebra (2003), as summarized by Holzinger and Knill, the concept of Bayesian learning is identified as "a mode of rational, experience-based learning" (2005: 783). In this conception, governments are modelled as perfectly rational learners in that "they update their beliefs on the consequences of policies with all available information about policy outcomes in the past and elsewhere. They choose the policy that is expected to yield the best results" (2005: 783).

In more recent studies, Alcantara, et al. (2012: 116) identify policy learning as "an attempt to improve or enhance policy-making based on the assessment of past experiences" associated with own jurisdictions and foreign precedents. Three typologies of policy learning are identified by Alcantara (2012: 116, citing from Bennett and Howlett, 1992): government learning, lessondrawing, and social learning, for which the sources are policy officials, policy networks, and policy communities, respectively.

An examples of policy learning offered by Simmons and Elkins (2004: 171) is that of governments evaluating foreign political economic models that may fail to take into account the socio-cultural differences between individual countries. In this scenario, policy learning involves a very rational approach of selecting only those policy components that may be successful. Another example is policy learning through negotiations, such as trade agreements between nations (e.g. NAFTA in North America; the Canada-European Union Comprehensive Economic and Trade Agreement or CETA). In this process, governments "learn" through negotiation and discussion, but economic policies are selected after careful consideration of multiple internal and external factors (2004: 186). Within the context of the Great Lakes, policy learning and adaptation has been examined by Song et al. (2019: 5-6) and by Martin and Webb (forthcoming), including the transboundary policy networks between Canada and the United States. 
The studies by Hozinger, Knill and Sommerer (2011: 37-38), and by Jörgens, Lenshow and Liefferink (2014: 1-2) conclude that policy convergence is the norm in the environmental field among industrialized nations. This trend towards policy convergence has a direct relationship with causal factors in efforts to solve environmental issues, where policy transfer, diffusion and learning sometimes occur independently and sometimes lead to convergence.

Up to this point, we have identified relationships between the sustainable governance model and the trend towards policy convergence when dealing with common environmental issues. In the next section, these concepts will be connected with the concept of management system standards (MSSs). This is particularly relevant in Ontario, where a quality MSS was imposed on all municipalities in the province by legislation following the Walkerton tragedy (2000). This study claims that this policy has served as a catalyst for municipalities to adopt similar non-state MSSs for the management of their wastewater and stormwater systems voluntarily, and in some cases provided through by legislation. 


\section{APPENDIX D - EVOLUTION OF QMS AND EMS}

The historical events leading to MSS can be traced back to 1926 with the International Federation of the National Standardizing Associations, which disbanded in 1942, and was reintegrated after World War II with the formation in 1947 of the International Standards Organization (ISO).

The term "quality" came onto the ISO agenda in the 1970s when manufacturing and defence industries began exploring total quality management and total productive maintenance (Sivaram and Devadasan, 2012; Heras-Saizarbitoria and Boiral, 2013; Franceschini, Gelatto and Cecconi, 2006). The focus on quality management introduced the idea that standardizing management systems and quality manuals could enhance confidence in a product. In the UK, a national standard, BS-5750 (1979), developed out of the earlier BS-5179 guidelines (1974). This eventually led, in 1987, to the creation of the ISO 9000 family of standards.

The term "environment" was brought onto the ISO agenda in 1971. A year later, the United Nations held its Conference on the Human Environment in Stockholm, and a declaration was made for the preservation and enhancement of the human environment. In 1987, a World Commission on the Environment and Development provided the first globally accepted definition of "sustainable development". The British standard BS 7750 was the first EMS to be established, in 1992. Other events of significance include the 1992 Rio Declaration to protect the global environment; the establishment in 1993 of the ISO/TC 207 Technical Committee for the development of the ISO 14000 family of standards; the creation in 1993 of the European EMAS standard; and the 1996 ISO 14001 EMS standard (Martincic, 1997).

Of particular relevance to QMS in Ontario was the Walkerton tragedy (2000), which led to the development of a regulated ISO 9001-like standard. Similar tragedies in Milwaukee (1993) and Flint (2014) also led to the adoption of ISO 9001-type approaches in the US states of Wisconsin, Michigan. Table 30Table 30 presents a modified version of a summary of a summary by Tovilla and Webb (2017a: 215) with the addition of events leading to the establishment of Ontario's drinking water quality management system. 
In the Ontario and Canadian context, but with global implications, the 1991 case of $R . v$. Bata Industries marked the first time that the directors of a large corporation were exposed to liability for environmental pollution. R. v. Bata Industries was a legally significant and highly influential case in relation to due diligence, criminal prosecution and directors' liability for environmental violations (Greenbaum and Wellington, 2010). Scholars have linked the origins of ISO 14001 to the Bata case as an important example of judicial recognition of the value of EMSs (Greenbaum and Wellington, 2010). The defence of due diligence failed and the case raised awareness among corporations, insurance companies, regulators, civil society and NGOs of the importance of an effective EMS.

R. v. Bata Industries case was a precedent-setting court-decision that pointed to the need to establish corporate policies and systems for pollution prevention, record-keeping and proper labelling of hazardous substances, as well as for ensuring supervision and regular reporting to directors, including notification of non-compliance in a timely manner and allocation of sufficient resources. These elements align well with the requirements of a properly operating EMS (such as ISO 14001). In the ruling, Judge Ormston of the Ontario Provincial Court stated that:

[....] the directors should stay informed of standards of their industry and other industries that deal with similar environmental pollutants or risks (2010).

The importance of the R. v. Bata Industries case is that it shone a spotlight on the value of an EMS as part of an organization's due diligence in complying with Ontario environmental legislation. In effect, voluntary standards such as those in the ISO 14000 series of standards, and audits performed by third-party organizations, became a useful tool to assist firms in meeting their due diligence requirements under Ontario environmental law. 
Table 30. Summary of Historical Events Leading to the ISO 9001, ISO 14001 and DWQMS

\begin{tabular}{|c|c|c|}
\hline Year & Event & Significance \\
\hline 1926 & ISA & $\begin{array}{l}\text { The Int'I Federation of the National Standardizing Associations, } \\
\text { focused on mechanical engineering. Disbanded in } 1942 .\end{array}$ \\
\hline 1947 & $\begin{array}{l}\text { ISO is established in } \\
\text { London, UK }\end{array}$ & $\begin{array}{l}\text { After WWII, ISA remnants re-group with } 65 \text { delegates from } 25 \\
\text { countries to form ISO. }\end{array}$ \\
\hline 1959 & Delphi Method & $\begin{array}{l}\text { A quality management approach developed by the RAND } \\
\text { Corporation for the US Armed Forces. }\end{array}$ \\
\hline 1971 & ISO environment agenda & After 24 years the environment appears on the ISO agenda. \\
\hline 1972 & $\begin{array}{l}\text { UN-Conference on the } \\
\text { Human Environment }\end{array}$ & $\begin{array}{l}\text { Meeting in Stockholm, concluding with a declaration for the } \\
\text { preservation and enhancement of the human environment. }\end{array}$ \\
\hline 1974 & British Standard 5179 & First guideline for the evaluation of quality assurance systems. \\
\hline 1979 & British Standard 5750 & First standard for quality management. BS 5750. \\
\hline 1981 & Deming Method of QM & 14-point quality management approach. \\
\hline 1987 & $\begin{array}{c}\text { Sustainable Development } \\
\text { defined }\end{array}$ & $\begin{array}{l}\text { The Brundtland Commission Report (World Commission on the } \\
\text { Environment and Development) issues the first definition of SD. }\end{array}$ \\
\hline 1987 & ISO 9000 & ISO 9000 family of quality management stds. is established. \\
\hline 1991 & $\begin{array}{l}\text { R. v. Bata Industries } \\
\text { Ontario }\end{array}$ & $\begin{array}{l}1^{\text {st }} \text { Canadian case where directors of large corporations are held } \\
\text { personally liable for env. violations (due diligence case). }\end{array}$ \\
\hline 1992 & UN - Rio Declaration & $\begin{array}{l}\text { Establishes a global partnership to protect the integrity of the } \\
\text { global environment and development. }\end{array}$ \\
\hline 1992 & British Standard 7750 & $\begin{array}{l}\text { First standard for environmental management systems. BS } 7750 \\
\text { is now compatible with ISO } 14001 \text { and EMAS. }\end{array}$ \\
\hline 1993 & $\begin{array}{l}\text { Milwaukee outbreak - } \\
\text { Cryptosporidiosis }\end{array}$ & $\begin{array}{l}400,000 \text { people become ill and } 104 \text { die in this outbreak, due to } \\
\text { contaminated water in Lake Michigan. }\end{array}$ \\
\hline 1993 & ISO/TC 207 & $\begin{array}{l}\text { Environmental technical committee } 207 \text { is established for } \\
\text { development of the ISO } 14000 \text { family of standards. }\end{array}$ \\
\hline 1993 & $\begin{array}{l}\text { Eco-Management and } \\
\text { Audit Scheme (EMAS) }\end{array}$ & $\begin{array}{l}\text { First European system for env. performance and continual } \\
\text { improvement. By } 2015,4,600 \text { firms and 7,900+ sites use EMAS. }\end{array}$ \\
\hline 1996 & ISO $14001 \mathrm{EMS}$ & ISO 14001 for EMS is established. \\
\hline 2000 & ISO 9001:2000 & ISO 9001 is updated, consolidating ISO 9001, 9002 and 9003. \\
\hline 2000 & Walkerton tragedy & $\begin{array}{l}\text { An estimated 2,300 people become seriously ill and } 7 \text { die from } \\
\text { exposure to microbially-contaminated drinking water. }\end{array}$ \\
\hline 2002 & Walkerton Inquiry & $\begin{array}{l}\text { After Justice O'Connor's recommendations, EMS and source } \\
\text { water protection emerge as regulatory requirements in Ontario. }\end{array}$ \\
\hline 2002 & Ontario's SDWA & The Safe Drinking Water Act receives royal assent in 2002. \\
\hline 2004 & ISO 14001 amended & ISO 14001 is amended for compatibility with ISO 9001 for QMS. \\
\hline 2006 & Ontario's DWQMS & The MECP publishes the Drinking Water QMS. \\
\hline 2007 & $\begin{array}{l}\text { Ontario's regulations for } \\
\text { water systems }\end{array}$ & $\begin{array}{l}\text { Ontario enacts Regulation for the Municipal Drinking Water } \\
\text { Licensing Program, and publishes accreditation guidelines. }\end{array}$ \\
\hline 2008 & ISO 9001:2008 & ISO 9001: 2000 is updated (for integration with other stds.). \\
\hline 2014 & Flint, Michigan crisis & Legionnaires' disease outbreak w/suspected link to Flint water. \\
\hline 2015 & $\begin{array}{l}\text { ISO } 14001 \text { and ISO } 9001 \\
\text { amended }\end{array}$ & $\begin{array}{l}\text { On Sep. 2015, ISO } 14001 \text { and ISO } 9000 \text { are amended to include } \\
\text { new concepts of eco-design and life cycle assessment. }\end{array}$ \\
\hline 2017 & DWQMS amended & $\begin{array}{l}\text { The MECP releases DWQMS version } 2.0 \text { after completing a } \\
\text { public consultation process that began in } 2015 \text {. }\end{array}$ \\
\hline
\end{tabular}




\section{APPENDIX E - CANADIAN LAWS - REFERENCES TO ISO 14001}

This section includes a more descriptive reference to the summary of Canadian laws directly and indirectly referencing MSSs, such as the ISO 14001, EMS and the DWQMS from Table 8.

\section{1) Municipal Act (1990)}

The 2006 amendment to the Municipal Act (1990) under Bill 130 recognized the possibility of municipalities adopting voluntary measures for accountability and transparency (Sec. 10 (2) 2 of Part II), which is an underlying principle of the ISO family of standards. Examples of voluntary measures noted in the Act included:

- the appointment of an Integrity Commissioner to independently ensure the municipality's adherence to the code of conduct, procedures, rules and policies (Sec. 223.3 (1) of Part V.1); and

- the appointment of an Ombudsman to independently investigate any decision or recommendation made, or any or omission in the course of the administration of the municipality (Sec. 223.13 (1) of Part V.1).

Ontario municipalities, in general, reacted negatively towards both the mandatory and voluntary policy changes under Bill 130. In the context of the bill, Alcantara et al. (2012) suggested that municipalities tend to respond to mandatory policy change by adopting the minimum requirements set out in provincial legislation, and that voluntary private standards are only adopted when similar provisions are already widely used at the local level (2012). These provisions align with ISO 14001 requirements, which require leadership accountability (ISO 14001, sec. 5.1 and 5.2) and internal audits (ISO 14001, sec. 9.1).

\section{2) Development Charges Act (1997)}

The 2015 amendments to the Development Charges Act (1997) introduced requirements for municipalities to have an asset management plan prior to passing any development charge bylaws. This requirement aligns with requirements under the ISO 14001, which requires life cycle considerations for planning to fulfill environmental obligations (ISO 14001, sec. 6.2). 


\section{3) Infrastructure for Jobs and Prosperity Act (2015)}

The new Infrastructure for Jobs and Prosperity Act (2015), sec.3 (11) requires an evidence-based process to consider maintaining ecological biodiversity, and requires infrastructure to be "resilient to the impacts of climate change." Also, section 6(1) requires the preparation of evidence-based infrastructure asset management plans. These provisions align with the ISO 14000 family of standards, which include ISO 14006: 2011, guidelines for eco-design, ISO 14044:2006, for life cycle assessments, and ISO 55000 for asset management.

\section{4) Asset Management regulation, O. Reg. 588/17}

The new Asset Management regulation, O. Reg. 588/17, under sec. 3 (1), requires that municipalities prepare an asset management policy, including an "approach to continuous improvement," and to consider "levels of service and lifecycle management [....] mitigation approaches to climate change, and disaster planning." These provisions align with ISO 14044: 2006, guidelines for life cycle assessments.

\section{5) Environmental Penalties Regulation (O. Reg. 222/07)}

The Environmental Penalties Regulation (O. Reg. 222/07), under the Ontario EPA, provides for the assessment of environmental penalties in a manner that encourages regulated persons to, among other things, implement an EMS. Specifically, section 1(c) of O. Reg. 222/07 states:

[t]he purpose of this Regulation is to provide for the assessment of environmental penalties in a manner that encourages regulated persons to [....] implement environmental management systems.

The O. Reg. 222/07, section $17(1)$ specifies provisions for reduced penalties in the event that the regulated person had in place an EMS with valid audits within three years before the contravention, and that the audit confirmed its validity under the following terms:

1. [....] that at the time of the audit, the environmental management system was certified as meeting the standard set out in the document entitled "Environmental management systems -Requirements with guidance for use" and designated as CAN/CSA-ISO 14001:04, published by the Canadian Standards Association, as amended from time to time, by an environmental management systems registrar that has been accredited by:

A. the Standards Council of Canada, or 
B. an accreditation body outside of Canada that is a signatory to the International Accreditation Forum Multilateral Recognition Arrangement, and $[\ldots .$.

2. [t]hat at the time of the audit, the environmental management system was determined to be compliant with the standard set out in the document referred to in paragraph 1" by an independent auditor (who is not an employee or contractor), and according to the code of conduct as per CSA/ISO 19011:2003.

While the Environmental Penalties Regulation (O. Reg. 222/07) was enacted to penalize industries regulated under the Effluent Monitoring and Effluent Limits (e.g., mining and other industrial sectors), it demonstrates provincial government recognition of the value of the use of ISO 14001 certification by "regulated persons" as defined in O. Reg. 222/07," i.e. a person who owns or operates a MISA (Municipal Industrial Strategy for Abatement) or MISA-like facility. The Environmental Commissioner of Ontario ${ }^{109}$ (ECO) supports the Environmental Penalties regulation as it provides "ministry staff with a faster, less resource intensive, and less costly means of bringing contraveners into compliance with provincial environmental laws" and it "may result in a reduction in the total number of cases prosecuted by MECP" (ECO 2008). Furthermore, the Source Water Protection Plans (prepared by independent and multistakeholder Source Water Protection Committees) approved in 2015 and 2016 by the MECP under the SDWA and O. Reg. 284/07 references O. Reg. 222/07, as a way to assess environmental penalties and encourage environmental protection.

\footnotetext{
109 The position of the Environmental Commissioner of Ontario (ECO) was established in 1994 as an officer of the Legislative Assembly of Ontario. As such, the ECO does not report to any Ministry, but rather to the Legislature itself. A change to this reporting relationship was made in November 2018, when the ECO was merged into the auditor general's office, [Online]: https://eco.on.ca/ [10 Feb 2019]
} 


\section{APPENDIX F - SHORT SUMMARIES OF MUNICIPAL ISO 14001 EXPERIENCE}

This appendix provides short summaries of specific municipalities and their experiences with ISO 14001 and ISO 9001, drawing on publicly available information and interviews with municipal officials met at water conferences from 2016 to 2019 attended by the author. This section is organized in three groups:

a) Court Decision Ordering EMSs
1) City of Calgary
2) Alberta Capital Region Wastewater Commission

b) Court Decisions Leading Municipalities to Adopt EMS-type Corrective Actions
1) City of Kingston
5) Metro Vancouver
2) City of Hamilton
6) City of Timmins
3) EPCOR - City of Edmonton
7) City of Winnipeg
4) City of Ottawa

c) Municipalities Drawing on MSSs for their Wastewater and Stormwater Systems
1) Lake Huron and Elgin Area Water
Supply systems
4) Halifax Water
5) Quebec City
2) City of Collingwood
6) Regional District of Nanaimo
3) Halton Region
7) City of Toronto

\section{A. Court Decisions Ordering EMSs}

\section{1) City of Calgary}

There are three cases associated with the City of Calgary:

- R. v City of Calgary (2000)

- a City of Calgary spill in 2005, reported by Environment Canada's National Enforcement Management Information and Intelligence System (NEMISIS)

- R. v City of Calgary (2014)

In the R. v City of Calgary (2000) case, the city entered a guilty plea to charges under Alberta's Environmental Protection and Enhancement Act (Ecolog, 2000). On March 24, 1998, 
the ventilation system of the Bearspaw water treatment plant was not operating properly and allowed approximately 160 kilograms of chlorine gas to escape into the atmosphere.

[t]he fact that we do not believe this incident affected the environment or human health does not make it any less serious. It had the potential to do so, and our legislation on that is straightforward. If you release a substance that could potentially harm the environment, you can expect us to take enforcement action (Environment Minister Halvar Jonson quoted in Ecoweek, 2000, p. $1^{110}$ ).

The court sentencing required the City to commit to obtaining ISO 14001 certification for its Bearspaw and Glenmore water treatment plants by August 2003. In addition, the sentence included a fine of $\$ 1,000$, plus creative sentencing of $\$ 200,000$ for the Environmental Damage Fund. It also included a requirement for the City to make a presentation at the Western Canada Water and Wastewater Association's annual meeting in October 2001 (Ecolog 2000). The City website states:

[i]n 1999, the City of Calgary began implementing an organization-wide environmental management system for all City operations under ISO 14001 accreditation [....] The City of Calgary is noted as the first municipality in North America to register an EMS for the entire corporation (Calgary, 2018).

In 2005, the City of Calgary had a wastewater spill that was reported as the largest spill on record in Alberta until 2010 (Rennie, 2010). The City's Bonnybrook wastewater treatment plant, which handles most of the City's sewage (which was not covered by the city's ISO 14001 certification), had a storm and flood that led to a spill of 30 million cubic metres of sewage (Rennie, 2010).

In the case of R. v City of Calgary (2014), the city entered a guilty plea for charges under the Fisheries Act. The City was sentenced to a $\$ 10,000$ penalty, and ordered to implement upgrades to two lift stations located along West Nose Creek to be completed by June 8,2014 . The upgrades included $\$ 190,000$ of work to upgrade the lift station alarms and monitoring infrastructure to prevent future releases from lift stations into West Nose Creek.

${ }^{110}$ Ecoweek, Sep 2000, [Online]: www.ecoweek.ca/issues/ISarticle.asp?aid=1000184595 [09 Jan 2017] 
In light of this information some clarification of the City of Calgary's EMS is necessary. Established in 2002 and known as "EnviroSystem"111 the City's EMS was based on multiple certifications that evolved over time from a facility-based into a business unit-based certification structure (prior to 2009, the City had 11 separate ISO 14001 registrations). Since 2009, the City has transitioned from the EMS model to a consolidated registration for the entire corporation including audit processes.

In response to the case of R. $v$ City of Calgary (2014), the City expanded EnviroSystem's reach. Since 2014, the City of Calgary's Environmental Policy also mandates its contractors to adhere to environmental responsibilities. These responsibilities are included in the City's Contractor Environmental Regulations, ${ }^{112}$ which requires any contractor working with the city to comply with corporate procedures applicable to contractors, involving environmental performance protocols and controls (e.g. awareness, competence, erosion \& sediment control, dewatering, soil conservation, tree protection and recycling).

These court cases and the City of Calgary's response to them provide support for the proposition that courts and municipalities are recognizing the value of adopting ISO 14001 to enhance due diligence for regulatory compliance, and to assist in addressing risk and emergency management aspects of system operations, including with respect to the transfer of EMS policy and requirements to third party service providers. In this regard, they offer evidence of vertical policy convergence in the use of non-state EMS standards across federalprovincial-municipal governments and the courts. This is reflective of the vertical and quasivertical policy convergence towards the use of ISO 14001 in municipal wastewater operations.

\section{2) Alberta Capital Region Wastewater Commission}

The ACRWC provides wastewater and conveyance services to 13 member municipalities in Alberta, in the region around Edmonton. The ACRWC was formed as a result of a 1977 study which recommended centralizing the wastewater system. The study was necessary in light of the rapid growth of Edmonton and its surrounding municipalities. In 1980, the Province of

\footnotetext{
${ }^{111}$ City of Calgary's Auditor Report, Sep. 2016 [Online]: https://pubcalgary.escribemeetings.com/filestream.ashx?Documentld=2231 [29 Mar 2017]

${ }^{112}$ City of Calgary's Contractor Environmental Regulations [Online]: www.calgary.ca/UEP/ESM/Pages/Contractorenvironmental-responsibilities/Working-with-The-City-of-Calgary.aspx [29 Mar 2017]
} 
Alberta decided to build a new regional treatment plant and trunk sewers, and by 1985, a new provincial regulation created the ACRWC to service the municipalities surrounding Edmonton. ${ }^{113}$ The ACRWC is governed by a Board of Directors formed by appointed members (one from each municipality it serves). In its current form, the ACRWC has five remote pumping stations, and its forcemains are integrated with the City of Edmonton's system, including its wastewater treatment plant (Darbyshire, 2016). Funding for the ACRWC comes from bulk water consumption and contaminant strength charged to each of the 13-member municipalities. ${ }^{114}$

On August 9, 2012, the electrical control system of one of the ACRWC's remote sewage pumping stations, the Gibbons Pump Station, which services a population of approximately 3,000, had a complete electrical failure. For 12 hours, raw sewage bypassed the treatment facility and an estimated volume of 500 cubic metres spilled into the Sturgeon River, a tributary of the North Saskatchewan River (Darbyshire, 2016).

This spill was considered by the court to be a second offence. The first was a minor offence of a failed wastewater toxicity test that had occurred 15 years erlier (Darbyshire, 2016). As part of its due process investigation into the 2012 event, the Court compared the ACRWC's emergency response procedures with those of neighbouring operators, including private operators (EPCOR, whose operations are accredited to ISO 14001), and determined that the ACRWC's standards were not at par with industry standards (noted by the ACRWC representative at the 2016 Canadian Water and Wastewater Conference).

In 2014, the Alberta Capital Region Wastewater Commission (ACRWC) entered a guilty plea for the 2012 spill event charges under the Fisheries Act, sec.36, for the raw sewage spill into a creek draining into the Sturgeon River. The sentence included a requirement to update their existing ad-hoc environmental management system and adhere to ISO 14001 (Darbyshire, 2016). The Alberta Court sentenced the ACRWC as follows (Darbyshire, 2016):

- $\quad$ ACRWC was added to the Environmental Offenders Registry.

\footnotetext{
${ }^{113}$ ACRWC History, [Online]: https://acrwc.ab.ca/about-acrwc/, [27 Jul 2019]

${ }^{114}$ ACRWC 2018 Annual Report, [Online]: https://acrwc.ab.ca/wp-content/uploads/2019/04/ACRWC-2018-AnnualReport.pdf [27 Jul 2019]
} 
- $\quad$ ACRWC were required to pay a $\$ 20,000$ fine and make a $\$ 180,000$ donation to the Environmental Damages Fund to promote the proper management and protection of fish and fish habitat in and around the area impacted.

- Improvements were mandated to the ACRWC by the court to revise its standard operating procedures and employee training (which are two critical elements of the existing ACRWC EMS). The existing environmental "management system improvements included: root cause analysis, capital and maintenance risk-based priority settings, and organizational engagement" (Darbyshire, 2016).

As noted by Darbyshire (2016) concerning the investigation and the guilty plea:

[t]he investigators, Crown Prosecutor and Judge all understood that equipment breaks down; it was our response to the incident that didn't meet expectations [....] having pleaded guilty to a charge of discharging a deleterious substance under the Fisheries Act, the next time ACRWC could face a penalty of up to $\$ 1,000,000$, plus prison time. So, in our risk assessments, a failure that would lead to a discharge to a water course has the highest consequence rating.

The ACRWC 2016 Annual Report states in relation to the current EMS:

[....] [the ACRWC's] EMS progressed into its second three-year cycle. A successful surveillance audit to international EMS standard ISO 14001:2004 by ACRWC's external registrar was conducted. Preliminary planning was conducted to determine how to achieve compliance to the newly revised ISO standard (ISO 14001: 2015) (ACRWC 2016 Annual Report p.11).

The ACRWC case also supports the proposition that courts and municipalities are recognizing the value of adopting ISO 14001 to improve regulatory compliance and to assist in addressing risk and emergency aspects of system operations. In addition, it offers further evidence in support of vertical and quasi-vertical convergence and policy transfer concerning the use of non-state EMS standards across federal, provincial and municipal governments and the courts. 


\section{B. Court Decisions Leading Municipalities to Adopt EMS-type Corrective Action}

\section{1) City of Kingston}

In 1998, the case of Fletcher v. Kingston (City), a private prosecution initiated by Janet Fletcher with the assistance of Sierra Legal Defence Fund (now Ecojustice), resulted in a conviction against the City of Kingston under the Fisheries Act and a fine of $\$ 120,000$. At the time, this was one of the highest fines ever levied against a municipality for environmental offences. The allegation involved contaminants harmful to the fish in the Cataraqui River, leaked from a closed landfill site. As soon as the charges were laid, the City installed pumps and a collection system to prevent the leachate from polluting the river. Later, the case was appealed and the conviction on the private information charges was overturned (Swaigen, 2013).

While this case did not involve an MSS, could be assumed that it raised the profile of riskmanagement approaches for addressing environmental protection. In 2005, two ENGOs, Lake Ontario Waterkeeper (now Swim Drink Fish) and CELA, filed an administrative request for stricter permits, asking that the City be required to provide public notice, monitoring, and cleanup of raw sewage spills (Neild, 2005). The request came after raw sewage washed up on Wolfe Island following one of the City's common sewage overflows. The MECP accepted a commitment by the City under voluntary abatement rather than imposing enforceable rules (Neild, 2005).

In 2013 the City adopted an Environmental Risk Management System (ERMS), which includes internal audits and a corporate environmental policy, but is not ISO 14001 certified. The ERMS covers the City of Kingston's public works areas such as construction, land development, real estate and acquisitions, the operation of the marina and sports arena, and the transit system (interview respondent, $\mathrm{M}-19$ ). It has also been noted by a municipal representative from Kingston, interviewed as part of this study, that there have been preliminary discussions with Utilities Kingston (the owner and operator of the municipal drinking water and wastewater systems) to expand the scope of the ERMS to include water and wastewater services.

Concerns by Lake Ontario Waterkeeper and CELA are well founded. Despite efforts to reduce combined sewer overflows (CSOs), discharges of untreated sewage have continued. In 2017, 
364,000 cubic metres of CSOs from the combined sewer system (CSS) were discharged into the river, representing more than three times the volume of Kingston's CSOs in 2016 (MacAlpine, 2017).

In May 2017, the City of Kingston and Utilities Kingston launched a real-time, web-based overflow tracking system. ${ }^{115}$ Only weeks before the May 2017 announcement, Utilities Kingston reported CSOs of 80,000 cubic metres into the river, and 67,000 more the week before that, and 214,000 cubic metres the previous month (MacAlpine, 2017). This real-time tracking tool was supported by Lake Ontario Waterkeeper, the ENGO referred to above. As reported by MacAlpine, the ENGO had been critical of the city's management of local waterways. Regarding the response to these criticisms Krystyn Tully, founder and vice-president of Lake Ontario Waterkeeper remarked:

[....] I think it's a testament to how far this city has come and how responsive both the city and Utilities Kingston have been to the public's concerns and comments. Now they are developing technology that's becoming the gold standard to which all communities in Ontario should be performing. It's really remarkable (MacAlpine, 2017:n/p).

Interestingly, in their proposed Made-in-Ontario Environmental Plan, the Ontario provincial government (newly elected in 2018) would require municipalities to have real-time monitoring and reporting to the public for CSOs and spills (MECP, 2018).

This case arguably illustrates the concept of sustainable governance, where non-state actors (such as citizens and NGOs) add a dynamic of checks and balances, and as illustrated here, assist in holding municipalities accountable for water violations. Under this type of situation, there is a potential competitive "edge" gained by municipalities that adopt an environmental management system in the form of ISO 14001 certification (i.e. they can claim that they are more environmentally responsible municipalities than others that don't have ISO 14001 certification), and the EMS might assist the municipality in building a due diligence defence, or reducing penalties in cases of convictions.

115 Utilities Kingston Real-Time Overflow [Online]: https://utilitieskingston.com/News/Article/Real-time-publicnotification-of-sewer-overflows-May-2018 [29 Mar 2017] 


\section{2) City of Hamilton}

In 2000, a private citizen successfully launched a private prosecution against the City of Hamilton (population 534,000), which entered a guilty plea to charges under the OWRA in relation to a landfill contamination with a leachate of polychlorinated biphenyls (PCBs) (a known carcinogenic chemical) discharging to Redhill Creek. The case resulted in a $\$ 450,000$ fine, which at the time was a record for a prosecution of this kind (Lake Ontario Waterkeeper, 2011).

The City of Hamilton had begun working towards an EMS in 2005. However, a change of elected officials and senior management in 2012 resulted in a change of priorities, and the ISO 14001 initiative it had been working on was abandoned, while keeping the elements developed up to that point. As pointed out by an MSS consultant interviewed for this study and familiar with the process:

[....] consultants were brought to develop the EMS for the City through 2013. Much documentation, procedures and guidance was developed. Then, a new [municipal] government occurred and they abandoned the effort. It was too annoying and frustrating (interview respondent, C-1).

The City of Hamilton had a water and wastewater system privatization contractual arrangement in place from 1994 to 2004 (Ohemeng and Grant, 2008). In 2004, the City decided not to renew its contract with America Water Services. At the time, privatization of municipal water and wastewater was under scrutiny in Ontario. A number of issues had been reported while the system remained privatized: labour force reduction, non-compliance with provincial regulations, lack of maintenance of infrastructure, and ineffective capital improvement plans (Ohemeng and Grant, 2008). In this case, the union played a role in ensuring the city did not renew the contract, which indirectly encouraged the city to adopt an EMS based on ISO 14001.

Commentators like Brubaker (2003) report that privatization schemes associated with the delivery of government services became popular in the 1990s as "it was a decade of experimentation with asset sales" (Brubaker 2003: 1). By the late 1990s, private companies seeking to operate municipal water systems sought ISO 14001 certifications, as a way of signalling environmental responsibility and thereby securing an advantage over other 
competitors (Halley \& Boiral 2009). Arguably, this move towards privatization provided an increased impetus during the 2000's for adopting EMS for water management activities, since it creates the possibility of protection with a seamless environmental management system across state entities and their privatization partners.

This case highlights both the influence of judicial prosecutions (fines for environmental violations), external factors (such as privatization schemes in a unionized environment) and top management's leadership role in encouraging governments to develop EMSs for their system operations. The Halton Region summary, provides some continuity to the Hamilton experience.

\section{3) EPCOR - City of Edmonton}

Since 1996, water and wastewater services for the City of Edmonton, Alberta, have been provided by EPCOR, ${ }^{116}$ a public and independent utility company fully owned by the City of Edmonton. EPCOR operates in Edmonton, and also provides water and wastewater services to 75 communities and industrial sites in Alberta, British Columbia, and Ontario. In addition, through a subsidiary, EPCOR USA provides water operation services in Arizona, Texas, and New Mexico in the United States (EPCOR, 2015).

In 2003, the City of Edmonton was charged by the Province of Alberta under the Environmental Protection and Enhancement Act over the release of PCB oils at the Commonwealth Stadium during an international sports championship event in 2001 . The maximum penalty faced by the City was reported to be $\$ 4.5$ million (Mahoney, 2003). The adoption by the City of Edmonton of ISO 14001 for most public works followed in 2004. In a 2004 Policy, the City "establish(ed) the ISO 14001 [.... for] practices across the city." This policy established that "the City will promote ISO 14001 with other government agencies, municipalities, environmental groups, and related contractors" (Policy No. C505, City of Edmonton, 2004).

EPCOR adopted the EMS on a facility-basis approach. Each water and wastewater treatment plant followed a rigorous process to obtain ISO 14001 certification. Relevant to this study, EPCOR recognizes the competitive advantage to have ISO 14001 as part of its marketing strategy. In a 2015 Media Release, EPCOR noted:

${ }^{116}$ EPCOR [Online]: www.epcor.com/learn/our-stories/Pages/125-years-and-counting.aspx [29 Mar 2017] 
[w] require each facility to have an environmental management system (EMS) which is based on ISO 14001 standard [....] Water and wastewater technologies and supporting processes are continuing to evolve and be influenced by more stringent regulation and environmental challenges. Failure to identify and deploy viable new technologies to meet these regulations and challenges could undermine the competitiveness of EPCOR's market position and exclude it from some market opportunities (EPCOR, 2015: 21).

Of significance to this study is that EPCOR has confirmed that their EMS and ISO 14001 certification across the entire Edmonton Water System was transitioned from ISO 14001:2004 to the new version, ISO 14001:2015. The 2018 Envirovista Report states that:

The Edmonton Water System completed transition of the registration of the Environmental Management System (EMS) to the new international standard, ISO14001:2015. EPCOR has maintained a fully registered EMS since 2017 (EPCOR, 2019:4).

The City of Edmonton/EPCOR experience supports the proposition that municipalities, in light of potential legal fines, are recognizing the value of adopting ISO 14001 to improve regulatory compliance and to assist in addressing risk aspects of system operations. This also suggests further evidence in support of vertical and horizontal convergence and policy transfer concerning the use of non-state EMS standards, between state actors (provincial and municipal) drawing on non-state rule instruments such as ISO standards.

\section{4) City of Ottawa}

The City of Ottawa provides drinking water, wastewater and stormwater services to its approximately one million residents. ${ }^{117}$ In 2006 and 2007, the City was responsible for raw sewage spills into the Ottawa River of about 20 to 90 million cubic metres. This event generated significant media coverage, which referred to the spills as "Sewergate" (Reevely, 2008). Storm events in July and August 2006 leading to the spills were not reported to the MECP until the spring of 2007. The issue became public a year later (2008), when a community group and a City councillor touring the main wastewater treatment plant were told about it (Ruppert and Greenberg, 2008).

\footnotetext{
${ }^{117}$ City of Ottawa population (2016), [Online]: https://ottawa.ca/en/city-hall/get-know-your-city/statistics-andeconomic-profile/statistics/2016-census [29 Mar 2017]
} 
The City's internal 2006/2007 investigation reported spills going back to 2004, with a spill over a four-day period due to a faulty sewer gate. Further spills were also confirmed by city staff for 2006 and 2008 (Rennie, 2010). A series of management issues leading to the spills were noted as part of the reports including (Ruppert and Greenberg, 2008):

- inadequate preventative maintenance to address faulty equipment;

- failure to report spills to city management, provincial government, and local public department of health;

- poor record-keeping; and

- lack of training and standard procedures.

In October 2008, the City Ottawa entered a guilty plea and was sentenced to charges under the OWRA in connection with the spill of sewage into the Ottawa River in August 2006. ${ }^{118}$ The offences included the discharge of sewage and failing to notify the Ministry forthwith, in contravention of the OWRA, section 30(1) and (2), respectively. As part of the sentence, the City was fined $\$ 450,000$, plus a $\$ 112,500$ victim surcharge. In relation to this incident, Ottawa Riverkeeper ${ }^{119}$ noted on their website that before the sentencing the city had already "agreed to award $\$ 50,000$ to Ottawa Riverkeeper to help monitor the city's future actions" (Neild, 2008). This shows connections between government and civil society in support of municipal environmental protection, in keeping with the sustainable governance concept discussed in Chapter 2.1.2.

The City Auditor General's Report found that managers “didn't really think it was a spill, and for about a year classified the event as normal overflow before reporting to the Ministry of the Environment" (Ruppert and Greenberg, 2008). The report concluded that 16 other spills dating back to 1998 were not reported until September 2008, and that management used to treat those events as routine (Rennie, 2010). The Environment Commissioner at the time, Gord Miller, was reported as stating:

\footnotetext{
118 Ontario Newsroom - Archived Bulletin: City of Ottawa fined \$450,000 for August 2006 sewage discharge into Ottawa River, [Online]: https://news.ontario.ca/ene/en/2008/10/city-of-ottawa-fined-450000-for-august-2006sewage-discharge-into-the-ottawa-river.html. [29 Mar 2017]

119 The Ottawa Riverkeeper is a non-profit organization with the mandate to protect the Ottawa River and reduce Combined Sewer Overflows (CSOs), [Online]: https://www.ottawariverkeeper.ca/ [29 Mar 2017]
} 
[....] [the City of Ottawa Auditor's Report] shows a disturbing culture of acceptance of spills [....] clearly the internal auditor has shown there was a Walkerton-like attitude amongst staff on the sewer side. [....] [I want] to know whether the province ever required the city to produce a plan to contain future spills and how often ministry officials inspected the system (Ruppert and Greenberg, 2008)

The city reportedly implemented the auditor's recommendations as follows (Ruppert and Greenberg, 2008):

- filing breach of their duty-of-care with the provincial engineer's association against the city professional engineers;

- firing two managers and a supervisor and suspending another manager for 20 days without pay; and

- implementing environmental management and safety standards, reviewing the reporting system, and ensuring better monitoring of the sewer system.

In the face of significantly negative public opinion, the City of Ottawa began planning in 2008 the development of an EMS. The City of Ottawa since then created a Quality Management group in 2010 and has developed elements of an EMS for their wastewater collection system based on the ISO 14001 pillars but does not have an accredited ISO 14001 certification at this time (interview respondent, $\mathrm{M}-20$ ).

The EMS approach has migrated to other public services programs as well. However, the City's environmental web portal (2018) states the following in relation to their biosolids program, ${ }^{120}$ a program that manages the sewage sludge and green bin programs:

[t]he City of Ottawa Biosolids Beneficial Use Program is guided by the principles of the (ISO) 9001, 14001, and 18001, and is governed by Ontario Ministry of Agriculture and Food, the Environmental Protection Act and the Nutrient Management Act. It is also governed by the City's own policies and protocols.

According to an ENGO representative in 2018:

[....] the Ottawa Riverkeeper pushed for the City to implement a wastewater management system. The Ottawa Riverkeeper had citizens send letters to the City

\footnotetext{
${ }^{120}$ City of Ottawa - Biosolids Beneficial Use Program [Online]: http://app06.ottawa.ca/calendar/ottawa/citycouncil/riac/2009/07-21/03\%20-\%20Biosolids\%20\%20Participant\%20Letter\%20of\%20Introduction.htm [29 Mar 2017]
} 
Councillors. Now Ottawa has a 75 -year plan ${ }^{121}$, has been able to reduce $85 \%$ of CSOs, and citizens were and continue to be informed (ENGO representative interviewed as part of this study, $\mathrm{N}-3$ ).

This case provides an example of how civil society (represented by ENGOs), media pressure, and public input from elected officials assisted in stimulating the City to adopt an aggressive CSO reduction program, to adopt an EMS with elements of ISO 14001, and to put in place public notification protocols. What was originally a water issue, broadened into a multiple MSS approach (ISO 9001, ISO 14001, and ISO 18001) that also addressed the City's biosolids program.

An ENGO representative noted that historically, ENGOs have used private prosecution or other legal alternatives, as primary means to stimulate environmental performance (as opposed to non-legal approaches) but that this approach appears to be changing:

[....] I think the main reason we shifted from legal work to more tools-based, and public engagement work was that this is seemingly more effective in making a change. So instead of taking the provincial and federal government to court, we engage local citizens in the issues, which can then sway political change (ENGO representative interviewed as part of this study, N-3).

The ENGO representative also noted that legal work is very expensive, labour intensive, and does not engage the public about the issues being dealt with. This representative stated preference was to use community-based initiatives that engage local groups.

The City of Ottawa experience further supports the concept of sustainable governance, whereby non-state actors (such as citizens and public opinion) assist in holding municipalities accountable for water violations. Although the City of Ottawa has not formally adopted ISO 14001, they developed an EMS based on the ISO 14001 model. This suggests further evidence in support of horizontal convergence in a municipal government drawing on non-state EMSs.

\section{5) Metro Vancouver}

The Greater Vancouver Sewerage and Drainage District (GVSDD) maintains and operates the regional trunk sewers, pumping stations and wastewater treatment plants that connect with

\footnotetext{
${ }^{121}$ City of Ottawa - Ottawa River Action Plan (ORAP), [Online]: https://ottawa.ca/en/residents/water-andenvironment/air-land-and-water/beaches-rivers-and-streams/ottawa-river-action-plan [12 Jan 2019]
} 
municipal sewer systems, serving approximately 2.5 million people in the Greater Vancouver District. $^{122}$

In 2011, a release of untreated sewage into Burrard Inlet occurred when one of the pumps at the Chilco Sewage Pump Station became partially plugged with debris. An estimated 650,000 litres of untreated sewage was discharged into Burrard Inlet through a combined sewage outfall near Brockton Point in Stanley Park.

In 2014, GVSDD entered a guilty plea in the British Columbia Provincial Court for charges laid under the Fisheries Act (Dobrovolny, 2017). The GVSDD was sentenced to pay a $\$ 110,000$ penalty, $\$ 5,000$ being a fine under the Fisheries $A c t$, and the remaining $\$ 105,000$ to be paid into the Environmental Damages Fund (EDF).

The EDF funds from the GVSDD were directed towards projects to properly manage and control fisheries or fish habitat, or the conservation and protection of fish or fish habitat. Overflows at the same location originating from the Chilco pumping station continued to occur until 2017, and emergency protocols and actions pursuant to the EMS have been taken proactively by Metro Vancouver (Dobrovolny, 2017).

Still in the process of developing and implementing an EMS based on the ISO 14001 model (GVSDD, 2014), the City of Vancouver experience is a good example of another Canadian municipality outside Ontario proactively working towards EMS. In its 2014 Annual Report, the City of Vancouver states:

[a]n EMS is a management framework for identifying and addressing how a business interacts with the environment, complying with environmental regulations, ensuring due diligence, and continuously improving environmental performance in operations [....] defined by international standards (the most widely followed is ISO - International Organization for Standardization), giving state of the art specifications for good practice (GVSDD, 2014: 167).

The scope of the EMS is limited to the operation of the existing drinking water and wastewater systems and their responses to emergencies like spills. The public work areas of design and construction are not within its scope, nor is the stormwater system, which is under the

\footnotetext{
${ }^{122}$ Metro Vancouver - Liquid Waste Services [Online]: www.metrovancouver.org/services/liquidwaste/Pages/default.aspx [29 Mar 2018]
} 
authority of the individual municipalities within the Metro region. However, Metro Vancouver, adopted a Sustainable Infrastructure and Building Policy that uses rating systems or standards such as Envision and LEED for design and construction. ${ }^{123}$

This experience provides further support for the proposition that municipalities are recognizing the value of adopting ISO 14001 to improve regulatory compliance and to assist in reducing environmental penalties and liabilities. This illustrates more evidence in support of vertical and horizontal convergence and policy transfer concerning the use of non-state EMS standards, between state actors (three levels of government) drawing on non-state rule instruments such as ISO standards.

\section{6) City of Timmins}

In 2012, the City of Timmins (est. population 42,000) received a Provincial Officer's Order to address flooding issues in certain areas of town (ECO Report, 2018). The MECP investigation led to a continual improvement plan to ensure no homes in these areas were connected to the stormwater system (ECO Report, 2018). In response to this order, the City introduced a municipal bylaw for a 6-year monitoring and reporting contract for water quality sampling of the Porcupine Lake and local tributaries at a cost of $\$ 158,000$ (City of Timmins, 2013).

The City failed to meet the deadlines to upgrade its wastewater system set out in 2012. In a 2017 application to the Environmental Commissioner of Ontario (ECO) for investigation, the applicants stated that deterioration of the City's sewage system had caused sewage to bypass treatment and discharge into Porcupine Lake, and cross-connections, whereby sanitary sewers from new homes in one area were hooked up directly to the stormwater system, as opposed to the sanitary system (ECO Report, 2018). As part of the response to the MECP investigation triggered by the ECO, the City issued a new bylaw (2017-8130) to upgrade its wastewater system at a cost of $\$ 80$ million, to increase its capacity and reliability (ES\&E, 2018). Although the City of Timmins has not adopted an EMS, it has implemented many important elements of ISO 14001, such as monitoring and reporting, risk assessment, and continual improvement.

\footnotetext{
${ }^{123}$ Metro Vancouver - Sustainability policy, [Online]: www.metrovancouver.org/services/housing/housing/sustainability/Pages/default.aspx [12 Jan 2019] 


\section{7) City of Winnipeg}

The City of Winnipeg (est. population 730,000) is the largest urban centre in the Province of Manitoba. The City provides drinking water, wastewater management, and stormwater services to its residents, among other public works and municipal services.

On September 2002, a mechanical failure at the City of Winnipeg's North End Water Pollution Control Centre resulted in a spill of raw sewage into Red River. The release continued over a 57-hour period during which time 47 million cubic metres of untreated sewage was discharged. The spill reportedly caused great public concern and generated significant media coverage.

In October 2002, the Minister of Conservation called on the Manitoba Clean Environment Commission (MCEC) to organize a public hearing to formulate recommendations. Several investigative reports were produced by different agencies such as the City's Environmental Impact Statement (EIS), to support the MCEC's review. The Public Hearing Report (2003), recommended the development and implementation of an EMS. In parallel, another report by the Manitoba Conservation and Associated Engineering and Environment Canada also recommended EMS adoption (Duguid, 2003).

A notice of public hearing was issued in October 2002, through government agencies, websites, and local media. The hearings were held in Winnipeg from January 20 to 23 , and again from April 14 to 16, 2003; and at a separate location from January 27 to 28, 2003. About 750 people attended the hearings, and a total of 126 exhibits were submitted during the nine days of public hearings. At three points in the report there are recommendations to develop and implement an EMS registered under ISO 14001 for Winnipeg's wastewater treatment facilities. In addition, the report also recommended for the city:

- to complete an adequate EIS, as the one completed in the month after the spill was deficient, omitted important considerations, and did not follow EIS industry standards for consultation;

- to develop a nutrient reduction plan for its wastewater system and surface waters; and

- to have the city develop a pollution prevention plan to reduce the number of SSO, as the existing 50-year plan was considered inadequate (Duguid, 2003). 
Since 2005, Winnipeg's wastewater facilities have been compliant with ISO 14001, and the City has adopted an environmental policy that now covers drinking water, wastewater, and waste management services.

Although there was no prosecution involved, the Winnipeg experience highlights the sustainable governance approach, in which civil society pressure assisted in stimulating use of non-state MSS standards to improve management of water/wastewater systems. In this case the City of Winnipeg proactively decided to implement the recommendations of a public hearing report, in part to fill gaps in provincial/municipal legislation and develop a more active form of due diligence to protect the environment (Duguid, 2003).

Even though there was no litigation involved, the Winnipeg experience shows multistakeholder support for use of non-state MSS standards to improve management of water/wastewater systems, in keeping with the sustainable governance approach. In effect, the City of Winnipeg proactively decided to implement the recommendations of a public hearing report without waiting to be prosecuted.

\section{Municipalities Drawing on MSSs for their Wastewater and Stormwater Systems}

\section{1) Lake Huron and Elgin Area Water Supply Systems}

The Lake Huron and Elgin Area Water Supply Systems currently employ an Environmental Management System (ISO 14001) implemented in 2003, and a Quality Management System (DWQMS) implemented in $2006^{124}$. These two water systems supply drinking water to a population of approximately 375,000 from a water treatment plant located north of the village of Grand Bend in South Huron, which supplies water to the municipalities of London, Lambton Shores, North Middlesex, South Huron, Bluewater, Middlesex Centre, Lucan-Biddulph and Strathroy-Caradoc. ${ }^{125}$

The decision to implement the EMS was made in 2000 as part of the creation and establishment of these entities, considered public bodies under the Municipal Water Act

\footnotetext{
${ }^{124}$ Lake Huron \& Elgin Area - EMS \& QMS [Online]: https://huronelginwater.ca/about-us/management-systems/ [29 Mar 2019]

125 Lake Huron \& Elgin Area Water Supply System were created under the Municipal Water and Wastewater Transfer Act. [Online]: https://huronelginwater.ca/about-us/ [29 Mar 2019]
} 
(interview respondent, M-12). Prior to 2000, the regional water system was owned and operated by the Province of Ontario. A municipal senior official from Lake Huron and Elgin Area Water Supply Systems, who has been involved in the implementation since its initial adoption, highlighted the desire at the time:

[....] to become more resource efficient and lessen the overall impact on the environment. I also liked the standardization and continual improvement approach that came with the management system implementation. This mantra has become part of the mainstay in our administration and is apparent when you look at our approach within the Financial Plan, Asset Management Plan, and Master Water Plan, which incorporates the customer levels of service framework and risk mitigation strategy (interview respondent M-12).

In 2006, at the time that the Walkerton Inquiry recommendation for a provincially required QMS for drinking water systems was being developed, the Lake Huron and Elgin Area Water Systems pilot tested the implementation of the DWQMS, including the external audit protocols (City of London, 2008). It was based on the success of this test that the MECP moved ahead with O. Reg. 188/07, requiring a phased implementation of the DWQMS (Focus Group participant, Fp2)

The actual operation and maintenance of the infrastructure is carried out on a competitive basis through contractors (interview respondent $\mathrm{M}-12$ ). A condition of bidding on the operation and maintenance service agreement is the use and maintenance of the EMS certification for both the Lake Huron and the Elgin Area Water Supply Systems (interview respondent, M-12).

In 2009, building on their DWQMS and ISO 14001 implementation, both the Lake Huron and the Elgin Area Water Supply Systems, in addition of complying with the DWQMS and conforming with ISO 14001 for their overall operations, implemented an Incident and Emergency Management System ${ }^{126}$ based on the national Incident Command System standard. ${ }^{127}$ This suggests perceived value in municipal use of non-state MSSs to supplement

\footnotetext{
${ }^{126}$ City of London - Water Supply, [Online]: pub-london.escribemeetings.com/filestream.ashx?Documentld=26749 [29 Mar 2019]

127 Incident Command System (ICS Canada) is a standardized on-site management system designed to enable effective and efficient incident management response, [Online]: www.icscanada.ca/ [29 Mar 2019]
} 
existing state-based requirements, both with respect to environmental management and emergency management.

\section{2) City of Collingwood}

The City of Collingwood, a community of 20,000 (2016), is located on Nottawasaga Bay, part of Georgian Bay, Ontario. As noted by a municipal official working with the City, Collingwood was an early adopter of ISO 14001 for its drinking water treatment plant (interview respondent M15), which obtained ISO 14001 accreditation in 2009. The main driver for the adoption of the standard was a municipal infraction in 2008 for bypassing primary treatment (interview respondent $\mathrm{M}-15)$. This was a violation of Collingwood's own municipal bylaw, which triggered their action to obtain ISO 14001 certification. As it had already developed the DWQMS in 2008, it was a simple exercise to add environmental protection elements to the quality management elements already in place. Accreditation was maintained until 2014. The City's Annual Water Compliance Report for that year stated:

[t]he annual ISO 14001 surveillance audit was conducted [.... [t]he audit was successful. The Auditor noted that all outstanding minor non-conformities had been closed and that corrective action plans had been accepted and implemented. At the conclusion of the surveillance audit the auditor noted [....] [t] he system is working effectively (City of Collingwood, 2014: 7).

However, a change in the City's senior leadership in 2015 resulted in the City deciding to abandon its accredited status, while keeping the associated EMS procedures in place. In an interview conducted by the author, a Collingwood City senior official, remarked:

[i]t is unfortunate that we need to educate politicians every time [they are elected] so they understand its benefits [....] [the EMS] risk management approach is the way of the future, as it promotes the continual improvement. The EMS goes beyond regulatory compliance. If we stay in check with conformance with the EMS, we don't have to worry about compliance. The MECP should do a bulletin or guideline and leave it voluntary before making it mandatory. This way, small municipalities will have enough notice and will start working on it (interview respondent, $\mathrm{M}-15$ ).

The Collingwood experience suggests that leadership - not only from elected officials (as occurred in Durham Region), but also leadership at the municipal staff level - can play a role in municipal decisions to adopt or abandon a voluntary MSS. 


\section{3) Halton Region}

With a population of one million people encompassing eight lower tier municipalities, Halton Region is an upper-tier municipality that is located west of Peel Region and Toronto. Halton Region is another example of a municipality that has adopted an integrated management system (IMS) with multiple standards but has not sought accreditation. In 2014, new senior management initiated the adoption of an EMS based on ISO 14001, for the entire Region's public services areas, including water, wastewater and stormwater. Its IMS is still under development and at some point accreditation will be sought. One Halton Region senior official noted that:

[....] the new commissioner, who came from Hamilton, brought standardization of business practices up to international industry standards. A new organization structure is now in charge of the development and implementation of an integrated management system, reporting directly to the commissioner. Also, since these are administrative decisions, City Council is not involved, and probably that [is] the reason why Halton will not seek accreditation, so to keep politicians' decisions at bay. This [IMS] is here to stay (interview respondent $\mathrm{M}-17$ ).

According to a Halton municipal representative, the IMS for Halton Region covers all public works areas (water, wastewater, stormwater, roads, transit, housing, etc.) and integrates ISO 9001 (QMS), ISO 14001 (EMS), and ISO 45001 (H\&SMS). The Halton Region experience seems to provide support for the proposition that senior municipal staff senior leadership can play a key role in deciding whether to adopt (and the extent of the scope of) a voluntary MSS.

\section{4) Halifax Water}

The Halifax Regional Water Commission (Halifax Water) is a municipal water, wastewater, and stormwater utility serving the residents of the City of Halifax, a community of approximately half a million people. Halifax Water operates its facilities as ISO 14001 certified treatment plants. Halifax Water established its EMS in 2003 for drinking water and in 2016 for its wastewater system. Its environmental management policy is aligned with the ISO 14001 (Halifax Water, 2016a).

A council report concerning the Halifax Water 2018/19 Business Plan highlighted the value of the ISO 14001 by stating: 
[s]ince 2003, Halifax Water has obtained certification for [its drinking water facilities] [....] which are the only ISO certified water supply plants in Atlantic Canada. In December 2016, [the wastewater facilities] [....] became the first wastewater facility in Atlantic Canada to obtain an ISO 14001 Certification. Through the EMS program, Halifax Water has developed an increased awareness of compliance obligations, managed waste and energy more efficiently, reduced risk, improved emergency management and created a culture of continuous improvement (Halifax Water, 2018: 8).

Furthermore, contractors working for Halifax Water are required to comply with Halifax Water's EMS as a condition of tender. In the 2019 tender form work to be done on Halifax Water's JD Kline Water Treatment Plant, the contractual documentation states:

[....] tenderer agrees that the Contract Documents [includes] [....] Appendix C Environmental Management System (Halifax Water, 2019: Tender Form, pp. 1-2).

The Halifax experience provides support for the proposition that municipalities are recognizing the value of adopting ISO 14001 to increase awareness of compliance obligations, to assist in addressing resource, risk, emergency and energy aspects of system operations and to assist in creating a culture of continuous improvement, including with respect to the transfer of EMS policy and requirements to third-party service providers.

\section{5) Quebec City}

With an estimated population of 530,000 (2016), the City of Quebec operates a treatment plant whose treated effluent discharges to the St. Lawrence River. A 2004 report by the Labour Environmental Alliance Society, and the Suzuki Foundation noted that the city had an estimated 50 combined sewage overflows (CSOs) each year, and that the it had objectives to reduce these to 5 events per year plant (SLDF, 2004: 38). The report also noted that the city obtained ISO 14001 certification in 2001 for the operation and maintenance of its wastewater treatment plant (SLDF, 2004: 38).

Nevertheless, large quantities of raw sewage discharges to the St. Lawrence continue to occur regularly. In 2016, there was a discharge of 135 thousand cubic metres into the St. Lawrence, and in February 2018, there was a water advisory issued to the public by Quebec City for the planned discharge of 4.5 thousand cubic metres of raw sewage "necessary to do 
maintenance work on the Saint-Pascal pumping station" (Page, 2018). Information on whether Quebec City still has an EMS for their wastewater systems could not be obtained by the author.

The Quebec experience provides support for the proposition that ENGOs can play an important role in monitoring and providing checks-and-balances to ensure compliance with laws and with MSS requirements that went above and beyond those set by the law.

\section{6) Regional District of Nanaimo}

Since 2005, the Regional District of Nanaimo in British Columbia, serving a population of 10,000 on Vancouver Island, has had its Wastewater Services Department certified under ISO 14001. ${ }^{128}$ Their Environmental Management System ${ }^{129}$ (EMS) require all contractors and/or suppliers working on behalf of the Wastewater Services Department to follow the environmental procedures outlined in the department's EMS. These procedures stipulate the following:

[a]II Wastewater Services contractors and suppliers whose activities have the potential to cause environmental harm are given the chance to receive EMS training. Training will inform contractors of all operational and emergency procedures to which they must comply. ${ }^{130}$

This Nanaimo experience provides support for the idea that not only large municipalities, but also certain smaller municipalities perceive value in adopting MSSs, such as the ISO 14001 standard, and in being able to impose MSS-related contractual obligations on third-party service providers.

\section{7) City of Toronto - Environmental Defense's Blue Flag Program}

Although the City of Toronto does not have any water services certified under ISO 14001, it is actively working towards an EMS for its wastewater facilities (according to a City of Toronto official at the MWWRC Conference in Barrie, ON, 2016). It is important to note, however, in the context of this study, that since 2005 , the City of Toronto has been awarded the Blue Flags at eight of its 11 swimming beaches. ${ }^{131}$ The Blue Flag is a non-state international program of the

\footnotetext{
128 See Footnote No. 43

129 See Footnote No. 43

130 See Footnote No. 43

${ }^{131}$ City of Toronto Blue Flag Beaches, [Online]: www.toronto.ca/311/knowledgebase/kb/docs/articles/torontowater/blue-flag-beaches-status-of-beaches.html [18 Jan 2019]
} 
Foundation for Environmental Education and is administered in Canada by the ENGO Environmental Defence. ${ }^{132}$

By 2017, Canada had 27 beaches and 8 marinas with Blue Flag eco-certification. An ENGO representative interviewed as part of this study asserted that "maintaining Blue Flag status should be an incentive for governments to improve beach quality". The Blue Flag looks at environmental management criteria, environmental education, and safety, in addition to complying with local water quality requirements in order to provide the eco-certification.

The Blue Flag designation of a swimming beach means that a beach is open $80 \%$ of the time during the beach season. Toronto has one of the toughest quality standards for determining whether beaches are safe for swimming. Toronto water quality criteria follows Ontario's criteria (max. e.coli of 100 per 100 millilitres of water; Canada's limit is 200 per $100 \mathrm{ml}$ ).

The City of Toronto Blue Flag experience provides support for the proposition that non-state ENGO-initiated and operated environmental stewardship and water quality programs can act as useful checks and balances in support of municipal water protection efforts. Withdrawal of Blue Flag certification or the announcement of days when the beach does not meet Blue Flag standards constitute examples of non-state programs signaling problems with a municipality's wastewater and stormwater systems (Martin and Webb, forthcoming: 10-12). In this sense, the non-state Blue Flag certification could be interpreted as representing an additional rule system in support of municipal (state) water protection, building on federal and provincial regulatory requirements, and ISO certifications (if any).

\footnotetext{
${ }^{132}$ Environmental Defence - Blue Flag, [Online]: https://environmentaldefence.ca/2017/05/17/record-numbercanadian-beaches-marinas-fly-prestigious-blue-flag/ [18 Jan 2019]
} 


\section{$\begin{array}{ll}\text { Research } \\ \text { Ryerson } & \text { Ethics Board }\end{array}$}

To: Edgardo Tovilla

Environmental Applied Science and Management (EnSciMan)

Re: REB 2016-278: Examining the Evolving Environmental Protection Policy Convergence in the Ontario Municipal Water, Wastewater and Stormwater Sectors

Date: August 16, 2016

Dear Edgardo Tovilla,

The review of your protocol REB File REB 2016-278 is now complete. The project has been approved for a one year period. Please note that before proceeding with your project, compliance with other required University approvals/certifications, institutional requirements, or governmental authorizations may be required.

This approval may be extended after one year upon request. Please be advised that if the project is not renewed, approval will expire and no more research involving humans may take place. If this is a funded project, access to research funds may also be affected.

Please note that REB approval policies require that you adhere strictly to the protocol as last reviewed by the REB and that any modifications must be approved by the Board before they can be implemented. Adverse or unexpected events must be reported to the REB as soon as possible with an indication from the Principal Investigator as to how, in the view of the Principal Investigator, these events affect the continuation of the protocol.

Finally, if research subjects are in the care of a health facility, at a school, or other institution or community organization, it is the responsibility of the Principal Investigator to ensure that the ethical guidelines and approvals of those facilities or institutions are obtained and filed with the REB prior to the initiation of any research.

Please quote your REB file number (REB 2016-278) on future correspondence.

Congratulations and best of luck in conducting your research.

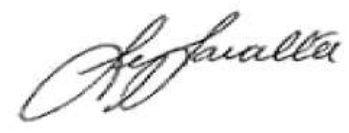

Lynn Lavallée, $\mathrm{Ph} . \mathrm{D}$.

Chair, Research Ethics Board 


\section{Ryerson Ethics Board}

To: Edgardo Tovilla

Environmental Applied Science and Management (EnSciMan)

Re: REB 2016-278: Examining the Evolving Environmental Protection Policy Convergence in the Ontario Municipal Water, Wastewater and Stormwater Sectors

Date: August 9, 2019

\section{Dear Edgardo Tovilla,}

The annual review of your protocol REB File REB 2016-278 is now complete. Ethics approval has been renewed for an additional year and will now expire on August 16, 2020. Please note that before proceeding with your project, compliance with other required University approvals/certifications, institutional requirements, or governmental authorizations may be required.

This approval may be extended after one year upon request. Please be advised that if the project is not renewed, approval will expire and no more research involving humans may take place. If this is a funded project, access to research funds may also be affected.

Please note that REB approval policies require that you adhere strictly to the protocol as last reviewed by the REB and that any modifications must be approved by the Board before they can be implemented. Adverse or unexpected events must be reported to the REB as soon as possible with an indication from the Principal Investigator as to how, in the view of the Principal Investigator, these events affect the continuation of the protocol.

Finally, if research subjects are in the care of a health facility, at a school, or other institution or community organization, it is the responsibility of the Principal Investigator to ensure that the ethical guidelines and approvals of those facilities or institutions are obtained and filed with the REB prior to the initiation of any research.

Please quote your REB file number (REB 2016-278) on future correspondence.

Congratulations and best of luck in conducting your research.

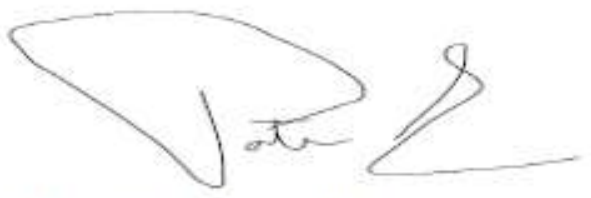

Dr. Patrizia Albanese, $\mathrm{PhD}$

Chair, Ryerson University Research Ethics Board 


\section{REFERENCES}

Abouchar, J. (2003) 'Walkerton: its impact on groundwater protection law in Canada', The Environmental Law Reporter, ELR, Vol. 33, No. 7, pp. 10514-10521.

Abouchar, J. and Vince, J (2010) 'Ten years after Walkerton - Ontario's drinking water protection framework update, Report No. 403101, pp. 1-16, Canadian Bar Association, [Online], Available: www.cba.org/cba/cle/PDF/ENV11 Abouchar paper.pdf, [12 Jan 2019].

Abouchar, J. and Petersen, N. (2015) Ontario source water protection plan update, Willms \& Shier Environmental Lawyers LLP, [Online], Available:

https://www.willmsshier.com/docs/default-source/articles/2015-2-19 source-waterprotection-plan-approval-update article julie-abouchar nicole-petersen-(clean-wateract south-georgian-bay-lake-simcoe first-nation-drinking-water-systems).pdf [12 Jan 2019].

AECOM (2015) National Water and Wastewater Benchmarking Initiative - 2014-2015 - Final report, Project No. 60312280, AECOM: Vancouver.

Alcantara, C., Leone, R., and Spicer, Z. (2012) Responding to policy change from above:

Municipal accountability and transparency regimes in Ontario, Journal of Canadian Studies, Vol. 46, No. 1, pp. 112-137.

Alvarez-Garcia, J., and RioRama, M. (2016) 'Sustainability and EMAS: Impact of Motivations and Barriers on the Perceived Benefits from the Adoption of Standards', Sustainability, Vol. 8, No. 10, pp. 1-18.

Amsler, L. B. (2016) Collaborative governance: Integrating management, politics and law, Public Administration Review, Vol. 76, No. 5, pp. 700-711.

Ansell, C., and Gash, A. (2007) Collaborative governance in theory and practice, Journal of Public Administration Research and Theory, Vol.18 No.4, pp. $534-571$.

Arimura, T. H., Hibiki, A., and Katayama H. (2008) Is a voluntary approach an effective environmental policy instrument? A case for environmental management systems, Journal of Environmental Economics and Management, Vol. 55, pp. 281-295.

AWWA (2009) Utility Management System: Operational Guide to AWWA G400, Editors: Ginley, J. and Humphrey, T., AWWA Publications.

Babbie, E.R. (2010) The Practice of Social Research, 12th ed., Belmont, CA: Wadsworth Cengage.

Bache, I., and Flinders, M. (2004) Multi-level governance, Sheffield, UK: Oxford Scholarship Online. 
Bacivarov, I. (2015) Coordinating editor's prologue - The standard ISO 9001:2015 - A milestone in the evolution of quality management, Quality Assurance, Vol. 21, No. 83, pp. 1-4, [Online], Available: www.asigurareacalitatii.ro/wp-content/uploads/83-02.pdf [16 Nov 2015].

Barbour, R. (2014) 'Introducing qualitative research - A student's guide', $2^{\text {nd }}$ Edition, Thousands Oaks, CA: Sage.

Baumgartner, T., and Pahl-Wostl, C. (2013) UN-Water and its role in global water governance. Ecology and Society, Vol. 18, No. 3, pp.3. [Online], Available: www.ecologyandsociety.org/vol18/iss3/art3/ [02 Jun 2019].

Behm, D. (2013) Milwaukee marks 20 years since Cryptosporidium outbreak, Milwaukee Wisconsin Journal Sentinel, April 6, 2013, [Online], Available: www.jsonline.com/news/milwaukee/milwaukee-marks-20-years-since-cryptosporidiumoutbreak-099dio5-201783191.html [09 Jan 2016].

Bennett, C. J. (1991) What is policy convergence and what causes it?, British Journal of Political Science, Vol. 21, No. 2, pp. 215-233.

Bernard, H.R. (2000) Social research methods: Qualitative and quantitative approaches. Thousand Oaks, CA: Sage Publications.

Bevir, M. (2011) The SAGE handbook of governance, First edition, India: SAGE Publications. Bhatt, A., Bradford, A., and Abbassi, B. E. (2019) Cradle-to-grave life cycle assessment (LCA) of low-impact-development (LID) technologies in southern Ontario, Journal of Environmental Management, Vol. 231, pp. 98-109.

Boas, M. (1998) Governance as multilateral development bank policy: The cases of the African Development Bank and the Asian Development Bank, The European Journal of Development Research, Vol. 10, No. 2, pp. 117-134.

Boiral, O. (2007) Corporate Greening through ISO 14001: A Rational Myth?, Organization Science, Vol. 18, No. 1, pp. 127-146. [Online], Available: https://pubsonline.informs.org/doi/abs/10.1287/orsc.1060.0224 [10 Jun 2018].

Botcheva, L., and Martin, L.L. (2001) Institutional effects on state behaviour: convergence and divergence, International Studies Quarterly, Vol. 45, No. 1, pp. 1-26.

Bouckaert, F., Wei., Y., Hussey, K., Pittock, J., and Ison, R. (2018) Improving the role of river basin organizations in sustainable river basin governance by linking social institutional capacity and basin biophysical capacity, Environmental Sustainability, Vol. 33, pp. 70-79.

Bradford, A. and Gharabaghi, B. (2004) Evolution of Ontario's stormwater management planning and design guidance, Water Quality Resources Journal of Canada, Vol. 39, No. 4, pp. 343-355. 
Brubaker, E. (2003) Revisiting water and wastewater utility privatization. Government of Ontario Panel on the Role of Government, Faculty of Law, University of Toronto, October 3, 2003, (online), available from:

www.probeinternational.org/envirowaterarticles/revistingutilityprivatization.pdf (16 Jan 2017).

BSI (2015) BSI obtains first global accreditation from ANAB to certify organizations to the new Quality Management standard ISO 9001:2015, [Online], Available: www.bsigroup.com/enGB/about-bsi/media-centre/press-releases/2015/august/BSI-obtains-first-global-accreditationfor-the-new-Quality-Management-standard-ISO-90012015-from-ANAB/\#.Vkq38v2FOUm [15 Nov 2015].

BSI (2019) Benefits of an integrated management system, Webinar dated March 13, 2019.

Cairney, P. (2012) Understanding public policy, $1^{\text {st }}$ edition. ISBN 978-0-230-22971-6, Cina: Palgrave Macmillan.

Cairney, P. (2015) How can policy theory have an impact on policymaking? The role of theoryled academic practitioner discussions, Teaching Public Administration, Vol. 33, No. 1, pp. 22-39.

Calgary City, (2018) 'EnviroSystem', [Online], Available: www.calgary.ca/UEP/ESM/Pages/OurEnvironmental-Management-System/EnviroSystem.aspx, [23 Feb 2018].

Canadian Council of Ministers of the Environment - CCME (2006) Municipal Wastewater Effluent in Canada, [Online], Available:

www.ccme.ca/files/Resources/municipal wastewater_efflent/mwwe general backgrounder e .pdf [10 Feb 2016].

Canadian Nuclear Safety Commission -CNSC (2017) Environmental protection - Environmental principles, assessments and protection measures, REGDOC-2.9.1, ver. 1.1, ISBN 978-0-66006255-6, [Online], Available: www.nuclearsafety.gc.ca/eng/acts-and-regulations/regulatorydocuments/history/regdoc2-9-1.cfm [02 Sep 2018].

Carter, N., Bryant-Lukosius, D., DiCenso, A., Blythe, J., and Neville, A., J. (2014) The use of triangulation in qualitative research, Oncology Nursing Forum, Vol. 41, No. 5, pp. 545-547.

CELA (2011) Ontario Safe Drinking Water Act, 2002 \& its regulations: FAQs, Canadian Environmental Law Association, November 25, 2011, [Online], Available: http://www.cela.ca/sites/cela.ca/files/Water-FAQs-Eng.pdf [12 Jan 2019].

Chatterji, A. K., and Toffel, M. W. (2010) How firms respond to being rated, Strategic Management Journal, Vol. 31, No. 9, pp. 917-945.

Cherchi, C., Badruzzman, M., Oppenheimer, J., Bros, C.M., and Jacangelo, J.G. (2014) Energy and water quality management systems for water utility operations: a review, Journal of Environmental Management, Vol. 153, pp. 108-120. 
City of Collingwood (2014) 2014 Annual Water Compliance Report, [Online], Available: www.collingwood.ca/sites/default/files/docs/cpu 2014 annual compliance report.pdf [01 Jan 2019].

City of Edmonton (2004) Edmonton's environmental management system, Office of the Environment, City of Edmonton, Policy C505, Council Ref: 20040511, [Online], Available: www.edmonton.ca/city government/documents/PoliciesDirectives/C505.pdf [12 Jan 2019].

City of Gastonia 2000 Wastewater Treatment ISO 14001 Environmental Management System Manual, North Carolina, (Online), available from: http://infohouse.p2ric.org/ref/13/12200.pdf (09 May 2017).

City of London (2008) Regional Water Boards Receive Ontario Public Works Association Awards - Staff Report of January 28, 2008, [Online], Available:

http://council.london.ca/meetings/Archives/Agendas/Environment\%20and\%20Transportation \%20Committee\%20Agendas/ETC\%20Agendas\%202008/2008-01-28\%20Agenda/item\%201.pdf [15 Nov 2015].

City of Timmins (2013) City of Timmins By-Law No. 2013-7354, [Online], Available: https://timmins.civicweb.net/document/24214 [18 Jan 2019].

City of Timmins (2017) City of Timmins By-Law No. 2017-8130, [Online], Available: https://timmins.civicweb.net/document/61157/20178130.pdf?handle=D136BB629D264BBCB0DF19AE98EF2680 [18 Jan 2019].

CNN (2019) Flint water crisis fast facts, CNN Library, published on June 14, 2019, [Online], Available: www.cnn.com/2016/03/04/us/flint-water-crisis-fast-facts/index.html [21 Jun 2019].

Corbett, C.J. and Yeung, A.C.L. (2008) Special issue on meta-standards in operations management: cross-disciplinary perspective, International Journal of Production Economics, Vol. 133, pp. 1-2.

Corbin, J. and Strauss, A. (1990), 'Grounded theory research: Procedures, canons, and evaluative criteria', Qualitative Sociology, vol. 13, no. 1, pp. 3-21.

Coutard, O. (2001) The governance of large technical systems, $2^{\text {nd }}$ Ed., London, UK: Routledge. Cresswell, J.W. (2014) Research Design: Qualitative, Quantitative, and Mixed Method Approaches, 4th edition (book preview), [Online], Available: http://scholar.google.ca/ [5 Nov 2013]. Thousand Oaks: Sage Publications.

Cresswell, J.W., Plano Clark, V. L., Gutmann, M. L. and Hanson, W.E. (2007) An Expanded Typology for Classifying Mixed Methods Research into Designs, Chapter 7 - Advanced Mixed Methods Research Designs, Thousand Oaks: Sage Publications.

CSA Group (2016) Member On-boarding Bulletin, Toronto: CSA Group. 
CSA Group (2019) CSA Wastewater Management Standard, Municipal Water and Wastewater Regulatory Committee, Hamilton, ON March 29, 2019, [Online], Available:

www.weao.org/wastewater practitioners group [12 Aug 2019].

CTV News (2018) First Nations face dozens of boil water advisories on World Water Day, CTV News, March 22, 2018, [Online], Available: www.ctvnews.ca/canada/first-nations-face-dozensof-boil-water-advisories-on-world-water-day-1.3855150 [12 Jan 2019].

Dahlström, K., Howes, C., Leinster, P., and Skea, J. (2003) Environmental management systems and company performance: assessing the case for extending risk-based regulation, European Environment Journal, Vol. 13, pp. 187-203.

Damikouka, I., Katsiri, A., and Tzia, C. (2007) Application of HACCP principles in drinking water treatment, Desalination Journal, pp. 138-145.

Darbyshire, M. 2016 Gibbons Pump Station Bypass - Our experience with a Fisheries Act violation. Presentation at the CWWA National Water and Wastewater Conference, November 2016, Ontario: Toronto.

Darnall, N., and Sides, S. (2008) Assessing the performance of voluntary environmental programs: Does certification matter?, The Policy Studies Journal, Vol. 36, No. 1, pp. 95-117.

Darnall, N., Potoski, M. and Prakash, A. (2010) 'Sponsorship matters: Assessing business participation in government- and industry-sponsored voluntary environmental programs'. J. Public Admin. Res. Theory, Vol. 20, No. 2, pp. 283-307.

DeLeon, P., and Resnick-Terry, P. (1999) Comparative policy analysis: deja' vu all over again? J. Comp. Policy Anal. Res. Pract. Vol.1, No. 1, pp. 9-22.

Delmas, M.A., and Montes-Sancho, M.J. (2011) An institutional perspective on the diffusion of international management system standards: the case of the Environmental Management Standard ISO 14001, Business Ethics Quarterly, Vol. 21, No. 1, pp. 103-132.

Delmas, M. A., and Montiel, I. (2008) The diffusion of voluntary international management standards: Responsible care, ISO 9000, and ISO 14001 in the chemical industry, Policy Studies Journal, Vol. 36, No. 1, pp. 65-93.

Deming, W. E., and Salkin, S. (1992) Total quality management: fast track for the '90s, Institutional Distribution (Business Insights Global), Vol. 25, No. 4.

Demuijnck, G., and Fasterling, B. (2016) The social license to operate, Journal of Business Ethics, Vol. 136, No. 4, pp. 675-685.

Detroit News (2019) Editorial: Dismiss criminal charges for good, Published June 19, 2019, [Online], Available: www.detroitnews.com/story/opinion/editorials/2019/06/20/editorialdismiss-flint-criminal-charges-good/1456358001/ [21 Jun 2019]. 
Dietz, T., Ostrom, E., and Stern, P. (2003) The struggle to govern the commons'. Science, Vol. 302 No. 5652, pp. $1907-1912$.

Dobrovolny, J (2017) Metro Chilco pump station sewer overflow, Metro Vancouver, Memo of May 26, 2017.

Dolowitz, D.P., and Marsh, D. (2000) Learning from abroad: the role of policy transfer in contemporary policy-making, Governance: An International Journal of Policy and Administration, Vol. 13, No. 1, pp. 5-24.

Drinking Water Inspectorate (1998) Cryptosporidium in Water Supplies (Bouchier Report), Third Report of the Group of Experts to the Department of the Environment, Transport and the Regions \& Department of Health, Chapter 3: Lessons learnt from outbreaks of waterborne cryptosporidiosis, [Online], Available: www.dwi.gov.uk/research/bouchier/ [09 Jan 2016].

Driscoll, E. and Webb, K. (forthcoming), 'Food Safety Governance at the Global Level: An Examination of the Global Food Safety Initiative Model,' International Journal of Food Safety, Nutrition and Public Health (accepted for publication subject to submission of revisions).

Duguid, T. (2003) 'Better Treatment - Taking Action to Improve Water Quality - Report on Public Hearings for the City of Winnipeg Wastewater Collection and Treatment System', Manitoba Clean Environment Commission, Manitoba, Winnipeg.

Durham Region (2009) Integrated Management System - Policy Manual, Policy IMS-01 to 20 Plant Operations and Maintenance Operations, Whitby, Ontario.

Ecolog Network (2000) The City of Calgary was fined and pleaded guilty to environmental offenses, Ecoweek, September 2000, [Online], Available:

www.ecoweek.ca/issues/ISarticle.asp?aid=1000184595 [04 Feb 2017].

Ecoweek, (2000) 'September 2000 - Companies in the news', [Online], Available: www.ecoweek.ca/issues/ISarticle.asp?aid=1000184595, [23 Feb 2018].

Eisenhardt, K.M. (1989) 'Building theories from case study research', Academy of Management Review, Vol. 14, No. 4, pp. 532-550.

Engineers Canada (2018) Developing a stormwater quality management standard (QMS) - in light of a changing climate, Seed document to support national standard development, November 2018, Prepared by Zizzo Strategy and Credit Valley Conservation, [Online], Available: www.scc.ca/en/about-scc/publications/general/developing-a-stormwater-qualitymanagement-standard-qms [12 Jan 2019].

Environment and Climate Change Canada (ECCC) (2015) Water Governance \& Legislation, Provincial/Territorial, Shared Responsibility, [Online], Available: www.ec.gc.ca/eauwater/default.asp?lang=En\&n=24C5BD18-1 [21 Dec 2015]. 
Environment Canada (2001) A protocol guide for an environmental management system audit, ISBN 0-662-31019-5. Ontario: Ottawa [Online], Available:

http://publications.gc.ca/site/eng/104414/publication.html [21 Dec 2016].

Environmental Commissioner of Ontario, ECO (2008) "Environmental Penalty Regulations." Getting to K(No)w, ECO Annual Report, 2007-08. Toronto, ON: Environmental Commissioner of Ontario. 98-102, [Online], Available:

www.ecoissues.ca/MOE\%27s Environmental Penalty Regulations\#ECO Comment [8 Feb 2016].

Environmental Commissioner of Ontario, ECO (2004) “2003-2004 Annual Report." Choosing our legacy. Toronto, ON: Environmental Commissioner of Ontario, [Online], Available:

http://docs.assets.eco.on.ca/reports/environmental-protection/2003-2004/2003-04-AR.pdf [8 Aug 2019].

Environmental Commissioner of Ontario, ECO (2018) 2018 Environmental Protection Report, Chapter 2 - EBR Applications for Review and Investigation, Toronto, ON: Environmental Commissioner of Ontario, [Online], Available:

https://docs.assets.eco.on.ca/reports/environmental-protection/2018/Back-to-BasicsVolume1-Ch2.pdf [18 Jan 2019].

Environmental Science \& Engineering - ES\&E (2018) Timmins approves \$2.2M upgrade for northern Ontario wastewater treatment plant, ES\&E magazine, April 23, 2018, [Online], Available: https://esemag.com/wastewater/timmins-approves-2-2m-upgrade-for-northernontario-wastewater-treatment-plant/ [18 Jan 2019].

EPCOR (2015) EPCOR Announces 2014 Financial Results - Media Release, Epcor.com [Online], Available:

www.epcor.com/about/Documents/EPCOR\%202014\%20Year\%20End\%20Financial\%20Press\%2 ORelease\%20and\%20MDA.pdf [10 Jun 2018].

Federation of Canadian Municipalities and National Research Council (FCM / NRC) (2005) Environmental management systems for municipal infrastructure, [Online], Available: www.fcm.ca/Documents/reports/Infraguide/Environmental_Management Systems for_Munic ipal Infrastructure EN.pdf [10 Dec 2016].

Foray, D. (2018) On sector-non-neutral innovation policy: towards new design principles, Journal of Evolutionary Economics, pp. 1-19, [Online], Available: https://doiorg.ezproxy.lib.ryerson.ca/10.1007/s00191-018-0599-8 [20 Jun 2019].

Franceschini, F., Gelatto, M., and Cecconi, P. (2006) A worldwide analysis of ISO 9000 standard diffusion: Considerations and future development, Benchmarking in Total Supply Management, Vol. 13, No. 4, pp. 523-541. 
Fulponi, L. (2006) Private voluntary standards in the food system: The perspective of major food retailers in OECD countries, Food Policy, Vol. 31, No. 1, pp. 1-13.

Fung, A., and Wright, E. O. (2001) Deepening democracy: Innovations in empowered participatory governance. Politics \& Society, Vol. 29, No. 5, pp. 5-41. London: Verso.

Gagnon, Y.C. (2011) The case study as research method: a practical handbook, International Studies in the Philosophy of Science, vol. 25, No. 3, pp. 293-305.

Giacomini, D., Rocca, L., Carini, C., and Mazzoleni, M. (2018) Overcoming the barriers to the diffusion of sustainability reporting in Italian LGOs: Better stick or carrot?, Sustainability, Vol. 10, No. 131, pp. 1-14.

Gibson, R. B. (1999) Voluntary Initiatives - The new politics of corporate greening, Peterborough: Broadview Press.

Gislason, M.K. (2013) West Nile Virus: the production of a public health pandemic, Sociology of Health and IIIness, Vol. 35, No. 2, pp. 188-199.

Goodman, J. B. and Loveman, G. W. (1991) Does privatization serve the public interest?, Harvard Business Review, Nov-Dec 1991, [Online], Available: https://hbr.org/1991/11/doesprivatization-serve-the-public-interest [09 Jun 2019].

Government of Canada (2018) Policy on Green Procurement, Public Services and Procurement Canada, [Online], Available: www.canada.ca/en/treasury-boardsecretariat/services/innovation/greening-government/strategy.html [12 Jan 2019].

Gray, C. (2000) A “Hollow state"? - R. Pyper and L Robins. United Kingdom Governance. Basingstoke: Palgrave Macmillan.

Greenbaum, A. \& Wellington, A. (2010) Environmental Law and Policy in the Canadian Context, Captus Press, Concord, Ontario.

GVSDD (2014) Wastewater - The Greater Vancouver Sewerage and Drainage District Environmental Management and Quality Control Annual Report 2014, Metro Vancouver, ISSN 1496-9602, [Online], Available: www.metrovancouver.org/services/liquidwaste/LiquidWastePublications/2014 Wastewater Quality Control Annual Report.pdf [12 Jan 2019].

Halifax Water (2016a) Environmental Management System Manual - Environmental Policy Procedure HW-EMW-02, Halifax Regional Water Commission, [Online], Available: www.halifax.ca/sites/default/files/documents/homeproperty/water/EnvironmentalManagementSystemPolicy.pdf [10 Jun 2018] 
Halifax Water (2016b) Request for Standing Offer - Supply of Carbon Dioxide, Halifax Regional Water Commission, [Online], Available:

https://novascotia.ca/tenders/pt files/tenders/PA082016.pdf [10 Jun 2018].

Halifax Water 2017 Lake Major Water Supply Plant New Standby Power System - Tender document. Procurement Services, Halifax Regional Water Commission, Halifax.

Halifax Water (2018) Halifax Water 2018/19 Business Plan, Halifax Regional Council Item No. 9.1, February 27, 2018, [Online], Available: www.halifax.ca/sites/default/files/documents/cityhall/regional-council/180320rc91.pdf [04 Aug 2019].

Halpern, D. (2015) Inside the Nudge Unit - How Small Changes can Make a Big Difference. WH Allen - Penguin Random House, London.

Harrison, K. (2002) Ideas and environmental standard-setting: a comparative study of regulation of the pulp and paper industry, Governance, Policy, Administration and Institutions, Vol. 15, No. 1, pp. 65-96.

Hart, S. L., and Milstein, M. B. (2003) 'Creating Sustainable Value', Acad. Manag. Exec., Vol. 17, No. 2, pp. 56-69.

Hatfield-Dodds, S., Nelson, R., Cook, D. (2007) Adaptive governance: and introduction and implications for public policy, Paper presented at the $51^{\text {st }}$ annual conference of the Australian Agricultural and Resource Economics Society, Queenstown NZ, February 2007, [Online], Available: https://ageconsearch.umn.edu/record/10440/ [19 Jun 2019].

Heichel, S., Pape, J., and Sommerer, T. (2005) Is there convergence research? An overview of empirical studies on policy convergence, Journal of European Public Policy, Vol. 12, No. 5, pp. 817-840.

Hennink, M. M., (2014) 'Understanding qualitative research - Focus group discussions', New York: Oxford University Press.

Henriques, I., and Sadorsky, P. (2008) 'Voluntary environmental programs: A Canadian perspective'. Policy Stud. J., Vol. 36, No. 1, pp. 143-166.

Heras-Saizarbitoria, I. and Boiral, O. (2013) ISO 9001 and ISO 14001: Towards a research agenda on management system standards, International Journal on Management Reviews, Vol. 15, pp. 47-65.

Herstein, L. M. (2015) The water provision system: Developing and applying a conceptual systems framework for provincial and state water provision dynamics, PhD thesis, University of Toronto

Hessing, M., Howlett, M., and Summerville, T. (2005) Canadian Natural Resource and Environmental Policy: Political Economy and Public Policy, UBC Press: Vancouver. 
Hogl, K., Kvarda, E., Nordbeck, R., and Pregernig, M. (2012) Part I The Challenge of Participation - Legitimacy and effectiveness of environmental governance, concepts and perspectives, Environmental Governance, Edward Elgar Publishing Limited. ProQuest Ebook Central, Northampton, MA, pp. 1-26.

Holzinger, K., and Knill, C. (2005) Causes and conditions of cross-national policy convergence, Journal of European Public Policy, Vol. 12, No. 5, pp. 775-796.

Hood, C. (1995) The "New Public Management" in the 1980's: Variations on a theme, Accounting, Organization and Society, Vol. 20, No. 2/3, pp. 93-105.

Hooghe, L. and Marks, G. (2003) Unraveling the central state, but how? Types of multi-level governance, American Political Science Review, Vol. 97, No. 2, pp. 233-243.

Howlett, M., and Joshi-Koop, S. (2010) Transnational learning, policy analytical capacity, and environmental policy convergence: Survey results from Canada, Global Environmental Change, Vol. 21, No.1, pp. 85-92.

Hrudey, S. E., and Hrudey, E.J. (2002) Safe Drinking Water: Lessons learned from Recent Outbreaks in affluent nations, IWA Publishing: London, UK.

Ionascu, M., Ionascu, I., Sacarin, M. \& Minu, M. 2017 Exploring the Impact of ISO 9001, ISO 14001, and OHSA 1801 certification on financial performance: The case of companies listed on the Bucharest stock exchange. Bucharest Acad. Econ. Stud. 19(44), 166-180.

ISO (2015) Structure and governance, ISO Website [Online], Available: www.iso.org/iso/home/about/about governance.htm [15 Nov 2015].

ISO (2017) The ISO Survey of Management System Standards Certifications 2016 - ISO 14001 by Industrial Sector, [Online], Available: https://www.iso.org/the-iso-survey.html [03 Aug 2018].

ISO 14001 (2015), The Newly revised ISO 14001 is here, ISO Website [Online], Available: www.iso.org/iso/home/news index/news archive/news.htm?refid=Ref1999 [17 Oct 2015].

ISO 14001 (2017), The ISO 14001 Environmental Management Systems - A Practical Guide for SMEs, ISO Website [Online], Available: https://www.iso.org/files/live/sites/isoorg/files/store/en/iso 14001 guide preview.pdf [10 Jun 2018].

ISO 140012015 Environmental Management System Standard. ISO, Switzerland.

ISO 14044 (2006) Environmental Management - Life Cycle Assessment, Requirements and Guidelines, Switzerland: ISO.

ISO 2015 Structure and governance, ISO Website (online), available from: www.iso.org/iso/home/about/about governance.htm (15 Nov 2015). 
Ivanova, A., Gray, J. \& Sinha, K. 2014 Towards a unifying theory of management standard implementation: The case of ISO 9001/ISO 14001. Int. J. Oper. Product. Manage. Vol. 34, No. 10, pp. 1269-1306.

Johns, C. M., (2014a) 'Conceptualizing and assessing governance and policy capacity in the North American Great Lakes region: The case for integrating network analysis and policy capacity', Draft paper presented at the $23^{\text {rd }}$ World Congress of the International Political Science Association, Montreal, pp. 1-31, [Online], Available: http://paperroom.ipsa.org/papers/paper 35864.pdf [30 Jun 2018].

Johns, C. M., (2014b) The Walkerton inquiry and policy change, Commissions of Inquiry and Policy Change, University of Toronto Press: Toronto, pp. 214-243.

Johns, C., Thorn, A. \& VanNijnatten, D. (2018) Environmental regime effectiveness and the North American Great Lakes water quality agreement, International Environmental Agreements: Politics, Law and Economics, Vol. 18, No. 3, pp. 315-333.

Jörgens H., Lenshow, A., and Liefferink, D. (2014) Understanding Environmental Policy Convergence, The power of words, rules and money, Cambridge University Press: Cambridge.

Kafetzopoulos, D. P. \& Psomas, E. L. 2015 The impact of quality management systems on the performance of manufacturing firms. Int. J. Qual. Reliab. Manage. Vol. 32, No.4, pp. 381-399.

Kaye, P., (2011) 'Legislative research service - When do Ontario Acts and regulations come into force1?', (online), available from: www.ontla.on.ca/bills/generalinformation/files pdf/files en/rp b31.pdf (22 February 2018).

Khemai, J. (2016) Self-inspection of Drinking Water Systems - A Pilot project between MECP and York Region, Ontario, Newmarket.

King, A. A., Lenox, M. J. (2001) Who adopts management standards early? An examination of ISO 14001 certifications, Academy of Management Proceedings, Vol. 8, No. 1, pp. A1-A6.

Knill, C. (2005) Introduction: Cross-national policy convergence: concepts, approaches and explanatory factors, Journal of European Public Policy, Vol. 12, No. 5, pp. 764-774.

Kohler-Koch, B. (2010) Civil society and EU democracy: 'Astroturf' representation?, Journal of European Public Policy, Vol. 17, No. 1, pp. 100-116.

Kooiman, J. (1993) Socio-political governance: Introduction. London: Sage.

Kooiman, J. (1999) Socio-political governance: Overview, reflections and design. Public Management: An International Journal of Research and Theory, Vol. 1, No. 1, pp. 67-92. 
Kollman, K. \& Prakash, A. 2002 EMS-based environmental regimes as club goods: Examining variations in firm-level adoption of ISO 14001 and EMAS in U.K., U.S. and Germany. Policy Sci. $35,43-67$.

Krippendorff, K. (2004) Content analysis: An introduction to its methodology ( $2^{\text {nd }}$ ed.), Thousand Oaks, CA: Sage.

Krueger, R. A., Casey, M. A., (2015) 'Focus groups - A practical guide for applied research', $5^{\text {th }}$ Edition, Los Angeles: SAGE.

Kvale, S. (2007) Doing Interviews, Thousand Oaks, CA: Sage Publications.

Lake Ontario Waterkeeper (2011) Darlington New Nuclear Power Plant Project - Joint Review Panel, Written Submission from Lake Ontario Waterkeeper, PMD 11-P1.164, File: 8.01.07 of 2011-02-21, [Online], Available: https://ceaa-acee.gc.ca/050/documents/48116/48116E.pdf [12 Jan 2019].

Leehane, N. 2015 ISO 14001: 2015 - Benefits of the new standard, BSI website (online), available from: www.bsigroup.com/en-GB/iso-14001-environmental-management/ISO-14001revision-new/ (18 Nov 2015).

Lemos, M.C, and Agrawal, A. (2006) Environmental governance, Annual Review of Environment and Resources, Vol. 31, pp. 297-325.

Lenschow, A., Liefferink, D, and Veenman, S. (2005) When the birds sing: A framework for analysing domestic factors behind policy convergence, Journal of European Public Policy, Vol. 12, No. 5, pp. 797-816.

Lewandowska, A., and Matuszak-Flejszman (2014) Eco-design as a normative element of environmental management systems -the context of the revised ISO 14001-2015, International Journal of Life Cycle Assessment, Vol.19, pp. 1794-1798.

Liamputtong, P., (2011) 'Focus group methodology: principles and practice', Thousands Oaks, CA: Sage.

Lin, J. (2011) The environmental regulation of biofuels: limits of the meta-standard approach, Carbon and Climate Law Review, Vol. 5, No.1, pp. 34-43.

Lindgren, K, O., Persson, T. (2011) Participatory governance in the EU: Enhancing or endangering democracy and efficiency?. London, UK: Palgrave McMillan.

Llerena, P. and Matt, M. (2005) Innovation policy in a knowledge-base economy, Strasbourg, France: Springer. 
Lombardi, P. (2018) Thompson Fuels order to pay costs. Siskind Environmental Law, May 28, 2018, [Online], Available: https://www.siskinds.com/thompson-fuels-ordered-pay-costs/ [17 Nov 2019].

Lukasik, L. (2003) Storm, sewer bylaw should show how water connected, The Hamilton Spectator, Hamilton, ON, March 25, 2003.

Lynn, L. E., Heinrich, C. J.; and Hill, C. J. (2000) Studying governance and public management: Challenges and prospects, Public Administration Research, Vol. 10, No. 2, pp. 233-261.

Ma, Z., Zhou, L., and Sheng, W. (2014) Analysis of the new asset management standard ISO 55000 and PAS 55, 2014 China International Conference on Electricity Distribution (CICED), pp. 1668-1674.

MacAlpine, I. (2017) City launches real-time sewage overflow tracking, The Kingston WhigStandard (May 18, 2017), [Online], Available: www.thewhig.com/2017/05/18/city-launchesreal-time-sewage-overflow-tracking/wcm/c7f66855-ddde-fcf2-6395-a5bd46513f63 [24 Dec 2018).

MacDonald E. and Lintner A. (2010) Summary of Concerns: Municipal Industrial Strategy for Abatement (MISA) Regulations. Ecojustice.

Mahoney, J. (2003) Edmonton facing provincial charges after PCB leaks, The Globe and Mail, January 25, 2003, updated April 17, 2018, [Online], Available:

www.theglobeandmail.com/news/national/edmonton-facing-provincial-charges-after-pcbleaks/article4126366/ [12 Jan 2019].

Marks, G. (1993) Structural policy and multi-level governance in the EC, in A. Cafruny and G. Rosenthal (eds), The State of the European Community: The Maastricht Debate and Beyond, Boulder, CO: Lynne Rienner, pp. 391-411.

Martin, M., and Webb, K. (forthcoming), 'Water Quality Protection of the Canada-U.S. Great Lakes: Examining the Emerging State/Non-State Governance Approach,' Progress in Industrial Ecology, an International Journal (accepted for publication).

Martincic, C. 1997 The ISO 14000 series of standards - A brief history of ISO (online), available from: www.sis.pitt.edu/mbsclass/standards/martincic/iso14000.htm (12 Nov 2015).

McKenzie, R. W., Hoxie, N. J., Proctor, M. E., Gradus, M. S., Blair, K. A., Peterson, D. E., Kazmierczak, J. J., Addiss, D. G., Fox, K. R., Rose, J. B., and Davis, J. B. (1994) A Massive Outbreak in Milwaukee of Cryptosporidium Infection Transmitted through the Public Water Supply, The New England Journal of Medicine, Vol. 331, pp. 161-167.

MECP (1994) Water Management Policies, Guidelines - Provincial Water Quality Objectives, Ontario: Ontario MECP. 
MECP (1994) Water Management Policies, Guidelines - Provincial Water Quality Objectives. Ontario MECP, Ontario.

MECP (2003) Ontario Stormwater Management Planning and Design Manual. MECP, Toronto.

MECP (2006) Drinking Water Quality Management Standard, October 2006, Ministry of the Environment, Conservation and Parks, Ontario.

MECP (2008) Ontario Design Guidelines for Sewer Works. MECP, Toronto, [Online], Available: www.ontario.ca/document/design-guidelines-sewage-works-0 [1 Jul 2019].

MECP (2010) Environmental Compliance Approval 7829-888JGN, Harmony Creek Water Pollution Control Plant, Durham Region, MECP, issued December 20, 2010 (online), available from: www.accessenvironment.ene.gov.on.ca/instruments/8886-882REB-14.pdf (02 Jan 2017).

MECP (2012) Environmental Compliance Approval 3274-8RGPZB, Monahan Landing Subdivision, South Kanata Development Corporation, MECP, issued April 5, 2012 (online), available from: www.accessenvironment.ene.gov.on.ca/instruments/9344-8PCRN5-14.pdf (02 Jan 2017).

MECP (2013a) Environmental Compliance Approval 1545-9B7PT7, The Burlington-Skyway Wastewater Treatment Plant, Regional Municipality of Halton, issued November 22, 2013, (online), available from: www.accessenvironment.ene.gov.on.ca/instruments/5456-9ATRJT14.pdf (02 Jan 2017).

MECP (2013b) Environmental Compliance Approval 2401-9BFRGH, The Sewage Collection System servicing the Burlington-Skyway Wastewater Treatment Plant, Regional Municipality of Halton, issued November 22, 2013 (online), available from:

www.accessenvironment.ene.gov.on.ca/instruments/3078-9ATRLY-14.pdf (02 Jan 2017).

MECP (2014a) Environmental Compliance Approval 1978-9CXQJL (2014) The Sudbury Wastewater Treatment Plant and Sewage Collection System, The City of Sudbury, issued May 27, 2014 (online), available from: www.accessenvironment.ene.gov.on.ca/instruments/80389CHLLR-14.pdf (02 Jan 2017).

MECP (2014) Minister's Annual Report on Drinking Water 2014. MECP, Toronto.

MECP (2014b) Environmental Compliance Approval 5531-9FJJT5 (2014) Duffin Creek Water Pollution Control Plant, Durham and York Regions, issued March 3, 2014 (online), available from: www.accessenvironment.ene.gov.on.ca/instruments/2785-9CZRG6-14.pdf (02 Jan 2017).

MECP (2016) 2015-2016 Chief Drinking Water Inspector Annual Report, Nov 2016, Ontario: Ontario MECP. [Online], Available: https://news.ontario.ca/ene/en/2016/11/ontarios-drinkingwater-remains-among-best-protected-in-the-world.html [10 Dec 2016].

MECP (2016) Chief Drinking Water Inspector Annual Report 2014-2015, [Online], Available: www.ontario.ca/page/chief-drinking-water-inspector-annual-report-2014-2015 [12 Feb 2017]. 
MECP (2017) Drinking Water Quality Management Standard - Version 2.0, February, 2017, [Online], Available: www.downloads.ene.gov.on.ca/envision/env reg/er/documents/2017/0125530 FinalStandard.pdf [12 Jan 2019].

MECP (2018) A Made-in-Ontario Environmental Plan, Ministry of the Environment, Conservation and Parks, Ontario, 2018, EBR 013-4208, [Online], Available: https://prodenvironmental-registry.s3.amazonaws.com/2018-11/EnvironmentPlan.pdf [12 Jan 2019].

MECP (2019) Environmental Compliance Approval Template, Ontario MECP, Water Environment Association of Ontario - Practitioners Group, [Online], Available: www.weao.org/wastewater_practitioners_group [24 Mar 2019].

MISA (1992) Municipal-Industrial Strategy for Abatement, MECP, [Online], Available: http://odesi2.scholarsportal.info/documentation/PHIRN/MISA/municipalindustr00ontauoft.pdf [17 Nov 2019].

Metz, F., and Fischer, M. (2016) Policy diffusion in the context of international river basin management, Environmental Policy and Governance, Vol. 26, pp. 257-277.

Michigan State (2018) The Michigan guide to environmental, health and safety regulations, [Online], Available: www.michigan.gov/documents/deq/deq-tou-EHSguidecomplete 604181 7.pdf [21 Jun 2019].

Milward, H. B., Provan, K. G. (2000) Governing the hollow state, Public Administration Research and Theory, Vol. 10, No. 2, pp. 359-380.

Minnesota State (2019) Great Lakes - Upper Mississippi River Board (GLUMRB) 10 State Standards, Minnesota Department of Health, [Online], Available: www.health.state.mn.us/communities/environment/water/tenstates/index.html [1 Jul 2019].

Ministry of Labour -MOL (2017) Bulletin: Ontario Seeking Public input to strengthen worker safety, [Online], Available: https://news.ontario.ca/mol/en/2017/11/ontario-seeking-publicinput-to-strengthen-worker-safety.html [02 Sep 2018].

Ministry of Municipal Affairs -MMA (2016) Common language guide to municipal financial statements, [Online], Available: www.mah.gov.on.ca/AssetFactory.aspx?did=15792 [12 Jan 2019].

Nagendra, H., and Ostrom, E. (2012) Polycentric governance of multifunctional forested ladscapes, International Journal of the Commons, Vol. 6, No. 2, pp. 104-133.

Naumova, E. N., Egorov, A. I., Morris, R. D., and Griffiths, J. K. (2003) The elderly and waterborne Cryptosporidium infection: Gastroenteritis hospitalizations before and during the 1993 Milwaukee outbreak, Emerging Infectious Diseases, Vol. 9, No. 4, pp. 418-425. 
Neild, D. (2005) Kingston avoids cleanups: MEO approves, Ottawa Riverkeeper News of December 18, 2005' [Online], Available:

https://www.waterkeeper.ca/blog/2602?rq=kingston\%20sewage [12 Jan 2019].

Neild, D. (2008) Sewage dumping may cost Ottawa \$-millions in fines, Ottawa Riverkeeper News of October 7, 2008' [Online], Available: https://www.waterkeeper.ca/blog/8011 [12 Jan 2019].

Nelson, R.R. (1959) The simple economics of basic scientific research, Journal of Political Economy, Vol. 67, pp. 323-348.

Newig, J. (2012) Part I The Challenge of Participation - More effective natural resource management through participatory governance? Taking stock of the conceptual and empirical literature and moving forward, edited by Karl Hogl et al., Edward Elgar Publishing Limited. ProQuest Ebook Central, Northampton, MA, pp. 46-68.

New York State (2014) New York State Design Standards for Intermediate Sized Wastewater Treatment Systems, NY Department of Environmental Conservation, Division of Water, [Online], Avaliable: www.dec.ny.gov/docs/water pdf/2014designstd.pdf [1 Jul 2019].

Nichols, A. W. 2013 Exploring the Myths Surrounding ISO9000: A Practical Implementation Guide. IT Governance Publishing, Cambridgeshire

NSF International Strategic Registrations (2015) Certificate of Registration - Town of Richmond Hill ISO 14001:2004, Contained in SREIS.16.007 [Online], Available:

https://webcache.googleusercontent.com/search?q=cache:KU sHh3fOUEJ:https://calendar.rich mondhill.ca/council/ Download/10e6800d-ec5e-40bb-afaba6990159c55f+\&cd=1\&hl=en\&ct=clnk\&gl=ca [25 Nov 2015].

O'Connor, D. R. (The Honorable Dennis R. O'Connor) (2002a) Part One of the Report of the Walkerton Inquiry, Ministry of the Attorney General (online), available from: http://www.archives.gov.on.ca/en/e records/walkerton/index.html (12 Nov 2015).

O'Connor, D. R. (The Honorable Dennis R. O'Connor) (2002b) Part Two of the Report of the Walkerton Inquiry - A strategy for safe drinking water, Ministry of the Attorney General (online), available from: www.archives.gov.on.ca/en/e records/walkerton/report2/index.html (12 Nov 2015).

Ogden, S. and Watson, R. (1999) Corporate performance and stakeholder management: balancing shareholder and customer interest in the UK privatized water industry, The Academy of Management Journal, Vol. 42, No. 5, pp. 526-538.

Ohemeng, F. K., Grant, J. K., (2008) "When markets fail to deliver: An examination of the privatization and de-privatization of water and wastewater services delivery in Hamiton, Canada", Canadian Public Administration, vol. 51, no. 3, pp. 475-499. 
Ontario Municipal CAO's Benchmarking Initiative (2012) OMBI 2012 Performance measurement report - Partnering for service excellence, OMBI.

Ostrom, E. (1994) Neither market nor state: Governing common pool resources in the twenty first century, International Food Policy Research Institute Lecture Series: 2

Ostrom, E. (1999) Coping with tragedies of the commons, Annual Review of Political Science, Vol. 2, No. 1, pp. 493-535.

OSWCA (2016) Creating water infrastructure sustainability through a provincial rate setting authority - White paper, Ontario Sewer and Watermain Construction Association, May 2016, [Online], Available: www.oswca.org/uploads/may-2016-white-paper-creating-waterinfrastructure-sustainability-through-a-provincial-rate-setting-authority.pdf (12 Jan 2019).

Page, J. (2018) Quebec city to dump 46 million of litres of sewage waste into the St. Lawrence River, CBC News, February 22, 2018, [Online], Available: www.cbc.ca/news/canada/montreal/quebec-city-sewage-dump-1.4546694 [12 Jan 2019].

Penn State Food Science (2005) HACCP Historical Timeline - Food Safety \& Sanitation, [Online], Available: http://sart.psu.edu/foodsafety/angel stuff2/fssbook/docs/HACCP history.pdf [1 Nov 2015].

Peters, G., and Pierre, J. (1998) Governance without government? Rethinking public administration, Journal of Public Administration Research and Theory, Vol. 8, No. 2, pp. 223243.

Prakash, A., Potoski, M. (2006) "Racing to the bottom: Trade, environmental governance, and ISO 14001", American Journal of Political Science, Vol. 50, no. 2, 350-364. [Online], Available: https://onlinelibrary.wiley.com/doi/full/10.1111/i.1540-5907.2006.00188.x [01 Jun 2018].

Psomas, E. L., Fotopoulos, C. V., and Kafetzopoulos, D. P. (2011) Motives, difficulties and benefits in implementing the ISO 14001 Environmental Management System. Management of Environmental Quality: An International Journal, Vol. 22, No. 4, pp. $502-521$.

Reevely, D. 2008 The Mayor Declares War to City Staff, Ottawa Citizen, May 27, 2008 (online), available from: http://ottawacitizen.com/news/local-news/the-mayor-declares-war-on-citystaff (05 Feb 2017).

Rennie, S., (2010) "Millions of litres of pollutants dumped in cities: analysis", TheStar.com, Jun 13, 2010 [Online], Available:

www.thestar.com/news/canada/2010/06/13/millions of litres of pollutants dumped in citi es analysis.html [24 Feb 2018].

Rhodes, R.A.W. (2007) Understanding governance: Then years on, Organization Studies, Vol. 28, No. 8, pp. 1243-1264. 
Rhodes, R.A.W., and Marsh, D. (1992) New directions in the study of policy networks, European Journal of Political Research, Vol. 21, pp. 181-205.

Rhoads, W.J., Garner, E., Ji, P., Zhu, N., Parks, J., Schwake, D.O., Pruden, A., and Edwards, M.A. (2017) Distribution efficiencies operational deficiencies coincide with reported Legionnaire disease clusters in Flint, Michigan, Environmental Science and Technology, Vol. 51, No. 20, pp. 11986-11995.

Richmond Hill (2016a) Drinking Water Quality Management System - Operational Plan for Richmond Hill Distribution System, [Online], Available: www.richmondhill.ca/en/sharedcontent/resources/documents/drinking-water-operational-plan.pdf [22 Jan 2017].

Richmond Hill (2016b) Greening the Hill Report (Environmental Strategy Update), and Environmental Management System Re-registration Update, SREIS.16.007 [Online], Available: https://webcache.googleusercontent.com/search?q=cache:KU sHh3fOUEJ:https://calendar.rich mondhill.ca/council/ Download/10e6800d-ec5e-40bb-afaba6990159c55f+\&cd=1\&hl=en\&ct=clnk\&gl=ca [22 Jan 2017].

Rogers, E.M. (1983) Diffusion of Innovations, Third Edition, Detroit, USA: The Free Press. Rogers, E.M. (2003) Diffusion of Innovations, Fifth Edition, New York, USA: The Free Press. Rose, R. (1991) What is lesson-drawing?, Journal of Public Policy, Vol. 11, No. 3, pp. 3-30. Rosenbloom, D. H.; Gong, T. (2013) Co-producing "clean" collaborative governance, Public Performance and Management Review, Vol. 36, No. 4, pp. 544-561.

Rosenberg, J. P., Yates, P. M. (2007) Schematic representation of case study research designs, Journal of Advance Nursing, vol. 60, no. 4, pp. 447-452.

Rosenau, J. N., and Czempiel, E. O. (1992) Governance without government: Order and change in world politics, Cambridge, UK: Cambridge University Press.

Ruppert, J., Greenberg, L., (2008) “Attitude of staff tied to river spill 'Walkerton-like', City auditor blames massive sewage leak on 'incompetence'", Ottawa Citizen, Oct 23, 2008, [Online], Not available link. Accessed [5 Feb 2017].

Salkind, N. J. (2012) Exploring Research, 8th edition, New Jersey: Pearson Education.

Saxe, D. (2011) WSER Legal Perspectives, Canadian Water and Wastewater Association (CWWA), November 25, 2011, [Online], Available: http://envirolaw.com/wpcontent/uploads/CCWA Nov25-for-posting.pdf [15 Apr 2016].

Saxe, D. (2012) Creative sentencing - brilliant or cheap?, Siskind Environmental Law, May 1, 2012, [Online], Available: www.siskinds.com/envirolaw/creative-sentencing/ [11 Dec 2016]. 
Saxe, D. (2013) Model Sewer Bylaw Spreading Across Canada, Mondaq Business Briefing, Oct 4, 2013. Business Insights: Global, [Online], Available:

http://bi.gale.com.ezproxy.lib.ryerson.ca/global/article/GALE|A344699176?u=rpu main [15 Apr 2016].

Searcy, C., Morali, O., and Karapetrovic, S. (2012) An analysis of ISO 14001 and suggested improvements, Journal of Global Responsibility, Vol. 2, No. 2, pp. 278-293.

Shier, D, and Remedios, S. (2016) Small fines; big consequences: The hidden costs of pleading guilty, Environmental Science \& Engineering, August 23, 2016, [Online], Available:

https://esemag.com/news/small-fines-big-consequences-hidden-costs-pleading-guilty/ [12 January 2017].

Sierra Legal Defense Fund - SLDF (2004) The National Sewage Report Card - Grading the sewage treatment of 22 Canadian cities, Report No. 3, September 2004, [Online], Available: www.bucksuzuki.org/images/uploads/docs/sewage report card III.pdf [12 Jan 2016].

Siggelkow, N. (2007) Persuasion with case studies, Academy of Management, vol. 50, no. 1, pp. 20-24.

Simmons, B. A., and Elkins, Z. (2004) The globalization of liberalization: Policy diffusion in the international political economy, American Political Science Review, Vol. 98, No. 1, pp. 171-189.

Simpson, D., and Sroufe, R. (2014) Stakeholders, reward expectations and firms' use of the ISO14001 management standard, International Journal of Operations \& Production Management, Vol. 34, No. 7, pp. 830-852.

Sinclair, D. (1997) Self-regulation versus command and control? Beyond false dichotomies, Law and Policy - University of Denver, Vol. 19, No. 4, pp. 529-559.

Sivaram, N. M., and Devadasan, S. R. (2012), A literature review on the integration of total productive maintenance elements with ISO 9001 standard, International Journal of Productivity and Quality Management, Vol. 9, No. 3, 281-308.

Song, A.M., Temby, O., Kim, D., Saavedra, A., and Hickey, G.M. (2019) Measuring, mapping and quantifying the effects of trust and informal communication on transboundary collaboration in the Great Lakes fisheries policy network, Global Environmental Change, Vol. 54, pp. 6-18.

Spitzig, K. (2016) “Integrated Management System - York Region Environmental Services", Municipal Water and Wastewater Regulatory Committee - March 23, 2016, Barrie, ON

Stake, R.E. (2000) Case studies handbook of qualitative research, ( $2^{\text {nd }}$ ed). Thousand Oaks, CA: Sage

Stamatis, D. H. (2003) Failure mode and effect analysis, $\left(2^{\text {nd }}\right.$ ed). Milwaukee, WI: ASQ Quality Oress. 
Stanwell-Smith, R. (1997) UK reports first outbreak of Cryptosporidiosis associated with filtered borehole water, Eurosurveillance, Vol. 1, No. 16.

Stemler, S. (2001) 'An overview of content analysis', Practical Assessment, Research \& Evaluation, Vol. 7, no. 17, [Online], Available: http://pareonline.net/getvn.asp?v=7\&n=17 [September 21, 2013].

Stephenson, P. (2013) Twenty years of multi-level governance: where does it come from? What is it? Where is it going?, Journal of European Public Policy, Vol. 20, No. 6, pp. 817-837.

Steurer, R. (2013) Disentangling governance: a synoptic view of regulation by government, business and civil society, Policy Sciences, Vol. 46, No. 4, pp. 387-410.

Stewart D. W., Shamdasani, P. N., (2015) 'Focus groups: theory and practice', $3^{\text {rd }}$ Edition, Thousands Oaks, CA: Sage.

Stoker, G. (2006) Public value management - A new narrative of networked governance, American Review of Public Administration, Vol. 36, No. 1, pp. 41-57.

Stone, D. (1999) Learning lessons and transferring policy across time, space and disciplines, Political Studies Association, Vol. 10, No. 1, pp. 51-59.

Strang, D., and Macy, M. W. (2001) In search of excellence: Fads, success stories and adaptive emulation, Annual Review of Sociology, Vol. 24, pp. 265-290.

Strang, D., and Meyer, J. W. (1993) Institutional conditions for diffusion, Theory and Society, Vol. 22, No. 4, pp. 487-511.

Strang, D., and Soule, S. A. (1998) Diffusion in organization and social movements: From hybrid corn to poison pills, American Journal of Sociology, Vol. 107, No. 1, pp. 147-182.

Strong, R. (n/d) The importance of CAPA and root cause analysis for the food industry, SAI Global Assurance Services.

Sutton, R.I., and Staw, B.M. (1995), 'What theory is not', Administrative Science Quarterly, Vol. 40, pp. 371-384.

Swaigen, J., Koehl, A., and Hatt, C. (2013) Private prosecutions revisited: the continuing importance of private prosecutions in protecting the environment, Symposium of environment in the courtroom (II): environmental prosecutions, March 2013, University of Ottawa, [Online], Available: https://cirl.ca/files/cirl/john swaigen and albert koehl and charles hatt-en.pdf [September 21, 2018].

Tollefson, C., Zito, A. R. \& Gale, F. (2012) Symposium overview: Conceptualizing new governance arrangements, Public Administration, Vol. 90, No. 1, pp. 3-18. 
Tovilla, E., Duong, J., and Benkovich, N. (2014) Municipal system wide environmental compliance approval, Water Environment Association of Ontario (WEAO) 2014 Technical Conference Proceedings, London: WEAO.

Tovilla, E. (2016) ISO 14001 for Municipal water, wastewater and stormwater services, Municipal Water Wastewater Regulatory Committee - Annual Workshop, Barrie, ON.

Tovilla, E. (2017) Adoption of ISO 14001 EMS in Ontario municipal wastewater systems - A case study for Durham Region and Richmond Hill, 2017 Water Environment Association of Ontario, Ottawa, ON, April 2017.

Tovilla, E. (2018) Experience on System-wide ECAs for Wastewater Collection by Ontario Municipalities, WEAO, MECP $11^{\text {th }}$ Engineer's Professional Development Day, May 2018, Available:

https://d3n8a8pro7vhmx.cloudfront.net/weao/pages/43/attachments/original/1530822909/20 180509 Experience of Wastewater System Wide ECA by Ontario.pdf?1530822909 [15 May 2018].

Tovilla, E., Webb, K. (2017a) 'Examining the emerging environmental protection policy convergence in the Ontario municipal drinking water, wastewater and stormwater sectors', Water Quality Research Journal, vol. 52, no. 3, pp. 209-228.

Tovilla, E. and Webb, K. (2017b) Non-state approaches to tailings dams regulation - Drawing on the BC Mount Polley and Brazil Samarco tailings dam spill experiences, a paper presented at the IAIA17, April 5, 2017. International Association of Impact Assessment, annual conference in Montreal, QC.

Tovilla, E. and Webb, K. (2018) Is there value in creating and establishing a municipal WW and SWM EMS standard?... Should it be mandatory?, 2018 National Water and Wastewater Conference, Montreal, QC, November 2018.

Town of Richmond Hill (2015) Environmental Management System Certification: ISO 14001, [Online], Available: www.richmondhill.ca/subpage.asp?textonly=\&pageid=epw environment [25 Nov 2015].

Trieb, O., Bahr, H. \& Falkner, G. (2007) Modes of governance: Towards a conceptual clarification, Journal of European Public Policy, Vol. 14, pp. 1-20.

U.S. District Court Eastern District of Michigan (US DCED Michigan) (2015) Class action lawsuit No. 15, filed on Nov 13, 2015.

U.S. Food and Drug Administration (2015) Hazard analysis critical control point - HACCP Principles and Application Guidelines, FDA Website, [Online], Available: www.fda.gov/Food/GuidanceRegulation/HACCP/ [18 Nov 2015]. 
US. EPA (2005) Guide for Evaluating Capacity, Management, Operation, and Maintenance (CMOM) Programs at Sanitary Sewer Collection Systems, [Online], Available:

www3.epa.gov/npdes/pubs/cmom guide for collection systems.pdf [2 Jan 2017].

Wang, J., Ran, B. (2018) Sustainable collaborative governance in supply chain, Sustainability, Vol. 10, No. 1, pp. 171.

WEAO (2018a) A WEAO review and recommendations to the MECP about system-wide approaches for sanitary and stormwater collection systems, WEAO Government Affairs Committee, Influents Magazine, Fall 2018, pp. 52-53, [Online], Available:

https://www.weao.org/influents [11 Mar 2019].

WEAO (2018b) WEAO partners with OWWA, OMWA and MECP to discuss strategic topics of common interest, WEAO Government Affairs Committee, Influents Magazine, Summer 2018, pp. 60-61, [Online], Available: https://www.weao.org/influents [12 Dec 2018].

WEAO (2019) MECP wastewater design criteria and holistic approach for collection and stormwater approvals, WEAO Government Affairs Committee, Influents Magazine, Spring 2019, pp. 71, [Online], Available: https://www.weao.org/influents [10 May 2019].

Water Environment Federation -WEF (not/dated) The O\&M in CMOM: Operation and Maintenance - A reference guide for utility operators, WEF Collection Systems Committee, CMOM Project (O\&M Ver. 2.3a), [Online], Available:

www.cmom.net/WEF CMOM O\&M V23a.doc [02 Sep 2018].

Webb, K. (2004) Understanding the voluntary codes phenomenon. In: Webb, K. (ed.). Voluntary Codes: Private Governance, the Public Interest and Innovation. Carleton University Research Unit for Science and Innovation, Ottawa, pp. 3-31.

Webb, K. and Morrison, A. (2004) The law and voluntary codes" examining the entangled "web", Voluntary Codes: Private Governance, the Public Interest and Innovation. Carleton University Research Unit for Science and Innovation, Ottawa, pp. 97-174.

Webb, K. (2005) Sustainable governance in the twenty first century: Moving beyond instrument choice. In: Elias, P., Hill, M. \& Howlett, M. (eds). Designing Government: from Instruments to Governance. McGill-Queen's Press, Montreal, pp. 242-280.

Webb, K. (2012a) Political risk insurance, CSR and the mining sector - An illustration of the regulatory effects of contracts, International Journal of Law and Management, Vol. 54, No. 5, pp. 394-415.

Webb, K. (2012b) Chapter 6 - Corporate Social Responsibility: The Canadian Experience. Business Ethics, Emond Montgomery Publications: Toronto, pp.75-89.

Webb, K. (2012c) Multi-level corporate responsibility and the mining sector: learning from the Canadian experience in Latin America, Business and Politics, Vol. 14, No. 3, pp. 1-42. 
Webb, K. (2015a) 'ISO 26000 social responsibility standard as 'proto law' and a new form of global custom: Positioning ISO 26000 in the emerging transnational regulatory governance rule instrument architecture', Transnational Legal Theory Journal, Vol. 5, No. 4, pp. 1-35.

Webb, K. (2015b) MB8612 CSR and Sustainable Mining, Corporate Social Responsibility class presentations. Yates School of Graduate Studies, Toronto.

Webb, K. (2015c) Re-thinking public, private and civil society governance roles and modalities in operationalizing sustainability, RIODD 10 ${ }^{\text {th }}$ Congress, UQAM Montreal, July 2015.

Webb, K., Cruz, R., Walsh, P. (2017) 'A comparative review of the role of markets and institutions in sustaining innovation in cleantech: a critical mass approach," International Journal of Innovation and Sustainable Development, Vol. 11 Iss. 2/3, pp. 149 - 169.

Weber, K.M., and Rohracher, H. (2012) Legitimatizing research, technology and innovation policies for transformative change combining insights from innovation systems and multi-level perspective in a comprehensive failures framework, Research Policy, Vol. 41, pp. 1037-10.47.

Wellington, A., Burley, C., and Rollinson-Lorimer, M. (2010) Chapter 14, The Walkerton Tragedy: A Comprehensive Chronology, Environmental Law and Policy in the Canadian Context, Captus Press: Concord, pp. 511-538.

Weiss, T. G., (2000) Governance, good governance and global governance: Conceptual and actual challenges, Third World Quarterly, Vol. 21, No. 5, pp. 795-814.

White, M. D., and Marsh, E.E. (2006) Content Analysis: A Flexible Methodology, John Hopkins University Press Library Trends, Vol. 55, No. 1, pp. 22-45.

Willms, J. (2013) City of Kawartha Lakes loses fight over "unfair" oil spill clean-up order, Legal Issues - Environmental Science \& Engineering Magazine, Summer 2013, [Online], Available: www.willmsshier.com/docs/defaultsource/articles/kawartha lakes fights moe order to pay.pdf [12 January 2019].

Wisconsin Department of Natural Resources - WDNR (2014) Green Tier - Biennial Report, [Online], Available: http://dnr.wi.gov/files/PDF/pubs/co/CO574.pdf [18 Nov 2015].

Wong, G. (2013) Optimizing the water lifecycle with real time data, Municipal World, June 2013, p. 13-14, 36.

Wong, K. C. (2011) Using an Ishikawa diagram as a tool to assist memory and retrieval of relevant medical cases from the medical literature, Journal of Medical Case Reports, Vol. 120, No. 5

Wood, S. \& Johannson, L. 2008 How not to incorporate voluntary standards into smart regulation: ISO 14001 and Ontario's Environmental Penalties Regulations. Comparative Research in Law \& Political Economy - York University, CLPE Research Paper, 4(2), 1-72. 
World Bank (1994) Governance, The World Bank Experience, Washington DC: The World Bank, May 1994, pp. XIV.

Yin, R. K. (1993) Applications of Case Study Research, 1st edition, Newbury Park: Sage Publications.

Yin, R. K. (2003) Case study research: Design and methods ( $3^{\text {rd }}$ ed.), Thousand Oaks, CA: Sage.

York Region (2004) Proposed regulatory changes - Drinking water quality management standard under the SDWA, Staff Report no. 1, December 16, 2004, (online), available from:

http://archives.york.ca/councilcommitteearchives/pdf/rpt\%201\%20cls\%201-71.pdf (02 Dec 2016).

York Region (2015) "Staff Report No.6 - 2014 Integrated Management System Update for Water, Wastewater and Waste Management" [Online], Available:

https://www.york.ca/wps/wcm/connect/yorkpublic/ee02ca91-6588-4792-a71f-

968b2121db49/mar+12+integrated+ex.pdf?MOD=AJPERES [22 Feb 2018].

Yukon Territory (2005) Report on the Audit of the Yukon's Government's Performance under the Environment Act, Government of Yukon, [Online], Available: Available:

http://www.eco.gov.yk.ca/pdf/environment act 2000-2003.pdf [10 Jun 2018].

Zahran, S., McElmurry, S.P., Kilgore, P.E., Mushinski, D., Press, J., Love, N.G., Sadler, R.C., and Swanson, M.S. (2018) Assessment of the Legionnaire's disease outbreak in Flint, Michigan, [Online], Available: www.pnas.org/cgi/doi/10.1073/pnas.1718679115 [23 Jun 2019]. 